\title{
WestVirginiaUniversity
}

THE RESEARCH REPOSITORY @ WVU

Graduate Theses, Dissertations, and Problem Reports

2005

\section{Synthesis of novel alkaloids using squaric acid esters}

Peter S. Zehr

West Virginia University

Follow this and additional works at: https://researchrepository.wvu.edu/etd

\section{Recommended Citation}

Zehr, Peter S., "Synthesis of novel alkaloids using squaric acid esters" (2005). Graduate Theses,

Dissertations, and Problem Reports. 2273.

https://researchrepository.wvu.edu/etd/2273

This Dissertation is protected by copyright and/or related rights. It has been brought to you by the The Research Repository @ WVU with permission from the rights-holder(s). You are free to use this Dissertation in any way that is permitted by the copyright and related rights legislation that applies to your use. For other uses you must obtain permission from the rights-holder(s) directly, unless additional rights are indicated by a Creative Commons license in the record and/ or on the work itself. This Dissertation has been accepted for inclusion in WVU Graduate Theses, Dissertations, and Problem Reports collection by an authorized administrator of The Research Repository @ WVU.

For more information, please contact researchrepository@mail.wvu.edu. 


\title{
Synthesis of Novel Alkaloids Using Squaric Acid Esters
}

\author{
Peter S. Zehr \\ Dissertation submitted to the Eberly College of Arts and Sciences \\ at West Virginia University \\ in partial fulfillment of the requirements for \\ the degree of \\ Doctor of Philosophy \\ in \\ Organic Chemistry
}
Björn C. Söderberg, Ph.D., Chair John H. Penn, Ph.D.
Alan M. Stolzenberg, Ph.D.
Kung K. Wang, Ph.D.
Peter M. Gannett, Ph.D.

Department of Chemistry
Morgantown, West Virginia
2005

Keywords: quinoline, squaric acid, indoloquinone, ring expansion, cyclopenta[b]quinolines 


\section{Abstract \\ Synthesis of Novel Alkaloids Using Squaric Acid Esters}

Peter S. Zehr

A novel route to cyclopenta[b]quinoline-1-ones and -ols has been developed.

Substituted cyclopenta[b]quinolin-1-ones were prepared by thermal ringexpansion of substituted $\mathrm{N}$-BOC protected 4-(2-aminophenylethynyl)-4-hydroxy2-cyclobuten-1-ones forming the corresponding 2-aminophenylmethylidene substituted 4-cyclopentene-1,3-diones. Deprotection of the amine resulted in spontaneous condensation to give cyclopenta[b]quinolin-1-ones. Sodium borohydride reduction of these products produced cyclopenta[b]quinolin-1-ols. The key step in the sequence is a thermally induced ring-expansion of 4-(2aminophenylethynyl)-4-hydroxy-2-cyclobuten-1-ones. Changing the amino protecting group had no effect on the ring size selectivity of the thermal ring expansion. The thermal ring expansion of the corresponding nitro derivative suggests that electron withdrawing substituents may alter the selectivity of the ring formation. The attempted base mediated, copper mediated, copper catalyzed and palladium catalyzed indolization reaction were not further examined since the desired products were not obtained. The $\mathrm{N}$-iodosuccinimide, $\mathrm{N}$-chlorosuccinimide mediated and palladium catalyzed ring expansion reactions were also not further examined. The copper acetate catalyzed indolization of the $\mathrm{N}$-acetyl derivative may lead to the preparation of novel 2-substituted indoles. In the Cul mediated reactions with $N$-benzyl the project was dropped since the starting material was difficult to synthesize. A novel route to indoloquinones has been developed. This methodology may lead to the synthesis of a natural product, as well as several novel indoloquinones. 


\section{Acknowledgments}

I would like to thank my research advisor, Dr. Björn C. Söderberg, for all his guidance, patience and support. I also thank and greatly appreciate my research committee members, Drs. John H. Penn, Kung K. Wang, Alan M. Stolzenberg and Peter M. Gannett, for their time, guidance and patience. My sincere gratitude goes to Drs. Peter M. Gannett, Jonathan Daft and Klaus Bergander (Muenster University, Germany) for their significant contributions to my better understanding of modern NMR techniques. I would like to thank Dr. Kou Hiroya of Tohoku University, Japan for his correspondence. I also wish to thank Dr. John Penn for his guidance, hospitality and friendship.

I wish to thank my family, especially my brothers, for their constant love, support and encouragement through all the years of my graduate career.

The financial support of the Department of Chemistry at West Virginia University, EPSCoR and NIH is also thankfully acknowledged. 


\section{Table of Contents}

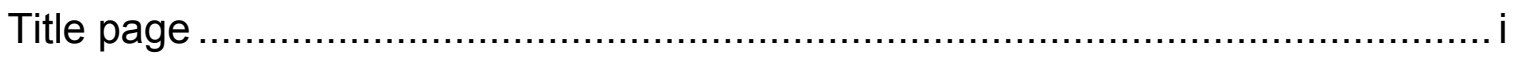

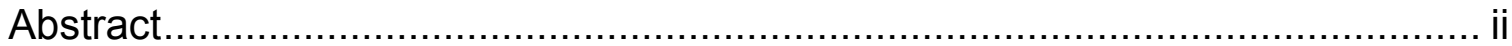

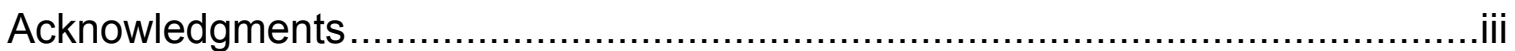

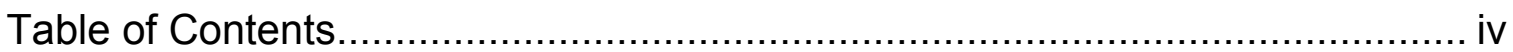

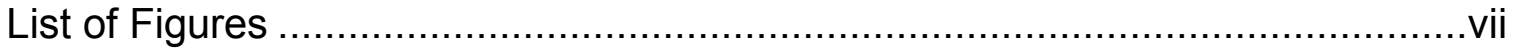

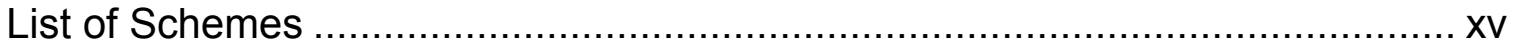

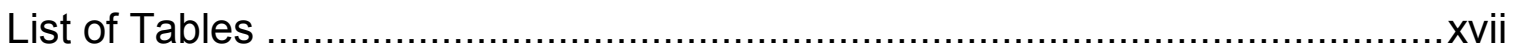

\section{Part I}

A Novel Entry to Cyclopenta[b]quinolines via Thermal RingExpansion of (2-Aminophenyl)-Ethynyl-Substituted Cyclobutenone Derivatives

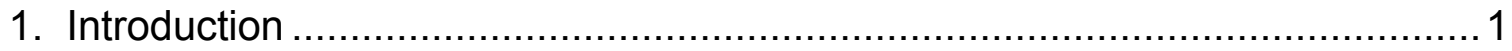

a. 1.1. Quinoline Syntheses: Intramolecular Cyclization of Anilines ...........2

b. 1.2. Quinoline Syntheses: Cyclization of Ortho-Disubstituted

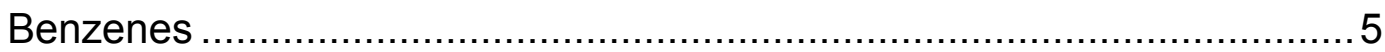

c. 1.3. Modern Quinoline Syntheses ................................................ 7

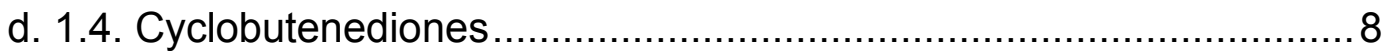

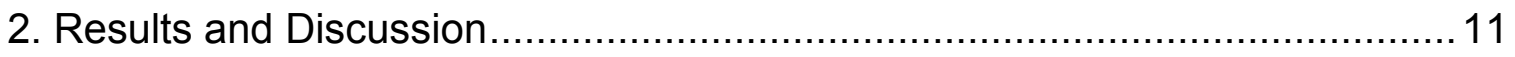

a. 2.1. N-BOC Protected Derivatives................................................. 12

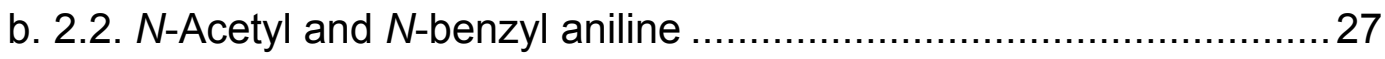




\section{Part II}

\section{Attempted Indolizations and Additional Ring Expansions}

1. Introduction

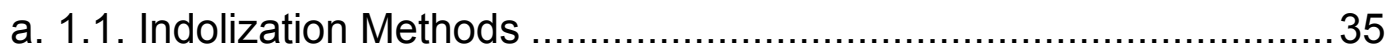

b. 1.2. Electrophilic Ring Expansions 4-Hydroxy-2-cyclobuten-1-ones ....38

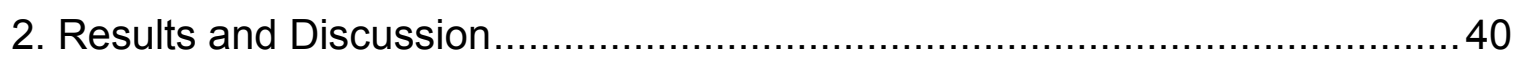

a. 2.1. Base Mediated Indole Formation ........................................... 41

b. 2.2. Attempted Copper Mediated Indole Formation............................. 42

c. 2.3. Copper Acetate Catalyzed Indole Formation............................... 44

d. 2.4. Attempted Palladium Catalyzed Indole Formation or Ring

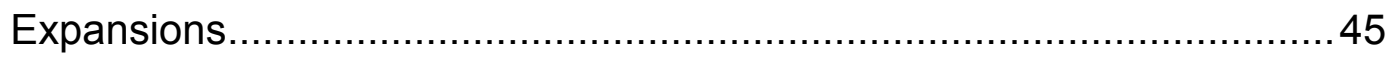

e. 2.5. $\mathrm{N}$-lodosuccinimide Mediated Ring Expansion .............................45

f. 2.6. $\mathrm{N}$-Chlorosuccinimide Mediated Ring Expansion ...........................46

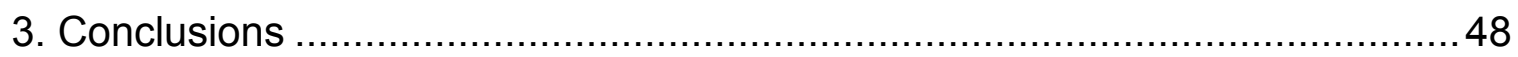




\section{Part III}

\section{Synthesis of Novel Indoloquinones}

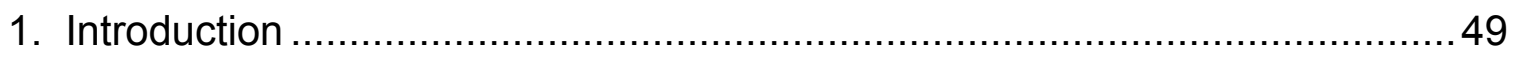

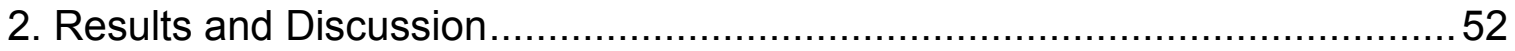

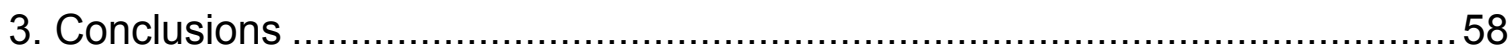

\section{Part IV \\ Experimental Section}

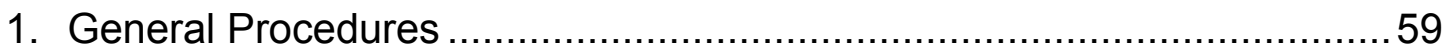

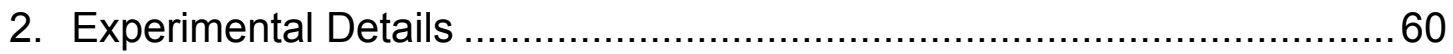

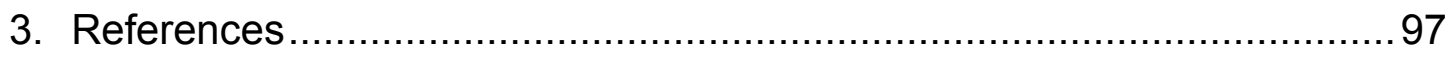

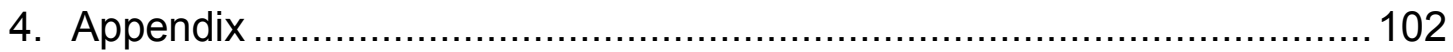




\section{List of Figures}

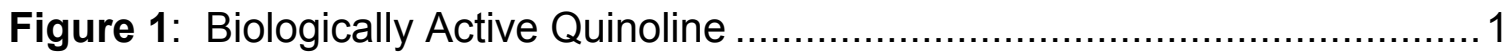

Figure 2: Gradient Heteronuclear Multiple Quantum Coherence Spectrum of 35

Figure 3: Gradient Heteronuclear Multiple Bond Coherence Spectrum of 35

Figure 3A: Indoloquinone Containing Natural Products

Figure 4: ${ }^{1} \mathrm{H}$ Spectrum of (4-Chloro-2-iodophenyl)-carbamic acid 1,1-

dimethylethyl ester $\mathbf{3 7 b}$.

Figure 5: ${ }^{13} \mathrm{C}$ Spectrum of (4-Chloro-2-iodophenyl)-carbamic acid 1,1dimethylethyl ester $\mathbf{3 7 b}$.

Figure 6: ${ }^{1} \mathrm{H}$ Spectrum of (2-lodo-5-methoxy-phenyl)-carbamic acid 1,1dimethylethyl ester 37c. 105

Figure 7: ${ }^{13} \mathrm{C}$ Spectrum of (2-lodo-5-methoxy-phenyl)-carbamic acid 1,1dimethylethyl ester 37c

Figure 8: ${ }^{1} \mathrm{H}$ Spectrum of (2-lodo-5-methylphenyl)-carbamic acid 1,1dimethylethyl ester $\mathbf{3 7 d}$.

Figure 9: ${ }^{13} \mathrm{C}$ Spectrum of (2-lodo-5-methylphenyl)-carbamic acid 1,1dimethylethyl ester $\mathbf{3 7 d}$. 108

Figure 10: ${ }^{1} \mathrm{H}$ Spectrum of (4-Chloro-2-(trimethylsilylethynyl)phenyl)-carbamic acid 1,1-dimethylethyl ester $\mathbf{3 8 b}$

Figure 11: ${ }^{13} \mathrm{C}$ Spectrum of (4-Chloro-2-(trimethylsilylethynyl)phenyl)-carbamic acid 1,1-dimethylethyl ester $\mathbf{3 8 b}$

Figure 12: ${ }^{1} \mathrm{H}$ Spectrum of (5-Methoxy-2-trimethylsilylethynylphenyl)-carbamic acid 1,1-dimethylethyl ester 38c

Figure 13: ${ }^{13} \mathrm{C}$ Spectrum of (5-Methoxy-2-trimethylsilylethynylphenyl)-carbamic acid 1,1-dimethylethyl ester 38c

Figure 14: ${ }^{1} \mathrm{H}$ Spectrum of (5-Methyl-2-trimethylsilylethynylphenyl)-carbamic acid 1,1-dimethylethyl ester 38d 
Figure 15: ${ }^{13} \mathrm{C}$ Spectrum of (5-Methyl-2-trimethylsilylethynylphenyl)-carbamic acid 1,1-dimethylethyl ester $\mathbf{3 8 d}$

Figure 16: ${ }^{1} \mathrm{H}$ Spectrum of (4-trimethylsilylethynyl-3-pyridinyl)-carbamic acid 1,1dimethylethyl ester $\mathbf{3 8 e}$

Figure 17: ${ }^{13} \mathrm{C}$ Spectrum of (4-trimethylsilylethynyl-3-pyridinyl)-carbamic acid 1,1dimethylethyl ester $\mathbf{3 8 e}$ 116

Figure 18: ${ }^{1} \mathrm{H}$ Spectrum of (4-Chloro-2-ethynylphenyl)-carbamic acid 1,1dimethylethyl ester $\mathbf{2 6 b}$

Figure 19: ${ }^{13} \mathrm{C}$ Spectrum of (4-Chloro-2-ethynylphenyl)-carbamic acid 1,1dimethylethyl ester 26b.

Figure 20: ${ }^{1} \mathrm{H}$ Spectrum of (2-Ethynyl-5-methoxyphenyl)-carbamic acid 1,1dimethylethyl ester 26c

Figure 21: ${ }^{13} \mathrm{C}$ Spectrum of (2-Ethynyl-5-methoxyphenyl)-carbamic acid 1,1dimethylethyl ester 26c

Figure 22: ${ }^{1} \mathrm{H}$ Spectrum of (2-Ethynyl-5-methylphenyl)-carbamic acid 1,1dimethylethyl ester $\mathbf{2 6 d}$

Figure 23: ${ }^{13} \mathrm{C}$ Spectrum of (2-Ethynyl-5-methylphenyl)-carbamic acid 1,1dimethylethyl ester 26d

Figure 24: ${ }^{1} \mathrm{H}$ Spectrum of (4-Ethynyl-3-pyridinyl)-carbamic acid 1,1dimethylethyl ester 26e

Figure $25:{ }^{13} \mathrm{C}$ Spectrum of (4-Ethynyl-3-pyridinyl)-carbamic acid 1,1dimethylethyl ester 26e 124

Figure 26: ${ }^{1} \mathrm{H}$ Spectrum of [2-(1-Hydroxy-2,3-bis(1-methylethoxy)-4-oxocyclobut-2-enylethynyl)phenyl]-carbamic acid 1,1-dimethylethyl ester 28a 125

Figure 27: ${ }^{13} \mathrm{C}$ Spectrum of [2-(1-Hydroxy-2,3-bis(1-methylethoxy)-4-oxocyclobut-2-enylethynyl)phenyl]-carbamic acid 1,1-dimethylethyl ester 28a

Figure 28: ${ }^{1} \mathrm{H}$ Spectrum of [4-Chloro-2-(1-hydroxy-2,3-di(1-methylethoxy)-4-oxocyclobut-2-enylethynyl)phenyl]-carbamic acid 1,1-dimethylethyl ester 28b 127

Figure 29: ${ }^{13} \mathrm{C}$ Spectrum of [4-Chloro-2-(1-hydroxy-2,3-di(1-methylethoxy)-4-oxocyclobut-2-enylethynyl)phenyl]-carbamic acid 1,1-dimethylethyl ester 28b 128 
Figure 30: ${ }^{1} \mathrm{H}$ Spectrum of [2-(1-Hydroxy-2,3-di(1-methylethoxy)-4-oxo-cyclobut2-enylethynyl)-5-methoxyphenyl]-carbamic acid 1,1-dimethylethyl ester 28c and butyl addition product of diisopropyl squarate.... 129

Figure 31: ${ }^{13} \mathrm{C}$ Spectrum of [2-(1-Hydroxy-2,3-di(1-methylethoxy)-4-oxo-cyclobut2-enylethynyl)-5-methoxyphenyl]-carbamic acid 1,1-dimethylethyl ester 28c and butyl addition product of diisopropyl squarate. 130

Figure 32: ${ }^{1} \mathrm{H}$ Spectrum of [2-(1-Hydroxy-2,3-di(1-methylethoxy)-4-oxo-cyclobut2-enylethynyl)-5-methoxyphenyl]-carbamic acid 1,1-dimethylethyl ester 28c ...131

Figure 33: ${ }^{13} \mathrm{C}$ Spectrum of [2-(1-Hydroxy-2,3-di(1-methylethoxy)-4-oxo-cyclobut2-enylethynyl)-5-methoxyphenyl]-carbamic acid 1,1-dimethylethyl ester 28c ... 132

Figure 34: ${ }^{1} \mathrm{H}$ Spectrum of [2-(1-Hydroxy-2,3-di(1-methylethoxy)-4-oxo-cyclobut2-enylethynyl)-5-methylphenyl]-carbamic acid 1,1-dimethylethyl ester 28d ......133

Figure 35: ${ }^{13} \mathrm{C}$ Spectrum of [2-(1-Hydroxy-2,3-di(1-methylethoxy)-4-oxo-cyclobut2-enylethynyl)-5-methylphenyl]-carbamic acid 1,1-dimethylethyl ester 28d ...... 134

Figure 36: ${ }^{1} \mathrm{H}$ Spectrum of [4-(1-Hydroxy-2,3-di(1-methylethoxy)-4-oxo-cyclobut2-enylethynyl)-pyridin-3-yl]-carbamic acid 1,1-dimethylethyl ester 28e. 135

Figure 37: ${ }^{13} \mathrm{C}$ Spectrum of [4-(1-Hydroxy-2,3-di(1-methylethoxy)-4-oxo-cyclobut2-enylethynyl)-pyridin-3-yl]-carbamic acid 1,1-dimethylethyl ester $\mathbf{2 8 e}$ 136

Figure 38: ${ }^{1} \mathrm{H}$ Spectrum of [2-(3,4-Di(1-methylethoxy)-2,5-dioxo-3-cyclopenten-1ylmethyl)phenyl]-carbamic acid 1,1-dimethylethyl ester 33a 137

Figure 39: ${ }^{13} \mathrm{C}$ Spectrum of [2-(3,4-Di(1-methylethoxy)-2,5-dioxo-3-cyclopenten1-ylmethyl)phenyl]-carbamic acid 1,1-dimethylethyl ester 33a. 138

Figure 40: ${ }^{1} \mathrm{H}$ Spectrum of [4-Chloro-2-(3,4-di(1-methylethoxy)-2,5-dioxo-3cyclopenten-1-ylmethyl)phenyl]-carbamic acid 1,1-dimethylethyl ester 33b .....139

Figure 41: ${ }^{13} \mathrm{C}$ Spectrum of [4-Chloro-2-(3,4-di(1-methylethoxy)-2,5-dioxo-3cyclopenten-1-ylmethyl)phenyl]-carbamic acid 1,1-dimethylethyl ester 33b .....140

Figure 42: ${ }^{1} \mathrm{H}$ Spectrum of [2-(3,4-di(1-methylethoxy)-2,5-dioxo-3-cyclopenten-1ylmethyl)-5-methoxy-phenyl]-carbamic acid 1,1-dimethylethyl ester 33c 141

Figure 43: ${ }^{13} \mathrm{C}$ Spectrum of [2-(3,4-di(1-methylethoxy)-2,5-dioxo-3-cyclopenten1-ylmethyl)-5-methoxy-phenyl]-carbamic acid 1,1-dimethylethyl ester 33c 142 
Figure 44: ${ }^{1} \mathrm{H}$ Spectrum of [2-(3,4-di(1-methylethoxy)-2,5-dioxo-3-cyclopenten-1methylidene)-5-methyl-phenyl]-carbamic acid 1,1-dimethylethyl ester 33d ......143

Figure 45: ${ }^{13} \mathrm{C}$ Spectrum of [2-(3,4-di(1-methylethoxy)-2,5-dioxo-3-cyclopenten1-methylidene)-5-methyl-phenyl]-carbamic acid 1,1-dimethylethyl ester 33d ... 144

Figure 46: ${ }^{1} \mathrm{H}$ Spectrum of [4-(3,4-Di(1-methylethoxy)-2,5-dioxo-3-cyclopenten-1ylmethyl)-3-pyridinyl]-carbamic acid 1,1-dimethylethyl ester 33e 145

Figure 47: ${ }^{13} \mathrm{C}$ Spectrum of [4-(3,4-Di(1-methylethoxy)-2,5-dioxo-3-cyclopenten1-ylmethyl)-3-pyridinyl]-carbamic acid 1,1-dimethylethyl ester 33e. 146

Figure 48: ${ }^{1} \mathrm{H}$ Spectrum of 2,3-Di(1-methylethoxy)cyclopenta[b]quinolin-1-one $34 a$

Figure 49: ${ }^{13} \mathrm{C}$ Spectrum of 2,3-Di(1-methylethoxy)cyclopenta[b]quinolin-1-one $34 a$

Figure 50: ${ }^{1} \mathrm{H}$ Spectrum of 7-Chloro-2,3-di(1-methylethoxy)cyclopenta[b]quinolin1-one 34b 149

Figure 51: ${ }^{13} \mathrm{C}$ Spectrum of 7-Chloro-2,3-di(1methylethoxy)cyclopenta[b]quinolin-1-one 34b

Figure 52: ${ }^{1} \mathrm{H}$ Spectrum of 2,3-Di(1-methylethoxy)-6methoxycyclopenta[b]quinolin-1-one 34c.

Figure 53: ${ }^{13} \mathrm{C}$ Spectrum of 2,3-Di(1-methylethoxy)-6methoxycyclopenta[b]quinolin-1-one 34c.

Figure 54: ${ }^{1} \mathrm{H}$ Spectrum of 2,3-Di(1-methylethoxy)-6-methylcyclopenta[b]quinolin1-one 34d 153

Figure 55: ${ }^{13} \mathrm{C}$ Spectrum of 2,3-Di(1-methylethoxy)-6methylcyclopenta[b]quinolin-1-one $34 \mathrm{~d}$ 154

Figure 56: ${ }^{1} \mathrm{H}$ Spectrum of 2,3-Di(1-methylethoxy)-6-aza-cyclopenta[b]quinolin-1one $34 \mathrm{e}$ 155

Figure 57: ${ }^{13} \mathrm{C}$ Spectrum of 2,3-Di(1-methylethoxy)-6-aza-cyclopenta[b]quinolin1 -one $34 \mathrm{e}$ 156

Figure 58: ${ }^{1} \mathrm{H}$ Spectrum of 2,3-Di(1-methylethoxy)cyclopenta[b]quinolin-1-ol $35 a$ 
Figure 59: ${ }^{13} \mathrm{C}$ Spectrum of 2,3-Di(1-methylethoxy)cyclopenta[b]quinolin-1-ol $35 a$

Figure 60: ${ }^{1} \mathrm{H}$ Spectrum of 7-Chloro-2,3-di(1-methylethoxy)cyclopenta[b]quinolin1-ol 35b 159

Figure $61:{ }^{13} \mathrm{C}$ Spectrum of 7-Chloro-2,3-di(1methylethoxy)cyclopenta[b]quinolin-1-ol 35b 160

Figure 62: ${ }^{1} \mathrm{H}$ Spectrum of 2,3-Di(1-methylethoxy)-6methoxycyclopenta[b]quinolin-1-ol 35c. 161

Figure 63: ${ }^{13} \mathrm{C}$ Spectrum of 2,3-Di(1-methylethoxy)-6methoxycyclopenta[b]quinolin-1-ol 35c.

Figure 64: ${ }^{1} \mathrm{H}$ Spectrum of 2,3-Di(1-methylethoxy)-6-methylcyclopenta[b]quinolin1 -ol 35d. 163

Figure $65:{ }^{13} \mathrm{C}$ Spectrum of 2,3- $\mathrm{Di}(1-$ methylethoxy)-6methylcyclopenta[b]quinolin-1-ol 35d. 164

Figure 66: ${ }^{1} \mathrm{H}$ Spectrum of 2,3-Di(1-methylethoxy)-6-azacyclopenta[b]quinolin-1ol $35 \mathbf{e}$ 165

Figure $67:{ }^{13} \mathrm{C}$ Spectrum of 2,3-Di(1-methylethoxy)-6-azacyclopenta[b]quinolin-1ol $35 \mathbf{e}$ 166

Figure 68: ${ }^{1} \mathrm{H}$ Spectrum of [2-(1-Hydroxy-2-(1-methylethoxy)-3-methyl-4-oxocyclobut-2-enylethynyl)-phenyl]-carbamic acid 1,1-dimethylethyl ester 41 .... 167

Figure 69: ${ }^{13} \mathrm{C}$ Spectrum of [2-(1-Hydroxy-2-(1-methylethoxy)-3-methyl-4-oxocyclobut-2-enylethynyl)-phenyl]-carbamic acid 1,1-dimethylethyl ester 41 ....... 168

Figure 70: ${ }^{1} \mathrm{H}$ Spectrum of E- and Z-[2-(3-(1-methylethoxy)-4-methyl-2,5-dioxo-3cyclopenten-1-ylmethyl)phenyl]-carbamic acid 1,1-dimethylethyl ester 42 .......169

Figure 71: ${ }^{13} \mathrm{C}$ Spectrum of E- and Z-[2-(3-(1-methylethoxy)-4-methyl-2,5-dioxo3-cyclopenten-1-ylmethyl)phenyl]-carbamic acid 1,1-dimethylethyl ester 42 ....170

Figure 72: ${ }^{1} \mathrm{H}$ Spectrum of 2-(1-Methylethoxy)-3-methylcyclopenta[b]quinolin-1one 43

Figure 73: ${ }^{13} \mathrm{C}$ Spectrum of 2-(1-Methylethoxy)-3-methylcyclopenta[b]quinolin-1one 43 
Figure 74: ${ }^{1} \mathrm{H}$ Spectrum of 2-(1-methylethoxy)-3-methylcyclopenta[b]quinolin-1-ol 44

Figure 75: ${ }^{13} \mathrm{C}$ Spectrum of 2-(1-methylethoxy)-3-methylcyclopenta[b]quinolin-1ol 44

Figure 76: ${ }^{1} \mathrm{H}$ Spectrum of $\mathrm{N}$-[2-(1-Hydroxy-2,3-diisopropoxy-4-oxo-cyclobut-2enylethynyl)-phenyl]-acetamide 46 .

Figure 77: ${ }^{13} \mathrm{C}$ Spectrum of N-[2-(1-Hydroxy-2,3-diisopropoxy-4-oxo-cyclobut-2enylethynyl)-phenyl]-acetamide 46 176

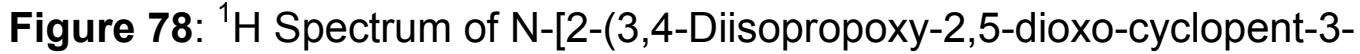
enylidenemethyl)-phenyl]-acetamide 51

Figure 79: ${ }^{13} \mathrm{C}$ Spectrum of $\mathrm{N}$-[2-(3,4-Diisopropoxy-2,5-dioxo-cyclopent-3enylidenemethyl)-phenyl]-acetamide 51

Figure 80: ${ }^{1} \mathrm{H}$ Spectrum of 3-(1-Acetyl-1H-indol-3-yl)-4-isopropoxy-cyclobut-3ene-1,2-dione. $\mathbf{7 0}$.

Figure 81: ${ }^{13} \mathrm{C}$ Spectrum of 3-(1-Acetyl-1H-indol-3-yl)-4-isopropoxy-cyclobut-3ene-1,2-dione. $\mathbf{7 0}$. 180

Figure 82: ${ }^{1} \mathrm{H}$ Spectrum of $\mathrm{N}$-[2-(2-Isopropoxy-3,4-dioxo-cyclobut-1-enylethynyl)phenyl]-acetamide $\mathbf{7 1}$

Figure 83: ${ }^{13} \mathrm{C}$ Spectrum of $\mathrm{N}$-[2-(2-Isopropoxy-3,4-dioxo-cyclobut-1enylethynyl)-phenyl]-acetamide 71

Figure 84: ${ }^{1} \mathrm{H}$ Spectrum of tert-butyl 2-(2-(2-isopropoxy-3,4-dioxocyclobut-1enyl)ethynyl)phenylcarbamate $\mathbf{7 2}$

Figure 85: ${ }^{13} \mathrm{C}$ Spectrum of tert-butyl 2-(2-(2-isopropoxy-3,4-dioxocyclobut-1enyl)ethynyl)phenylcarbamate 72

Figure 86: ${ }^{1} \mathrm{H}$ Spectrum of 4-(2-Benzylamino-phenylethynyl)-4-hydroxy-2,3diisopropoxy-cyclobut-2-enone 48

Figure 87: ${ }^{13} \mathrm{C}$ Spectrum of 4-(2-Benzylamino-phenylethynyl)-4-hydroxy-2,3diisopropoxy-cyclobut-2-enone 48 ....

Figure 88: ${ }^{1} \mathrm{H}$ Spectrum of 9-Benzyl-2,3-diisopropoxy-9H-carbazole-1,4-dione 69. 
Figure 89: ${ }^{13} \mathrm{C}$ Spectrum of 9-Benzyl-2,3-diisopropoxy-9H-carbazole-1,4-dione 69 188

Figure 90: ${ }^{1} \mathrm{H}$ Spectrum of 4-(4-Benzylamino-but-1-ynyl)-4-hydroxy-2,3diisopropoxy-cyclobut-2-enone 88

Figure 91: ${ }^{13} \mathrm{C}$ Spectrum of 4-(4-Benzylamino-but-1-ynyl)-4-hydroxy-2,3diisopropoxy-cyclobut-2-enone 88 . 190

Figure 92: ${ }^{1} \mathrm{H}$ Spectrum of 1-Benzyl-5,6-diisopropoxy-2,3-dihydro-1H-indole-4,7dione 91 191

Figure 93: ${ }^{13} \mathrm{C}$ Spectrum of 1-Benzyl-5,6-diisopropoxy-2,3-dihydro-1H-indole-4,7dione 91 192

Figure 94: ${ }^{1} \mathrm{H}$ Spectrum of 5,6-Diisopropoxy-2,3-dihydro-1H-indole-4,7-dione 93.

Figure 95: ${ }^{13} \mathrm{C}$ Spectrum of 5,6-Diisopropoxy-2,3-dihydro-1H-indole-4,7-dione 93.

Figure 96: ${ }^{1} \mathrm{H}$ Spectrum of 1-Benzyl-5,6-diisopropoxy-1H-indole-4,7-dione 94.

Figure 97: ${ }^{13} \mathrm{C}$ Spectrum of 1-Benzyl-5,6-diisopropoxy-1H-indole-4,7-dione 94.

Figure 98: ${ }^{1} \mathrm{H}$ Spectrum of tert-butyl benzyl-4-(1-hydroxy-2,3-diisopropoxy-4oxocyclobut-2-enyl)but-3-ynylcarbamate 89

Figure 99: ${ }^{13} \mathrm{C}$ Spectrum of tert-butyl benzyl-4-(1-hydroxy-2,3-diisopropoxy-4oxocyclobut-2-enyl)but-3-ynylcarbamate 89

Figure 100: ${ }^{1} \mathrm{H}$ Spectrum of tert-butyl benzyl-2-(4,5-diisopropoxy-3,6dioxocyclohexa-1,4-dienyl)ethylcarbamate 92

Figure 101: ${ }^{13} \mathrm{C}$ Spectrum of tert-butyl benzyl-2-(4,5-diisopropoxy-3,6dioxocyclohexa-1,4-dienyl)ethylcarbamate 92

Figure 102: ${ }^{1} \mathrm{H}$ Spectrum of 4-hydroxy-2,3-diisopropoxy-4-(2-(2nitrophenyl)ethynyl)cyclobut-2-enone 51a 201

Figure 103: ${ }^{13} \mathrm{C}$ Spectrum of 4-hydroxy-2,3-diisopropoxy-4-(2-(2nitrophenyl)ethynyl)cyclobut-2-enone 51a 202 
Figure 104: ${ }^{1} \mathrm{H}$ Spectrum of 2-(2-nitrobenzylidene)-4,5-diisopropoxycyclopent-4ene-1,3-dione 51d

Figure 105: ${ }^{13} \mathrm{C}$ Spectrum of 2-(2-nitrobenzylidene)-4,5-diisopropoxycyclopent-4ene-1,3-dione $\mathbf{5 1 d}$

Figure 106: ${ }^{1} \mathrm{H}$ Spectrum of 2,3-diisopropoxy-5-(2-nitrophenyl)cyclohexa-2,5diene-1,4-dione 51c 205

Figure 107: Expanded view of gHMBC Spectrum of 2,3-Di(1methylethoxy)cyclopenta[b]quinolin-1-ol 35a 206

Figure 108: Expanded view of gHMQC Spectrum of 2,3-Di(1methylethoxy)cyclopenta[b]quinolin-1-ol 35a 


\section{List of Schemes}

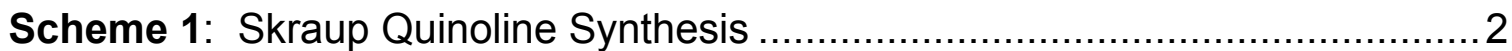

Scheme 2: Doebner-von Miller Quinoline Synthesis ....................................... 3

Scheme 3: Knorr Quinoline Synthesis .................................................... 4

Scheme 4: Conrad-Limpach Quinoline Synthesis ...................................... 4

Scheme 5: Similarities of the Conrad-Limpach and Knorr Quinoline Synthesis ...5

Scheme 6: Friedländer Quinoline Synthesis ............................................ 6

Scheme 7: Pfitzinger Quinoline Synthesis...............................................

Scheme 8: Ruthenium Catalyzed Quinoline Synthesis ................................ 8

Scheme 9: Microwave Assisted Quinoline Synthesis ..................................... 8

Scheme 10: Natural Products Synthesized from Squarate Derivatives ............. 10

Scheme 11: Synthesis of Assoanine from Dimethyl Squarate ....................... 11

Scheme 12: Initially Planned Reaction Sequence ....................................... 13

Scheme 13: General Reaction Sequence for the Synthesis of Novel

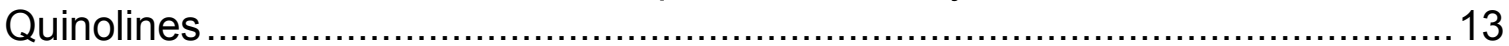

Scheme 14: Proposed Mechanism for the Formation of the Alkylidene ........... 15

Scheme 15: Synthesis of the N-BOC Protected Starting Materials .................. 19

Scheme 16: Alkylation of Diisopropyl Squarate .........................................20

Scheme 16a: Alkylation of Diisopropyl Squarate with other N-BOC Protected

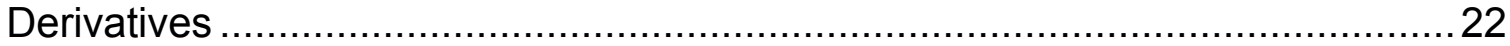

Scheme 17: Alternate Method for the Synthesis of Alkylation Products ............23

Scheme 18: Expansion, Deprotection and Reduction of BOC Protected

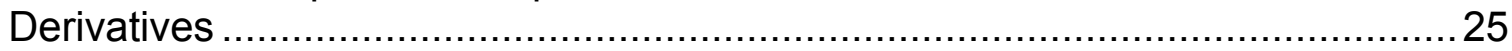

Scheme 19: Air Oxidation of the Quinolinol ..............................................26

Scheme 20: Reaction Sequence for the Semisquarate Derivative ..................27

Scheme 21: Alkylation Diisopropyl Squarate with $45 \ldots \ldots \ldots \ldots \ldots \ldots \ldots \ldots \ldots \ldots \ldots \ldots . . .28$

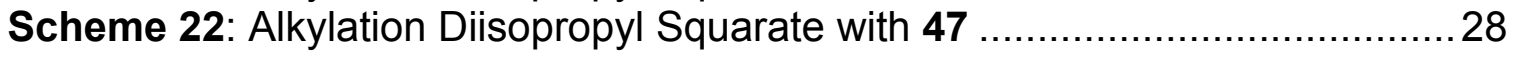

Scheme 23: Sonogashira Coupling of the Acetanilide (49) and N-benzyl (50)

Derivatives

Scheme 24: Thermal Ring Expansion of the Acetanilide............................... 30

Scheme 25: Sonogashira Coupling of 2-lodonitrobenzene ............................. 32

Scheme 26: Thermal Ring Expansion of Nitrobenzene Derivative .................... 32

Scheme 27: Thermal Ring Expansion of a Cyclobutenone Substituted Indole.. 35

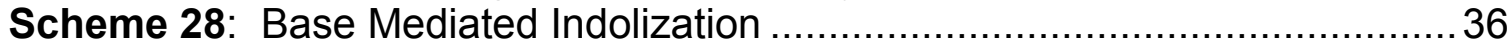

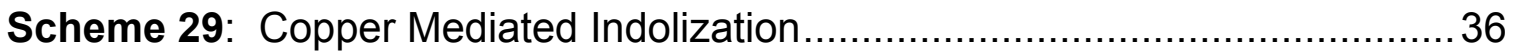

Scheme 30: Copper Acetate Catalyzed Indolization ..................................... 37

Scheme 31: Palladium Catalyzed Indolization ............................................ 38

Scheme 32: N-lodosuccinimide Mediated Ring Expansion .............................. 39

Scheme 33: N-Chlorosuccinimide Mediated Ring Expansion .......................... 39

Scheme 34: Palladium Catalyzed Ring Expansion..................................... 40

Scheme 35: Base Mediated Indolization ................................................. 41

Scheme 36: Copper Mediated Reaction Scheme for N-BOC Protected 28a...... 42

Scheme 37: Copper lodide Mediated Indolization for N-Benzyl Protected 48 ... 44

Scheme 38: Copper Acetate Catalyzed Indolization ...................................45

Scheme 39: Attempted $N$-lodosuccinimide Mediated Ring Expansion ............... 46 
Scheme 40: Attempted N-Chlorosuccinimide Mediated Ring Expansion ...........47

Scheme 41: Halide Mediated Cyclobutenone Rearrangement......................... 47

Scheme 42: Existing Synthesis of Drupella fragum Indoloquinones $\mathbf{7 9}$ and 82

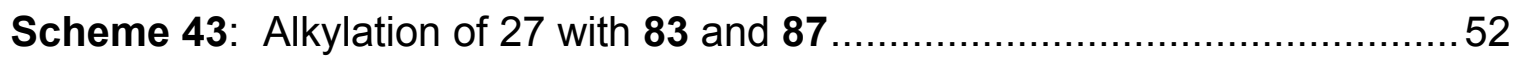

Scheme 44: Ring Expansion and Cyclization of 89 to 91 53

Scheme 45: Proposed Mechanism for the Tandem Expansion/Cyclization of

89 54

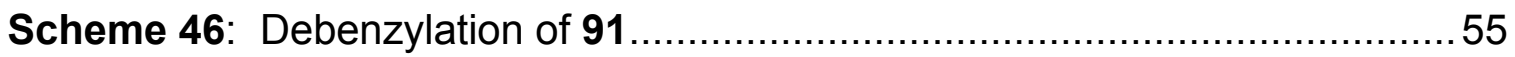

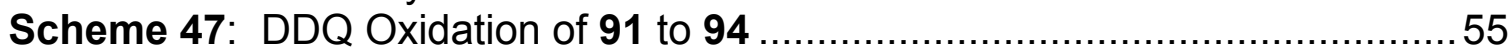

Scheme 48: Proposed Route for the Synthesis of 79 .................................56

Scheme 49: Ring Expansion of 89 to Quinone 92 …................................56

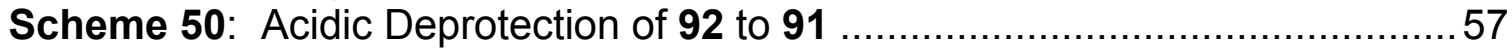

Scheme 51: Proposed Future Research with Butyne Derivatives ....................57 


\section{List of Tables}

Table 1: Summary of NMR Data for the Structural Determination of 35a ......... 14

Table 2: Alkylation Conditions of 26a to give 28a .......................................20

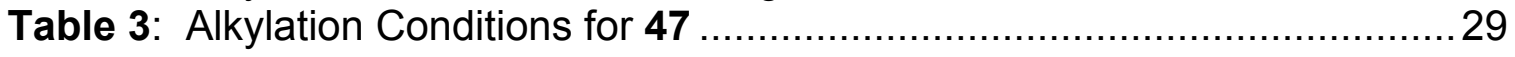

Table 4: Copper Mediated Reaction Conditions for 28a ................................ 43

Table 5: Copper Mediated Reaction Conditions for 28a ................................ 94 


\section{Part I}

\section{A Novel Entry to Cyclopenta[b]quinolines via Thermal Ring- Expansion of (2-Aminophenyl)-Ethynyl-Substituted Cyclobutenone Derivatives}

\section{Introduction}

Quinoline derivatives are found in a significant number of natural products and pharmaceuticals. ${ }^{1}$ These alkaloids exhibit a wide array of biological activities including antimalarial, antibacterial, antidiabetic, anti-inflammatory ${ }^{2}$ and antitumor behaviors. ${ }^{3}$ Examples of biologically active quinolines are quinine and 20-(S)-campthothecin. Quinine (1) ${ }^{4}$ and 20-(S)-campthothecin (2) ${ }^{3}$ exhibit antimalarial and excellent antitumor activities, respectively (Figure 1).

\section{Figure 1: Biologically Active Quinolines}

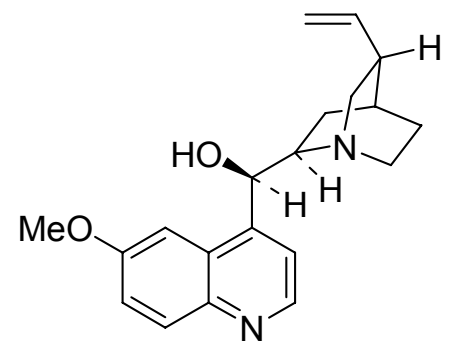

Quinine (1)<smiles>CC[C@]1(C)C(=O)OCc2c1cc1n(c2=O)Cc2cc3ccccc3nc2-1</smiles>

20-(S)-campthothecin (2)

Due to the significant biological activity exhibited by quinolines, development of novel synthetic methods of the quinoline core is of great interest to researchers. 
Classical syntheses of quinolines typically fall into one of two major classes, cyclization of monosubstituted benzenes, usually $\mathrm{N}$-substituted anilines, and cyclizations of ortho-disubstituted benzenes. The first class includes the Skraup, Doebner-von Miller, Knorr and Conrad-Limpach reactions as well as numerous modifications thereof and several less utilized reactions. ${ }^{5}$ The second major class of quinoline syntheses involves either an intramolecular or intermolecular condensation of ortho-disubstituted benzenes. These synthetic methods include the Friedländer and Pfitzinger reactions in addition to several minor variations. ${ }^{5}$

\subsection{Quinoline Syntheses: Intramolecular Cyclization of Anilines}

The Skraup ${ }^{6}$ reaction is one of the oldest methods for the synthesis of quinolines. ${ }^{5}$ For example, quinoline (5) was obtained in moderate yield by heating aniline (3), glycerol (4) and sulfuric acid in nitrobenzene (Scheme 1). This reaction sequence occasionally suffers from the disadvantage of proceeding with extreme violence. ${ }^{5,7}$ Moderators such as acetic or boric acid were eventually added to avoid the fierce nature of these reactions. The reaction is thought to proceed through a Schiff base from the condensation of acrolein, generated in situ, with aniline followed by acid mediated cyclization. Acrolein is known to be the product of acidic treatment of glycerol. ${ }^{7}$

\section{Scheme 1: Skraup Quinoline Synthesis}

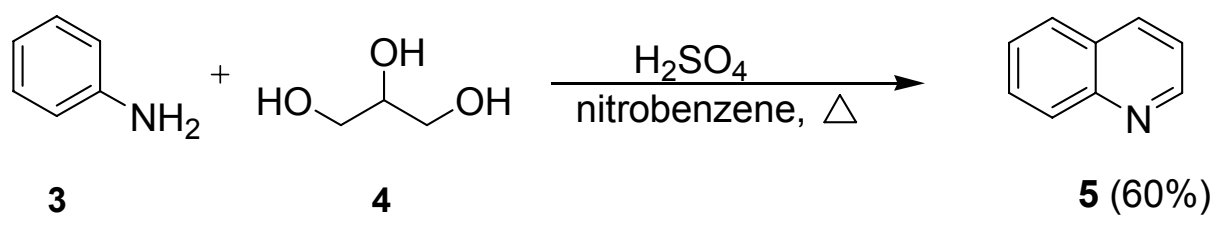


Doebner and von Miller ${ }^{8}$ modified the Skraup procedure by substituting ethylene glycol (6) for glycerol. 2-Methylquinoline (7) was prepared in good yield by the apparent Michael addition of the aniline to crotonaldehyde formed in situ from ethylene glycol (Scheme 2). ${ }^{7}$ Crotonaldehyde is formed via aldol condensation of acetaldehyde in turn formed from ethylene glycol. Mechanistically, the Doebner von-Miller is similar to the Skraup reaction.

\section{Scheme 2: Doebner-von Miller Quinoline Synthesis}

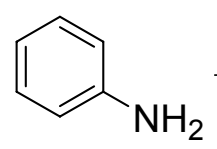

3<smiles>OCCO</smiles>

6

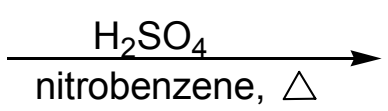<smiles>Cc1ccc2ccccc2n1</smiles>

$7(75 \%)$

The Knorr ${ }^{9}$ quinoline synthesis was the first cyclization involving an acetanilide intermediate. Knorr was able to demonstrate his reaction sequences were applicable to acetoacetylated aryl amines with vacant ortho positions.

For example, 2-hydroxy-4-methylquinoline (9) was formed in good yield from the reaction of ethyl acetoacetate (8) with aniline (Scheme 3). Formation of the acetanilide intermediate is fairly straightforward. The aniline nitrogen attacks the ester carbonyl of the $\beta$-ketoester, which loses an equivalent of alcohol and forms the acetanilide. Cyclization and dehydration is brought about by the heating of the acetanilide in the presence of acid, forming a quinolone intermediate. The quinolone then tautomerizes to produce a hydroxyquinoline. ${ }^{10}$ 


\section{Scheme 3: Knorr Quinoline Synthesis}

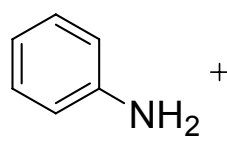

3<smiles>CCOC(=O)CC(C)=O</smiles>

8

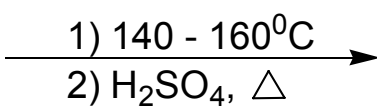

2) $\mathrm{H}_{2} \mathrm{SO}_{4}, \triangle$<smiles>Cc1cc(O)nc2ccccc12</smiles>

$9(70 \%)$

Conrad and Limpach ${ }^{11}$ developed a milder approach to quinoline formation with regiochemical outcomes different from the Knorr reaction. 4-Hydroxy-2methylquinoline (10) was obtained in moderate yield from the acid catalyzed reaction of aniline and ethyl acetoacetate (Scheme 4). ${ }^{12}$ The aniline nitrogen condenses with the $\beta$-carbonyl carbon of the $\beta$-ketoester to form an enamine intermediate. Two mechanisms have been suggested for the formation of the quinoline upon heating. The first mechanism involves enolization of the enamine, $6 \pi$ electrocyclization, loss of alcohol and tautomerization. The second mechanism suggested involves the loss of alcohol to give a ketene, $6 \pi$ electrocyclization and tautomerization. ${ }^{10}$

\section{Scheme 4: Conrad-Limpach Quinoline Synthesis}

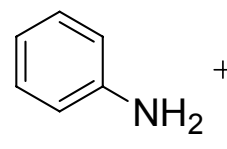

3<smiles>CCOC(=O)CC(C)=O</smiles>

8<smiles>Cc1cc(O)c2ccccc2n1</smiles>

$10(60 \%)$

The regiochemical outcome of the Conrad-Limpach reaction can be affected by the careful adjustment of the reaction conditions. The anilide (11) and enamine 
(12) could be interconverted in the presence of an acid catalyst and an appropriate drying agent at room temperature or by gentle heating. However, the Conrad-Limpach enamino-ester intermediate (12) cannot be converted to the Knorr regiochemistry with direct acidic treatment (Scheme 5). ${ }^{10}$ Heating 12 produces 4-Hydroxy-2-methylquinoline (10). Acid mediated cyclization and dehydration of 11 produces $9 \mathrm{a}$, which tautomerizes to $\mathbf{9}$.

\section{Scheme 5: Similarities of the Conrad-Limpach and Knorr Quinoline \\ Synthesis}

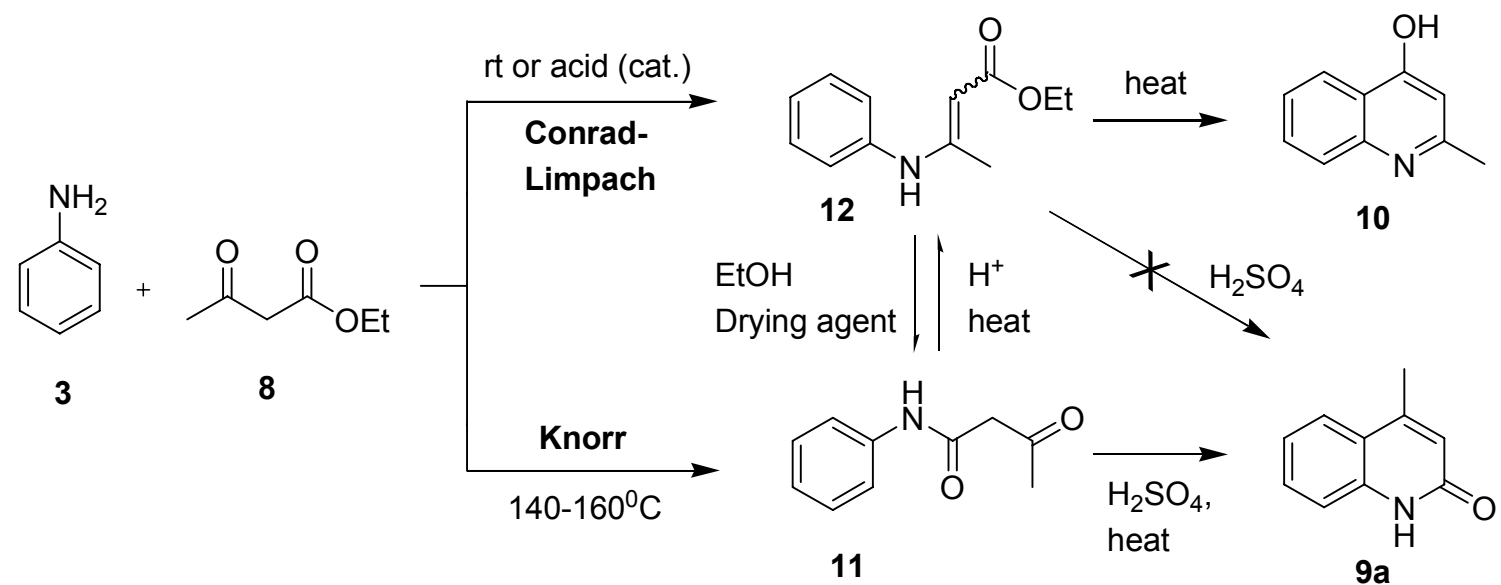

\subsection{Quinoline Syntheses: Cyclization of Ortho-Disubstituted Benzenes}

The Friedländer ${ }^{13}$ synthesis typically involves the condensation of an ortho-amino aldehyde or ketone with another aldehyde or ketone to produce the quinoline core. This reaction sequence is somewhat limited in scope since the orthoamino benzaldehydes are susceptible to self condensation. An intermediate (15) in a synthesis of mappicine was prepared in excellent yield using a protected 2aminobenzaldehyde 13 and ketone 14 (Scheme 6). Two mechanisms have been 
proposed for the Friedländer reaction. The first proposed mechanism proceeds through the formation of the imine followed by an intramolecular Claisen condensation. The second mechanism proposed an intermolecular Claisen condensation followed by cyclization via imine formation. ${ }^{10}$

\section{Scheme 6: Friedländer Quinoline Synthesis}<smiles>O=Cc1ccccc1NC(=O)OCc1ccccc1</smiles>

13

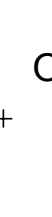<smiles>CCC(OCc1ccccc1)c1cc2n(c(=O)c1C)CCC2=O</smiles>

14

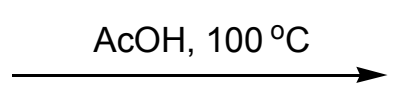

$15(85 \%)$

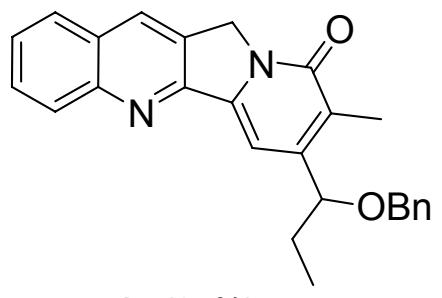

Pfitzinger ${ }^{14}$ improved the Friedländer synthesis by the use of isatin (16) which is significantly more stable than the Friedländer starting materials. ${ }^{10}$

2-Methylquinoline-4-carboxylic acid (18) was synthesized in excellent yield through a Friedländer type reaction (Scheme 7) ${ }^{15}$ The mechanism probably proceeds via isatic acid (17), is formed from base mediated ring opening of isatin (16), followed by an intermolecular condensation to form a Schiff base, usually with acetone. Cyclization of the Schiff base via Claisen condensation occurs between the benzylic carbonyl and the $\alpha$-methylene of the imine intermediate. ${ }^{10}$ 
Scheme 7: Pfitzinger Quinoline Synthesis<smiles>O=C1Nc2ccccc2C1=O</smiles>

16

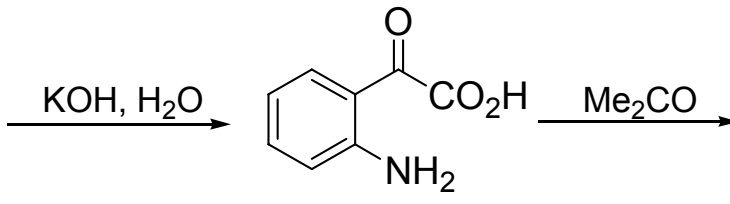

17<smiles>Cc1cc(C(=O)O)c2ccccc2n1</smiles>

$18(91 \%)$

\subsection{Modern Quinoline Syntheses}

More modern syntheses have been developed which are significantly milder than the "witch's brews" of many of the classical methods. A catalytic rutheniumgrafted hydrotalcite $(\mathrm{HT})$ route has been developed. This method uses an amino benzyl alcohol (19), an acetophenone (20) in the presence of molecular oxygen. 2-Substituted quinolines are formed from this reaction. As an example, compound $\mathbf{2 1}$ was formed in good yield. This reaction is superior to the Friedländer reaction since the starting materials are more stable. This is also the first reported example one-pot quinoline synthesis using heterogeneous catalysts. The catalyst was formed by mixing a dilute solution of $\mathrm{RuCl}_{3} \cdot n \mathrm{H}_{2} \mathrm{O}$ with hydrotalcite $\left(\mathrm{Mg}_{6} \mathrm{Al}_{2}(\mathrm{OH})_{16} \mathrm{CO}_{3}\right)$ and triethylamine. During the development of this catalyst system it was noticed that no reaction occurred in the absence of an amine (designated as $\mathrm{N}$ ) or the ruthenium (Scheme 8$).{ }^{16}$ 


\section{Scheme 8: Ruthenium Catalyzed Quinoline Synthesis}<smiles>Nc1ccccc1CO</smiles>

19<smiles>COc1ccc(C(C)=O)cc1</smiles>

20

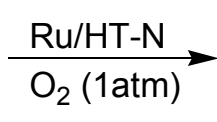<smiles>COc1ccc(-c2ccc3ccccc3n2)cc1</smiles>

$21(79 \%)$

Microwave-assisted reaction technology of small organic molecules has become an attractive tool in organic synthesis. Microwave reactors are simple to operate and significantly enhance reaction rates. A three-component one-pot quinoline synthesis has been developed using aryl aldehydes, aryl amines and alkynes. Brief pulsed microwave irradiation of 22, 23 and 24 in the presence of a copper (I) salt impregnated montmorillonite clay gave the complex quinoline (25) in excellent yield (92\%) (Scheme 9). ${ }^{2}$ In the absence of the montmorillonite clay the reactions typically produced poor yields.

\section{Scheme 9: Microwave Assisted Quinoline Synthesis}

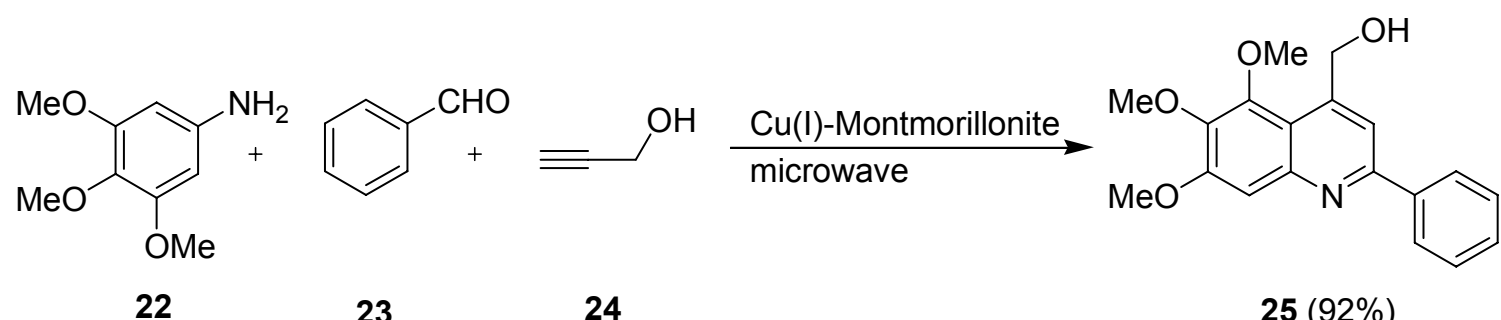

\subsection{Cyclobutenediones}

Cyclobutenediones, "squarate" derivatives, have been shown to be highly versatile $\mathrm{C}_{4}$-synthons that can undergo thermal rearrangement. These building 
blocks and have been utilized for the synthesis of many polysubstituted cyclic compounds including heterocycles. ${ }^{17}$ Thermally induced ring-expansions of 4 alkynyl-4-hydroxy-2-cyclobuten-1-ones are known to produce both 1,4benzoquinones and 5-alkylidenecyclopentenediones. ${ }^{18}$ In general, alkylsubstituted alkynes offer clean conversion to quinones, ${ }^{19}$ whereas TMS-alkyne, alkynes with electron-withdrawing groups or alkenyl-substituted alkynes affords only 5-membered products. Alkynes with electron-donating groups, and arylsubstituted alkynes afford mixtures of 5- and 6-membered rings. Several natural products such as assoanine, ${ }^{19 f}$ perezone, isoperezone,$^{20}$ echinochrome $\mathrm{A}^{21}$ and pentalenene $^{22}$ have been synthesized from squaric acid derivatives (Scheme 10). An example of the squarates being used in an alkylation ring expansion fashion is the synthesis of assoanine. Dimethyl squarate $\mathbf{2 5 b}$ was alkylated with propargyl alkyne 25 a to give $25 \mathrm{c}$ in $87 \%$ yield. Thermal ring expansion and cyclization in $p$-xylene at $138{ }^{\circ} \mathrm{C}$ yielded the tetracyclic hydroxyquinone intermediate $25 \mathrm{~d}$ in $40 \%$ yield. Subsequent conversion to the diphosphonate ester followed by reduction gave assoanine in $18 \%$ yield over two steps (Scheme 11). Due to the versatility of the squarates we sought to use them to synthesize novel heterocycles. 


\section{Scheme 10: Natural Products Synthesized from Squarate Derivatives}

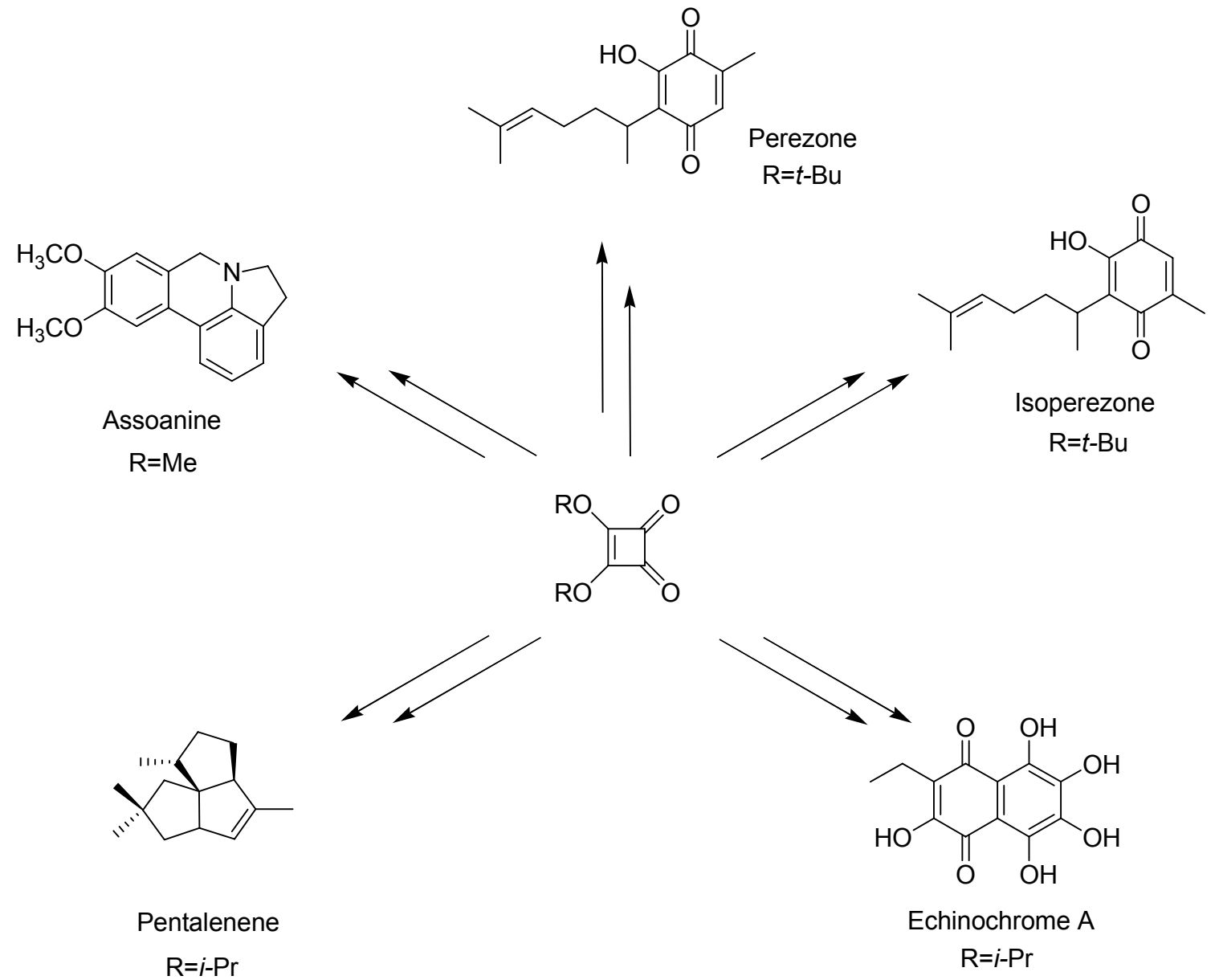




\section{Scheme 11: Synthesis of Assoanine from Dimethyl Squarate}

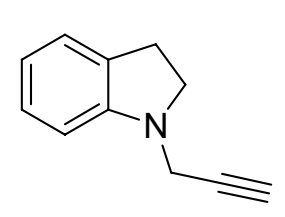

$25 a$

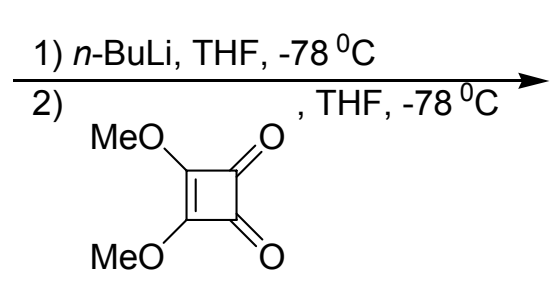

$25 b$

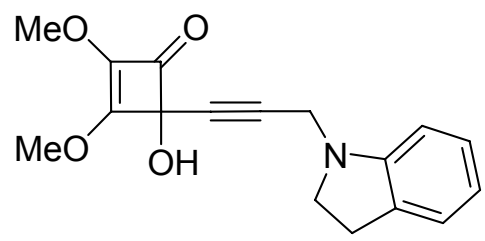

$25 \mathrm{c}(87 \%)$

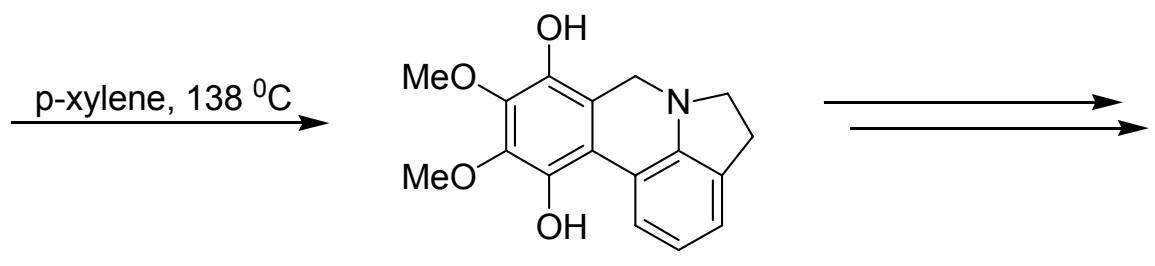

25d $(40 \%)$

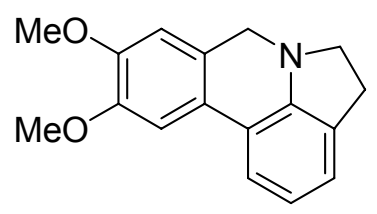

assoanine

25e $(18 \%)$ two steps

\section{Results and Discussion}

Thermal reactions of alkyne substituted cyclobutenone derivatives were examined as a part of a larger project to prepare complex heterocyclic compounds. We envisioned a synthesis proceeding via a ring-expansion of 4hydroxy-2-cyclobuten-1-ones having heteroatoms tethered to the cyclobutenone in the 4-position via an alkyne (Scheme 12). 


\subsection{N-BOC Protected Derivatives}

In our initial reaction, compound 28 a was obtained via dilithiation of the $N$ protected 2-aminophenylalkyne $\mathbf{2 6 a}$ followed by alkylation with 2,3-bis(1methylethoxy)-2-cyclobuten-1,4-dione (diisopropyl squarate 27). Cyclobutenone 28a was dissolved in toluene and heated at reflux overnight. Workup and purification by chromatography on silica gel gave a new compound initially thought to be the 1,4-quinone 29 based on NMR data. Deprotection of the putative compound produced a new product seemingly derived from the formation of a quinone-imine 31. However, upon attempted sodium borohydride reduction of 31 , the spectral data of the product did not correspond to the expected hydroxycarbazole 32. A new methine having a carbon resonance at $68.9 \mathrm{ppm}$ and its corresponding proton resonance at $5.05 \mathrm{ppm}$ was observed. These resonances cannot be assigned to any of the carbons or protons expected for hydroxycarbazole 32. Submitting the reduction product to gHMQC (gradient Heteronuclear Multiple Quantum Coherence, one bond ${ }^{1} \mathrm{H}$ and ${ }^{13} \mathrm{C}$ heterocorrelation) (Figure 2) and gHMBC (gradient Heteronuclear Multiple Bond Coherence, two to four bond ${ }^{1} \mathrm{H}$ and ${ }^{13} \mathrm{C}$ hetero-correlation) (Figure 3) NMR experiments revealed that the product was in fact the fused quinolinol 35a and not the hydroxycarbazole 32 . The ${ }^{1} \mathrm{H},{ }^{13} \mathrm{C}$, gHMBC and gHMBC data are summarized in Table 1. This in turn means that the ring-expansion did not yield the 1,4-quinone $\mathbf{2 9}$ but its five-membered counterpart 33a. It should be noted that, this reaction was very selective with regard to ring-size. Only the fivemembered ring was observed by ${ }^{1} \mathrm{H}$ NMR of the crude reaction mixture and the 
purified product. Subsequent removal of the BOC group gave the fused quinoline 34a and reduction yielded the fused quinolinol 35a (Scheme 13).

\section{Scheme 12: Initially Planned Reaction Sequence}

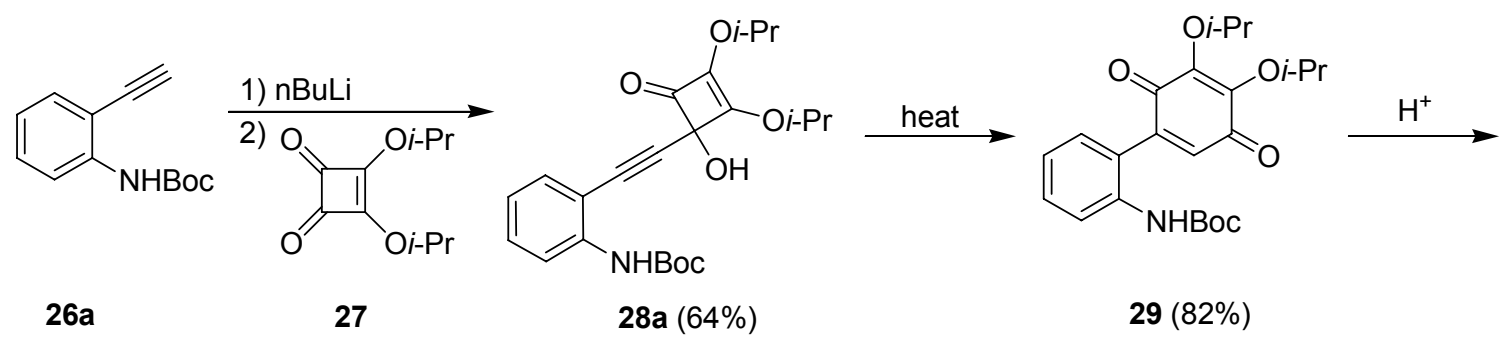

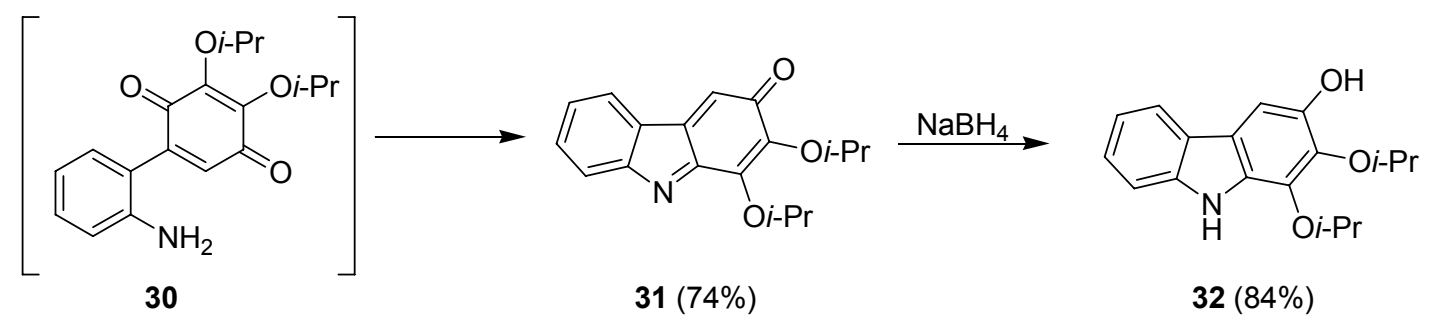

Scheme 13: General Reaction Sequence for the Synthesis of Novel

\section{Quinolines}<smiles>CCCOC1=C(O[GaH])C(C)C1(O)C#Cc1ccccc1N[R6](=O)OC</smiles>

$28 a$<smiles>CCCOC1=C(O[PH2+][PH2+])C(=O)C(=Cc2ccccc2N)C1=O</smiles>

33a $(82 \%)$<smiles>[Y]c1ccc2cc3c(nc2c1)C(OP)=C(O[In])C3=O</smiles>

$34 a(74 \%)$<smiles>[BH3-][13NH2]</smiles><smiles>CCCOC1=C(OCCC)C(O)c2cc3ccccc3nc21</smiles>

$35 a(84 \%)$ 
Table 1: Summary of NMR Data for the Structural Determination of 35a

\begin{tabular}{|c|c|c|c|}
\hline Position & $\delta_{\mathrm{C}}$ & $\delta_{\mathrm{H}}{ }^{\mathrm{a}}$ & HMBC \\
\hline 1 & 68.9 & $5.05 \mathrm{~s}$ & $\mathrm{C}-2, \mathrm{C}-3, \mathrm{C}-9 \mathrm{a}, \mathrm{C}-3 \mathrm{a}, \mathrm{C}-9$ \\
\hline 2 & 159.8 & & \\
\hline 3 & 151.2 & & \\
\hline $3 \mathrm{a}$ & 131.1 & & \\
\hline 4 & & & \\
\hline $4 \mathrm{a}$ & 126.4 & & \\
\hline 5 & 128.0 & $7.64 \mathrm{~d}$ & $\mathrm{C}-8 \mathrm{a}, \mathrm{C}-7, \mathrm{C}-4 \mathrm{a}, \mathrm{C}-8$ \\
\hline 6 & 124.9 & $7.36 \mathrm{t}$ & $\mathrm{C}-8, \mathrm{C}-4 \mathrm{a}, \mathrm{C}-7$ \\
\hline 7 & 128.8 & $7.56 \mathrm{t}$ & $\mathrm{C}-8 \mathrm{a}, \mathrm{C}-5, \mathrm{C}-9, \mathrm{C}-8$ \\
\hline 8 & 128.6 & $7.97 \mathrm{~d}$ & C-4a, C-6 \\
\hline $8 \mathrm{a}$ & 148.4 & & \\
\hline & & & $\begin{array}{c}\text { C-2, C-8a, C-9a, C-1, C-8, } \\
\text { C-6, C-4a }\end{array}$ \\
\hline 9 & 128.2 & $7.78 \mathrm{~s}$ & \\
\hline $9 \mathrm{a}$ & 133.9 & & \multicolumn{2}{c}{} \\
\hline
\end{tabular}

Note: a) Correlations of ${ }^{1} \mathrm{H}$ and ${ }^{13} \mathrm{C}$ made by gHMQC (Figure 2)

The proposed mechanism of the ring expansion of $\mathbf{2 8 a}$ is depicted in Scheme 14. The mechanism probably proceeds through the electrocyclic ring opening of $\mathbf{2 8 a}$ to give ketene 29a followed by the 5-endo-dig cyclization forming intermediate 29d. Subsequent hydrogen atom abstraction followed to give the diradical $29 \mathrm{e}$ and later 5-alkylidenecyclopentendione (33a). The anticipated mechanism for the ring expansion to give the 1,4-benzoquinones also depicted in Scheme 14. It should be noted that this mechanistic pathway did not occur since we did not observe the benzoquinone. The mechanism would probably proceed through the electrocyclic ring opening of $\mathbf{2 8 a}$ to give ketene 29 a followed by the 6 -endo-dig cyclization forming intermediate $\mathbf{2 9 b}$. Subsequent hydrogen atom abstraction followed to give the diradical $29 \mathrm{c}$ and later 1,4-quinone formation (29). 
Scheme 14: Proposed Mechanism for the Formation of the Alkylidene
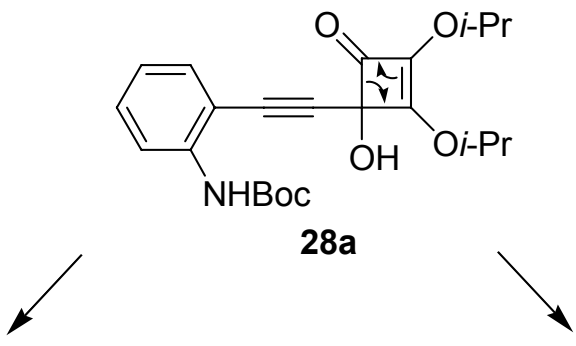

$$
[
$$<smiles>CCCOc1c(O)c(O)c(C#Cc2ccccc2N)c(OCCC)c1OCC</smiles>

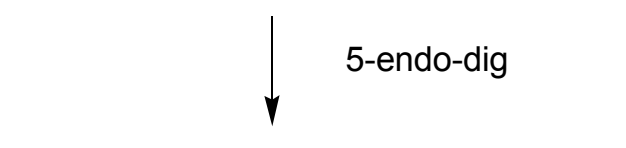<smiles>C1CC1</smiles>

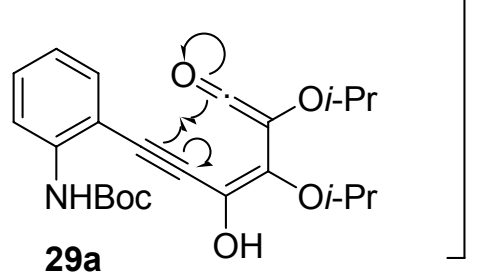<smiles>C1CC1</smiles><smiles>CCCOC1=C(O)C(OCCC)=C(O)C1=Cc1ccccc1N</smiles>
29d<smiles>CC=C[AlH]</smiles><smiles>C1CC1</smiles><smiles>C1CC1</smiles><smiles>CCCOC1(OC)COC(=O)/C1=C\c1ccccc1N</smiles>

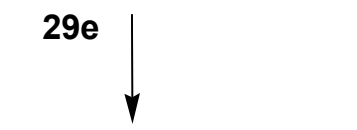<smiles>CCCOC1=C(OCCC)C(=O)C(=Cc2ccccc2N)C1=O</smiles> 

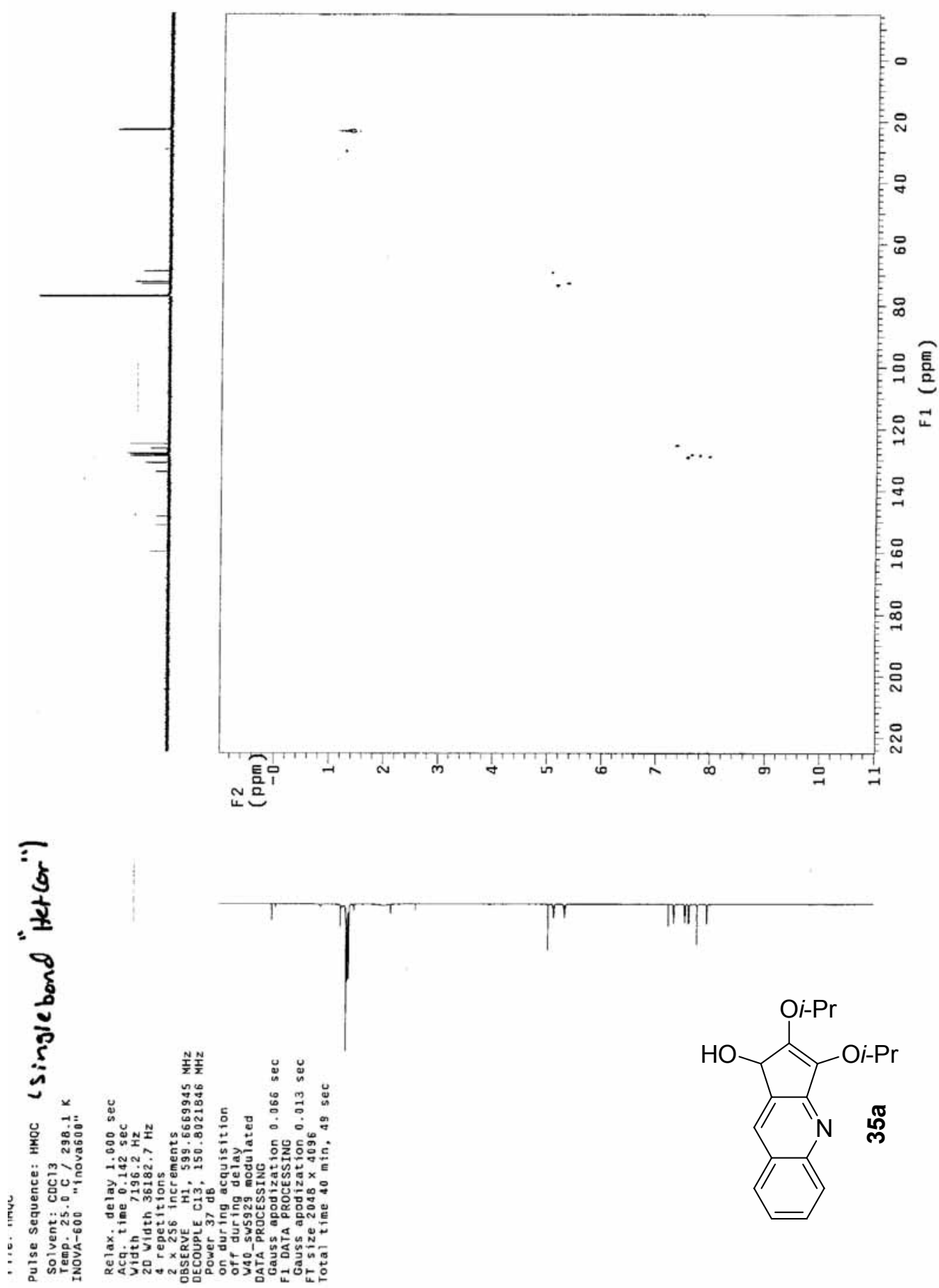

Figure 2: Gradient Heteronuclear Multiple Quantum Coherence Spectrum of 35 

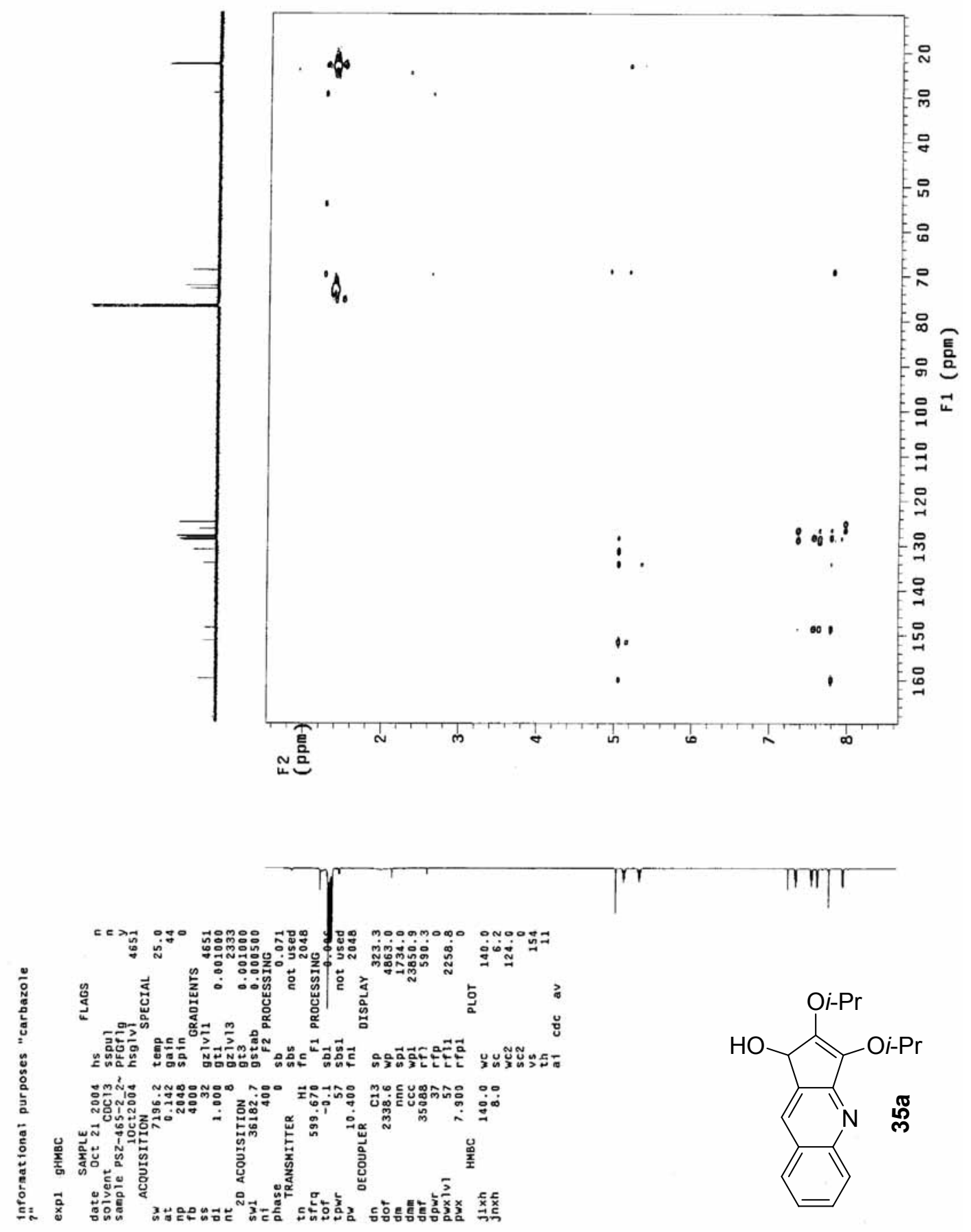

Figure 3: Gradient Heteronuclear Multiple Bond Coherence Spectrum of 35 
With this novel route to highly functionalized fused quinolines in hand the scope and limitations were examined. The starting materials were prepared from 2iodoarylamines via a sequence of steps consisting of $\mathrm{N}-\mathrm{BOC}$ protection of the amino group, Sonogashira coupling using ethynyl trimethylsilane and desilylation. The first three steps generally proceeded smoothly and often in excellent yield (Scheme 15). The $\mathrm{N}$-BOC protection reactions proved best when the free aniline was treated with excess NaHMDS ${ }^{23}$ followed by the dropwise addition of a $\mathrm{BOC}_{2} \mathrm{O} / \mathrm{THF}$ solution. Several other reaction conditions were attempted for the $\mathrm{N}$-BOC protection of the anilines, but all gave poor yields of products. The Sonogashira ${ }^{24}$ reactions initially gave a significant amount of homocoupling of trimethylsilyl acetylene product which were hard to separate from the desired product. The homocoupling problem was alleviated by reducing the amount of the alkyne from 1.1 equivalents to 1.05 equivalents. The two methods ${ }^{65,25}$ used for the desilylation of the TMS-protected products (38b-38e), NaOH and KF. Deprotection using $\mathrm{NaOH}$ often gave higher yields however, the KF method was significantly faster. In addition, the KF method was superior to the $\mathrm{NaOH}$ method for the pyridine derivative (38e). 


\section{Scheme 15: Synthesis of the N-BOC Protected Starting Materials}

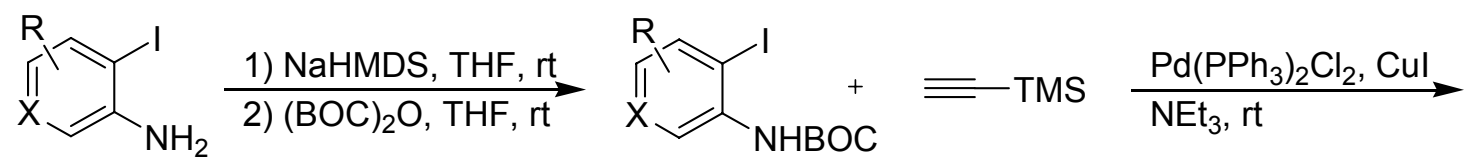

36b $\mathrm{R}=4-\mathrm{Cl}, \quad \mathrm{X}=\mathrm{CH}$

36c $\mathrm{R}=5-\mathrm{OMe}, \mathrm{X}=\mathrm{C}$

36d $R=5-M e, \quad X=C$

36e $\mathrm{R}=\mathrm{H}, \quad \mathrm{X}=\mathrm{N}$
$37 \mathrm{~b} 81 \%$

37 c $92 \%$

$37 d 88 \%$

37 e $60 \%{ }^{26}$

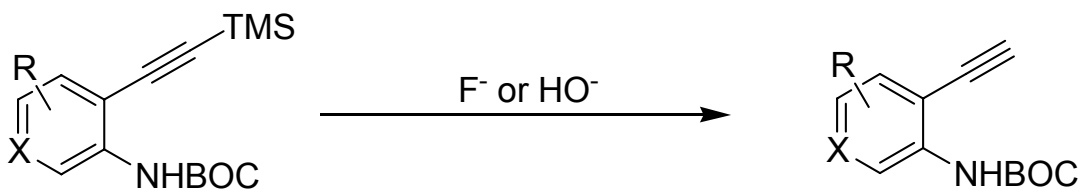

\begin{tabular}{|c|c|c|c|}
\hline $\begin{array}{l}\text { 38b } R=4-C l, \\
\text { 38c } R=5-O M e, \\
\text { 38d } R=5-M e, \\
\text { 38e } R=H,\end{array}$ & $\begin{array}{l}X=\mathrm{CH} \\
X=\mathrm{C} \\
X=\mathrm{C} \\
X=N\end{array}$ & $\begin{array}{l}91 \% \\
80 \% \\
100 \% \\
95 \%\end{array}$ & $\begin{array}{l}\text { 26b } 92 \%^{a} \\
\text { 26c } 84 \%^{a} \\
\text { 26d } 79 \%^{a} \\
\text { 26e } 61 \%^{a}\end{array}$ \\
\hline
\end{tabular}

Notes: a) $\mathrm{NaOH}, \mathrm{EtOH}$ b) $\mathrm{KF}, \mathrm{MeOH}$

The terminal alkynes were dilithiated and reacted with diisopropyl squarate. The alkylations were problematic and significant amounts of the alkyne starting material was often recovered (Scheme 16). One explanation for recovering significant amounts of the starting alkyne could be due to lower solubility of the dianion in the colder solutions. Multiple reaction conditions were investigated to optimize the alkylation conditions (Table 2). 


\section{Scheme 16: Alkylation of Diisopropyl Squarate}

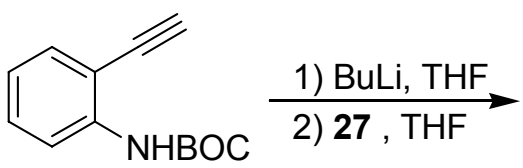

$26 a$

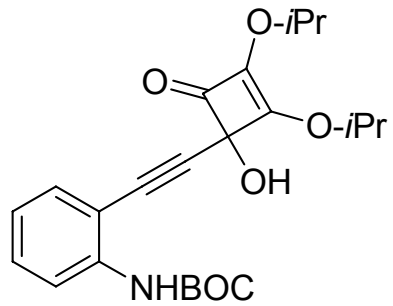

28a

Table 2: Alkylation Conditions of 26a to give 28a

\begin{tabular}{|c|c|c|c|}
\hline Entry & Base & Reaction Conditions & Yield 28a \\
\hline $1^{a}$ & 2.0 eq. $n$-BuLi & $-78{ }^{\circ} \mathrm{C}, 20 \mathrm{~min}$. , then $27,-78{ }^{\circ} \mathrm{C}, 30 \mathrm{~min}$. & $48 \%$ \\
\hline $2^{a}$ & 2.5 eq. $n$-BuLi & $\begin{array}{l}-78^{\circ} \mathrm{C}, 20 \text { min., then } 27,-78^{\circ} \mathrm{C}-\mathrm{rt}, 30 \\
\text { min. }\end{array}$ & $62 \%^{\mathrm{c}}$ \\
\hline $3^{b}$ & 3.0 eq. $n$-BuLi & $-78{ }^{\circ} \mathrm{C}, 20 \mathrm{~min}$. , then $27,-78{ }^{\circ} \mathrm{C}, 30 \mathrm{~min}$. & NR \\
\hline $4^{\mathrm{b}}$ & 2.5 eq. $t$-BuLi & $-78{ }^{\circ} \mathrm{C}, 30 \mathrm{~min}$., then $27,-78{ }^{\circ} \mathrm{C}-\mathrm{rt}, 1 \mathrm{~h}$. & unidentifiable \\
\hline $5^{b}$ & 2.5 eq. $t$-BuLi & $\begin{array}{l}-78^{\circ} \mathrm{C}, 30 \text { min., then } 27,-78{ }^{0} \mathrm{C}-\mathrm{rt}, 30 \\
\text { min. }\end{array}$ & $31 \%$ \\
\hline $6^{\mathrm{b}}$ & 3.0 eq. $t$-BuLi & $-78{ }^{\circ} \mathrm{C}, 1 \mathrm{~h}$. , then $27,-78{ }^{\circ} \mathrm{C}-\mathrm{rt}, 12 \mathrm{~h}$ & unidentifiable \\
\hline $7^{\mathrm{b}}$ & 2.5 eq. $n$-BuLi & $\begin{array}{l}-78{ }^{\circ} \mathrm{C} 1 \mathrm{~h} \text {, to }-20{ }^{\circ} \mathrm{C}, 1 \mathrm{~h} ., \text { then } 27,-78{ }^{\circ} \mathrm{C} \\
-\mathrm{rt}, 1 \mathrm{~h} \text {. }\end{array}$ & unidentifiable \\
\hline $8^{a}$ & 2.5 eq. $t$-BuLi & $-78{ }^{\circ} \mathrm{C}, 30 \mathrm{~min} .$, then $27,-78{ }^{\circ} \mathrm{C}-\mathrm{rt}, 1 \mathrm{~h}$. & $20 \%$ \\
\hline $9^{a}$ & \begin{tabular}{|l|}
2.5 eq. \\
NaHMDS \\
\end{tabular} & $-78{ }^{\circ} \mathrm{C}, 1 \mathrm{~h}$, then $27,-78{ }^{\circ} \mathrm{C}, 18 \mathrm{~h}$. & NR \\
\hline $10^{\mathrm{a}}$ & 2.5 eq. $n$-BuLi & $-78{ }^{\circ} \mathrm{C}, 1 \mathrm{~h}$, then $27, \mathrm{CeCl}_{3},-78{ }^{\circ} \mathrm{C}, 1 \mathrm{~h}$. & NR \\
\hline $11^{\mathrm{b}}$ & 2.5 eq. $n$-BuLi & $-10{ }^{\circ} \mathrm{C}, 15 \mathrm{~min}$., then $27,-10{ }^{\circ} \mathrm{C}, 30 \mathrm{~min}$. & $64 \%^{d}$ \\
\hline
\end{tabular}

Notes: All reactions in this table used 1 equivalent of $26 a$ and 27 a) The dilithiated aniline was added to the squaric acid derivative, b) The squaric acid derivative was added to the dilithiated aniline c) High yield obtained in one case, repeated reaction gave inconsistent results d) Consistent results 
It should also be noted that adding two equivalents of the alkyne (26a) gave only a $64 \%$, based on the converted squarate, yield of $\mathbf{2 8 a}$. This reaction sequence was subsequently abandoned since only approximately $30 \%$ of the alkyne $\mathbf{2 6 a}$ was converted. It was discovered that the conditions of entry 11 gave the most consistent alkylation results. Therefore, these conditions were used without modification for the alkylation of the other derivatives (26b-26d) with the exception of the pyridine (26e). It was found that the pyridine derivative (28e) was obtained in slightly higher yields (approximately 10\%) when allowed to warm to room temperature over the last 10 minutes of the reaction, prior to quenching. Upon alkylation of the 5-methoxy-substituted substrate (26c), an inseparable mixture of the expected alkylation product $\mathbf{2 8 c}$ and alkylation of the squarate $\mathbf{2 7}$ with excess butyl lithium was isolated (structure not shown) (Scheme 16). Alkylation of diisopropyl squarate (27) was only seen in the case of the 5methoxy-substituted substrate (26c) (Scheme 16a). 


\section{Scheme 16a: Alkylation of Diisopropyl Squarate with other N-BOC Protected Derivatives}<smiles>[R]c1ccc(N)c(C#C)c1[R9]</smiles>

$\frac{\text { 1) } n \text {-BuLi, THF, }-10{ }^{\circ} \mathrm{C}}{2)}$<smiles>[R]c1cc(N[R16]([H])([H])[H])c(C#CC2(O)C(=O)C(OC(C)C)=C2OC(C)C)c[Y]1[H]</smiles>

26b R=4- $\mathrm{Cl} ; \quad \mathrm{X}=\mathrm{CH}$

26c $\mathrm{R}=5-\mathrm{OMe}, \mathrm{X}=\mathrm{C}$

26d 5-Me, $\quad X=C$

26e $\mathrm{R}=\mathrm{H}, \quad \mathrm{X}=\mathrm{N}$ 28b $76 \%$

28d $50 \%$

28e $57 \%^{\text {b }}$ 28c not calculated ${ }^{a}$

Notes: a) Inseparable mixture with the butyl addition product of diisopropyl squarate, b) The reaction was warmed to room temp for 10 minutes prior to quench

The Sonogashira reaction was also briefly investigated as an alternative to deprotonation and alkylation of the $N$-protected ethynyl anilines. Squarate derivative ${ }^{27} 39$ was stirred briefly with $5 \% \mathrm{Pd}\left(\mathrm{PPh}_{3}\right)_{2} \mathrm{Cl}_{2}$ and $5 \% \mathrm{Cul}$ in triethylamine followed by the addition of $N$-protected aryl iodide 37 a were allowed to stir overnight at room temperature. Unfortunately, a low yield of the anticipated product 28a was obtained. Addition of a full equivalent of Cul was found to increase the yields. Generally, the deprotonation route was better except in one case (Scheme 17). Apart from the anisole derivative 28c that was cleanly synthesized in $65 \%$ yield, the deprotonation-alkylation route gave a better yield of product. We were somewhat surprised that the toluene derivative (37d) did not react under the Sonogashira reaction conditions. 


\section{Scheme 17: Alternate Method for the Synthesis of Alkylation Products}

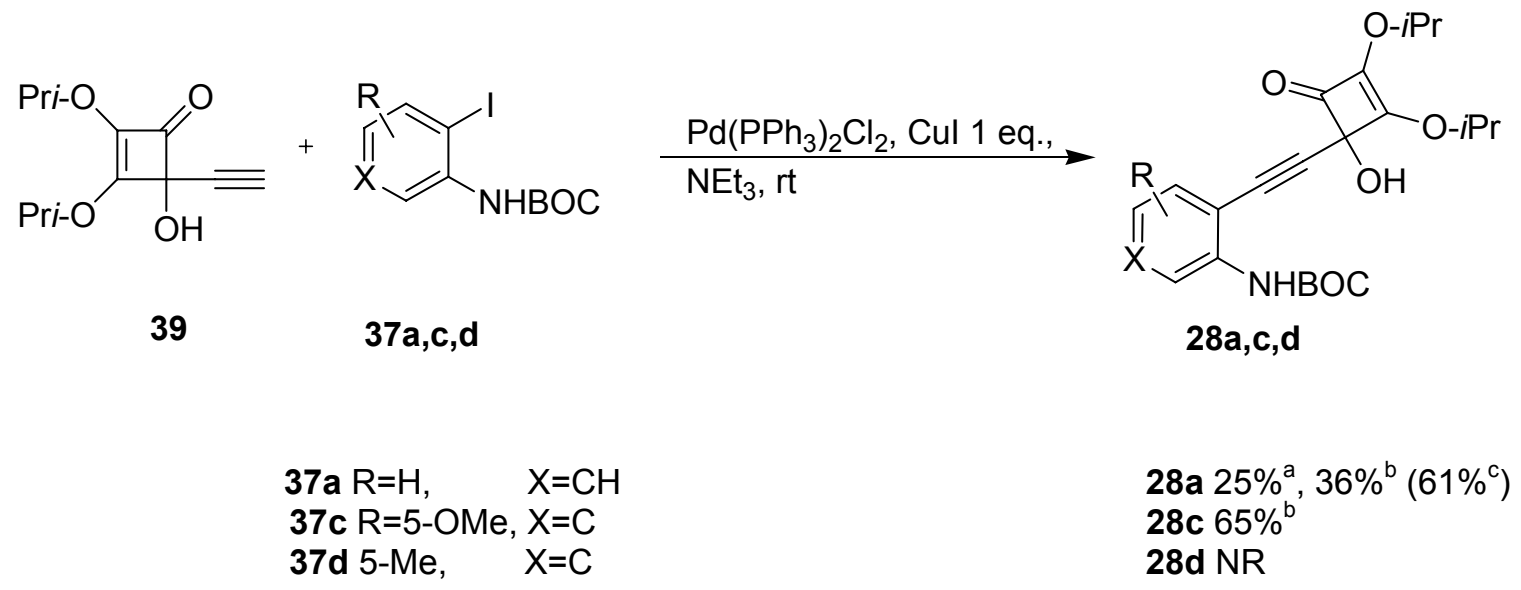

Notes: a) $5 \%$ Cul added, b) 1 equivalent of Cul was added, c) based on recovered iodide

With a number of alkyne-cyclobutenones in hand the ring expansion to form cyclopenta[b]quinolines was examined (Scheme 18). Thermal ring-expansion of 28a-28e gave in all cases the expected cyclopentenediones 33a-33e. Toluene was found in general to be a good solvent for the ring expansions with the exception of the pyridine derivative. However, a cleaner conversion of the pyridine $33 \mathrm{e}$ was observed in 1,2-dichloroethane (1,2-DCE). ${ }^{70}$ Again, all thermal reactions were selective with regard to ring-size, and only five-membered rings were observed by ${ }^{1} \mathrm{H}$ NMR. Acidic removal of the BOC-group and spontaneous cyclization gave the expected cyclopenta[b]quinoline-1-ones 34a-34e. The pyridine derivative (33e) proved to be more difficult to deprotect compared to the toluene (33d), anisole (33c) and chloro (33b) derivatives. $\mathrm{HCl}$ in EtOAc or $\mathrm{HCl}$ in $\mathrm{MeOH}$ for the $\mathrm{N}$-deprotection of the pyridine derived compound yielded neither starting material nor any product. The use of $\mathrm{TMSI}^{28}$ is typically a very fast method for the removal of $\mathrm{N}$-BOC groups, however, in the case of $33 \mathrm{e}$ only $3 \%$ of the fused aza-quinolone $34 \mathrm{e}$ was obtained. Trifluoroacetic acid in $\mathrm{CH}_{2} \mathrm{Cl}_{2}$ at 
reflux was the only successful deprotection of the pyridine and yielded the azaquinolone $34 \mathrm{e}$ in $86 \%$ yield. Finally, sodium borohydride reduction of $34 a-34 e$ furnished the cyclopenta[b]quinoline-1-ols 35a-35e (Scheme 17). The reduction product 35 e was not fully characterized due to rapid decomposition and was therefore only tentatively assigned as the aza-quinolinol.

${ }^{1} \mathrm{H}$ NMR data was used to identify which stage the reactions were. We were able to identify the basic structures by observing the chemical shifts of the isopropyl methine (heptets) and the isopropyl methyls (doublets). Upon reduction we were also able to track the new methine formed. The typical range for the resonances of the alkylation products (28a-28e) ranged from $4.90-4.85$ and 5.02 for the methine signals and 1.47-1.46 and 1.32-1.29 for the isopropyl methyls. For the ring expansion (33a-33e) the methine protons ranged from 5.61-5.55 as overlapping heptets, the methyl doublets overlapped with a range of 1.42-1.36. The quinolinone (43a-43e) methines ranged from 5.72-5.62 and 5.32-5.23 as separate signals, the methyl resonances ranged from $1.48-1.51$ and $1.34-1.38$ as separate signals. The quinolinol (35a-35d) methine signals ranged from 5.255.38 and $5.12-5.15$ as separate signals and the methyls $1.37-1.34$. The new methine for the reduction ranged from 5.01-5.06 ppm. 


\section{Scheme 18: Expansion, Deprotection and Reduction of BOC Protected}

\section{Derivatives}

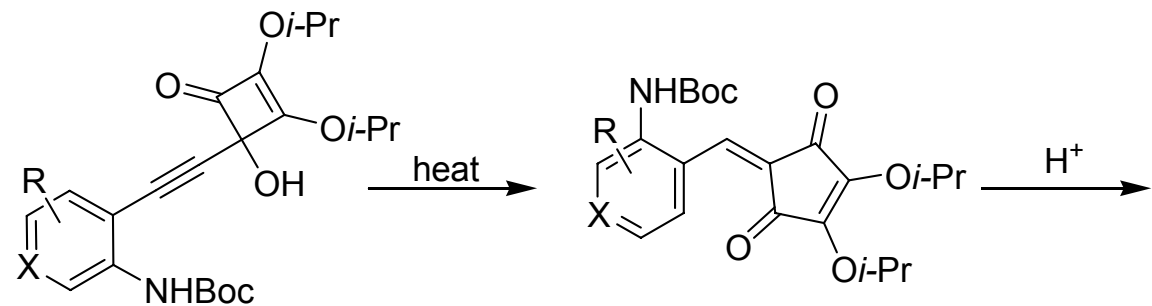

\begin{tabular}{|c|c|}
\hline $\begin{array}{l}\text { 28a } \mathrm{R}=\mathrm{H}, \\
\text { 28b } \mathrm{R}=4-\mathrm{Cl} ; \\
\text { 28c } \mathrm{R}=5-\mathrm{OMe}, \mathrm{X} \\
\text { 28d } \mathrm{X}=5-\mathrm{Me}, \\
\text { 28e } \mathrm{R}=\mathrm{H},\end{array}$ & $\begin{array}{l}X=\mathrm{CH} \\
X=\mathrm{CH} \\
X=\mathrm{C} \\
X=\mathrm{C} \\
X=\mathrm{N}\end{array}$ \\
\hline
\end{tabular}<smiles>[Y]c1ccc2nc3c(cc2c1)C(O)C(O[Po])=C3O[Ga]</smiles>

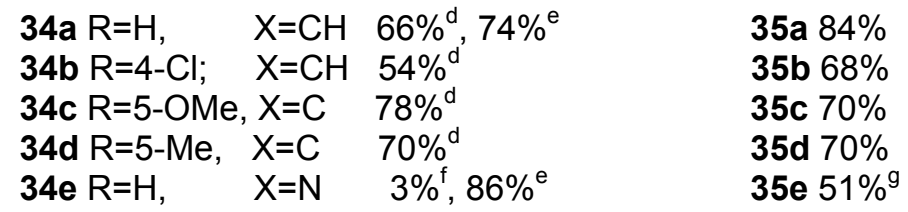

Notes: a) In refluxing toluene, b) Yield calculated over two steps, c) refluxing 1,2-DCE, d) $\mathrm{HCl}$ was used for the deprotection e) TFA was used for the deprotection f) TMSI was used for the deprotection g) Tentative assignment due to rapid decomposition

The cyclopenta[b]quinoline-1-ols (35a-35d) were slowly oxidized to the corresponding cyclopenta[b]quinoline-1-ones (34a-34d) upon standing in air as determined via ${ }^{1} \mathrm{H}$ NMR, the yields were not calculated for this oxidation (Scheme 19). 


\section{Scheme 19: Air Oxidation of the Quinolinol}<smiles>[R17]OC1=C(O[R16])c2nc3c[X]c([R])cc3cc2C1=O</smiles>

As a final example, 3-(1-methylethoxy)-4-methyl-3-cyclobutene-1,2-dione ${ }^{69}$ was reacted with the dianion formed from $\mathbf{2 6 a}$ to give the expected alkylation product 41 as a single regioisomer in $48 \%$ (59\% based on recovered 26a). The alkylation occurred on the more electrophilic carbonyl carbon. The carbonyl in conjugation with the alkoxy-group is typically less reactive due to resonance contributions from the alkoxy oxygen. Ring-expansion of 41 in 1,2-DCE at reflux furnished the expected cyclopentendione $\mathbf{4 2}$ as an 8.3:1 E/Z (by NMR integration) mixture in $49 \%$ overall yield. A poor yield of $\mathbf{4 2}$ was obtained in refluxing toluene. The E-isomer has previously been shown to be the kinetic product from ring-expansions of related compounds. ${ }^{29}$ Although condensation of the free amine with the carbonyl having a conjugated alkoxy-group is expected to be much slower, we were surprised to observe only one isomer (43) upon BOCprotecting group removal. The product is derived from cyclization of the thermodynamically more stable Z-isomer. This observation can be explained by a facile $E$ to $Z$ isomerization of the alkene prior to cyclization. Isomerization of E42 to Z-42 was observed by ${ }^{1} \mathrm{H}$ NMR simply by allowing the NMR sample to sit for a few hours at ambient temperature. Reduction of $\mathbf{4 3}$ gave $\mathbf{4 4}$ however, this compound was not fully characterized due to very rapid decomposition and was 
only tentatively assigned as 44 (Scheme 20 ). ${ }^{1} \mathrm{H}$ and ${ }^{13} \mathrm{C}$ NMR spectra of 44 were in full agreement with the structure of $\mathbf{4 4 .}$

\section{Scheme 20: Reaction Sequence for the Semisquarate Derivative}
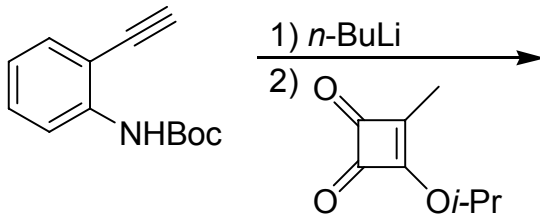

$26 a$

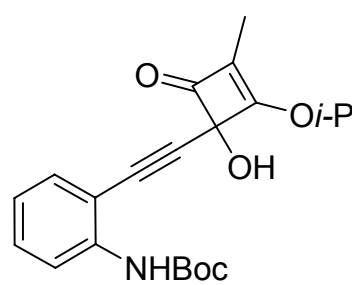

$41(59 \%)$

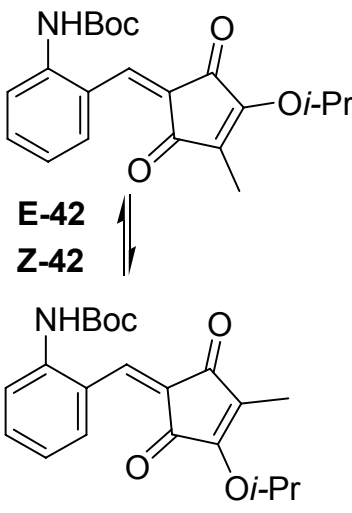

(49\%) 8.3:1 E:Z<smiles>CCCOC1=C(C)C(=O)c2cc3ccccc3nc21</smiles>

$\stackrel{\mathrm{NaBH}_{4}}{\longrightarrow}$<smiles>CCCOC1=C(C)C(O)c2cc3ccccc3nc21</smiles>

$43(56 \%)$

$44(81 \%)$ rapid decomposition

\section{2. $\mathbf{N}$-Acetyl and $\mathbf{N}$-benzyl aniline}

As a subproject to the $\mathrm{N}-\mathrm{BOC}$ protected anilines two additional amino protective groups were studied. Our goal was to test the theory that a change in the amino protecting group would affect the thermal ring expansion i.e. 5- versus 6membered ring formation. The $\mathrm{N}$-acetyl and the $\mathrm{N}$-benzyl protective groups were studied. The $N$-acetyl ${ }^{30}(\mathbf{4 5})$ and $N$-benzyl ${ }^{31}(\mathbf{4 7})$ derivatives were synthesized according to literature procedures. Diisopropyl squarate (27) was alkylated by 
the $\mathrm{N}$-acetyl derivative (45) in $72 \%$ yield by the addition of the dianion to the squarate derivative. The yields were approximately $20 \%$ lower when the squarate was added to the dianion (Scheme 21). Alkylations using N-Benzyl aniline (47) proved to be very problematic and only poor yields were obtained (Scheme 22). Multiple conditions for the alkylation of the $N$-benzyl derivative (47) were investigated all giving disappointing results (Table 2). It should also be noted that alkylation of the free aniline (not depicted) gave unidentifiable products.

\section{Scheme 21: Alkylation of Diisopropyl Squarate with 45}<smiles>C#Cc1ccccc1NC(C)=O</smiles>

45

\author{
1) n-BuLi, THF, $-78{ }^{\circ} \mathrm{C}, 20 \mathrm{~min}$. \\ 2) $27, \mathrm{THF},-78^{\circ} \mathrm{C}, 30 \mathrm{~min}$
}

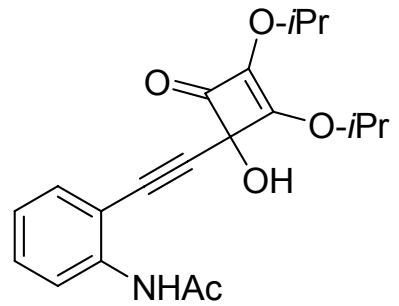

$46(72 \%)$

\section{Scheme 22: Alkylation of Diisopropyl Squarate with 47}<smiles>C#Cc1ccccc1NCc1ccccc1</smiles>

47

$$
\underset{\text { 1) } n \text {-BuLi, THF }}{\stackrel{27, \text { THF }}{\longrightarrow}}
$$

$48(24 \%, 39 \% a)$

Note: a) Yield based on recovered 47 
Table 3: Alkylation Conditions for $\mathbf{4 7}$

\begin{tabular}{|c|c|c|c|}
\hline Trial & Base & Reaction Conditions & Yield of $\mathbf{4 8}$ \\
\hline 1 & 1.05 eq. $n$-BuLi & $-40{ }^{\circ} \mathrm{C}, 15 \mathrm{~min}$., then $27,-40{ }^{\circ} \mathrm{C}, 30 \mathrm{~min}$. & $\begin{array}{l}19 \%, \\
50 \%{ }^{a}\end{array}$ \\
\hline 2 & 1.05 eq. $n$-BuLi & $-10{ }^{\circ} \mathrm{C}, 15 \mathrm{~min}$. , then $27,-10{ }^{\circ} \mathrm{C}, 30 \mathrm{~min}$. & $\begin{array}{l}24 \%, \\
39 \%{ }^{a}\end{array}$ \\
\hline 3 & 2.05 eq. $n$-BuLi & $-10{ }^{\circ} \mathrm{C}, 30 \mathrm{~min}$. , then $27,-10{ }^{\circ} \mathrm{C}-\mathrm{rt}, 1 \mathrm{~h}$. & $14 \%$ \\
\hline 4 & 1.7 eq. $n$-BuLi & $-10{ }^{\circ} \mathrm{C}, 15 \mathrm{~min}$. , then $27,-10{ }^{0} \mathrm{C}-\mathrm{rt}, 30 \mathrm{~min}$. & NR \\
\hline 5 & 1.7 eq. $n$-BuLi & $-10{ }^{\circ} \mathrm{C}, 20$ min., then $27,-10{ }^{\circ} \mathrm{C}-\mathrm{rt}, 30 \mathrm{~min}$. & $10 \%$ \\
\hline 6 & 1.7 eq. $n$-BuLi & $-10{ }^{\circ} \mathrm{C}, 20 \mathrm{~min}$. , then $27,-10{ }^{\circ} \mathrm{C}-\mathrm{rt}, 1 \mathrm{~h}$. & $\begin{array}{l}21 \%, \\
26 \%{ }^{a}\end{array}$ \\
\hline 7 & 1.1 eq. $n$-BuLi & $-10{ }^{\circ} \mathrm{C}, 15 \mathrm{~min}$., then $27,-10{ }^{\circ} \mathrm{C}-\mathrm{rt}, 30 \mathrm{~min}$. & $23 \%$ \\
\hline 8 & 1.5 eq. $n$-BuLi & $-10{ }^{\circ} \mathrm{C}, 15 \mathrm{~min} .$, then $27,-10{ }^{\circ} \mathrm{C}-\mathrm{rt}, 30 \mathrm{~min}$. & $7 \%, 9 \%^{a}$ \\
\hline 9 & $\begin{array}{l}1.1 \text { eq. } \\
\text { NaHMDS }\end{array}$ & $-10{ }^{\circ} \mathrm{C}, 10 \mathrm{~min}$. , then $27,-10{ }^{\circ} \mathrm{C}, 30 \mathrm{~min}$. & $\begin{array}{l}10 \%, \\
12 \%^{a} \\
\end{array}$ \\
\hline 10 & $\begin{array}{l}1.1 \text { eq. } \\
\text { NaHMDS }\end{array}$ & $-40{ }^{\circ} \mathrm{C}, 30$ min., then $27,-40{ }^{\circ} \mathrm{C}, 1 \mathrm{~h}$. & $9 \%, 12 \%^{a}$ \\
\hline 11 & 1.1 eq. $n$-BuLi & $\begin{array}{l}\mathrm{Et}_{2} \mathrm{O},-78-0{ }^{\circ} \mathrm{C}, 30 \mathrm{~min} ., \text { then } 27, \mathrm{Et}_{2} \mathrm{O}, 0 \\
{ }^{0} \mathrm{C} 30 \mathrm{~min} .\end{array}$ & $10 \%$ \\
\hline
\end{tabular}

NOTE: Yield based on recovered 47

The Sonogashira reaction was also briefly investigated for the $\mathrm{N}$-acetyl and $\mathrm{N}$ benzyl derivatives. Squarate derivative ${ }^{27}(39)$ was briefly slurried with $5 \%$ $\mathrm{Pd}\left(\mathrm{PPh}_{3}\right)_{2} \mathrm{Cl}_{2}$, and one equivalent of $\mathrm{Cul}$ in triethylamine and then the protected aryl iodides were added and the resulting reaction mixture was allowed to stir overnight at ambient temperature. The coupling of the $\mathrm{N}$-acetyl (49) and $\mathrm{N}$ benzyl (50) derivatives gave the desired products in $45 \%$ and $4 \%$, respectively. In both cases the deprotonation-alkylation procedure, especially in the $\mathrm{N}$-acetyl case, was found to be a superior method (Scheme 23). 


\section{Scheme 23: Sonogashira Coupling of the Acetanilide (49) and $\mathbf{N}$-benzyl}

(50) Derivatives<smiles>C#CC1(O)C(=O)C(OCCC)=C1OCCC</smiles>

39<smiles>[R]Nc1ccccc1I</smiles>

$49 \mathrm{R}=\mathrm{Ac}$ $50 \mathrm{R}=\mathrm{Bn}$
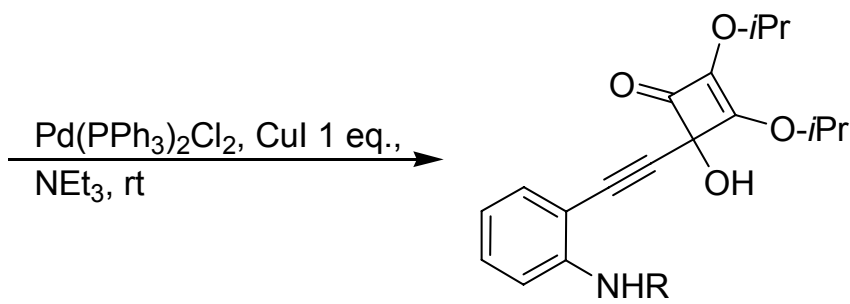

$46 \mathrm{R}=\mathrm{Ac} 45 \% 60 \%{ }^{\mathrm{a}}$

$48 \mathrm{R}=\mathrm{Bn} 4 \%$

Note: a) Based on recovered 49

The alkylated $\mathrm{N}$-acetyl protected compound $\mathbf{4 6}$ gave a good yield $(72 \%)$ of alkylidene $\mathbf{5 1}$ upon thermal ring expansion in toluene at reflux (Scheme 24). The $\mathrm{N}$-benzyl alkylation product $\mathbf{4 8}$ on attempted thermal ring expansion yielded only unidentifiable products in toluene at reflux and did no reaction was observed in 1,2-DCE at reflux with no starting material being recovered. The $N$-benzyl derivative was not further examined.

\section{Scheme 24: Thermal Ring Expansion of the Acetanilide}<smiles>CCCOC1=C(OCC)C(O)(C#Cc2ccccc2NC(C)(C)C)C1=O</smiles>

46<smiles>CCCOC1=C(OCCC)C(=O)C(=Cc2ccccc2N)C1=O</smiles>

$51(72 \%)$ 
Although the yield of the ring-expanded $\mathrm{N}$-acetyl protected product $\mathbf{5 1}$ was good we were unable remove amino protecting group using dilute $\mathrm{HCl}$ at reflux or hydrazine at reflux.

\subsection{Nitrobenzene Derivative}

The functional group was changed from a $\mathrm{N}$-protected aniline to a nitro group. This subproject examined the effect of the electron withdrawing group on the thermal ring expansion. Alkylation of $\mathbf{2 7}$ with ethynylnitrobenzene did not give the expected product, instead the Sonogashira reaction was investigated for nitro derivative 51a. Squarate derivative ${ }^{27} 39$ was stirred briefly with $5 \% \mathrm{Pd}\left(\mathrm{PPh}_{3}\right)_{2} \mathrm{Cl}_{2}$ and $5 \%$ Cul in triethylamine followed by the addition of 2-iodonitrobenzene $\mathbf{5 1 b}$. Unfortunately, a $9 \%$ yield of the anticipated product 51a was obtained. Addition of a full equivalent of Cul was found to increase the yields to $53 \% 51$ a (Scheme 25). Thermal ring expansion gave two products, the quinone 51c in $11 \%$ yield and the alkylidene $\mathbf{5 1 d}$ in $33 \%$ yield (Scheme 26). The assignments were made based the quinone and alkylidene protons, as compared to literature values of ring-expanded squarates. ${ }^{29}$ The literature values reported for a squarate based alkylidene and quinone were a singlet at $7.41 \mathrm{ppm}$ a singlet at $6.70 \mathrm{ppm}$, respectively. Compound $\mathbf{5 1 d}$ has a singlet at 7.69 ppm and $\mathbf{5 1 c}$ showed up at $6.47 \mathrm{ppm}$. The electron withdrawing group seems to have a greater selectivity for the 5-membered ring versus the 6 -membered ring formation. We were pleased to discover the 6-membered ring can be obtained from aryl-alkyne ring 
expansion, however we were disappointed in the subsequent yield of the quinone.

\section{Scheme 25: Sonogashira Coupling of 2-lodonitrobenzene}

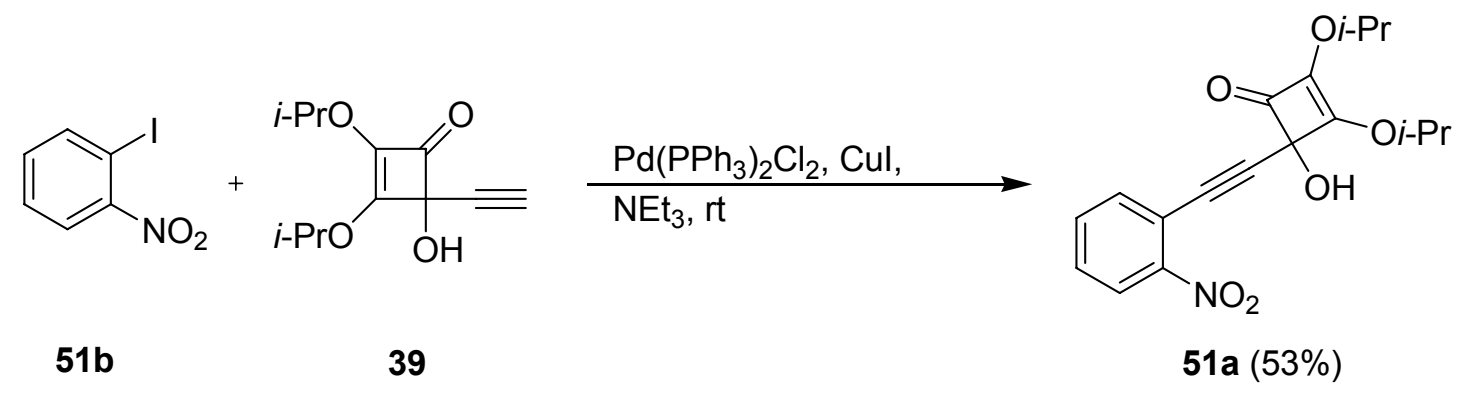

\section{Scheme 26: Thermal Ring Expansion of Nitrobenzene Derivative}<smiles>CCCOC1=C(OCCC)C(=O)C(c2ccccc2[N+](=O)[O-])=CC1=O</smiles>

\section{Conclusions}

A novel route to cyclopenta[b]quinoline-1-ones and -ols has been developed.

Substituted cyclopenta[b]quinolin-1-ones were prepared by thermal ringexpansion of substituted N-BOC protected 4-(2-aminophenylethynyl)-4-hydroxy2-cyclobuten-1-ones forming the corresponding 2-aminophenylmethylidene substituted 4-cyclopentene-1,3-diones. Deprotection of the amine resulted in spontaneous condensation to give cyclopenta[b]quinolin-1-ones. Sodium 
borohydride reduction of these products produced cyclopenta[b]quinolin-1-ols. The key step in the sequence is a thermally induced ring-expansion of 4-(2aminophenylethynyl)-4-hydroxy-2-cyclobuten-1-ones. Changing the amino protecting group had no effect on the ring size selectivity of the thermal ring expansion. The thermal ring expansion of the nitro derivative suggests that electron withdrawing substituents may slightly alter the size selectivity of the ring formation. 


\section{Part II}

\section{Attempted Indolizations and Additional Ring Expansions}

\section{Introduction}

Heterocycles play a central role in organic and medicinal chemistry since many of these compounds exhibit useful properties. ${ }^{32}$ The indole nucleus is found in a significant number of biologically active, naturally occurring products ${ }^{33}$ and are extremely valuable in medicinal chemistry. ${ }^{34}$ Common methods for indolization of 2-ethynylanilines include base,${ }^{35}$ and transition metal mediated and catalyzed cyclizations. $^{36}$

Ring-expansions of 4-alkynyl-4-hydroxy-2-cyclobuten-1-ones to give 5alkylidenecyclopentenediones have been reported that use palladium complexes and electrophilic reagents such as $\mathrm{N}$-iodosuccinimide ${ }^{37}, \mathrm{NIS}$, and $\mathrm{N}$ chlorosuccinimide, NCS. ${ }^{38}$ We envisioned using these different indolization methods to form the indole nucleus followed by a ring expansion/cyclization sequence to afford carbazolequinones. We also wanted to use the ring expansion routes to tune the product ring size of the squarate portion of the molecules to afford either a 1,4-quinone or a alkylidene cyclopentendione. The synthesis of carbazolequinones using cyclobutenone substituted indoles has been reported (Scheme 27) ${ }^{39}$ Squarate 67 a was alkylated with $\mathbf{6 7 b}$. The reaction was quenched with acetic anhydride and worked up giving 67c. 
Compound 67c was then immediately thermalized and oxidized with ceric ammonium nitrate, CAN, to give $\mathbf{6 7 d}$ as a single regioisomer.

\section{Scheme 27: Thermal Ring Expansion of a Cyclobutenone Substituted Indole}

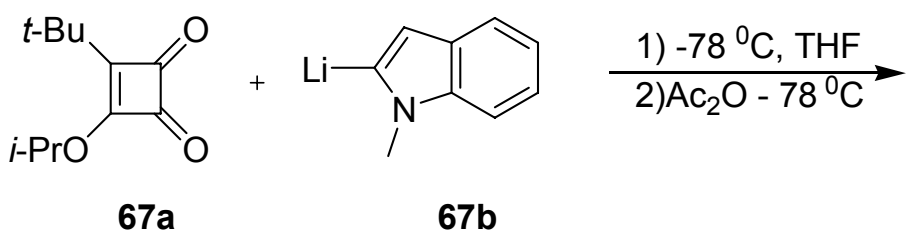

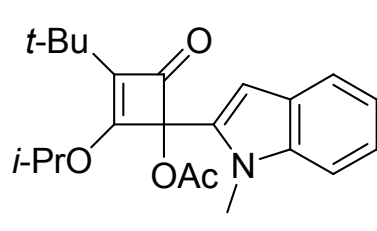

$67 c$

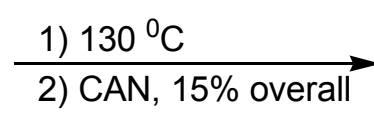<smiles>CC(C)OC1=C(C(C)(C)C)C(=O)c2c(n(C)c3ccccc23)C1=O</smiles>

$67 d$

\subsection{Indolization Methods}

Base mediated cyclization methods have been used extensively to form the indole nucleus. ${ }^{40}$ Silyl alkyne $\mathbf{5 2}$ was cyclized to give $\mathbf{5 3}$ (70\% yield) in the presence of potassium tert-butoxide in tert-butanol at $83{ }^{\circ} \mathrm{C}$ (Scheme 28). ${ }^{41}$ The proposed mechanism involves the deprotonation of the carbamate nitrogen followed by attack on the alkyne forming a 2-trimethylsilyl 1-tertbutoxycarbonylindole intermediate. Subsequent hydrolysis cleaves the tertbutoxycarbonyl and trimethylsilyl groups. ${ }^{40}$ 


\section{Scheme 28: Base Mediated Indolization}

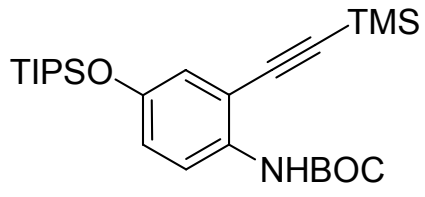

52

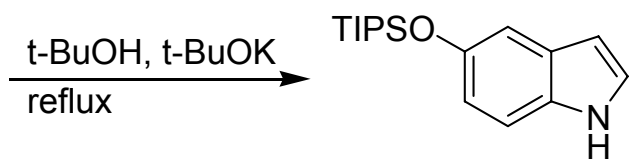

$53(70 \%)$

In the early 1960s Castro et al. developed copper (I) mediated methods for the cyclization of aminoalkynes to produce indoles. ${ }^{42}$ The 2-substituted indole $\mathbf{5 5}$ was synthesized in the presence of Cul (2 equivalents) in DMF at $136{ }^{\circ} \mathrm{C}$ in $45 \%$ yield (Scheme 29). The mechanism probably involves the copper complexing with the alkyne followed by intramolecular attack by the amino group. The subsequent steps likely involve a proteolytic cleavage of an intermediate $\sigma$ alkenylcopper complex forming the indole nucleus. ${ }^{43}$

\section{Scheme 29: Copper Mediated Indolization}

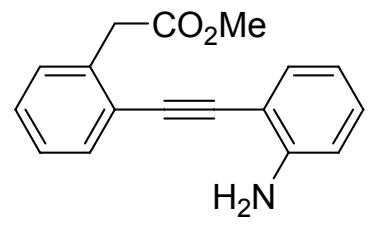

54

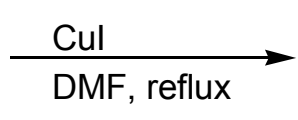

DMF, reflux

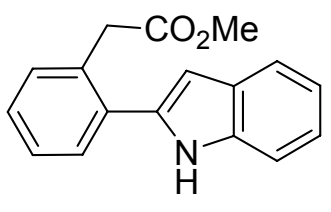

$55(45 \%)$

Copper acetate has also been used to catalyze the formation of the indole nucleus from various $N$-protected ethynylamines. The indole moiety in a synthesis of hippadine (58) was formed in $80 \%$ yield by copper (II) acetate 
catalysis in 1,2-DCE at $83^{\circ} \mathrm{C}$ (Scheme 30). The mechanism is thought to be similar to the Cul reactions. ${ }^{44}$

\section{Scheme 30: Copper Acetate Catalyzed Indolization}

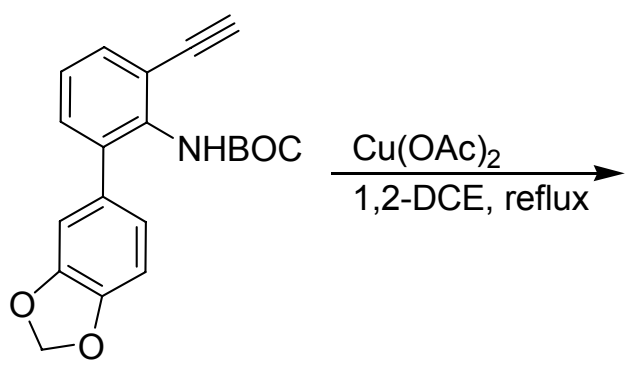

56

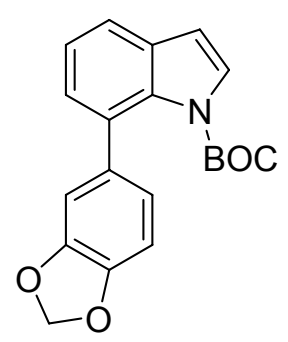

$57(80 \%)$

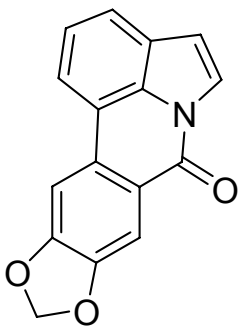

Hippadine (58)

Palladium (II) complexes can also catalyze the amination and cyclization of alkynes to form the indole core. ${ }^{45}$ An indole intermediate $\mathbf{6 0}$ in the synthesis of 61 was formed via palladium catalyzed amination of the alkyne (Scheme 31) ${ }^{46}$ Compound $\mathbf{6 1}$ is known to suppress apoptosis in human cells. The mechanism probably involves the coordination of the palladium to the alkyne followed by an intramolecular attack by the amino group to form the metallo-indole intermediate. The subsequent steps probably involve a proteolytic cleavage of the intermediate $\sigma$-alkenylpalladium complex thus forming the indole nucleus. ${ }^{45}$ 


\section{Scheme 31: Palladium Catalyzed Indolization}

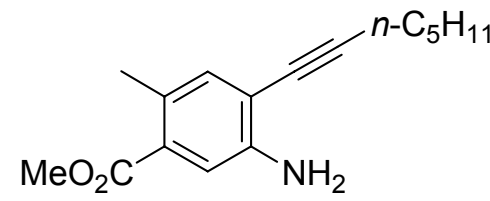

59

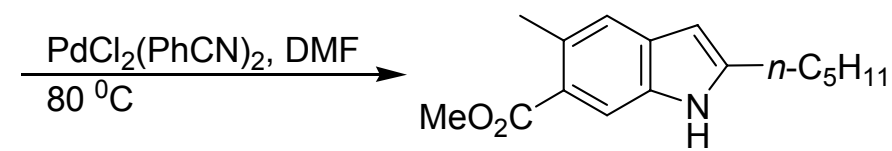

$60(87 \%)$

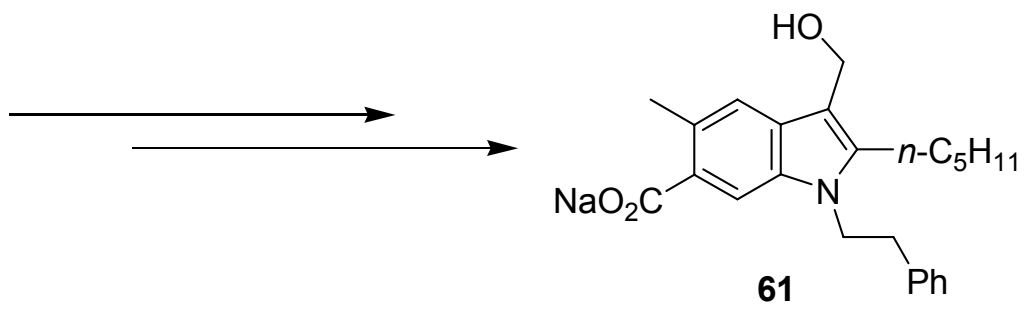

\subsection{Electrophilic Ring Expansions 4-Hydroxy-2-cyclobuten-1-ones}

$\mathrm{N}$-iodosuccinimide (NIS) mediated ring expansion has been used to form 5alkylidenecyclopentenediones from 4-alkynyl-4-hydroxy-2-cyclobuten-1-ones. The electrophilic ring expansion of $\mathbf{6 2}$ in the presence of excess NIS gave alkylidene 63 in $44 \%$ yield (Scheme 32). Two mechanisms have been suggested. The first step likely involves an $I^{+}$transfer to the hydroxyl group to form a hypoiodite intermediate. This intermediate then probably induces a 1,2acyl migration to the alkyne followed by the iodination forming the iodoalkylidene 63. The other possible mechanism involves the formation of an iodonium ion with the alkyne followed by a 1,2-acyl migration forming $63 .{ }^{47}$ 


\section{Scheme 32: $\mathbf{N}$-lodosuccinimide Mediated Ring Expansion}<smiles>CCCCC#CC1(O)C(=O)C(OCC)=C1OCC</smiles>

62<smiles>CN(C)S(C)(=O)=O</smiles>

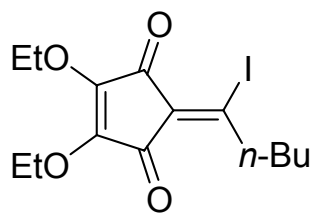

$63(44 \%)$

$\mathrm{N}$-chlorosuccinimide (NCS) has recently been used in ring expansions of 4alkynyl-4-hydroxy-2-cyclobuten-1-ones. ${ }^{48}$ Quinones 65 a and 65 were produced in $40 \%$ and $35 \%$, respectively. The mechanism is likely to involve thermal ringexpansion followed by radical chlorination of the diradical intermediate (Scheme 33).

\section{Scheme 33: N-Chlorosuccinimide Mediated Ring Expansion}<smiles>C#CC1(O)C(=O)C(OCCC)=C1OCCC</smiles>

64

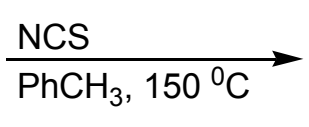

$65 a(40 \%)$<smiles>CCCOC1=C(OC(C)C)C(=O)C=CC1=O</smiles>

$65(35 \%)$

Palladium catalyzed ring expansion of 4-alkynyl-4-hydroxy-2-cyclobuten-1-ones to form 5-alkylidenecyclopentenediones has also been investigated. Compound 67 was prepared in moderate yield $(45 \%)$ with an $E: Z$ ratio of isomers of 12:1. The E-isomer was found to be thermodynamically more stable. ${ }^{49}$ This reaction was very selective with regard to ring size and only five membered rings were obtained. The mechanism likely involves the coordination of the palladium to the 
alkyne followed by 1,2-acyl migration and proteolytic cleavage of the $\sigma$ alkenylpalladium complex forming the alkylidene. The hydroxyl group is more likely to stabilize the positive charge left from the palladium induced 1,2-acyl migration (Scheme 34).

\section{Scheme 34: Palladium Catalyzed Ring Expansion}

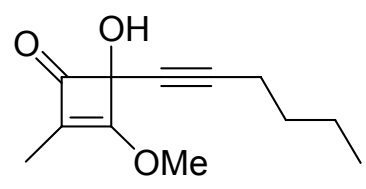

66

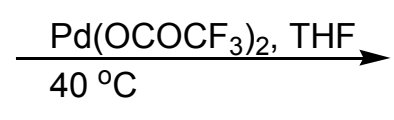

$\mathrm{MeO}$

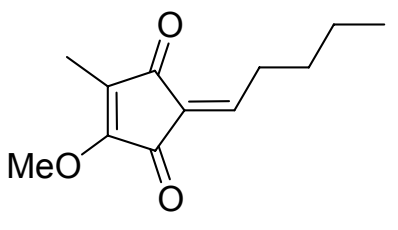

$67(45 \%)$

\section{Results and Discussion}

In the following paragraphs the base mediated, transition metal mediated and catalyzed reactions of heteroatom tethered 4-alkynyl-4-hydroxy-2-cyclobuten-1ones and electrophilic ring expansions of 4-alkynyl-4-hydroxy-2-cyclobuten-1ones will be discussed. We envisioned a cyclization route to the indole nucleus and later ring expansion/cyclization of the 4-alkynyl-4-hydroxy-2-cyclobuten-1ones to form the 1,4-quinone instead of the previously synthesized 5alkylidenecyclopentenediones. Several different methods for indole core and quinone formation were attempted. The methods tried were aimed at the formation of the indole nucleus and subsequent ring expansion to eventually form carbazolequinones.

The first set of these reactions, discussed above, included base mediated, copper mediated, copper and palladium catalyzed conditions. Electrophilic 
methods were attempted to affect the ring expansion of the cyclobutenone moiety. The second set of reactions, discussed above, included $\mathrm{N}$ iodosuccinimide mediated, $\mathrm{N}$-chlorosuccinimide mediated and palladium catalyzed ring expansions.

\subsection{Base Mediated Indole Formation}

The $\mathrm{BOC}$ protected alkylation product $28 \mathrm{a}$ was heated in dry $t-\mathrm{BuOH}$ at $83{ }^{\circ} \mathrm{C}$ in the presence of $t$-BuOK forming indole $\mathbf{6 8}$ in $20 \%$ yield. An explanation of this observation is that the base deprotonated the hydroxyl group of $\mathbf{2 8 a}$ and induced a retro-alkylation. There was no evidence of the cyclobutenone moiety in the crude mixtures or in the purified products. It should be noted that the indole core was actually formed. No reaction occurred when $t$-BuOK or KH in NMP were used. $\mathrm{N}$-acetyl derivative $\mathbf{4 6}$ was also reacted under the same conditions but yielded only unidentifiable products (Scheme 35). Based on this disappointing result no other base mediated indolizations were attempted.

\section{Scheme 35: Base Mediated Indolization}

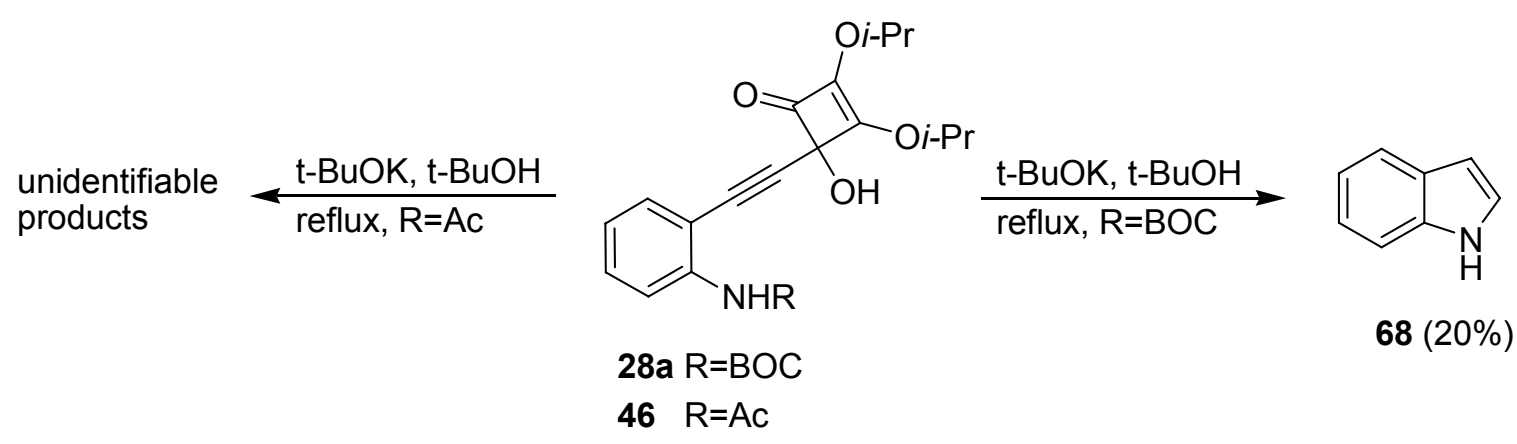




\subsection{Attempted Copper Mediated Indole Formation}

Examples of an attempted copper mediated indolization reaction are shown in Scheme 36 and Scheme 37. The reaction conditions attempted for the N-BOC protected 28a are summarized in Table 4. The yields were not corrected for the recovered starting material. In contrast to the reaction of the free amine shown in Scheme $25 \mathrm{~N}$-BOC protection appears to inhibit the reaction. It seems that these reactions are simply thermal ring expansions of the cyclobutenone portion of the molecule. The copper mediated reactions were not attempted on the other $N$ BOC (28b-28e) or the $N$-acetyl 46 derivatives.

Scheme 36: Copper Mediated Reaction Scheme for N-BOC Protected 28a<smiles>CCCOC1=C(O[GaH])C(=O)C1(O)C#Cc1ccccc1N[R6](=O)OC</smiles>

$28 a$

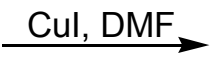<smiles>CCCOC1=C(O[GaH])C(=O)C(=Cc2ccccc2N[B]C(=O)OC)C1=O</smiles>

$33 a$ 
Table 4: Copper Mediated Reaction Conditions for 28a

\begin{tabular}{|c|c|c|c|}
\hline Temperature/Time & Cul (2 eq.) & 33a & Recovered 28a \\
\hline $75{ }^{\circ} \mathrm{C} / 24 \mathrm{~h}$ & Yes & No Reaction & Not Calculated \\
\hline $85^{\circ} \mathrm{C} / 24 \mathrm{~h}$ & Yes & $8 \%$ & $24 \%$ \\
\hline $100^{\circ} \mathrm{C} / 6 \mathrm{~h}$ & Yes & $11 \%$ & Not recovered \\
\hline $120^{\circ} \mathrm{C} / 1 \mathrm{~h}$ & Yes & $11 \%$ & $32 \%$ \\
\hline $120^{\circ} \mathrm{C} / 1 \mathrm{~h}$ & No & $23 \%$ & $18 \%$ \\
\hline
\end{tabular}

The Cul mediated reaction (Scheme 37) on the $\mathrm{N}$-benzyl derivative 48 appears to undergo both thermal ring expansion leading to 35 a and metal mediated indolization-ring expansion-cyclization sequence leading to 69 . The formation of carbazolequinone 69 likely involves the copper coordinating with the alkyne followed by an intramolecular attack of the amine forming a metallo-indole intermediate. Subsequent acyl migration to form a metallocycle and then reductive elimination would form carbazolequinone 69 . Quinoline $35 \mathrm{a}$ is likely formed from the thermal ring expansion of the cyclobutenone portion followed by the intramolecular iminium ion formation. It is likely that the benzyl group was removed from the iminium ion by a free iodide ion thus forming the quinoline $\mathbf{3 5 a}$. It should be noted that it is not clear whether the Cul affects any of the forementioned ring expansion. This portion of the project was also abandoned since 48 was difficult to synthesize (Table 3, Scheme 22) and the reaction gave low yields. 
Scheme 37: Copper lodide Mediated Indolization for N-Benzyl Protected 48

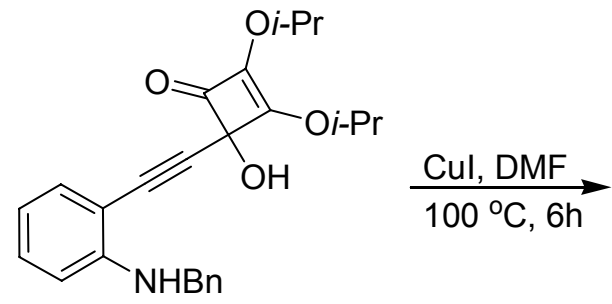

48<smiles>CCCOC1=C(O[18F])C(=O)c2c(c3ccccc3n2Cc2ccccc2)C1=O</smiles>

$69(12 \%)$<smiles>CCCOC1=C(OCC)c2nc3ccccc3cc2C1=O</smiles>

$35 a(10 \%)$

\subsection{Copper Acetate Catalyzed Indole Formation}

Copper acetate catalyzed indole formation was attempted on derivatives $\mathbf{2 8 a}$ and 46. To our surprise the reaction on $\mathrm{N}-\mathrm{BOC}$ protected compound 28 a cleaved the molecule into precursor alkyne and squaric acid derivative. The alkyne and squaric acid were recovered in $55 \%$ and $85 \%$, respectively. On the other hand, $\mathrm{N}$-acetyl compound $\mathbf{4 6}$ was cyclized to give the novel indole $\mathbf{7 0}$ in $72 \%$ yield (Scheme 38). The rearrangement of the squarate moiety is likely a consequence of acetic acid being liberated from the reaction. Acid catalyzed rearrangements of this type have been reported..$^{50,19 a}$ In the future this rearrangement could potentially be avoided by the addition of a mild scavenger base. This indolization reaction sequence was not attempted on other $N$-BOC (28b-28e) and N-benzyl (48) derivatives. The copper acetate catalyzed reactions were abandoned for the N-BOC case since the desired products, the indole moiety, were not obtained. 


\section{Scheme 38: Copper Acetate Catalyzed Indolization}

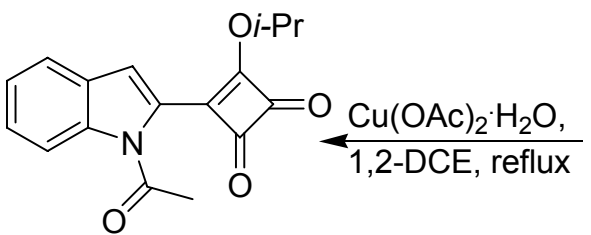

$70(72 \%)$

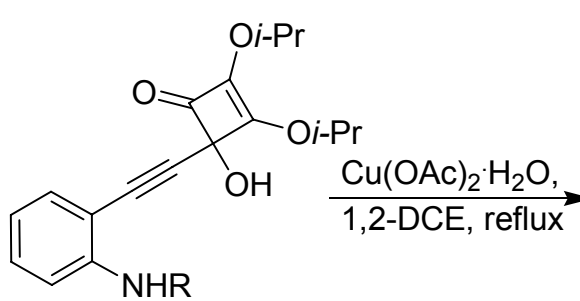

28a $\mathrm{R}=\mathrm{BOC}$

$46 \mathrm{R}=\mathrm{Ac}$

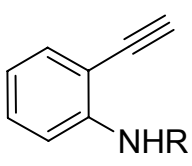

26a (55\%)

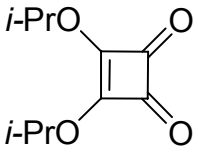

$27(86 \%)$

\subsection{Attempted Palladium Catalyzed Indole Formation or Ring Expansions}

Reaction of $\mathbf{2 8 a}$ and $\mathbf{4 8}$ with a number of palladium catalysts were examined. The catalysts used include bis(triphenylphosphine)palladium dichloride and bis(benzonitrile)palladium dichloride. The free amine might be a better choice for this reaction, but we were unable to prepare this compound. The palladium catalyzed reactions were not attempted on the other N-BOC (28b-28e) or Nacetyl (46) derivatives. The palladium catalyzed reactions were abandoned since the desired products, the indole moiety, were not obtained.

\section{5. $\mathbf{N}$-lodosuccinimide Mediated Ring Expansion}

$\mathrm{N}$-lodosuccinimide mediated ring expansions were attempted on 28a, 46 and $\mathbf{4 8 .}$ Two different reaction conditions were used for the $\mathbf{2 8 a}$ and $\mathbf{4 6}$. The first set of reaction conditions were tried on all three protecting group types. The compounds were dissolved in toluene and placed in thick walled flasks, sealed and heated to $150{ }^{\circ} \mathrm{C}$ in the presence of NIS. The second set of reaction 
conditions were performed on the $\mathrm{N}$-acetyl and $\mathrm{N}$-BOC protected compounds in 1,2-DCE at $83{ }^{\circ} \mathrm{C}$. In each case the expected products, iodoalkylidenes, (Scheme 39) were not obtained. The products were unidentifiable.

\section{Scheme 39: Attempted $\mathbf{N}$-lodosuccinimide Mediated Ring Expansion}

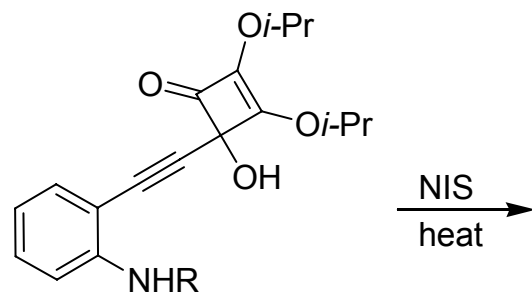

28a $\mathrm{R}=\mathrm{BOC}$

$46 \mathrm{R}=\mathrm{Ac}$<smiles>[R]/C(=C1\C(=O)C(O[PH])=C(O[PH2+])C1=O)c1ccccc1N</smiles>

$48 \mathrm{R}=\mathrm{Bn}$

28i $\mathrm{R}=\mathrm{BOC}$

46i $\mathrm{R}=\mathrm{Ac}$

48i $\mathrm{R}=\mathrm{Bn}$

\section{6. $\mathrm{N}$-Chlorosuccinimide Mediated Ring Expansion}

The $\mathrm{N}$-chlorosuccinimide ring expansions were attempted on 28a, $\mathbf{4 6}$ and $\mathbf{4 8}$ (Scheme 40). The NCS reaction with $\mathbf{2 8 a}$ was observed to cleave an isopropyl group and form dione $\mathbf{7 2}$ in $51 \%$ yield with alkyne still intact. The same result was observed for the reaction of $\mathbf{4 6}$ forming a $77 \%$ yield of $\mathbf{7 1}$. Unidentifiable products were obtained from reaction of 48 . This type of rearrangement has been reported in the past for iodide mediated ring expansions (Scheme 41). The proposed mechanism is thought to proceed by the squarate hydroxyl group coordinating to the halide (structure B) followed by the loss of that hydroxyl moiety leaving a carbocationic intermediate $\mathbf{C}$. Stabilization through the 
resonance contribution of the alkoxy "trans" from the hydroxyl group could then allow the alkyl group on the alkoxy to be more easily removed. Removal of the alkyl group is likely to occur by halide attack thus forming the carbonyl and rearranged cyclobutenone $\mathbf{D} .^{47}$ It is reasonable that the analogous reaction could occur using NCS. The NCS mediated ring expansions were not further examined using other $\mathrm{N}-\mathrm{BOC}(\mathbf{2 8 b} \mathbf{- 2 8} \mathbf{e})$ protected derivatives.

\section{Scheme 40: Attempted $\mathrm{N}$-Chlorosuccinimide Mediated Ring Expansion}

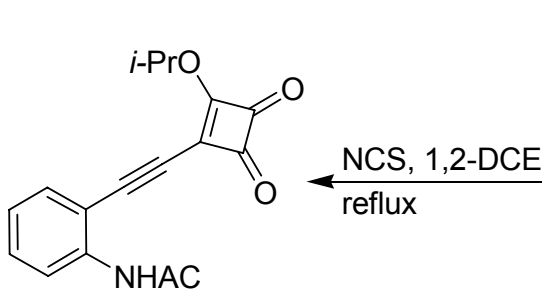

$71(77 \%)$

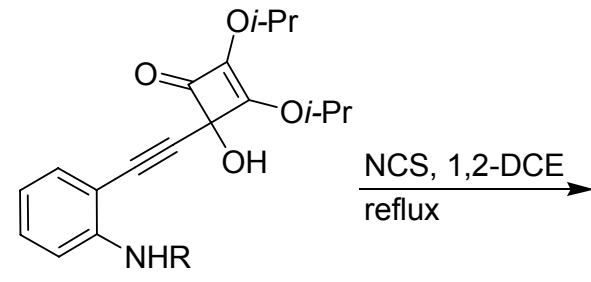

28a $R=B O C$

$46 \mathrm{R}=\mathrm{Ac}$

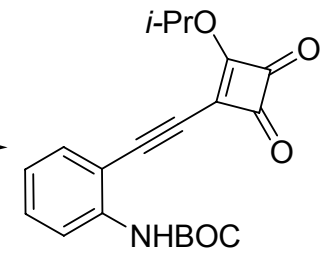

72 (51\%)

Scheme 41: Halide Mediated Cyclobutenone Rearrangement<smiles>CCOC1=C(OCC)C(O)(C#CBr)C1=O</smiles>

A<smiles>CCOC1=C(OCC)C(C#CBr)C1=O</smiles><smiles>[3H]OC1(C#CBr)C(=O)C(OCC)=C1OCC</smiles>

B<smiles>CCOc1c(C#CBr)c(=O)c1=O</smiles> 


\section{Conclusions}

These attempted indolization and ring expansion reactions were not further examined since the desired products were not obtained. The copper acetate catalyzed indolization of the $\mathrm{N}$-acetyl derivative led to the preparation of novel 2substituted indole. This methodology may be used in the future to prepare several other novel 2-substituted indoles. In the Cul mediated reactions with $\mathrm{N}$ benzyl the project was dropped since the starting material was difficult to synthesize. 


\section{Part III}

\section{Synthesis of Novel Indoloquinones}

\section{Introduction}

Indoloquinones are the core structure of many natural products including the mitosenes, isobatzellins, kinamycins and murrayaquinones. ${ }^{51}$ Many of these compounds are known to exhibit antitumor, ${ }^{52}$ antibacterial, antibiotic, ${ }^{53}$ antileukemia, antifungal, ${ }^{54}$ and myocardial contraction activity. ${ }^{55}$ For example, mitomycin C (73) exhibits both antitumor and antibiotic activity, ${ }^{51,52}$ isobatzellin A (74) exhibits antileukemia and moderate antifungal activities ${ }^{53}$ and murrayaquinone $\mathrm{A}(\mathbf{7 5})$ has been shown to induce myocardial contractions. ${ }^{54}$ Kinamycin $D(\mathbf{7 6})$ is strongly active against Gram-positive bacteria and less active against Gram-negative bacteria. ${ }^{52 c}$

Figure 3A: Indoloquinone Containing Natural Products<smiles>COC12C(COC(N)=O)C3=C(C(=O)C(C)=C(N)C3=O)N1CC1NC12</smiles>

Mitomycin C (73)<smiles></smiles>

Isobatzellin A (74)<smiles>CC1=CC(=O)c2[nH]c3ccccc3c2C1=O</smiles>

Murrayaquinone A (75)<smiles>CC(=O)OC1c2c3c(n(C#N)c2[C@H](OC(C)=O)[C@@](C)(O)[C@H]1O)C(=O)c1c(O)cccc1C3=O</smiles>

Kinamycin D (76) 
Indoloquinones $\mathbf{7 9}$ and $\mathbf{8 2}$ have been isolated from mid-intestinal gland of muricid gastropod Drupella fragum collected off the Japanese coast. These two compounds are shown to exhibit moderate antimicrobial activity against several bacterial strains. Compounds $\mathbf{7 9}$ and $\mathbf{8 2}$ were synthesized for structural confirmation. Isovanillin 77 was used to synthesize 79 in 7 steps. 77 was nitrated in the 2-position and the resulting hydroxybenzaldehyde 77a was acetylated $\mathbf{7 7 b}$. The aldehyde was then alkylated with nitromethane followed by dehydration to yield a dinitrostyrene followed by reductive indolization led to indole 78. Deprotection and oxidation of $\mathbf{7 8}$ with salcomine under an atmosphere of oxygen gave indoloquinone $\mathbf{7 9}$ with a $6 \%$ overall yield. Indoloquinone 82 was synthesized in seven steps from 2,3-dimethoxybenzaldehyde $\mathbf{8 0}$ in a similar fashion in $12 \%$ overall yield (Scheme 42$){ }^{56}$ 
Scheme 42: Existing Synthesis of Drupella fragum Indoloquinones 79 and

82

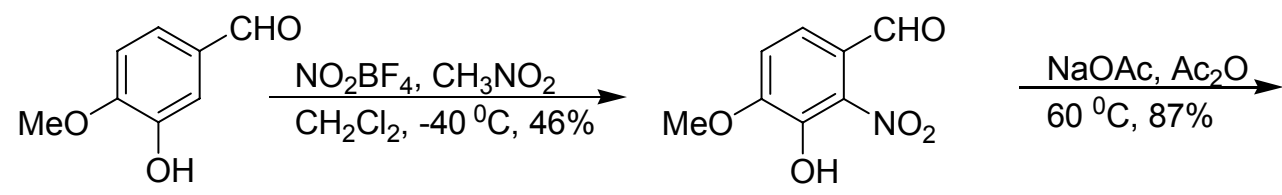

$77 a$<smiles>COc1ccc(C=O)c([N+](=O)[O-])c1OC(C)=O</smiles>

$77 b$ $\underset{\text { THF, }-78{ }^{0} \mathrm{C}-\mathrm{rt}, 92 \%}{\stackrel{\mathrm{KHMDS}, \mathrm{CH}_{3} \mathrm{NO}_{2},}{\longrightarrow}}$<smiles>COc1ccc(C(O)C[N+](=O)[O-])c([N+](=O)[O-])c1OC(C)=O</smiles>

1) $\mathrm{MsCl}, \mathrm{CH}_{2} \mathrm{Cl}_{2}, 0{ }^{0} \mathrm{C}-\mathrm{rt}$

2) $\mathrm{Fe}, \mathrm{SiO}_{2}, \mathrm{AcOH}, \mathrm{PhCH}_{3}, 90{ }^{0} \mathrm{C}$, $29 \%$ two steps<smiles>COc1ccc2cc[nH]c2c1OC(C)=O</smiles>

78

1) $\mathrm{NaOH}, \mathrm{Na} 2 \mathrm{~S} 2 \mathrm{O} 4, \mathrm{DMF}, 5 \mathrm{OC}, 98 \%$

2) $\mathrm{O}_{2}$, salcomine, rt, $60 \%$<smiles>COC1=CC(=O)c2cc[nH]c2C1=O</smiles>

79<smiles>COc1cccc(C=O)c1OC</smiles>

80<smiles>COc1ccc2[nH]ccc2c1O</smiles>

81<smiles>COC1=CC(=O)c2[nH]ccc2C1=O</smiles>

82 


\section{Results and Discussion}

We envisioned that the synthesis of indoles using aliphatic aminoalkynes (83 and 87) and a squarate derivative (27). The butyne starting materials were synthesized according to literature procedures. ${ }^{57,58}$ Alkylation of $\mathbf{2 7}$ with $\mathbf{8 3}$ and alkylation of $\mathbf{8 7}$ was obtained in excellent yield (85\%). Cyclobutenone 89 was produced in $62 \%$ yield along with a number of inseparable products, probably rotomers of the carbamate (Scheme 43). As we observed previously addition of the squarate derivatives was the most consistent method for alkylation.

\section{Scheme 43: Alkylation of 27 with 83 and 87}

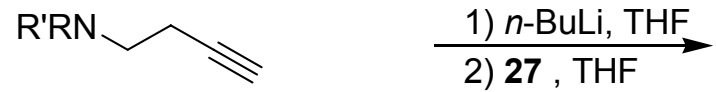

$83 \mathrm{R}=\mathrm{Bn}, \mathrm{R}^{\prime}=\mathrm{H}$ $87 \mathrm{R}=\mathrm{Bn}, \mathrm{R}^{\prime}=\mathrm{Boc}$

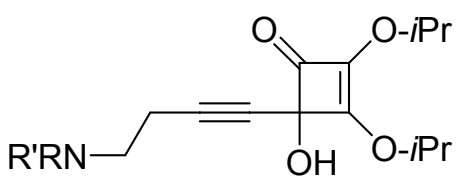

$88^{\mathrm{a}} \mathrm{R}=\mathrm{Bn}, \mathrm{R}^{\prime}=\mathrm{H}, 85 \%$ $89^{b} R=B n, R^{\prime}=B o c, 62 \%$

Notes: a) $-40{ }^{\circ} \mathrm{C}$ b) $-78{ }^{\circ} \mathrm{C}$

Upon thermal ring expansion of $\mathbf{8 8}$ and subsequent purification we were surprised to discover we had synthesized a novel 2,3-dihydroindoloquinone 91 in $51 \%$ yield (Scheme 44$)$. During the separation the crude material changed color from yellow to green and finally to blue. Several other ring expansion conditions were attempted using xylenes $\left(138^{\circ} \mathrm{C}\right)$ and 1,2 -DCE $\left(83^{\circ} \mathrm{C}\right)$. Reaction in xylenes led to faster conversion to $\mathbf{8 8}$ than compared to toluene but did not offer clean conversion to the indoloquinone (91). No reaction was observed using 1,2DCE $\left(83^{\circ} \mathrm{C}\right)$ after 24 hours. 


\section{Scheme 44: Ring Expansion and Cyclization of 89 to 91}<smiles>CCCOc1c(O)c2c(c(O)c1OCCC)N(Cc1ccccc1)CC2</smiles>

The proposed mechanism of the ring expansion, cyclization and oxidation is depicted in Scheme 45. The mechanism probably proceeds through the electrocyclic ring opening of $\mathbf{8 8}$ to give ketene $\mathbf{8 8 a}$ followed by the 6 -endo-dig cyclization forming intermediate $\mathbf{8 8 b}$. Subsequent hydrogen atom abstraction followed to give the diradical $\mathbf{8 8 c}$ and later 1,4-quinone formation (88d). The next step probably was a Michael addition of the amine to the quinone followed by proton shift and tautomerization forming the hydroquinone $\mathbf{9 0}$. Chromatography on silica gel probably caused the oxidation to indoloquinone $\mathbf{9 1}$. 
Scheme 45: Proposed Mechanism for the Tandem Expansion/Cyclization of 89

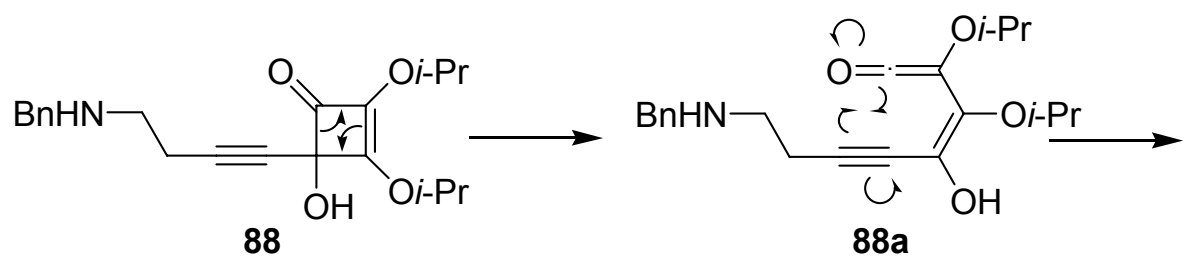

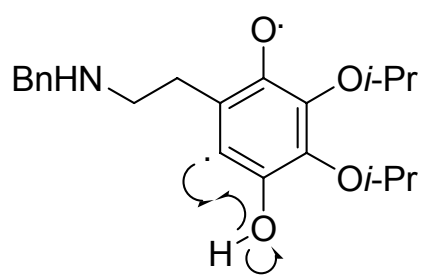

88b<smiles>CCCOC1=C(OCCC)C(=O)C2(CCNCC2)C(=O)C1=O</smiles>

88d<smiles>CCCOC1=C(O[Ga]C)C(=O)C2C(=C1O)CCN2Cc1ccccc1</smiles>

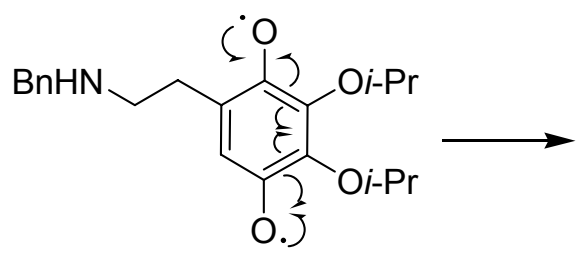

88c<smiles>CCCOC1=C(O[Ga])C(=O)C2C(=C1[O-])CC[NH+]2Cc1ccccc1</smiles>

$88 \mathrm{e}$<smiles>CCCOc1c(O)c2c(c(O)c1OCCC)N(Cc1ccccc1)CC2</smiles>

90<smiles>CCCOC1=C(OCCC)C(=O)C2=C(CCN2Cc2ccccc2)C1=O</smiles>

91 
Ammonium formate in the presence of $\mathrm{Pd} / \mathrm{C}$ in refluxing $\mathrm{MeOH}$ has been reported to cleave the benzyl protecting groups. ${ }^{59}$ Compound 91 was subjected to these reaction conditions but 93 was formed in a disappointing $28 \%$ yield (Scheme 46).

\section{Scheme 46: Debenzylation of 91}<smiles>CCCOC1=C(OCC)C(=O)C2=C(CCN2Cc2ccccc2)C1=O</smiles>

91<smiles>CCCOC1=C(O[GaH])C(=O)C2=C(CCN2)C1=O</smiles>

$93(28 \%)$

DDQ has been used to oxidize dihydropyrroles to pyrroles ${ }^{60}$ and dihydroindoles to indoles ${ }^{61}$. Compound 94 was produced in $65 \%$ yield via DDQ oxidation (Scheme 47).

\section{Scheme 47: DDQ Oxidation of 91 to 94}

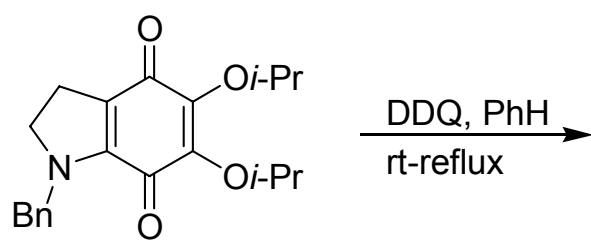

91<smiles>CCCOC1=C(O[Ga])C(=O)c2c(ccn2Cc2ccccc2)C1=O</smiles>

$94(65 \%)$

A shorter synthesis of $\mathbf{7 9}$ was envisioned using a ring expansion methodology.

The proposed synthetic steps are outlined in Scheme 48. 


\section{Scheme 48: Proposed Route for the Synthesis of 79}

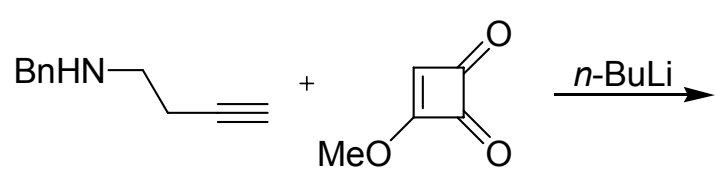

83

84

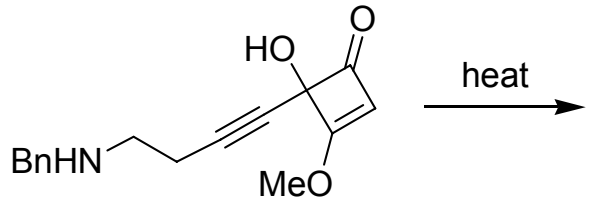

85<smiles>COC1=CC(=O)C2=C(NCC2)C1=O</smiles>

86

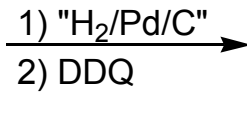<smiles>C=C(NC)C(=O)C(=C)OC</smiles>

79

Ring expansion of $\mathbf{8 9}$ is somewhat problematic in toluene affording a number of inseparable products. However the ring expansion was cleaner in 1,2-DCE in a sealed tube at $100{ }^{\circ} \mathrm{C}$ giving 92 in $48 \%$ yield (Scheme 49 ).

\section{Scheme 49: Ring Expansion of 89 to Quinone 92}

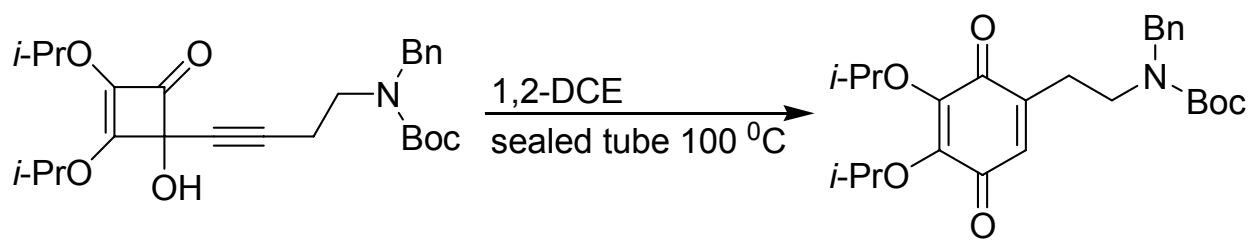

89 $92(48 \%)$

Quinone 92 was deprotected with TFA and produced indoloquinone 91 in 51\% yield (Scheme 50). 
Scheme 50: Acidic Deprotection of 92 to 91<smiles>CC(C)OC1=C(O)C(=O)C(CCN(Cc2ccccc2)C(=O)OC(C)(C)C)=CC1=O</smiles>

92

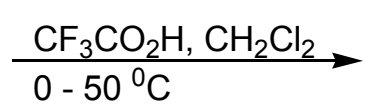
Bn'<smiles>CCCOC1=C(OCCC)C(=O)C2=C(CCN2Cc2ccccc2)C1=O</smiles>

$91(51 \%)$

Future work should involve the synthesis of differently substituted alkynes to give 5 and 6 membered rings (Scheme 51).

\section{Scheme 51: Proposed Future Research with Butyne Derivatives}

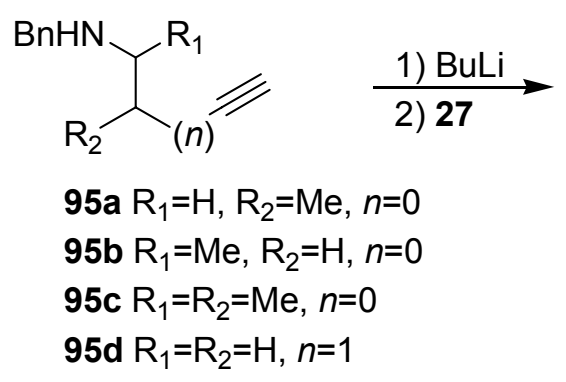

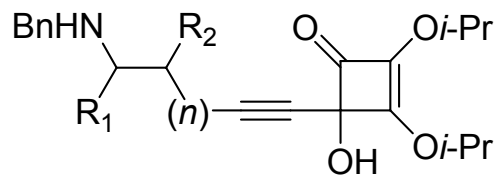

96a $\mathrm{R}_{1}=\mathrm{H}, \mathrm{R}_{2}=\mathrm{Me}, n=0$ 96b $\mathrm{R}_{1}=\mathrm{Me}, \mathrm{R}_{2}=\mathrm{H}, n=0$ 96c $\mathrm{R}_{1}=\mathrm{R}_{2}=\mathrm{Me}, n=0$ 96d $\mathrm{R}_{1}=\mathrm{R}_{2}=\mathrm{H}, n=1$

heat<smiles>[R]C1[Te]C2=C(C(=O)C(O[PH])=C(O[PH])C2=O)N(Cc2ccccc2)C1[R]</smiles>

97a $\mathrm{R}_{1}=\mathrm{H}, \mathrm{R}_{2}=\mathrm{Me}, n=0$

97b $\mathrm{R}_{1}=\mathrm{Me}, \mathrm{R}_{2}=\mathrm{H}, n=0$

97c $\mathrm{R}_{1}=\mathrm{R}_{2}=\mathrm{Me}, n=0$

97d $\mathrm{R}_{1}=\mathrm{R}_{2}=\mathrm{H}, n=1$ 


\section{Conclusions}

In conclusion a novel route to indoloquinones has been discovered and may lead to the synthesis of a natural product, as well as several novel indoloquinones. 


\section{Part IV}

\section{Experimental}

General Procedures. All NMR spectra were determined in $\mathrm{CDCl}_{3}$ at $600 \mathrm{MHz}\left({ }^{1} \mathrm{H}\right.$ NMR) and $150 \mathrm{MHz}\left({ }^{13} \mathrm{C}\right.$ NMR) unless otherwise stated. The chemical shifts are expressed in $\delta$ values relative to $\mathrm{Me}_{4} \mathrm{Si}\left(0.0,{ }^{1} \mathrm{H}\right.$ and $\left.{ }^{13} \mathrm{C}\right)$ or $\mathrm{CDCl}_{3}\left(77.0,{ }^{13} \mathrm{C}\right)$ internal standards. ${ }^{1} \mathrm{H}-{ }^{1} \mathrm{H}$ coupling constants are reported as calculated from spectra; thus, a slight difference between $J_{a, b}$ and $J_{b, a}$ is usually obtained. Results of APT (attached proton test) and DEPT- ${ }^{13} \mathrm{C}$ NMR experiments are shown in parentheses where, relative to $\mathrm{CDCl}_{3}$, (-) denotes $\mathrm{CH}_{3}$ or $\mathrm{CH}$ and $(+)$ denotes $\mathrm{CH}_{2}$ or $\mathrm{C}$. For ${ }^{1} \mathrm{H}$ NMR, the assignments are: $\mathrm{q}=$ quartet, $\mathrm{t}=$ triplet, $\mathrm{d}=$ doublet, $\mathrm{s}$ $=$ singlet, $\mathrm{br}=$ broad, and $\mathrm{m}=$ multiplet. Multiplet refers to unresolved resonances from one or more protons having intractable ${ }^{1} \mathrm{H}-{ }^{1} \mathrm{H}$ coupling constants. Tetrahydrofuran (THF), toluene, dichloromethane, triethylamine, and diethyl ether were dried by passing through a steel column filled with activated alumina ( $8 \times 14$ mesh, Sorbent Technology) using argon pressure. Hexanes, EtOAc, and 1,2dichloroethane (1,2-DCE) were distilled from calcium hydride. Chemicals prepared according to literature procedures have been footnoted first time used; all other reagents were obtained from commercial sources and used as received. All reactions were performed in oven-dried glassware. $n$-BuLi concentrations were determined by titrating with either diphenyl acetic acid in THF or with tertbutanol, 1,10-phenanthroline in THF. Solvents were removed on a rotary evaporator at water aspirator pressure unless otherwise stated. 
(4-Chloro-2-iodophenyl)-carbamic acid 1,1-dimethylethyl ester (37b). To a solution of 4-chloro-2-iodo-1-aminobenzene (36b) (1.44 g, $5.67 \mathrm{mmol})$ in THF (5 $\mathrm{mL}$ ) sodium bis(trimethylsilyl)amide (NaHMDS) (1.0 M in THF, $12.5 \mathrm{ml}, 12.5$ mmol) was added via syringe over a 15 min period. A solution of $\mathrm{BOC}_{2} \mathrm{O}(1.24 \mathrm{~g}$, $5.67 \mathrm{mmol})$ in THF $(5 \mathrm{~mL})$ was added dropwise to the reaction mixture. The reaction mixture was then stirred at ambient temperature $(24 \mathrm{~h})$. The solvent was removed under reduced pressure and the residue was partitioned between $\mathrm{HCl}$ (aq., $0.1 \mathrm{M}, 50 \mathrm{~mL}$ ) and $\mathrm{EtOAc}(20 \mathrm{~mL})$. The layers were separated and the aqueous layer was treated with sodium bicarbonate (saturated aq., $10 \mathrm{~mL}$ ). The resulting aqueous phase was extracted with EtOAc $(2 \times 20 \mathrm{~mL})$. The organic layers were combined, dried $\left(\mathrm{MgSO}_{4}\right)$, filtered, and the solvent was removed under reduced pressure. The crude product was purified by chromatography $\left(\mathrm{SiO}_{2}\right.$, hexanes:EtOAc, $\left.95: 5\right)$ to give $37 \mathrm{~b}(1.63 \mathrm{~g}, 4.60 \mathrm{mmol}, 81 \%)$ as an offwhite solid. mp $42-45^{\circ} \mathrm{C} ;{ }^{1} \mathrm{H}$ NMR $(270 \mathrm{MHz}) \delta 8.00(\mathrm{~d}, 1 \mathrm{H}, \mathrm{J}=8.9 \mathrm{~Hz}), 7.72(\mathrm{~d}$, $1 \mathrm{H}, J=2.4 \mathrm{~Hz}), 7.28(\mathrm{dd}, 1 \mathrm{H}, \mathrm{J}=8.9$ and $2.4 \mathrm{~Hz}), 6.79(\mathrm{br} \mathrm{s}, 1 \mathrm{H}), 1.53(\mathrm{~s}, 9 \mathrm{H}) ;{ }^{13} \mathrm{C}$ NMR (67.5 MHz) $\delta 152.3(+), 137.7(-), 137.6(+), 129.1(-), 128.4(+), 120.4(-)$, $88.2(+), 81.4(+), 28.2(-) ; \operatorname{IR~}\left(\mathrm{CCl}_{4}\right) 3400,2980,1738,1157 \mathrm{~cm}^{-1}$.

\section{(2-lodo-5-methoxy-phenyl)-carbamic acid 1,1-dimethylethyl ester (37c).}

Reaction of 2-iodo-5-methoxyaniline ${ }^{62}$ (36c) (409 mg, $1.64 \mathrm{mmol}$ ), sodium bis(trimethylsilyl)amide (1.0 M in THF, $3.60 \mathrm{~mL}, 3.60 \mathrm{mmol}$ ), and $\mathrm{Boc}_{2} \mathrm{O}(355 \mathrm{mg}$, $1.63 \mathrm{mmol})$ in THF, as described above for $37 \mathrm{~b}(24 \mathrm{~h})$, gave after workup and chromatography $\left(\mathrm{SiO}_{2}\right.$, hexanes:EtOAc, 8:2) 37c (528 mg, $\left.1.51 \mathrm{mmol}, 92 \%\right)$ as 
an off-white solid. mp $37-39{ }^{\circ} \mathrm{C} ;{ }^{1} \mathrm{H}$ NMR $(270 \mathrm{MHz}) 7.79(\mathrm{~d}, 1 \mathrm{H}, \mathrm{J}=2.8 \mathrm{~Hz}), 7.57$ (d, $1 \mathrm{H}, J=8.9 \mathrm{~Hz}), 6.83(\mathrm{br} \mathrm{s}, 1 \mathrm{H}), 6.40(\mathrm{dd}, 1 \mathrm{H}, \mathrm{J}=8.9$ and $2.9 \mathrm{~Hz}), 3.80(\mathrm{~s}, 3 \mathrm{H})$, $1.54(\mathrm{~s}, 9 \mathrm{H}) ;{ }^{13} \mathrm{C}$ NMR $(67.5 \mathrm{MHz}) \delta 160.7(+), 152.4(+), 139.6(+), 138.7(-)$, $111.7(-), 105.1(-), 81.1(+), 55.4(-), 28.3(-)$; IR $\left(\mathrm{CCl}_{4}\right)$ 3396, 2981, 1734, 1158 $\mathrm{cm}^{-1}$.

(2-lodo-5-methylphenyl)-carbamic acid 1,1-dimethylethyl ester (37d).

Reaction of 2-iodo-5-methyl-1-aminobenzene ${ }^{63}$ (36d) (897 mg, $\left.3.84 \mathrm{mmol}\right)$, sodium bis(trimethylsilyl)amide (1.0 M in THF, $4.2 \mathrm{ml}, 8.4 \mathrm{mmol})$, and $\mathrm{BOC}_{2} \mathrm{O}$ (846 mg, $3.88 \mathrm{mmol}$ ) in THF, as described for $37 \mathrm{~b}$ (24 h), gave after workup and chromatography $\left(\mathrm{SiO}_{2}\right.$, hexanes:EtOAc, 8:2) $37 \mathrm{~d}(1.122 \mathrm{~g}, 3.38 \mathrm{mmol}, 88 \%)$ as an off-white solid. mp $79.5-82^{\circ} \mathrm{C} ;{ }^{1} \mathrm{H}$ NMR $(270 \mathrm{MHz}) \delta 7.91(\mathrm{~s}, 1 \mathrm{H}), 7.59(\mathrm{~d}, 1 \mathrm{H}$, $\mathrm{J}=8.2 \mathrm{~Hz}), 6.79(\mathrm{br} \mathrm{s}, 1 \mathrm{H}), 6.60(\mathrm{dd}, 1 \mathrm{H}, \mathrm{J}=1.6$ and $8.1 \mathrm{~Hz}), 2.31(\mathrm{~s}, 3 \mathrm{H}), 1.54(\mathrm{~s}$, $9 \mathrm{H}) ;{ }^{13} \mathrm{C}$ NMR (67.5 MHz) $\delta 152.5(+), 139.4(+), 138.4(+), 138.3(-), 125.7(-)$, $120.6(-), 84.6(+), 80.9(+), 28.3(-), 21.3(-)$; IR $\left(\mathrm{CCl}_{4}\right)$ 3396, 2979, 2360 1736, $1160 \mathrm{~cm}^{-1}$.

(4-Chloro-2-(trimethylsilylethynyl)phenyl)-carbamic acid 1,1-dimethylethyl ester (38b). A mixture of 37b (1.104 g, $3.12 \mathrm{mmol})$, bis(triphenylphosphine)palladium dichloride (22 mg, $0.031 \mathrm{mmol}$ ), copper iodide (7 mg, $0.037 \mathrm{mmol})$, and trimethylsilylethyne $(470 \mu \mathrm{L}, 3.30 \mathrm{mmol})$ in triethylamine $(20 \mathrm{~mL})$ was stirred at ambient temperature $(24 \mathrm{~h})$. The reaction was diluted with water $(50 \mathrm{~mL})$ and the resulting biphasic mixture was extracted with diethyl ether 
(3 $\times 50 \mathrm{~mL})$. The combined organic layers were washed with $\mathrm{NH}_{4} \mathrm{OH}(10 \%$ aq., $25 \mathrm{~mL})$, dried $\left(\mathrm{MgSO}_{4}\right)$, filtered, and the solvent were removed under reduced pressure. The crude product was purified by chromatography $\left(\mathrm{SiO}_{2}\right.$, hexanes: EtOAc, 95:5) to give $\mathbf{2 8 b}$ (924 $\mathrm{mg}, 2.84 \mathrm{mmol}, 91 \%$ ) as a yellow solid. $\mathrm{mp} 72-76$ ${ }^{\circ} \mathrm{C} ;{ }^{1} \mathrm{H}$ NMR $(270 \mathrm{MHz}) \delta 8.08(1 \mathrm{H}, \mathrm{J}=9.1 \mathrm{~Hz}), 7.34(\mathrm{~d}, 1 \mathrm{H}, \mathrm{J}=2.6 \mathrm{~Hz}), 7.31$ (br s, 1H), $7.25(\mathrm{dd}, 1 \mathrm{H}, \mathrm{J}=8.9$ and $2.4 \mathrm{~Hz}), 1.53(\mathrm{~s}, 9 \mathrm{H}), 0.29(\mathrm{~s}, 9 \mathrm{H}) ;{ }^{13} \mathrm{C}$ NMR $(67.5$ MHz) ọ $152.1(+), 138.8(+), 130.7(-), 129.8(-), 126.6(+), 118.3(-), 112.3(+)$, $103.4(+), 99.0(+), 80.9(+), 28.2(-),-0.3(-)$; IR $\left(\mathrm{CCl}_{4}\right)$ 3400, 2977, 2152, 1737, $1157 \mathrm{~cm}^{-1}$.

(5-Methoxy-2-trimethylsilylethynylphenyl)-carbamic acid 1,1-dimethylethyl ester (38c). Reaction of 37c (504 mg, $1.44 \mathrm{mmol})$, bis(triphenylphosphine)palladium dichloride (54 mg, $0.077 \mathrm{mmol}$ ), copper iodide (14 mg, $0.074 \mathrm{mmol})$, and trimethylsilylethyne $(230 \mu \mathrm{L}, 1.59 \mathrm{mmol})$ in triethylamine (30 mL), as described for $\mathbf{3 8 b}$ (ambient temperature, $24 \mathrm{~h}$ ), gave after workup and chromatography $\left(\mathrm{SiO}_{2}\right.$, hexanes:EtOAc, 95:5) 38c (360 mg, $1.16 \mathrm{mmol}, 80 \%$ ) off-white solid. mp $39-41^{\circ} \mathrm{C} ;{ }^{1} \mathrm{H}$ NMR $\delta 7.78(\mathrm{~s}, 1 \mathrm{H}), 7.39$ (s, 1H), $7.26(\mathrm{~d}, 1 \mathrm{H}, \mathrm{J}=9.0 \mathrm{~Hz}), 6.49(\mathrm{dd}, 1 \mathrm{H}, \mathrm{J}=7.8$ and $1.8 \mathrm{~Hz}), 3.82(\mathrm{~s}, 3 \mathrm{H}), 1.53$ (s, 9H), $0.28(\mathrm{~s}, 9 \mathrm{H}) ;{ }^{13} \mathrm{C}$ NMR $\delta 160.9(+), 152.3(+), 141.9(+), 132.2(-), 108.9(-$ ), $103.0(+), 102.1(-), 100.8(+), 100.5(+), 80.6(+), 55.4(-), 28.3(-),-0.1(-)$; IR $\left(\mathrm{CCl}_{4}\right) 3395,2963,2347,2144,1734,1157 \mathrm{~cm}^{-1}$. 
(5-Methyl-2-trimethylsilylethynylphenyl)-carbamic acid 1,1-dimethylethyl ester (38d). Reaction of $\mathbf{3 7 d}(450 \mathrm{mg}, 1.36 \mathrm{mmol})$, bis(triphenylphosphine)palladium dichloride (48 mg, $0.068 \mathrm{mmol}$ ), copper iodide (16 mg, $0.084 \mathrm{mmol})$, and trimethylsilylethyne $(200 \mu \mathrm{L}, 1.42 \mathrm{mmol})$ in triethylamine (10 mL), as described for $\mathbf{3 8 b}$ (ambient temperature, $24 \mathrm{~h}$ ), gave after workup and chromatography $\left(\mathrm{SiO}_{2}\right.$, hexanes: EtOAc, 95:5) 38d (409 mg, $1.35 \mathrm{mmol}, 100 \%)$ as a colorless oil. ${ }^{1} \mathrm{H}$ NMR $(270 \mathrm{MHz}) \delta 7.96(\mathrm{~s}, 1 \mathrm{H}), 7.40(\mathrm{br}$ s, 1H), $7.15(\mathrm{~d}, 1 \mathrm{H}, J=7.5 \mathrm{~Hz}), 6.75(\mathrm{~d}, 1 \mathrm{H}, J=7.7 \mathrm{~Hz}), 2.34(\mathrm{~s}, 3 \mathrm{H}), 1.53(\mathrm{~s}, 9 \mathrm{H})$,

0.28 (s, 9H); ${ }^{13} \mathrm{C}$ NMR $\delta 152.4(+), 140.5(+), 140.1(+), 131.0(-), 122.8(-), 117.7$ (-), $108.1(+), 101.3(+), 100.8(+), 80.5(+), 28.3(-), 22.0(-),-0.1(-)$; IR $\left(\mathrm{CCl}_{4}\right)$ $3396,2977,2348,2148,1736,1159 \mathrm{~cm}^{-1}$.

\section{(4-Trimethylsilylethynyl-3-pyridinyl)-carbamic acid 1,1-dimethylethyl ester} (38e). Reaction of (4-iodo-3-pyridinyl)-carbamic acid 1,1-dimethylethyl ester ${ }^{64}$ (37e) $(1.96 \mathrm{~g}, 6.14 \mathrm{mmol})$, bis(triphenylphosphine)palladium dichloride (65 mg, $0.093 \mathrm{mmol})$, copper iodide (17 $\mathrm{mg}, 0.89 \mathrm{mmol})$, and trimethylsilylethyne (1.33 $\mathrm{mL}, 6.45 \mathrm{mmol})$ in triethylamine $(20 \mathrm{~mL})$, as described for $37 \mathrm{~b}$ (ambient temperature, $24 \mathrm{~h})$, gave after workup and chromatography $\left(\mathrm{SiO}_{2}\right.$, hexanes:EtOAc, 1:1) 38e (1.78 g, $6.14 \mathrm{mmol}, 100 \%)$ as a brown solid. $\mathrm{mp} 59-61$ ${ }^{\circ} \mathrm{C} ;{ }^{1} \mathrm{H}$ NMR $(270 \mathrm{MHz}) \delta 9.39(\mathrm{~s}, 1 \mathrm{H}), 8.24(\mathrm{~d}, 1 \mathrm{H}, \mathrm{J}=4.9 \mathrm{~Hz}), 7.21(\mathrm{~d}, 1 \mathrm{H}, \mathrm{J}=4.9$ $\mathrm{Hz}), 7.12(\mathrm{br} \mathrm{s}, 1 \mathrm{H}), 1.55(\mathrm{~s}, 9 \mathrm{H}), 0.31(\mathrm{~s}, 9 \mathrm{H}) ;{ }^{13} \mathrm{C}$ NMR $(67.5 \mathrm{MHz}) \delta 151.8(+)$, $142.9(-), 139.9(-), 135.8(+), 124.2(-), 118.2(+), 106.9(+), 97.6(+), 81.4\left(^{+}\right)$, $28.1(-),-0.4(-)$; IR 3389, 2978, 2155, 1736, $1155\left(\mathrm{CCl}_{4}\right) \mathrm{cm}^{-1}$. 
(4-Chloro-2-ethynylphenyl)-carbamic acid 1,1-dimethylethyl ester (26b). To a solution of $38 \mathbf{b}(924 \mathrm{mg}, 2.85 \mathrm{mmol})$ in absolute ethanol:THF $(1: 1,30 \mathrm{~mL})$ was added a solution of $\mathrm{NaOH}^{65}(1 \mathrm{M}, 3 \mathrm{~mL})$ and the resulting reaction mixture was allowed to stir (ambient temperature, $2 \mathrm{~h}$ ). The solvents were removed at reduced pressure and the residue was suspended in water $(10 \mathrm{~mL})$ and extracted with diethyl ether $(3 \times 50 \mathrm{~mL})$. The organic layers were combined, dried $\left(\mathrm{MgSO}_{4}\right)$, filtered, and the solvent was removed under reduced pressure. The crude product was purified by chromatography $\left(\mathrm{SiO}_{2}\right.$, hexanes: EtOAc, 9:1) to give 26b (664 mg, $2.64 \mathrm{mmol}, 92 \%$ ) as an off-white solid. mp 61-63 ${ }^{\circ} \mathrm{C} ;{ }^{1} \mathrm{H}$ NMR $(270 \mathrm{MHz}) \delta 8.13(\mathrm{~d}, 1 \mathrm{H}, J=9.1 \mathrm{~Hz}), 7.39(\mathrm{~d}, 1 \mathrm{H}, J=2.4 \mathrm{~Hz}), 7.29$ (dd, 1H, J=9.1 and 2.6 Hz), $7.21(\mathrm{br} \mathrm{s}, 1 \mathrm{H}), 3.52(\mathrm{~s}, 1 \mathrm{H}), 1.53(\mathrm{~s}, 9 \mathrm{H}) ;{ }^{13} \mathrm{C}$ NMR $(67.5 \mathrm{MHz}) \delta$ $152.1(+), 138.9(+), 131.5(-), 130.1(-), 126.7(+), 118.7(-), 111.2(+), 85.1\left(^{+}\right)$, $81.2(+), 77.9(+), 28.2(-)$; IR $\left(\mathrm{CCl}_{4}\right) 3411,3305,2980,2361,1737,1156 \mathrm{~cm}^{-1}$.

\section{(2-Ethynyl-5-methoxyphenyl)-carbamic acid 1,1-dimethylethyl ester (26c).}

To a solution of $38 \mathrm{c}(603 \mathrm{mg}, 1.89 \mathrm{mmol})$ in methanol:THF:water $(5: 5: 1,11 \mathrm{~mL})$ was added anhydrous potassium fluoride (334 $\mathrm{mg}, 5.75 \mathrm{mmol}$ ) and the resulting mixture was stirred (ambient temperature, $1 \mathrm{~h}$ ). The reaction was diluted with water $(50 \mathrm{~mL})$ and extracted diethyl ether $(3 \times 50 \mathrm{~mL})$. The combined organic layers were washed with brine $(20 \mathrm{~mL})$, dried $\left(\mathrm{MgSO}_{4}\right)$, filtered, and the solvents were removed at reduced pressure. The crude product was purified by chromatography $\left(\mathrm{SiO}_{2}\right.$, hexanes:EtOAc, $\left.95: 5\right)$ to give $26 \mathrm{c}(366 \mathrm{mg}, 1.59 \mathrm{mmol}$, $84 \%)$ as a colorless solid. mp around ambient temperature. ${ }^{1} \mathrm{H}$ NMR $(270 \mathrm{MHz}) \delta$ 
$7.83(\mathrm{~d}, 1 \mathrm{H}, J=2.4 \mathrm{~Hz}), 7.32(\mathrm{~d}, 1 \mathrm{H}, J=8.5 \mathrm{~Hz}), 7.29(\mathrm{br} \mathrm{s}, 1 \mathrm{H}), 6.51$ (dd, $1 \mathrm{H}$, $J=8.7$ and $2.6 \mathrm{~Hz}), 3.83(\mathrm{~s}, 3 \mathrm{H}), 3.42(\mathrm{~s}, 1 \mathrm{H}), 1.53(\mathrm{~s}, 9 \mathrm{H}) ;{ }^{13} \mathrm{C}$ NMR $(67.5 \mathrm{MHz}) \delta$ $161.1(+), 152.3(+), 141.8(+), 133.1(-), 109.1(-), 102.4(-), 101.8\left(^{+}\right), 82.8(+)$, $80.9(+), 79.5(+), 55.4(-), 28.3(-)$; IR 3407, 3309, 2980, 2360, 1734, $1157 \mathrm{~cm}^{-1}$.

(2-Ethynyl-5-methylphenyl)-carbamic acid 1,1-dimethylethyl ester (26d). Reaction of $38 \mathrm{~d}(400 \mathrm{mg}, 1.32 \mathrm{mmol})$ with $\mathrm{NaOH}^{65}$ (1 M aq., $4 \mathrm{~mL}$ ) in absolute ethanol:THF (1:1, $20 \mathrm{~mL}$ ), as described for $\mathbf{2 6 b}$ (ambient temp., $2 \mathrm{~h}$ ), gave after workup and chromatography $\left(\mathrm{SiO}_{2}\right.$, hexanes: EtOAc, 9:1) 26d (241 mg, 1.05 mmol, $79 \%)$ as a yellow solid. mp $75-77^{\circ} \mathrm{C}{ }^{1} \mathrm{H}$ NMR $(270 \mathrm{MHz}) \delta 8.01(\mathrm{~s}, 1 \mathrm{H})$, $7.31(\mathrm{~d}, 1 \mathrm{H}, \mathrm{J}=7.9 \mathrm{~Hz}), 7.24(\mathrm{br} \mathrm{s}, 1 \mathrm{H}), 6.78(\mathrm{~d}, 1 \mathrm{H}, \mathrm{J}=7.9), 3.4(\mathrm{~s}, 1 \mathrm{H}), 2.35$ (s, 3H), $1.53(\mathrm{~s}, 9 \mathrm{H}) ;{ }^{13} \mathrm{C}$ NMR (67.5 MHz) $\delta 152.4(+), 140.7(+), 140.1(+), 131.9(-$ ), $122.9(-), 117.9(-), 106.9(+), 83.4(+), 80.7(+), 79.5(+), 28.3(-), 21.9(-) ;$ IR $\left(\mathrm{CCl}_{4}\right) 3408,3309,2978,2926,2347,1735,1157 \mathrm{~cm}^{-1}$.

\section{Alternative Procedure for: (2-Ethynyl-5-methylphenyl)-carbamic acid 1,1- dimethylethyl ester (26d).}

Reaction of 38d (389 mg, $1.29 \mathrm{mmol}$ ) with anhydrous fluoride dihydrate (226 mg, $3.89 \mathrm{mmol}$ ) in methanol:THF $(1: 1,20 \mathrm{~mL})$, as described for $\mathbf{2 6 \mathbf { d }}$ (ambient temperature, $1 \mathrm{~h})$, gave after workup and chromatography $\left(\mathrm{SiO}_{2}\right.$, hexanes: EtOAc, 9:1) (217 mg, $0.94 \mathrm{mmol}, 73 \%)$ a yellow solid.

(4-Ethynyl-3-pyridinyl)-carbamic acid 1,1-dimethylethyl ester (26e). Reaction of $38 \mathrm{e}(1.78 \mathrm{~g}, 6.14 \mathrm{mmol})$ with potassium fluoride dihydrate $(1.72 \mathrm{~g}, 18.3 \mathrm{mmol})$ 
in methanol:THF (1:1,15 mL), as described for 26c (ambient temperature, 20 min), gave after workup and chromatography $\left(\mathrm{SiO}_{2}\right.$, hexanes: EtOAc, 1:1) 26e (1.32 g, $6.08 \mathrm{mmol}, 99 \%)$ as a brownish solid. mp $77-80{ }^{\circ} \mathrm{C} ;{ }^{1} \mathrm{H}$ NMR $(270 \mathrm{MHz})$ $\delta 9.40(\mathrm{~s}, 1 \mathrm{H}), 8.26(\mathrm{~d}, 1 \mathrm{H} \mathrm{J}=4.9 \mathrm{~Hz}), 7.28(\mathrm{~d}, 1 \mathrm{H}, J=5.1 \mathrm{~Hz}), 7.09(\mathrm{br} \mathrm{s}, 1 \mathrm{H}), 3.69$ (s, 1H), $1.57(\mathrm{~s}, 9 \mathrm{H}) ;{ }^{13} \mathrm{C}$ NMR $(67.5 \mathrm{MHz}) \delta 151.9(+), 143.0(-), 140.4(-), 136.0$ (+), $125.2(-), 117.3(+), 88.1(+), 88.0(+), 81.7(+), 28.2(-)$; IR $\left(\mathrm{CCl}_{4}\right) 3407,3298$, $2982,2248,1727,1160 \mathrm{~cm}^{-1}$.

\section{Alternative Procedure for: (4-Ethynyl-3-pyridinyl)-carbamic acid 1,1- dimethylethyl ester (26e).}

Reaction of $38 \mathrm{e}(427 \mathrm{mg}, 1.48 \mathrm{mmol})$ with $\mathrm{NaOH}^{65}(1 \mathrm{M}$ aq., $5 \mathrm{~mL})$ in absolute ethanol:THF (1:1, $20 \mathrm{~mL}$ ), as described for 26c (ambient temp., $24 \mathrm{~h}$ ), gave after workup and chromatography $\left(\mathrm{SiO}_{2}\right.$, hexanes: EtOAc, 7:3) $(185 \mathrm{mg}, 0.85 \mathrm{mmol}$, $61 \%)$ as a brownish solid.

\section{[2-(1-Hydroxy-2,3-bis(1-methylethoxy)-4-oxo-cyclobut-2-} enylethynyl)phenyl]-carbamic acid 1,1-dimethylethyl ester (28a). To a $-5^{\circ} \mathrm{C}$ cold solution of (2-ethynylphenyl)-carbamic acid 1,1-dimethylethyl ester (26a) ${ }^{66}$ (155 mg, $0.71 \mathrm{mmol})$ in THF (10 mL) was slowly added $\mathrm{n}$-BuLi (1.6 M in hexanes, $1.1 \mathrm{~mL}, 1.8 \mathrm{mmol}$ ) via syringe. After $15 \mathrm{~min}, \mathrm{a}-5^{\circ} \mathrm{C}$ cold solution 3,4bis(1-methylethoxy)-3-cyclobutene-1,2-dione (27) (141 mg, $0.71 \mathrm{mmol}$ ) in THF $(10 \mathrm{~mL})$ was added to the dilithiated compound via a cannula. The resulting reaction mixture was stirred (ambient temperature, $30 \mathrm{~min}$ ) followed by the 
addition of water $(40 \mathrm{~mL})$. The biphasic mixture was extracted with diethyl ether $(3 \times 50 \mathrm{~mL})$ and the combined organic layers were dried $\left(\mathrm{MgSO}_{4}\right)$, filtered, and the solvents were removed under reduced pressure. The crude product was purified by chromatography $\left(\mathrm{SiO}_{2}\right.$, hexanes:EtOAc, 8:2) to afford $28 \mathbf{a}$ (189 mg,

$0.45 \mathrm{mmol}, 64 \%)$ as a brown oil and $26 \mathrm{a}(20 \mathrm{mg}, 0.09 \mathrm{mmol}) .{ }^{1} \mathrm{H}$ NMR $(270 \mathrm{MHz})$ $\delta 8.14(\mathrm{~d}, 1 \mathrm{H}, J=8.3 \mathrm{~Hz}), 7.40(\mathrm{dd}, 1 \mathrm{H}, J=7.7$ and $1.4 \mathrm{~Hz}), 7.32(\mathrm{dt}, 1 \mathrm{H}, J=8.7$ and 1.6 Hz), 7.14 (br s, 1H), 6.95 (dt, 1H, J=7.5 and $1.0 \mathrm{~Hz}$ ), 5.02 (heptet, $1 \mathrm{H}, J=6.1$ Hz), 4.92 (heptet, 1H, J=6.1 Hz), 3.07 (br s, 1H), $1.53(\mathrm{~s}, 9 \mathrm{H}), 1.48$ (d, 3H, J=6.3 $\mathrm{Hz}), 1.47(\mathrm{~d}, 3 \mathrm{H}, J=6.1 \mathrm{~Hz}) 1.33(\mathrm{~d}, 3 \mathrm{H}, J=6.1 \mathrm{~Hz}), 1.32(\mathrm{~d}, 3 \mathrm{H}, J=6.1 \mathrm{~Hz}) ;{ }^{13} \mathrm{C}$ NMR (67.5 MHz) $\delta 180.4(+), 164.1(+), 152.4(+), 139.7(+), 133.8(+), 132.2(-)$, $130.1(-), 122.0(-), 117.8(-), 109.9(+), 90.2(+), 83.8(+), 80.9(+), 78.9\left(^{+}\right), 78.1$ (-), $74.3(-), 28.3(-), 22.7(-), 22.6(-), 22.5(-)$; IR $\left(\mathrm{CCl}_{4}\right)$ 3402, 2980, 2933, 1734, $1158 \mathrm{~cm}^{-1}$.

\section{Alternative Procedure for: [2-(1-Hydroxy-2,3-bis(1-methylethoxy)-4-oxo- cyclobut-2-enylethynyl)phenyl]-carbamic acid 1,1-dimethylethyl ester (28a).} 4-Ethynyl-4-hydroxy-2,3-diisopropoxy-cyclobut-2-enone ${ }^{69}$ (39) (272 mg, 1.21 $\mathrm{mmol}$ ), bis(triphenylphosphine)palladium dichloride (45 mg, $0.063 \mathrm{mmol})$, copper iodide (238 mg, $1.25 \mathrm{mmol}$ ) were slurried in $30 \mathrm{~mL} \mathrm{NEt}_{3}$. 37 a (394 mg, 1.23 mmol) was added after five minutes and the reaction was allowed to stir. After 24 hours the reaction was diluted with $50 \mathrm{~mL}$ water and extracted with diethyl ether $(3 \times 50 \mathrm{~mL})$. The combined organic layers were washed with $20 \mathrm{~mL}$ 10\% $\mathrm{NH}_{4} \mathrm{OH}$, dried $\left(\mathrm{MgSO}_{4}\right)$, filtered, and the solvents were removed under reduced 
pressure. The crude product was purified by chromatography $\left(\mathrm{SiO}_{2}\right.$, hexanes:EtOAc, 8:2) to afford $28 \mathrm{a}(189 \mathrm{mg}, 0.35 \mathrm{mmol}, 36 \%)$ as a brown oil and $37 \mathrm{a}$ (155 mg, $0.48 \mathrm{mmol}, 61 \%)$.

\section{[4-Chloro-2-(1-hydroxy-2,3-di(1-methylethoxy)-4-oxo-cyclobut-2-} enylethynyl)phenyl]-carbamic acid 1,1-dimethylethyl ester (28b). Reaction of 26b (250 mg, $0.99 \mathrm{mmol}), n$-BuLi (2.65 M in hexanes, $0.93 \mathrm{~mL}, 2.4 \mathrm{mmol}$ ), and 3,4-bis(1-methylethoxy)-3-cyclobutene-1,2-dione (27) (198 mg, $1.00 \mathrm{mmol})$ in THF (20 $\mathrm{mL}$ total), as described for $\mathbf{2 8 a}$ (30 min), gave after workup and chromatography $\left(\mathrm{SiO}_{2}\right.$, hexanes:EtOAc, 8:2), 28b (349 mg, $\left.0.77 \mathrm{mmol}, 78 \%\right)$ as a yellow solid. mp $123-125{ }^{\circ} \mathrm{C} ;{ }^{1} \mathrm{H}$ NMR $(270 \mathrm{MHz}) \delta 8.08(\mathrm{~d}, 1 \mathrm{H}, \mathrm{J}=8.9 \mathrm{~Hz}), 7.34$ (d, $1 \mathrm{H}, J=2.4 \mathrm{~Hz}), 7.25(\mathrm{dd}, 1 \mathrm{H}, \mathrm{J}=2.6$ and $8.9 \mathrm{~Hz}$ ), 7.15 (br s, 1H), 5.02 (heptet, 1H, J=6.1 Hz), 4.89 (heptet, 1H, J=6.1 Hz), $3.74(\mathrm{br} \mathrm{s}, 1 \mathrm{H}), 1.53(\mathrm{~s}, 9 \mathrm{H}), 1.48(\mathrm{~d}$, $3 \mathrm{H}, J=6.1 \mathrm{~Hz}), 1.47(\mathrm{~d}, 3 \mathrm{H}, \mathrm{J}=6.1 \mathrm{~Hz}) ; 1.32(\mathrm{~d}, 6 \mathrm{H}, \mathrm{J}=6.1 \mathrm{~Hz}) ;{ }^{3} \mathrm{C}$ NMR $(67.5$ MHz) $\delta 180.6(+), 164.2(+), 152.3(+), 138.4(+), 133.8(+), 131.4(-), 130.1(-)$, $126.8(+), 119.1(-), 111.4(+), 91.3(+), 82.4(+), 81.2(+), 78.6(+), 78.2(-), 74.3$ (-), 28.2 (-), $22.7(-), 22.6(-), 22.5(-)$; IR ( $\left.\mathrm{CCl}_{4}\right)$ 3424, 2968, 2355, 1734, 1157 $\mathrm{cm}^{-1}$.

\section{[2-(1-Hydroxy-2,3-di(1-methylethoxy)-4-oxo-cyclobut-2-enylethynyl)-5-} methoxyphenyl]-carbamic acid 1,1-dimethylethyl ester (28c). Reaction of 26c (192 mg, $0.80 \mathrm{mmol}$ ), $n$-BuLi (1.4 M in hexanes, $1.43 \mathrm{~mL}, 2.01 \mathrm{mmol}$ ), and 3,4bis(1-methylethoxy)-3-cyclobutene-1,2-dione (27) (106 mg, $0.81 \mathrm{mmol}$ ) in THF 
(25 $\mathrm{mL}$ total) as described for $\mathbf{2 8 a}$ (30 $\mathrm{min}$ ), gave after workup and chromatography $\left(\mathrm{SiO}_{2}\right.$, hexanes:EtOAc, 8:2) an inseparable mixture of $28 \mathrm{c}$ and 4-butyl-4-hydroxy-2,3-di(1-methylethoxy)-2-cyclobuten-1-one (215 mg, 4:1 ratio). Spectral data from the mixture: ${ }^{1} \mathrm{H}$ NMR $(270 \mathrm{MHz}) \delta 7.80(\mathrm{~d}, 1 \mathrm{H}, \mathrm{J}=2.2 \mathrm{~Hz})$, $7.28(\mathrm{~d}, 1 \mathrm{H}, \mathrm{J}=8.3 \mathrm{~Hz}), 7.17(\mathrm{br} \mathrm{s}, 1 \mathrm{H}), 6.50(\mathrm{dd}, 1 \mathrm{H}, \mathrm{J}=8.5$ and $2.6 \mathrm{~Hz}), 5.02$ (heptet, 1H, J=6.1 Hz), 4.90 (heptet, 1H, J=6.3 Hz), $3.82(\mathrm{~s}, 3 \mathrm{H}$ ), 3.21 (br s, 1H), $1.53(\mathrm{~s}, 9 \mathrm{H}), 1.48(\mathrm{~d}, 3 \mathrm{H}, \mathrm{J}=6.3 \mathrm{~Hz}), 1.46(\mathrm{~d}, 3 \mathrm{H}, \mathrm{J}=6.1 \mathrm{~Hz}) 1.32(\mathrm{~d}, 3 \mathrm{H}, \mathrm{J}=6.1$ $\mathrm{Hz}), 1.31(\mathrm{~d}, 3 \mathrm{H}, \mathrm{J}=6.1 \mathrm{~Hz}) ;{ }^{13} \mathrm{C}$ NMR $(67.5 \mathrm{MHz}) \delta 180.7(+), 164.3(+), 161.1$ (+), $152.3(+), 141.3(+), 133.7(+), 133.1(-), 109.1(-), 102.5(-), 101.9(+), 89.1$ (-), $83.9(+), 80.9(+), 78.9(+), 74.2(-), 28.3(-), 22.7(-), 22.6(-), 22.5(-), 22.3(-$ ); IR $\left(\mathrm{CCl}_{4}\right) 3565,2989,2942,1731,1161 \mathrm{~cm}^{-1}$.

\section{Alternative Procedure for: [2-(1-Hydroxy-2,3-di(1-methylethoxy)-4-oxo- cyclobut-2-enylethynyl)-5-methoxyphenyl]-carbamic acid 1,1-dimethylethyl} ester (28c). 4-Ethynyl-4-hydroxy-2,3-diisopropoxy-cyclobut-2-enone ${ }^{69}$ (39) (581 $\mathrm{mg}, 2.59 \mathrm{mmol}$ ), bis(triphenylphosphine)palladium dichloride (91 mg, 0.013 mmol), copper iodide (496 mg, $2.61 \mathrm{mmol}$ ) were slurried in $30 \mathrm{~mL} \mathrm{NEt}$. (2-lodo5-methoxy-phenyl)-carbamic acid 1,1-dimethylethyl ester (37c) (912 mg, 2.61 mmol) was added after five minutes and the reaction was allowed to stir. After 20 hours the reaction was diluted with $50 \mathrm{~mL}$ water and extracted with diethyl ether $(3 \times 50 \mathrm{~mL})$. The combined organic layers were washed with $20 \mathrm{~mL} 10 \%$ $\mathrm{NH}_{4} \mathrm{OH}$, dried $\left(\mathrm{MgSO}_{4}\right)$, filtered, and the solvents were removed under reduced pressure. The crude product was purified by chromatography $\left(\mathrm{SiO}_{2}\right.$, 
hexanes:EtOAc, 8:2) to afford $\mathbf{2 8 c}(747 \mathrm{mg}, 1.68 \mathrm{mmol}, 65 \%)$ as fluffy orange yellow solid. $\mathrm{mp} 38-42{ }^{\circ} \mathrm{C} .{ }^{1} \mathrm{H}$ NMR $(270 \mathrm{MHz}) \delta 7.76(\mathrm{~d}, 1 \mathrm{H}, \mathrm{J}=2.4 \mathrm{~Hz}), 7.26$ (d, $1 \mathrm{H}, \mathrm{J}=8.7 \mathrm{~Hz}$ ), $6.48(\mathrm{dd}, 1 \mathrm{H}, \mathrm{J}=8.7$ and $2.6 \mathrm{~Hz}$ ), 5.03 (heptet, $1 \mathrm{H}, \mathrm{J}=6.1$ Hz), 4.88 (heptet, $1 \mathrm{H}, \mathrm{J}=6.1 \mathrm{~Hz}$ ), 3.94 (br. s, 1H), $3.82(\mathrm{~s}, 3 \mathrm{H}), 1.53(\mathrm{~s}, 9 \mathrm{H}), 1.47$ (overlapping d, 3H, J = 6.2 Hz), 1.46 (overlapping d, 3H, J = 6.1 Hz), $1.29(\mathrm{~d}, 6 \mathrm{H}$, $\mathrm{J}=6.1 \mathrm{~Hz}) ;{ }^{13} \mathrm{C} \operatorname{NMR}(67.5 \mathrm{MHz}) \delta 181.3(+), 164.8(+), 160.8(+), 152.2(+)$, $141.1(+), 133.3(+), 132.9(-), 108.9(-), 102.5(-), 101.9(+), 89.1(+), 83.6(+)$, $80.7(+), 78.6(+), 77.8(-), 73.9(-), 55.1(-), 28.1(-), 22.5(-), 22.4(-), 22.3(-)$; IR (neat) 3398 (br.), 2979, 2213, 1774, $1730 \mathrm{~cm}^{-1}$.

\section{[2-(1-Hydroxy-2,3-di(1-methylethoxy)-4-oxo-cyclobut-2-enylethynyl)-5-} methylphenyl]-carbamic acid 1,1-dimethylethyl ester (28d). Reaction of 11c (241 mg, $1.05 \mathrm{mmol}$ ), $n$-BuLi (1.6 M in hexanes, $1.64 \mathrm{~mL}, 2.62 \mathrm{mmol}$ ), and 3,4bis(1-methylethoxy)-3-cyclobutene-1,2-dione (27) (207 mg, $1.04 \mathrm{mmol}$ ) in THF (30 $\mathrm{mL}$ total), as described for $\mathbf{2 8 a}$ (30 min), gave after workup and

chromatography $\left(\mathrm{SiO}_{2}\right.$, hexanes:EtOAc, 8:2) $28 \mathrm{~d}(222 \mathrm{mg}, 0.52 \mathrm{mmol}, 50 \%)$ as a yellow oil and $26 \mathrm{c}(70 \mathrm{mg}, 0.30 \mathrm{mmol}) .{ }^{1} \mathrm{H}$ NMR $(270 \mathrm{MHz}) \delta 7.98(\mathrm{~s}, 1 \mathrm{H}), 7.26$ (d, 1H, J=7.9 Hz), $7.12(\mathrm{br} \mathrm{s}, 1 \mathrm{H}), 6.77(\mathrm{~d}, 1 \mathrm{H}, \mathrm{J}=7.9 \mathrm{~Hz}$ ), 5.02 (heptet, 1H, J=6.1 Hz), 4.90 (heptet, 1H, J=6.1 Hz), 3.16 (br s, 1H), 2.34 (s, 3H), 1.53 (s, 9H), 1.48 (d, 3H, J=6.3 Hz), $1.46(\mathrm{~d}, 3 \mathrm{H}, J=6.1 \mathrm{~Hz}) 1.32(\mathrm{~d}, 3 \mathrm{H}, \mathrm{J}=6.1 \mathrm{~Hz}), 1.31(\mathrm{~d}, 3 \mathrm{H}$, $J=6.1 \mathrm{~Hz}) ;{ }^{13} \mathrm{C}$ NMR $(67.5 \mathrm{MHz}) \delta 180.3(+), 164.1(+), 152.4(+), 140.9(+)$, $139.6(+), 133.9(+), 131.9(-), 123.0(-), 118.3(-), 106.9(+), 89.6(+), 84.1(+)$, 
$80.8(+), 78.9(+), 78.0(-), 74.3(-), 28.3(-), 22.7(-), 22.6(-), 22.5(-), 21.9(-)$; IR $\left(\mathrm{CCl}_{4}\right) 3424,2978,1731,1637,1161 \mathrm{~cm}^{-1}$.

\section{[4-(1-Hydroxy-2,3-di(1-methylethoxy)-4-oxo-cyclobut-2-enylethynyl)-} pyridin-3-yl]-carbamic acid 1,1-dimethylethyl ester (28e). Reaction of $26 e$ (1.05 g, $4.81 \mathrm{mmol}), n$-BuLi (2.89 $\mathrm{M}$ in hexanes, $4.16 \mathrm{~mL}, 12.04 \mathrm{mmol}$ ), and 3,4bis(1-methylethoxy)-3-cyclobutene-1,2-dione (27) (0.96 g, $4.83 \mathrm{mmol})$ in THF (40 $\mathrm{mL}$ total), as described for $\mathbf{2 8 a}$, gave after workup and chromatography $\left(\mathrm{SiO}_{2}\right.$, hexanes:EtOAc, 1:1), 28e (1.14 g, $2.74 \mathrm{mmol}, 57 \%)$ as a brown oil. ${ }^{1} \mathrm{H}$ NMR (270 MHz) $\delta 9.40$ (s, 1H), 8.24 (d, 1H, J=4.9 Hz), 7.24 (d, 1H, J=4.9 Hz), 6.99 (br s, 1H), 5.02 (heptet, 1H, J=6.1 Hz), 4.91 (heptet, 1H, J=6.1 Hz), 4.57 (br s, 1H), $1.53(\mathrm{~s}, 9 \mathrm{H}), 1.47$ (d, 3H, J=6.3 Hz), $1.46(\mathrm{~d}, 3 \mathrm{H}, \mathrm{J}=6.1 \mathrm{~Hz}) 1.32(\mathrm{~d}, 3 \mathrm{H}, \mathrm{J}=6.1$ $\mathrm{Hz}), 1.31(\mathrm{~d}, 3 \mathrm{H}, \mathrm{J}=6.1 \mathrm{~Hz}) ;{ }^{13} \mathrm{C}$ NMR $(67.5 \mathrm{MHz}) \delta 180.0(+), 164.0(+), 151.8$ (+), $142.3(-), 139.9(-), 139.8(-), 135.7(+), 133.8(+), 125.3(-), 118.0(+), 95.5$ $(+), 81.6(+), 80.5(+), 78.5(+), 78.1(-) .78 .0(-), 74.3(-), 74.2(-), 28.1(-), 22.6(-$ ), 22.5 (-), 22.4 (-); IR ( $\left.\mathrm{CCl}_{4}\right) 3405$ (br.), 2978, 2360, 1737, $1158 \mathrm{~cm}^{-1}$.

\section{[2-(3,4-Di(1-methylethoxy)-2,5-dioxo-3-cyclopenten-1-ylmethyl)phenyl]-} carbamic acid 1,1-dimethylethyl ester (33a). A solution of 28 a (325 mg, 0.78 $\mathrm{mmol})$ in toluene $(20 \mathrm{~mL})$ was heated at reflux overnight. The reaction was cooled to ambient temperature and the solvent was removed under reduced pressure. The crude residue was purified by chromatography $\left(\mathrm{SiO}_{2}\right.$, hexanes: EtOAc, $95: 5)$ to give $33 \mathrm{a}(265 \mathrm{mg}, 0.64 \mathrm{mmol}, 82 \%)$ as an orange solid. $\mathrm{mp} 93-$ 
$96{ }^{\circ} \mathrm{C} ;{ }^{1} \mathrm{H}$ NMR $(270 \mathrm{MHz}) \delta 7.91(\mathrm{dd}, 1 \mathrm{H}, \mathrm{J}=7.9$ and $1.6 \mathrm{~Hz}), 7.80(\mathrm{~d}, 1 \mathrm{H}, \mathrm{J}=8.1$

Hz), $7.44(\mathrm{~s}, 1 \mathrm{H})$, overlapping $7.40(\mathrm{t}, 1 \mathrm{H}, \mathrm{J}=8.7 \mathrm{~Hz}), 7.13(\mathrm{t}, 1 \mathrm{H}, \mathrm{J}=7.5 \mathrm{~Hz}), 6.54$ (br s, 1H), $5.59(\mathrm{~m}, 2 \mathrm{H}), 1.51(\mathrm{~s}, 9 \mathrm{H}), 1.40(\mathrm{~d}, 6 \mathrm{H}, \mathrm{J}=6.3 \mathrm{~Hz}), 1.37$ (d, 6H, J=6.1 $\mathrm{Hz}) ;{ }^{13} \mathrm{C}$ NMR $(67.5 \mathrm{MHz}) \delta 185.9(+), 184.4(+), 152.8(+), 151.9(+), 149.4(+)$, $137.8(+), 131.7(-), 131.5(-), 130.8(-), 127.3(+), 124.2(+), 123.4(-), 122.2(-)$, $80.9(+), 74.9(-), 74.8(-), 28.2(-), 22.9(-), 22.6(-)$; IR ( $\left.\mathrm{CDCl}_{3}\right) 3326$ (br), 2980, $2933,1733,1156 \mathrm{~cm}^{-1}$.

\section{[4-Chloro-2-(3,4-di(1-methylethoxy)-2,5-dioxo-3-cyclopenten-1-} ylmethyl)phenyl]-carbamic acid 1,1-dimethylethyl ester (33b). Reaction of 28b (452 mg, $1.00 \mathrm{mmol}$ ) in toluene $(20 \mathrm{~mL})$, as described for 33a, gave after workup and chromatography $\left(\mathrm{SiO}_{2}\right.$, hexanes:EtOAc, 8:2) 33b (307 mg, 0.68 mmol, 68\%) as a yellow solid. mp 57-62 ${ }^{\circ} \mathrm{C} ;{ }^{1} \mathrm{H}$ NMR $(270 \mathrm{MHz}) \oint 7.93(\mathrm{~d}, 1 \mathrm{H}$, $J=2.4 \mathrm{~Hz}), 7.79(\mathrm{~d}, 1 \mathrm{H}, J=8.5 \mathrm{~Hz}), 7.34(\mathrm{dd}, 1 \mathrm{H}, J=8.7$ and $2.4 \mathrm{~Hz}), 7.32(\mathrm{~s}, 1 \mathrm{H})$, $6.48(\mathrm{br} \mathrm{s}, 1 \mathrm{H}), 5.59(\mathrm{~m}, 2 \mathrm{H}), 1.51(\mathrm{~s}, 9 \mathrm{H}), 1.40(\mathrm{~d}, 6 \mathrm{H}, \mathrm{J}=5.5 \mathrm{~Hz}), 1.38(\mathrm{~d}, 6 \mathrm{H}$, $J=5.9 \mathrm{~Hz}) ;{ }^{13} \mathrm{C}$ NMR $\delta 185.4(+), 184.0(+), 152.7(+), 152.6(+), 149.8(+), 136.3$ $(+), 131.2(-), 131.0(-), 128.9(+), 128.7(-), 128.5(+), 81.3(+), 75.2(-), 75.1(-)$, $65.8(+), 28.2(-), 23.0(-), 23.0(-), 15.2(-)$; IR $\left(\mathrm{CDCl}_{3}\right)$ 3149, 2982, 2254, 1727, $1160 \mathrm{~cm}^{-1}$.

\section{[2-(3,4-di(1-methylethoxy)-2,5-dioxo-3-cyclopenten-1-ylmethyl)-5-methoxy-} phenyl]-carbamic acid 1,1-dimethylethyl ester (33c). Reaction of a 4:1 mixture of 28c:4-butyl-4-hydroxy-2,3-di(1-methylethoxy)-2-cyclobuten-1-one (215 mg) in toluene $(20 \mathrm{~mL})$, as described for $33 \mathrm{a}\left(110{ }^{\circ} \mathrm{C}, 18 \mathrm{~h}\right)$, gave after was 
chromatography $\left(\mathrm{SiO}_{2}\right.$, hexanes:EtOAc, 8:2) 33c $(84 \mathrm{mg}, 0.19 \mathrm{mmol}, 39 \%$ from 28c) as an orange-yellow solid. mp 99-102 ${ }^{\circ} \mathrm{C} ;{ }^{1} \mathrm{H} \mathrm{NMR}(270 \mathrm{MHz}) \delta 8.15(\mathrm{~d}, 1 \mathrm{H}$, $J=9.0 \mathrm{~Hz}), 7.48(\mathrm{br} \mathrm{s}, 1 \mathrm{H}), 7.38(\mathrm{~s}, 1 \mathrm{H}), 6.79(\mathrm{~s}, 2 \mathrm{H}), 6.68(\mathrm{dd}, 1 \mathrm{H}, \mathrm{J}=8.4$ and 2.4 $\mathrm{Hz}), 5.53(\mathrm{~m}, 2 \mathrm{H}), 3.85(\mathrm{~s}, 3 \mathrm{H}), 1.52(\mathrm{~s}, 9 \mathrm{H}), 1.39(\mathrm{~d}, 6 \mathrm{H}, \mathrm{J}=6.0 \mathrm{~Hz}), 1.38(\mathrm{~d}, 6 \mathrm{H}$, $J=6.0 \mathrm{~Hz}) ;{ }^{13} \mathrm{C}$ NMR $\delta 186.8(+), 185.0(+), 162.9(+), 152.5(+), 151.4(+), 148.4$ (+), $140.3(+), 133.8(-), 130.5(-), 124.5(+), 116.0(+), 110.1(-), 106.3(+), 81.1$ (+), $74.8(-), 74.7(-), 55.4(-), 28.2(+), 22.9(+)$; IR $\left(\mathrm{CCl}_{4}\right)$ 3445, 2980, 2933, $1733,1670,1156 \mathrm{~cm}^{-1}$.

\section{[2-(3,4-di(1-methylethoxy)-2,5-dioxo-3-cyclopenten-1-methylidene)-5-} methyl-phenyl]-carbamic acid 1,1-dimethylethyl ester (33d). Reaction of 28d (59 $\mathrm{mg}, 0.14 \mathrm{mmol})$ in toluene $(20 \mathrm{~mL}$ ), as described for 33a (reflux, overnight), gave after chromatography $\left(\mathrm{SiO}_{2}\right.$, hexanes:EtOAc, 8:2) 33d $(49 \mathrm{mg}, 0.11 \mathrm{mmol}$, 83\%) as a colorless oil. ${ }^{1} \mathrm{H}$ NMR $(270 \mathrm{MHz}) \delta \underset{7}{7} .89(\mathrm{~d}, 1 \mathrm{H}, \mathrm{J}=8.1 \mathrm{~Hz}), 7.65(\mathrm{~s}$, 1H), $7.42(\mathrm{~s}, 1 \mathrm{H}), 6.95(\mathrm{~d}, 1 \mathrm{H}, \mathrm{J}=7.1 \mathrm{~Hz}), 6.56(\mathrm{br} \mathrm{s}, 1 \mathrm{H}), 5.57(\mathrm{~m}, 2 \mathrm{H}), 2.37(\mathrm{~s}$,

$3 \mathrm{H}), 1.51(\mathrm{~s}, 9 \mathrm{H}), 1.40(\mathrm{~d}, 6 \mathrm{H}, \mathrm{J}=6.1 \mathrm{~Hz}), 1.37(\mathrm{~d}, 6 \mathrm{H}, \mathrm{J}=6.1 \mathrm{~Hz}) ;{ }^{13} \mathrm{C} N M R$ $(67.5 \mathrm{MHz}) \delta 186.3(+), 184.7(+), 152.8(+), 151.8(+), 149.1(+), 142.8(+), 137.9$ $(+), 131.8(-), 130.8(-), 126.4(+), 124.5(-), 122.5(-), 121.3(+), 80.9(+), 74.9(-)$, $74.8(-), 29.7(+), 28.3(-), 23.0(-), 21.8(-)$; IR $\left(\mathrm{CCl}_{4}\right)$ 3437, 2980, 2360, 1734, $1672,1157 \mathrm{~cm}^{-1}$.

[4-(3,4-Di(1-methylethoxy)-2,5-dioxo-3-cyclopenten-1-ylmethyl)-3-pyridinyl]carbamic acid 1,1-dimethylethyl ester (33e). Reaction of 28e (107 mg, 0.26 
$\mathrm{mmol})$ in refluxing 1,2 -dichloroethane ${ }^{70}(20 \mathrm{~mL}) 18 \mathrm{~h}$. The reaction was cooled to room temperature and the solvent was removed. The resulting residue was chromatographed $\left(\mathrm{SiO}_{2}\right.$, hexanes:EtOAc, $\left.6: 4\right) 33 \mathrm{e}(83 \mathrm{mg}, 0.20 \mathrm{mmol}, 78 \%)$ as a brown solid. mp 117-119 ${ }^{\circ} \mathrm{C} ;{ }^{1} \mathrm{H}$ NMR $\delta 8.99$ (s, 1H), 8.40 (d, 1H, J=5.3 Hz), 7.66 (d, 1H, J=5.2 Hz), $7.30(\mathrm{~s}, 1 \mathrm{H}), 6.45(\mathrm{br} \mathrm{s}, 1 \mathrm{H}), 5.61(\mathrm{~m}, 2 \mathrm{H}), 1.51(\mathrm{~s}, 9 \mathrm{H}), 1.41$ (d, 6H, J=6.3 Hz), 1.38 (d, 6H, J=6.3 Hz); ${ }^{13} \mathrm{C}$ NMR $\delta 184.5(+), 183.6(+), 153.1$ (+), $152.6(+), 150.8(+), 144.8(-), 144.3(-), 133.1(+), 132.3(+), 130.7(+), 127.3$ (-), $124.2(-), 81.6(+), 75.5(-), 75.4(-), 28.1(-), 23.0(-)$; IR (CCl 4$)$ 3000, 2960, $1740,1690,1160 \mathrm{~cm}^{-1}$.

\section{2,3-Di(1-methylethoxy)cyclopenta[b]quinolin-1-one (34a). A solution of 33a} (169 mg, $0.41 \mathrm{mmol}$ ) in EtOAc: $\mathrm{HCl}^{67}(1: 1,3 \mathrm{M}$ aq. $\mathrm{HCl}, 20 \mathrm{~mL}$ ) was stirred at ambient temperature $(6 \mathrm{~d})$. The solvents were removed under reduced pressure and the resulting residue was suspended in water $(20 \mathrm{~mL})$ and extracted with diethyl ether $(100 \mathrm{~mL})$. The organic layers were washed with $\mathrm{NaHCO}_{3}$ (aq. saturated $25 \mathrm{~mL})$, dried $\left(\mathrm{MgSO}_{4}\right)$, filtered, and the solvent was removed under reduced pressure. The crude product was purified by chromatography $\left(\mathrm{SiO}_{2}\right.$, hexanes:EtOAc, 8:2) to give $34 \mathrm{a}(112 \mathrm{mg}, 0.27 \mathrm{mmol}, 66 \%)$ as a yellow-orange solid. mp 59-61 ${ }^{\circ} \mathrm{C} ;{ }^{1} \mathrm{H}$ NMR $(270 \mathrm{MHz}) \delta 8.05$ (d, 1H, J=8.3 Hz), 7.79 (s, 1H), $7.71(\mathrm{dd}, 1 \mathrm{H}, \mathrm{J}=7.9$ and $1.4 \mathrm{~Hz}), 7.62(\mathrm{dt}, 1 \mathrm{H}, \mathrm{J}=7.1$ and $1.4 \mathrm{~Hz}), 7.42(\mathrm{dt}, 1 \mathrm{H}$, $J=8.1$ and $1.2 \mathrm{~Hz}$ ), 5.68 (heptet, $1 \mathrm{H}, J=6.3 \mathrm{~Hz}$ ), 5.26 (heptet, $1 \mathrm{H}, J=6.1 \mathrm{~Hz}$ ), 1.50 (d, 6H, J=6.1 Hz), 1.35 (d, 6H, J=6.1 Hz); ${ }^{13} \mathrm{C}$ NMR $(67.5 \mathrm{MHz}) \delta 187.2(+), 158.0$ $(+), 156.8(+), 149.2(+), 138.2(+), 130.6(-), 129.8(-), 129.7(-), 127.7(+), 126.8$ 
(-), $126.3(-), 123.7(+), 76.5(-), 73.8(-), 22.9(-), 22.8(-)$; IR $\left(\mathrm{CCl}_{4}\right)$ 3436, 2978, $1695,1102 \mathrm{~cm}^{-1}$.

\section{Alternative procedure for: 2,3-Di(1-methylethoxy)cyclopenta[b]quinolin-1-}

one (34a). A solution of 33a (566 mg, $1.36 \mathrm{mmol})$ in $\mathrm{CH}_{2} \mathrm{Cl}_{2}(20 \mathrm{~mL})$ was treated with $2.5 \mathrm{~mL} \mathrm{TFA}^{68}$ (trifluoroacetic acid) at $0{ }^{\circ} \mathrm{C}$ for 30 minutes. The reaction was then warmed to $50{ }^{\circ} \mathrm{C}$ for $3 \mathrm{~h}$. The reaction was cooled to room temperature and the solvents were removed under reduced pressure. The resulting residue was neutralized with $30 \mathrm{~mL}$ aqueous saturated $\mathrm{NaHCO}_{3}$ and extracted with $3 \mathrm{X} 30 \mathrm{~mL}$ portions of $\mathrm{CH}_{2} \mathrm{Cl}_{2}$. The organic layer was dried $\left(\mathrm{MgSO}_{4}\right)$, filtered, and the solvent was removed under reduced pressure. The crude product was purified by chromatography $\left(\mathrm{SiO}_{2}\right.$, hexanes:EtOAc, 8:2) to give 33a $(298 \mathrm{mg}, 1.00 \mathrm{mmol}$, $74 \%)$ as a yellow-orange solid.

7-Chloro-2,3-di(1-methylethoxy)cyclopenta[b]quinolin-1-one (34b). Reaction of 33b (163 mg, $0.44 \mathrm{mmol}$ ) in EtOAc: $\mathrm{HCl}^{67}(1: 1,3 \mathrm{M}$ aq. $\mathrm{HCl}, 30 \mathrm{~mL})$, as described for 34a (ambient temperature, $3 \mathrm{~d}$ ), gave after workup and chromatography $\left(\mathrm{SiO}_{2}\right.$, hexanes:EtOAc, 8:2), 34b (71 $\left.\mathrm{mg}, 0.24 \mathrm{mmol}, 54 \%\right)$ as an orange solid. mp $104-106{ }^{\circ} \mathrm{C} ;{ }^{1} \mathrm{H}$ NMR $(270 \mathrm{MHz}) \delta .99(\mathrm{~d}, 1 \mathrm{H}, \mathrm{J}=8.9 \mathrm{~Hz})$, $7.69(\mathrm{~s}, 1 \mathrm{H}), 7.68(\mathrm{~s}, 1 \mathrm{H})$ overlapping $7.61(\mathrm{~d}, 1 \mathrm{H}, \mathrm{J}=2.3 \mathrm{~Hz}), 7.55(\mathrm{dd}, 1 \mathrm{H}, \mathrm{J}=8.7$ and $2.3 \mathrm{~Hz}$ ), 5.66 (heptet, 1H, J=6.1 Hz), 5.28 (heptet, 1H, J=6.1 Hz), 1.51 (d, $6 \mathrm{H}, J=6.3 \mathrm{~Hz}), 1.36(\mathrm{~d}, 6 \mathrm{H}, \mathrm{J}=6.3 \mathrm{~Hz}) ;{ }^{13} \mathrm{C}$ NMR $(67.5 \mathrm{MHz}) \delta 186.5(+), 158.5$ $(+), 156.7(+), 147.5\left(^{+}\right), 138.4(+), 132.4(+), 131.0(-), 128.6(-), 128.5(-), 125.2$ 
(-), $124.6(+), 75.3(-), 73.9(-), 22.9(-), 22.8(-)$; IR ( $\left.\mathrm{CCl}_{4}\right)$ 3410, 2982, 2931, $2360,1700,1101 \mathrm{~cm}^{-1}$.

\section{2,3-Di(1-methylethoxy)-6-methoxycyclopenta[b]quinolin-1-one (34c).}

Reaction of 33c (154 mg, $0.35 \mathrm{mmol})$ in EtOAc: $\mathrm{HCl}^{67}$ (4:3, $3 \mathrm{M}$ aq. $\left.\mathrm{HCl}, 35 \mathrm{~mL}\right)$, as described for 34a (ambient temperature, $2 \mathrm{~d}$ ), gave after workup and chromatography $\left(\mathrm{SiO}_{2}\right.$, hexanes:EtOAc, 8:2) 34c (88 mg, $\left.0.27 \mathrm{mmol}, 78 \%\right)$ as a yellow oil. ${ }^{1} \mathrm{H}$ NMR $(270 \mathrm{MHz}) \delta 7.73(\mathrm{~s}, 1 \mathrm{H}), 7.60(\mathrm{~d}, 1 \mathrm{H}, J=8.7 \mathrm{~Hz}), 7.48(\mathrm{~d}, 1 \mathrm{H}$, $J=2.6 \mathrm{~Hz}$ ), $7.05(\mathrm{dd}, 1 \mathrm{H}, \mathrm{J}=8.7$ and $2.6 \mathrm{~Hz}$ ), 5.62 (heptet, $1 \mathrm{H}, J=6.1 \mathrm{~Hz}$ ), 5.23 (heptet, 1H, J=6.1 Hz), $3.92(\mathrm{~s}, 3 \mathrm{H}), 1.49(\mathrm{~d}, 6 \mathrm{H}, \mathrm{J}=6.1 \mathrm{~Hz}), 1.34(\mathrm{~d}, 6 \mathrm{H}, \mathrm{J}=6.1$ $\mathrm{Hz}) ;{ }^{13} \mathrm{C}$ NMR $(67.5 \mathrm{MHz}) \delta 187.6(+), 161.6(+), 159.2(+), 156.1(+), 151.0(+)$, $137.1(+), 130.6(-), 126.1(-), 121.9(+), 121.2(+), 117.9(-), 109.9(-), 74.8(-)$, $73.7(-), 55.5(-), 22.8(-), 22.7(-)$; IR $\left(\mathrm{CCl}_{4}\right)$ 2980, 2932, 2359, 1701, $1108 \mathrm{~cm}^{-1}$.

2,3-Di(1-methylethoxy)-6-methylcyclopenta[b]quinolin-1-one (34d). Reaction of 33d (185 mg, $0.43 \mathrm{mmol}$ ) in EtOAc: $\mathrm{HCl}^{67}(3: 2,3 \mathrm{M}$ aq. $\mathrm{HCl}, 25 \mathrm{~mL})$, as described for 34a (ambient temperature, $2 \mathrm{~d}$ ), gave after workup and chromatography $\left(\mathrm{SiO}_{2}\right.$, hexanes:EtOAc, 8:2) 34d (94 mg, $\left.0.30 \mathrm{mmol}, 70 \%\right)$ as a yellow-orange solid. mp $78-80{ }^{\circ} \mathrm{C} ;{ }^{1} \mathrm{H}$ NMR $(270 \mathrm{MHz}) \delta 7.85(\mathrm{~s}, 1 \mathrm{H}), 7.75$ (s, $1 \mathrm{H}), 7.60(\mathrm{~d}, 1 \mathrm{H}, \mathrm{J}=8.1 \mathrm{~Hz}), 7.26(\mathrm{dd}, 1 \mathrm{H}, \mathrm{J}=7.5 \mathrm{and} 1.4 \mathrm{~Hz}), 5.67$ (heptet, $1 \mathrm{H}$, $J=6.1 \mathrm{~Hz}), 5.22($ heptet, $1 \mathrm{H}, J=6.1 \mathrm{~Hz}), 2.46(\mathrm{~s}, 3 \mathrm{H}), 1.49(\mathrm{~d}, 6 \mathrm{H}, \mathrm{J}=6.1 \mathrm{~Hz}), 1.34$ $(\mathrm{d}, 6 \mathrm{H}, \mathrm{J}=6.1 \mathrm{~Hz}) ;{ }^{13} \mathrm{C}$ NMR $(67.5 \mathrm{MHz}) \delta 187.3(+), 158.5(+), 156.5(+), 149.2$ (+), $141.2(+), 137.8(+), 129.5(-), 129.4(-), 128.5(-), 126.2(-), 125.3(+), 122.8$ 
(+), $74.9(-), 73.7(-), 22.9(-), 22.7(-), 21.7(-)$; IR $\left(\mathrm{CCl}_{4}\right)$ 3000, 2950, 1715, 1645, $1155 \mathrm{~cm}^{-1}$.

2,3-Di(1-methylethoxy)-6-aza-cyclopenta[b]quinolin-1-one (34e). To a $0{ }^{\circ} \mathrm{C}$ cold solution of $33 \mathrm{e}$ (273 $\mathrm{mg}, 0.66 \mathrm{mmol})$ in $\mathrm{CH}_{2} \mathrm{Cl}_{2}(15 \mathrm{~mL})$ was slowly added trifluoroacetic $\operatorname{acid}^{68}(1.0 \mathrm{~mL}, 5.93 \mathrm{mmol})$. The reaction mixture was allowed to stir $\left(0^{\circ} \mathrm{C}, 4 \mathrm{~h}\right.$, then reflux, $\left.1 \mathrm{~h}\right)$. The solvent was removed under reduced pressure and the residue was suspended in $\mathrm{NaHCO}_{3}$ (aq. saturated, $10 \mathrm{~mL}$ ). The suspension was extracted with $\mathrm{CH}_{2} \mathrm{Cl}_{2}(100 \mathrm{~mL})$ and the combined organic layers were, dried $\left(\mathrm{MgSO}_{4}\right)$, filtered, and the solvents were removed under reduced pressure. The crude product was purified by chromatography $\left(\mathrm{SiO}_{2}\right.$, hexanes:EtOAc, 1:1) to give $34 \mathrm{e}(168 \mathrm{mg}, 0.56 \mathrm{mmol}, 86 \%)$ as an orange solid. mp 73-76 ${ }^{\circ} \mathrm{C} ;{ }^{1} \mathrm{H}$ NMR (270 MHz) $\delta 9.37$ (s, 1H), 8.55 (d, 1H, J=5.3 Hz), 7.74 (s, 1H), $7.55(\mathrm{~d}, 1 \mathrm{H}, J=5.2 \mathrm{~Hz}$ ), 5.71 (heptet, $1 \mathrm{H}, J=6.1 \mathrm{~Hz}$ ), 5.32 (heptet, $1 \mathrm{H}, J=6.1$ $\mathrm{Hz}), 1.51(\mathrm{~d}, 6 \mathrm{H}, \mathrm{J}=6.1 \mathrm{~Hz}), 1.36(\mathrm{~d}, 6 \mathrm{H}, \mathrm{J}=6.1 \mathrm{~Hz}) ;{ }^{13} \mathrm{C}$ NMR $\delta 185.6(+), 159.6$ (+), $156.9(+), 152.9(-), 145.4(-), 143.9(+), 139.8(+), 131.9\left(^{+}\right), 127.7(+), 124.2$ (-), $121.9(-), 75.6(-), 74.1(-), 22.9(-), 22.8(-)$; IR $\left(\mathrm{CHCl}_{3}\right)$ 2985, 2348, 2254, $1704,1094 \mathrm{~cm}^{-1}$.

2,3-Di(1-methylethoxy)cyclopenta[b]quinolin-1-ol (35a). To a $0{ }^{\circ} \mathrm{C}$ cold solution of $34 \mathrm{a}(96 \mathrm{mg}, 0.32 \mathrm{mmol})$ in THF $(10 \mathrm{~mL})$ was added $\mathrm{NaBH}_{4}(130 \mathrm{mg}$, $3.44 \mathrm{mmol})$ and the resulting mixture was allowed to stir $(3 \mathrm{~h})$. Methanol (1.55 $\mathrm{mL}, 35.51 \mathrm{mmol})$ was added and the mixture was diluted with water $(20 \mathrm{~mL})$ and 
extracted with EtOAc $(3 \times 30 \mathrm{~mL})$. The combined organic layers were dried $\left(\mathrm{MgSO}_{4}\right)$, filtered, and the solvents were removed under reduced pressure. The crude product was purified by chromatography $\left(\mathrm{SiO}_{2}\right.$, hexanes:EtOAc, 8:2) to afford 35a (81 mg, $0.27 \mathrm{mmol}, 84 \%)$ as a pale yellow oil. ${ }^{1} \mathrm{H}$ NMR $\delta 7.93(\mathrm{~d}, 1 \mathrm{H}$, $J=7.8), 7.78(\mathrm{~s}, 1 \mathrm{H}), 7.53(\mathrm{~m}, 2 \mathrm{H}), 7.32(\mathrm{dt}, 1 \mathrm{H}, \mathrm{J}=1.2,7.8 \mathrm{~Hz}), 5.29$ (heptet, $1 \mathrm{H}$, J=5.4 Hz), 5.13 (heptet, 1H, J=6.0 Hz), $5.02(\mathrm{br} \mathrm{s}, 1 \mathrm{H}), 2.75$ (br s, 1H), 1.36 (d, $3 \mathrm{H}, J=5.4 \mathrm{~Hz}$ ), 1.34 (d, 3H, J=6.0 Hz) $1.33(\mathrm{~d}, 3 \mathrm{H}, J=6.0 \mathrm{~Hz}), 1.31$ (d, 3H, J=6.0 $\mathrm{Hz}) ;{ }^{13} \mathrm{C}$ NMR $\delta 159.8(+), 151.5(+), 148.2(+), 133.8(+), 131.1(+), 128.7(-)$, $128.5(-), 128.1(-), 127.9(-), 126.4(+), 124.8(-), 72.9(-), 72.3(-), 68.7(-), 22.91$ (-), 22.90 (-), $22.64(-), 22.61(-)$; IR (CCl $)$ 3277, 3061, 2979, 2935, 2360, 1317, $1104 \mathrm{~cm}^{-1}$.

7-Chloro-2,3-di(1-methylethoxy)cyclopenta[b]quinolin-1-ol (35b). Reaction of 34b (80 mg, $0.27 \mathrm{mmol})$ with $\mathrm{NaBH}_{4}(106 \mathrm{mg}, 2.80 \mathrm{mmol})$, and methanol (1.30 $\mathrm{mL}, 29.58 \mathrm{mmol})$ in THF (10 mL), as described for $35 \mathrm{a}(3 \mathrm{~h})$, gave after workup and chromatography $\left(\mathrm{SiO}_{2}\right.$, hexanes:EtOAc, 8:2) 35b (55 mg, $\left.0.18 \mathrm{mmol}, 68 \%\right)$ as a light yellow oil. ${ }^{1} \mathrm{H}$ NMR $\delta 7.83(\mathrm{~d}, 1 \mathrm{H}, \mathrm{J}=9.0 \mathrm{~Hz}), 7.58(\mathrm{~s}, 1 \mathrm{H}), 7.51(\mathrm{~d}, 1 \mathrm{H}$, $J=1.8 \mathrm{~Hz}$ ), $7.47(\mathrm{dd}, 1 \mathrm{H}, J=8.4$ and $2.4 \mathrm{~Hz}$ ), 5.24 (heptet, $1 \mathrm{H}, \mathrm{J}=6.0 \mathrm{~Hz}$ ), 5.15 (heptet, 1H J=6.0 Hz), 5.01 (br s, 1H), $2.75(\mathrm{br} \mathrm{s}, 1 \mathrm{H}), 1.40(\mathrm{~d}, 3 \mathrm{H}, \mathrm{J}=6.0 \mathrm{~Hz}$ ), $1.36(\mathrm{~d}, 3 \mathrm{H}, J=6.0 \mathrm{~Hz}), 1.35$ (d, 3H, J=6.0 Hz), 1.34 (d, 3H, J=6.0 Hz); ${ }^{13} \mathrm{C}$ NMR $\delta$ $160.3(+), 152.2\left(^{+}\right), 146.8(+), 133.8(+), 132.2(+), 130.4(-), 130.1(-), 129.6(+)$ $127.3(-), 127.2(-), 126.9(+), 73.4(-), 72.7(-), 68.8(-), 23.17(-), 23.15(-), 22.87$ (-), 22.83 (-); IR $\left(\mathrm{CHCl}_{3}\right) 3366$ (br.), 2976, 1313, 1104. 
2,3-Di(1-methylethoxy)-6-methoxycyclopenta[b]quinolin-1-ol (35c). Reaction of 34c (61 mg, $0.19 \mathrm{mmol}), \mathrm{NaBH}_{4}(80 \mathrm{mg}, 2.11 \mathrm{mmol})$, and methanol $(0.91 \mathrm{~mL}$, $20.95 \mathrm{mmol})$ in THF (10 mL), as described for $35 \mathrm{a}$ (18h), gave after workup and chromatography $\left(\mathrm{SiO}_{2}\right.$, hexanes:EtOAc, 8:2) 35c (43 mg, $\left.0.13 \mathrm{mmol}, 70 \%\right)$ as a yellow oil. ${ }^{1} \mathrm{H}$ NMR $(270 \mathrm{MHz}) \delta 7.78(\mathrm{~s}, 1 \mathrm{H}), 7.56(\mathrm{~d}, 1 \mathrm{H}, \mathrm{J}=8.9 \mathrm{~Hz}), 7.40(\mathrm{~d}, 1 \mathrm{H}$, $J=2.4 \mathrm{~Hz}$ ), $7.03(\mathrm{dd}, 1 \mathrm{H}, \mathrm{J}=8.7$ and $2.6 \mathrm{~Hz}$ ), 5.34 (heptet, $1 \mathrm{H}, \mathrm{J}=5.7 \mathrm{~Hz}$ ), 5.12 (heptet, $1 \mathrm{H}, J=5.9 \mathrm{~Hz}), 5.06(\mathrm{~d}, 1 \mathrm{H}, \mathrm{J}=6.9 \mathrm{~Hz}), 3.92(\mathrm{~s}, 3 \mathrm{H}), 1.38(\mathrm{~m}, 12 \mathrm{H}) ;{ }^{13} \mathrm{C}$ NMR (67.5 MHz) $\delta 160.2(+), 159.9(+), 151.1(+), 149.7(+), 133.9(+), 128.8(+)$, $127.9(-), 120.9(+), 116.6(-), 107.9(-), 72.9(-), 72.3(-), 68.6(-), 55.4(-), 22.9(-$ ), 22.6 (-); IR ( $\left.\mathrm{CCl}_{4}\right) 3412,2977,2931,1105 \mathrm{~cm}^{-1}$.

2,3-Di(1-methylethoxy)-6-methylcyclopenta[b]quinolin-1-ol (35d). Reaction of 34d (94 mg, $0.30 \mathrm{mmol}), \mathrm{NaBH}_{4}(118 \mathrm{mg}, 2.80 \mathrm{mmol})$, and methanol (1.44 mL, $33.2 \mathrm{mmol})$ in THF (10 mL), as described for 35a (18h), gave after workup and chromatography $\left(\mathrm{SiO}_{2}\right.$, hexanes: EtOAc, 8:2) 35d (66 mg, $\left.0.21 \mathrm{mmol}, 70 \%\right)$ as a faint yellow oil. ${ }^{1} \mathrm{H}$ NMR $\delta 7.79(\mathrm{~s}, 2 \mathrm{H}), 7.58(\mathrm{~d}, 1 \mathrm{H}, \mathrm{J}=7.9 \mathrm{~Hz}), 7.21(\mathrm{~d}, 1 \mathrm{H}, J=9.1$ Hz), 5.39 (heptet, 1H, J=6.1 Hz), 5.15, (heptet, 1H, J=6.1 Hz), $5.04(\mathrm{~d}, J=5.1 \mathrm{~Hz}$ ), $2.51(\mathrm{~s}, 3 \mathrm{H}), 1.38(\mathrm{~m}, 12 \mathrm{H}) ;{ }^{13} \mathrm{C}$ NMR $\delta 159.6(+), 151.4(+), 148.1(+), 138.8(+)$, $133.7(+), 130.2(+), 127.9(-), 127.7(-), 127.5(-), 126.6(-), 124.1(+), 72.8(-)$, $72.2(-), 68.5(-), 22.9(-), 22.6(-), 21.6(-) ; \mathrm{IR}\left(\mathrm{CCl}_{4}\right)$ 3400, 2978, 2933, $1105 \mathrm{~cm}^{-}$ 1. 
2,3-Di(1-methylethoxy)-6-azacyclopenta[b]quinolin-1-ol (35e). To a $0{ }^{\circ} \mathrm{C}$ cold solution of 34e $(414 \mathrm{mg}, 3.36 \mathrm{mmol})$ in THF:MeOH $(1: 1,10 \mathrm{~mL})$ was added $\mathrm{NaBH}_{4}(110 \mathrm{mg}, 2.91 \mathrm{mmol})$. The reaction was stirred for $10 \mathrm{~min}$ at $0{ }^{\circ} \mathrm{C}$ and subsequently quenched with water $(20 \mathrm{~mL})$. The mixture was quickly extracted with ethyl acetate $(3 \times 50 \mathrm{~mL})$, and the combined organic layers were dried $\left(\mathrm{Na}_{2} \mathrm{SO}_{4}\right)$, filtered, and the solvents were removed under reduced pressure. The residue was purified by chromatography $\left(\mathrm{SiO}_{2}\right.$, hexanes:EtOAc, 3:7) to give $35 \mathbf{e}$ (212 $\mathrm{mg}, 0.71 \mathrm{mmol}, 51 \%$ ) as a white solid which quickly turned yellow. Tentative NMR assignments from a rapidly decomposing compound. ${ }^{1} \mathrm{H}$ NMR $(270 \mathrm{MHz}) \delta$ 9.25 (s, 1H), 8.39 (d, 1H, J=5.3 Hz), $7.77(\mathrm{~s}, 1 \mathrm{H}), 7.46$ (d, 1H, J=5.5 Hz), 5.25 (overlapping heptet, $2 \mathrm{H}), 5.07(\mathrm{~s}, 1 \mathrm{H}), 1.46-1.32(\mathrm{~m}, 12 \mathrm{H}) ;{ }^{13} \mathrm{C}$ NMR $(67.5 \mathrm{MHz})$ $\delta 161.5(+), 153.6(+), 151.6(-), 143.4(+), 142.2(-), 136.3(+), 133.5(+), 130.3$ (+), $126.1(-), 120.7(-), 73.4(-), 72.5(-), 68.3(-), 28.2(-), 22.9(-), 22.6(-)$.

\section{[2-(1-Hydroxy-2-(1-methylethoxy)-3-methyl-4-oxo-cyclobut-2-enylethynyl)-} phenyl]-carbamic acid 1,1-dimethylethyl ester (41). Reaction of 26a (406 mg, $1.87 \mathrm{mmol}$ ), $n$-BuLi (1.6 M in hexanes, $2.90 \mathrm{~mL}, 4.67 \mathrm{mmol}$ ), and 3-methyl-4-(1methylethoxy)-3-cyclobutene-1,2-dione ${ }^{69}$ (40) $(290 \mathrm{mg}, 1.88 \mathrm{mmol}$ ) in THF (30 $\mathrm{mL}$ total), as described for $\mathbf{2 8 a}$ (30 min), gave after workup and chromatography $\left(\mathrm{SiO}_{2}\right.$, hexanes: EtOAc, 8:2) $41(410 \mathrm{mg}, 1.10 \mathrm{mmol}, 48 \%)$ as a yellow solid and 26a (81 mg, $0.37 \mathrm{mmol}, 59 \%) .{ }^{1} \mathrm{H}$ NMR $(270 \mathrm{MHz}) \delta 8.11(\mathrm{~d}, 1 \mathrm{H}, \mathrm{J}=8.5 \mathrm{~Hz}), 7.33$ (dt, 1H, J=1.6, 7.5 Hz), 7.21 (br s, 1H), $6.93(\mathrm{dt}, 1 \mathrm{H}, J=7.5$ and $1.0 \mathrm{~Hz}$ ), 5.11 (heptet, 1H, J=6.3 Hz), 4.24 (br s, 1H), $1.71(\mathrm{~s}, 1 \mathrm{H}), 1.53(\mathrm{~s}, 9 \mathrm{H}), 1.49$ (d, 6H, 
$J=6.3 \mathrm{~Hz}) ;{ }^{13} \mathrm{C}$ NMR $(67.5 \mathrm{MHz}) \delta 187.6(+), 180.1(+), 152.5(+), 139.7(+)$, $132.1(-), 130.1(-), 124.3(+), 122.1(-), 118.0(-), 110.0(+), 90.1(+), 84.8(+)$, $83.2(+), 80.9(+), 78.5(-), 28.2(-), 22.9(-), 22.6(-), 6.5(-)$; IR $\left(\mathrm{CCl}_{4}\right)$ 3410, 2980, $2380,1735,1157 \mathrm{~cm}^{-1}$.

\section{E- and Z-[2-(3-(1-methylethoxy)-4-methyl-2,5-dioxo-3-cyclopenten-1-} ylmethyl)phenyl]-carbamic acid 1,1-dimethylethyl ester (42). Reaction of 41 (310 mg, $0.83 \mathrm{mmol})$ in 1,2-dichloroethane $(20 \mathrm{~mL}),{ }^{70}$ as described for $33 \mathbf{e}(18 \mathrm{~h})$, gave after chromatography $\left(\mathrm{SiO}_{2}\right.$, hexanes:EtOAc, 8:2) an inseparable mixture of E- and Z-42 (152 mg, $0.41 \mathrm{mmol}, 8.3: 1$ ratio, $49 \%$ ) as a yellow solid. $\mathrm{mp} 132-$ $136{ }^{\circ} \mathrm{C} ;{ }^{1} \mathrm{H}$ NMR $(270 \mathrm{MHz}) \delta 8.05(\mathrm{dd}, 1 \mathrm{H}, \mathrm{J}=7.9$ and $1.6 \mathrm{~Hz}), 7.76(\mathrm{~d}, 1 \mathrm{H}, \mathrm{J}=8.3$ $\mathrm{Hz}), 7.48(\mathrm{~s}, 1 \mathrm{H}), 7.43(\mathrm{dt}, 1 \mathrm{H}, \mathrm{J}=7.7$ and $1.6 \mathrm{~Hz}), 7.16(\mathrm{t}, 1 \mathrm{H}), 6.63(\mathrm{br} \mathrm{s}, 1 \mathrm{H})$, 5.73 (heptet, $1 \mathrm{H}, \mathrm{J}=6.1 \mathrm{~Hz}), 1.99(\mathrm{~s}, 3 \mathrm{H}), 1.51(\mathrm{~s}, 9 \mathrm{H}), 1.41(\mathrm{~d}, 6 \mathrm{H}, \mathrm{J}=5.9 \mathrm{~Hz}) ;{ }^{13} \mathrm{C}$ NMR $\delta(150 \mathrm{MHz}) 189.3(+), 188.2(+), 164.8(+), 152.9(+), 138.1(+), 137.5(+)$, $132.7(-), 132.2(-), 131.9(-), 131.5(-), 127.9(+), 123.7(-), 122.6(-), 80.9(+)$, 74.8 (-), 74.7 (-), 28.2 (-), $23.2(-), 7.2(-)$; IR $\left(\mathrm{CCl}_{4}\right)$ 3400, 2978, 2931, 2359, $1733,1156 \mathrm{~cm}^{-1}$.

2-(1-Methylethoxy)-3-methylcyclopenta[b]quinolin-1-one (43). Reaction of 42 (141 mg, $0.39 \mathrm{mmol})$ in EtOAc: $\mathrm{HCl}(3: 2,3 \mathrm{M}$ aq. $\mathrm{HCl}, 25 \mathrm{~mL}$ ), was stirred at room temperature for $3 \mathrm{~h}$ followed by heating at $60{ }^{\circ} \mathrm{C}$ for $1 \mathrm{~h}$. The solvents were removed under reduced pressure and the residue was diluted in $50 \mathrm{~mL} \mathrm{H}_{2} \mathrm{O}$. The aqueous phase was extracted with $3 X 50 \mathrm{~mL}$ of $\mathrm{Et}_{2} \mathrm{O}$, washed with $20 \mathrm{~mL}$ 
saturated $\mathrm{NaHCO}_{3}$, dried (MgSO4) and chromatographed on silica gel (hexanes:EtOAc, 8:2) gave 43 (54 mg, $0.21 \mathrm{mmol}, 56 \%$ ) as a yellow-orange solid. mp 78-80 ${ }^{\circ} \mathrm{C} ;{ }^{1} \mathrm{H}$ NMR $(270 \mathrm{MHz}) \delta 7.94(\mathrm{~d}, 1 \mathrm{H}, \mathrm{J}=8.3 \mathrm{~Hz}), 7.93(\mathrm{~s}, 1 \mathrm{H})$, $7.71(\mathrm{~d}, 1 \mathrm{H}, J=8.3 \mathrm{~Hz}), 7.63(\mathrm{t}, 1 \mathrm{H}, J=7.1 \mathrm{~Hz}), 7.39(\mathrm{t}, 1 \mathrm{H}, J=7.5 \mathrm{~Hz}), 5.28$ (heptet, $1 \mathrm{H}, \mathrm{J}=6.1 \mathrm{~Hz}$ ), 2.19 (s, 3H), 1.34 (d, 6H, J=6.1 Hz); ${ }^{13} \mathrm{C}$ NMR $\delta 189.4(+)$, $163.9(+), 156.1(+), 150.1(+), 139.0(+), 131.3(-), 130.5(-), 129.6(-), 128.1(-)$, $127.5(+), 126.6(-), 123.3(+), 73.9(-), 23.2(-), 8.3(-)$; IR $\left(\mathrm{CCl}_{4}\right)$ 2988, 2254, $1707,1636,1102 \mathrm{~cm}^{-1}$.

\section{2-(1-methylethoxy)-3-methylcyclopenta[b]quinolin-1-ol (44). Reaction of 43}

(90 mg, $0.36 \mathrm{mmol}), \mathrm{NaBH}_{4}(140 \mathrm{mg}, 3.70 \mathrm{mmol})$, and methanol $(1.7 \mathrm{~mL}, 39.1$ $\mathrm{mmol})$ in THF (10 mL), as described for $35 \mathrm{a}(3 \mathrm{~h})$, gave after workup and chromatography $\left(\mathrm{SiO}_{2}\right.$, hexanes:EtOAc) $44(73 \mathrm{mg}, 0.29 \mathrm{mmol}, 81 \%)$ as a yellow oil. Tentative NMR assignments from a rapidly decomposing compound: ${ }^{1} \mathrm{H}$ NMR $\delta 7.76(\mathrm{~d}, 1 \mathrm{H}, J=8.4 \mathrm{~Hz}), 7.53(\mathrm{dt}, 1 \mathrm{H}, J=7.8$ and $2.4 \mathrm{~Hz}), 7.24(\mathrm{dt}, 1 \mathrm{H}, J=8.4$ and $1.8 \mathrm{~Hz}$ ), 7.15 (dd, $1 \mathrm{H}, J=7.8$ and $1.8 \mathrm{~Hz}$ ), 6.99 (s, 1H), 5.01 (heptet, $1 \mathrm{H}, J=5.4$ Hz), $4.97(\mathrm{t}, 1 \mathrm{H}, J=1.8 \mathrm{~Hz}), 1.91(\mathrm{~d}, 3 \mathrm{H}, J=1.2 \mathrm{~Hz}), 1.46(\mathrm{~d}, 3 \mathrm{H}, J=6.6 \mathrm{~Hz}), 1.30$ (d, 3H, J=6.6 Hz); ${ }^{13} \mathrm{C}$ NMR $\delta 167.3(+), 164.7(+), 147.7(+), 132.1(+), 128.8(-)$, $128.3(-), 127.5(-), 127.4(+), 126.3(+), 124.1(-), 115.8(+), 72.7(-), 69.6(-)$, $23.3(-), 23.1(-), 6.9(-)$. 


\section{N-[2-(1-Hydroxy-2,3-diisopropoxy-4-oxo-cyclobut-2-enylethynyl)-phenyl]-}

\section{acetamide. (46)}

$\mathrm{N}$-(2-Ethynyl-phenyl)-acetamide ${ }^{71}$ (45) (330 mg, $2.07 \mathrm{mmol}$ ) was dissolved in 10 $\mathrm{mL}$ THF and cooled to $-78{ }^{\circ} \mathrm{C} . n$-BuLi (1.6M in pentane, $\left.3.40 \mathrm{~mL}, 5.41 \mathrm{mmol}\right)$ was added slowly via syringe and stirred for 15 minutes at $-78{ }^{\circ} \mathrm{C}$. The dilithiated acetanilide was then transferred via cannula to a cold $\left(-78^{\circ} \mathrm{C}\right) 3,4$-bis $(1-$ methylethoxy)-3-cyclobutene-1,2-dione (27) (415 mg, $2.09 \mathrm{mmol}) / \mathrm{THF}(10 \mathrm{~mL})$ solution and allowed to stir for 30 minutes. The reaction was then allowed to warm to room temperature over 20 minutes. The reaction was quenched with 20 $\mathrm{mL}$ water and $5 \mathrm{~mL}$ saturated $\mathrm{NH}_{4} \mathrm{Cl}$ solution. The resulting biphasic mixture was extracted with $(3 \times 50 \mathrm{~mL})$ diethyl ether. The organic layers were combined and washed with one portion of $30 \mathrm{~mL}$ saturated $\mathrm{NaCl}$ solution, dried $\left(\mathrm{MgSO}_{4}\right)$, filtered, and the solvent was removed under reduced pressure. The crude product was purified by chromatography $\left(\mathrm{SiO}_{2}\right.$, hexanes: EtOAc, $\left.1: 1\right)$ to give 46 (530 mg, $1.48 \mathrm{mmol}, 71 \%)$ as a thick orange oil. ${ }^{1} \mathrm{H}$ NMR $(270 \mathrm{MHz}) \delta \underline{8}$ 8.26-8.23 (m, 2H), 7.34-7.23 (m, 2H), 6.96 (t, 1H, J = 7.5 Hz), 5.96 (br. s, 1H), 5.06 (heptet, $1 \mathrm{H}, \mathrm{J}=6.1 \mathrm{~Hz}$ ), 4.79 (heptet, $1 \mathrm{H}, \mathrm{J}=6.1 \mathrm{~Hz}), 2.23(\mathrm{~s}, 3 \mathrm{H}), 1.46(\mathrm{~d}, 6 \mathrm{H}, \mathrm{J}=5.8$ $\mathrm{Hz}), ;{ }^{13} \mathrm{C}$ NMR (67.5 MHz) $\delta 182.2(+), 169.3(+), 165.1(+), 139.3(+), 133.6(+)$, $131.7(-), 129.9(-), 123.2(-), 120.1(-), 110.9(+), 90.4(+), 83.9(+), 78.4(-), 74.2$ (-), 24.5 (-), 22.6 (-), 22.4 (-). ; IR (neat) 3312 (br.), 2980, 1773, $1673 \mathrm{~cm}^{-1}$. 


\section{Alternative Procedure for: N-[2-(1-Hydroxy-2,3-diisopropoxy-4-oxo- cyclobut-2-enylethynyl)-phenyl]-acetamide (46).}

4-Ethynyl-4-hydroxy-2,3-diisopropoxy-cyclobut-2-enone ${ }^{69}$ (39) (391 mg, 1.74 $\mathrm{mmol}$ ), bis(triphenylphosphine)palladium dichloride (62 mg, $0.088 \mathrm{mmol}$ ), copper iodide (336 mg, $1.76 \mathrm{mmol}$ ) were slurried in $30 \mathrm{~mL} \mathrm{NEt}_{3}$. (49) $(912 \mathrm{mg}, 2.612$ mmol) was added after five minutes and the reaction was allowed to stir. After 24 hours the reaction was diluted with $50 \mathrm{~mL}$ water and extracted with diethyl ether $(3 \times 50 \mathrm{~mL})$. The combined organic layers were washed with $20 \mathrm{~mL} 10 \%$ $\mathrm{NH}_{4} \mathrm{OH}$, dried $\left(\mathrm{MgSO}_{4}\right)$, filtered, and the solvents were removed under reduced pressure. The crude product was purified by chromatography $\left(\mathrm{SiO}_{2}\right.$, hexanes: EtOAc, 1:1) to give 46 (278 $\mathrm{mg}, 0.78 \mathrm{mmol}, 45 \%)$ as a thick orange oil and 49 (118 mg, $0.45 \mathrm{mmol}, 60 \%)$.

\section{N-[2-(3,4-Diisopropoxy-2,5-dioxo-cyclopent-3-enylidenemethyl)-phenyl]-} acetamide (51).

$\mathrm{N}$-[2-(1-Hydroxy-2,3-diisopropoxy-4-oxo-cyclobut-2-enylethynyl)-phenyl]acetamide (46) (390 mg, $1.09 \mathrm{mmol}$ ) was dissolved in $100 \mathrm{~mL}$ toluene and heated to reflux for 18 hours. The reaction was allowed to cool to room temperature and the solvent was removed. The residue was chromatographed on silica gel (hexanes:EtOAc 1:1) to give 51 (281 mg, $0.78 \mathrm{mmol}, 72 \%$ ) as an

orange oil. ${ }^{1} \mathrm{H}$ NMR $(270 \mathrm{MHz}) \delta 7.99(\mathrm{br} . \mathrm{s}, 1 \mathrm{H}), 7.88(\mathrm{~d}, 1 \mathrm{H}, \mathrm{J}=7.5 \mathrm{~Hz}), 7.82$ $(\mathrm{d}, 1 \mathrm{H}, \mathrm{J}=8.1 \mathrm{~Hz}), 7.44$ (t overlapping with s seen at $7.41,1 \mathrm{H}, 7.1 \mathrm{~Hz}$ ), $7.41(\mathrm{~s}$ overlapping with t seen at 7.44, 1H), $5.54(\mathrm{~m}, 2 \mathrm{H}), 2.22(\mathrm{~s}, 3 \mathrm{H}), 1.36(\mathrm{~d}, 6 \mathrm{H}, \mathrm{J}=$ 
$6.1 \mathrm{~Hz}), 1.33(\mathrm{~d}, 6 \mathrm{H}, \mathrm{J}=6.1 \mathrm{~Hz}) ;{ }^{13} \mathrm{C}$ NMR $(67.5 \mathrm{MHz}) \delta 186.2(+), 184.9(+)$, $169.2(+), 150.6(+), 149.6(+), 137.9(+), 132.4(-), 131.9(-), 131.6(-), 125.9(+)$, $125.2(+), 124.4(-), 124.2(-), 75.1(-), 74.9(-), 24.0(-), 22.9(-), 22.6(-)$; IR (neat) $3321,2981,1703,1667 \mathrm{~cm}^{-1}$.

\section{3-(1-Acetyl-1H-indol-3-yl)-4-isopropoxy-cyclobut-3-ene-1,2-dione. (70)}

$\mathrm{N}$-[2-(1-Hydroxy-2,3-diisopropoxy-4-oxo-cyclobut-2-enylethynyl)-phenyl]acetamide (46) (116 mg, $0.323 \mathrm{mmol}$ ) was dissolved in $20 \mathrm{~mL}$ dry 1,2dichloroethane. $\mathrm{Cu}(\mathrm{OAc})_{2} \cdot \mathrm{H}_{2} \mathrm{O}(16 \mathrm{mg}, 0.078 \mathrm{mmol})$ was added and the reaction was refluxed under nitrogen for $24 \mathrm{~h}$. The solvent was removed under reduced pressure. The residue was chromatographed on silica gel yielding 70 (69 mg, $0.233 \mathrm{mmol}, 72 \%)$ as a red orange oil. ${ }^{1} \mathrm{H}$ NMR $(270 \mathrm{MHz}) \delta \delta 7.71(\mathrm{~d}, 1 \mathrm{H}, \mathrm{J}=$ $8.1 \mathrm{~Hz}), 7.53(\mathrm{dt}, 1 \mathrm{H}, \mathrm{J}=1.4,7.5 \mathrm{~Hz}), 7.38-7.31(\mathrm{~m}, 2 \mathrm{H}), 6.14(\mathrm{~s}, 1 \mathrm{H}), 5.62$ (heptet, 1H, J = 6.1 Hz), $2.43(\mathrm{~s}, 3 \mathrm{H}), 1.51(\mathrm{~d}, 6 \mathrm{H}, \mathrm{J}=6.1 \mathrm{~Hz}) ;{ }^{13} \mathrm{C}$ NMR $\delta 191.9$ $(+), 191.6(+), 191.0(+), 172.2(+), 157.7(+), 154.4(+), 140.4(+), 133.6(-)$, $128.3(-), 126.6(-), 123.7(-), 118.7(+), 86.8(-), 78.8(-), 23.1(-), 20.9(-)$; IR (neat) $3088,2985,1775,1725,1653,1239 \mathrm{~cm}^{-1}$.

\section{$\mathrm{N}$-[2-(2-Isopropoxy-3,4-dioxo-cyclobut-1-enylethynyl)-phenyl]-acetamide}

(71). N-[2-(1-Hydroxy-2,3-diisopropoxy-4-oxo-cyclobut-2-enylethynyl)-phenyl]acetamide (46) (164 mg, $0.46 \mathrm{mmol}$ ) was dissolved in $20 \mathrm{~mL}$ dry 1,2dichloroethane. $\mathrm{N}$-chlorosuccinimide $(64 \mathrm{mg}, 0.48 \mathrm{mmol}$ ) was added and the reaction was heated to reflux for 4 hours. After cooling to room temperature the 
solvent was removed under reduced pressure. The residue was

chromatographed on silica gel yielding $71(105 \mathrm{mg}, 0.35 \mathrm{mmol}, 77 \%)$ as a yellow solid. mp $139-141^{\circ} \mathrm{C} .{ }^{1} \mathrm{H}$ NMR $\delta 8.40(\mathrm{~d}, 1 \mathrm{H}, \mathrm{J}=8.4 \mathrm{~Hz}$ ), 7.95 (br. s, $1 \mathrm{H}), 7.46$ - $7.42(\mathrm{~m}, 2 \mathrm{H}), 7.08(\mathrm{t}, 1 \mathrm{H}, \mathrm{J}=7.2 \mathrm{~Hz}$ ), 5.43 (heptet, 1H, J = $6.0 \mathrm{~Hz}$ ), 2.27 (s, 3H), $1.54(\mathrm{~d}, 6 \mathrm{H}, \mathrm{J}=6.6 \mathrm{~Hz}) ;{ }^{13} \mathrm{C}$ NMR $\delta 194.1(+), 194.08(+), 190.5(+), 168.6$ (+), $159.4(+), 139.7(+), 132.6(-), 131.9(-), 123.6(-), 120.0(-), 114.0(+), 109.8$ (+), $82.3(+), 81.5(-), 24.7(-), 22.6(-)$; IR (neat) 3325, 2991, 2191, 1784, 1766, $1676 \mathrm{~cm}^{-1}$.

\section{tert-butyl 2-(2-(2-isopropoxy-3,4-dioxocyclobut-1-}

enyl)ethynyl)phenylcarbamate (72). [2-(1-Hydroxy-2,3-bis(1-methylethoxy)-4oxo-cyclobut-2-enylethynyl)phenyl]-carbamic acid 1,1-dimethylethyl ester (28a). (193 mg, $0.47 \mathrm{mmol}$ ) was dissolved in $20 \mathrm{~mL}$ dry 1,2-dichloroethane. $\mathrm{N}$ chlorosuccinimide $(71 \mathrm{mg}, 0.53 \mathrm{mmol})$ was added and the reaction was heated to reflux for 4 hours. After cooling to room temperature the solvent was removed under reduced pressure. The residue was chromatographed on silica gel yielding 72 as an orange oil $(85 \mathrm{mg}, 0.24 \mathrm{mmol}, 51 \%){ }^{1} \mathrm{H}$ NMR $\delta(270 \mathrm{MHz}) 8.22(\mathrm{~d}, 1 \mathrm{H}, \mathrm{J}$ $=8.3 \mathrm{~Hz}), 7.49-7.42(\mathrm{~m}, 2 \mathrm{H}), 7.13(\mathrm{br} . \mathrm{s}, 1 \mathrm{H}), 7.04(\mathrm{dt}, 1 \mathrm{H}, \mathrm{J}=1.0,7.5 \mathrm{~Hz}), 5.46$ (heptet, $1 \mathrm{H}, \mathrm{J}=6.3 \mathrm{~Hz}$ ), 1.57 (d overlapping s at 1.55, 6H, J = 6.3 Hz), 1.55 (s overlapping d at 1.57, 9H); ${ }^{13} \mathrm{C}$ NMR $\delta 194.7(+), 194.5(+), 189.9(+), 159.9(+)$, $152.0(+), 140.1(+), 132.4(-), 122.5(-), 118.2(), 113.9(-), 109.1(+), 81.8\left(^{+}\right)$, $81.4(+), 81.1(-), 28.6(-), 22.6(-)$. IR (neat) 3411, 2981, 2934, 2184, 1786, $1730,1089 \mathrm{~cm}^{-1}$. 


\section{4-(2-Benzylamino-phenylethynyl)-4-hydroxy-2,3-diisopropoxy-cyclobut-2- enone (48).}

Benzyl-(2-ethynyl-phenyl)-amine ${ }^{72}$ (47) $(410 \mathrm{mg}, 1.98 \mathrm{mmol})$ was dissolved in THF (10 mL) $n$-BuLi (2.82 M in hexanes, $0.74 \mathrm{~mL}, 2.09 \mathrm{mmol})$ was slowly added via syringe. After $20 \mathrm{~min}, \mathrm{a}-5^{\circ} \mathrm{C}$ cold solution 3,4-bis(1-methylethoxy)-3cyclobutene-1,2-dione (27) (394 mg, $1.99 \mathrm{mmol}$ ) in THF (10 mL) was added to the lithiated compound via cannula. The resulting reaction mixture was stirred ($5{ }^{\circ} \mathrm{C}, 30 \mathrm{~min}$ ) followed by the addition of water and saturated $\mathrm{NH}_{4} \mathrm{Cl}$ solution (30 $\mathrm{mL}$ and $5 \mathrm{~mL}$ respectively). The biphasic mixture was extracted with diethyl ether $(3 \times 50 \mathrm{~mL})$. The combined organic layers were washed with $30 \mathrm{~mL}$ brine, dried $\left(\mathrm{MgSO}_{4}\right)$, filtered, and the solvents were removed under reduced pressure. The crude product was purified by chromatography $\left(\mathrm{SiO}_{2}\right.$, hexanes:EtOAc, 8:2) to afford 48 (191 mg, $0.47 \mathrm{mmol}, 24 \%$ ) as a yellow brown solid. $\mathrm{mp} 134-135{ }^{\circ} \mathrm{C}$ and 47 (158 mg, $0.76 \mathrm{mmol}, 39 \%) .{ }^{1} \mathrm{H}$ NMR $(270 \mathrm{MHz}) \delta$ 7.34-7.21 (m, 5H), 7.11 (dt, $1 \mathrm{H}, \mathrm{J}=1.5$ and $7.1 \mathrm{~Hz}), 6.58(\mathrm{t}, 1 \mathrm{H}, \mathrm{J}=7.5 \mathrm{~Hz}), 6.49(\mathrm{~d}, 1 \mathrm{H}, \mathrm{J}=8.3 \mathrm{~Hz})$, 5.24 (br. s, 1H), 4.99 (heptet, 1H, J = $6.1 \mathrm{~Hz}$ ), 4.83 (heptet, 1H, J = $5.9 \mathrm{~Hz}$ ), 4.43 (s, 2H), 3.71 (br. s, 1H), 1.41 (d, 3H, J = 6.1 Hz), $1.36(\mathrm{~d}, 3 \mathrm{H}, \mathrm{J}=6.2 \mathrm{~Hz}), 1.27$ (overlapping $\mathrm{d}, 3 \mathrm{H}, \mathrm{J}=6.1 \mathrm{~Hz}$ ), 1.25 (overlapping $\mathrm{d}, 3 \mathrm{H}, \mathrm{J}=5.9 \mathrm{~Hz}$ ); ${ }^{13} \mathrm{C}$ NMR $\delta$ $182.0(+), 165.1(+), 149.2(+), 139.3(+), 133.6(+), 132.3(-), 130.4(-), 128.5(-)$, $126.9(-), 126.8(-), 116.0(-), 110.0(-), 105.9(+), 89.0(+), 85.8(+), 78.8(+), 78.2$ (-), $74.2(-), 47.2(+), 22.7(-), 22.6(-), 22.5(-), 22.4(-)$; IR (neat) 3383, 3207, $2976,2215,1770,1094 \mathrm{~cm}^{-1}$. 


\section{9-Benzyl-2,3-diisopropoxy-9H-carbazole-1,4-dione (69) and 2,3- diisopropoxy-1H-cyclopenta[b]quinolin-1-one (34a).}

4-(2-Benzylamino-phenylethynyl)-4-hydroxy-2,3-diisopropoxy-cyclobut-2-enone (48) (130 mg, $0.32 \mathrm{mmol}$ ) was slurried along with Cul (122 mg, $0.64 \mathrm{mmol})$ in dry DMF ( $3 \mathrm{~mL}$ ) and was heated to $100{ }^{\circ} \mathrm{C}$ for $3 \mathrm{~h}$. The reaction was cooled, diluted with $100 \mathrm{~mL} \mathrm{Et}_{2} \mathrm{O}$ and filtered through a small pad of Celite. The Celite was also washed with $\mathrm{Et}_{2} \mathrm{O}(3 \times 25 \mathrm{~mL})$. The combined organic layers were washed with $200 \mathrm{~mL}$ brine, dried $\left(\mathrm{Na}_{2} \mathrm{SO}_{4}\right)$, filtered, and the solvents were removed under reduced pressure. The crude product was purified by chromatography $\left(\mathrm{SiO}_{2}\right.$, hexanes:EtOAc, 9:1) to afford 69 (16 $\mathrm{mg}, 0.039 \mathrm{mmol}, 12 \%)$ as a yellowish oil and 34a (quinoline) (10 mg, $0.034 \mathrm{mmol}, 10 \%)$. NMR data for $69 .{ }^{1} \mathrm{H}$ NMR $\delta 7.5$ $(\mathrm{d}, 1 \mathrm{H}, \mathrm{J}=6.6 \mathrm{~Hz}), 7.37(\mathrm{~d}, 1 \mathrm{H}, \mathrm{J}=7.2 \mathrm{~Hz}), 7.33-7.26(\mathrm{~m}, 5 \mathrm{H}), 6.95(\mathrm{t}, 1 \mathrm{H}, \mathrm{J}=$ $7.8 \mathrm{~Hz}$ ), $6.76(\mathrm{t}, 1 \mathrm{H}, \mathrm{J}=7.2 \mathrm{~Hz}$ ), $6.00(\mathrm{~d}, 1 \mathrm{H}, \mathrm{J}=7.2 \mathrm{~Hz}$ ), 5.50 (heptet, 1H, J = $6.6 \mathrm{~Hz}$ ), 5.44 (heptet, $1 \mathrm{H}, \mathrm{J}=6.0 \mathrm{~Hz}$ ), $5.00(\mathrm{~s}, 2 \mathrm{H}$ ), 1.38 (overlapping d, 6H, J = $6.0 \mathrm{~Hz}$ ), 1.37 (overlapping d, 6H, J = 6.0 Hz); ${ }^{13} \mathrm{C}$ NMR $\delta 186.2(+), 185.3(+)$, $159.7(+), 155.7(+), 149.4(+), 148.2(+), 136.9(+), 131.7(-), 130.5(+), 128.5(-)$,

$128.4(-), 127.5(-), 124.2(-), 122.3(-), 106.6(-), 105.7(+), 74.5(-), 74.4(-), 54.0$ (+), $23.0(-), 22.9(-)$; IR (neat) 2980, 1730, 1667, $1090 \mathrm{~cm}^{-1}$.

\section{4-(4-Benzylamino-but-1-ynyl)-4-hydroxy-2,3-diisopropoxy-cyclobut-2-} enone (88).

Benzyl-but-3-ynyl-amine ${ }^{58}$ (83) (783 mg, $4.92 \mathrm{mmol}$ ) was dissolved in $10 \mathrm{~mL}$ of dry THF and subsequently cooled to $-40{ }^{\circ} \mathrm{C}$. $n$-BuLi $(2.0 \mathrm{M}$ in pentane, $2.50 \mathrm{~mL}$, 
$5.00 \mathrm{mmol}$ ) was added slowly via syringe and stirred for 15 minutes at $-40^{\circ} \mathrm{C}$. A cold (-40 $\left.{ }^{\circ} \mathrm{C}\right)$ 3,4-bis(1-methylethoxy)-3-cyclobutene-1,2-dione (27) (989 mg, 4.99 $\mathrm{mmol}) / \mathrm{THF}(10 \mathrm{~mL})$ solution was added to the lithiated butyne and stirred for 30 minutes at $-40{ }^{\circ} \mathrm{C}$. The reaction was quenched at $-40{ }^{\circ} \mathrm{C}$ with $30 \mathrm{~mL}$ water. The resulting mixture was extracted with $(3 \times 50 \mathrm{~mL})$ diethyl ether. The organic layers were combined, dried $\left(\mathrm{MgSO}_{4}\right)$, filtered, and the solvent was removed under reduced pressure. The crude product was purified by chromatography $\left(\mathrm{SiO}_{2}\right.$, EtOAc) to give $88(1.489 \mathrm{~g}, 4.02 \mathrm{mmol}, 85 \%)$ as a yellow oil. ${ }^{1} \mathrm{H}$ NMR $(270 \mathrm{MHz}) \delta 7.37-7.22(\mathrm{~m}, 5 \mathrm{H}), 4.93$ (overlapping heptet, 1H, J = 6.3 Hz), 4.86 (overlapping heptet, 1H, J = 6.3 Hz), $3.79(\mathrm{~s}, 2 \mathrm{H}), 2.76(\mathrm{t}, 2 \mathrm{H}, \mathrm{J}=6.5 \mathrm{~Hz}), 2.52(\mathrm{t}$,

$2 \mathrm{H}, \mathrm{J}=6.5 \mathrm{~Hz}), 1.39(\mathrm{~d}, 6 \mathrm{H}, \mathrm{J}=6.3 \mathrm{~Hz}), 1.29(\mathrm{dd}, 6 \mathrm{H}, \mathrm{J}=3.94,5.94 \mathrm{~Hz}) ;{ }^{13} \mathrm{C}$ NMR $\delta 181.8(+), 165.1(+), 138.9(+), 133.1(+), 128.4(-), 128.3(-), 127.1(-)$ $86.5(+), 77.8(-), 77.4(+), 77.3(+), 73.7(-), 22.7(-), 22.6(-), 22.5(-), 22.4(-)$, 19.5 (+); IR (neat) 3293 (br.), 2231, 2060, 2978, 1772, $1623 \mathrm{~cm}^{-1}$.

\section{1-Benzyl-5,6-diisopropoxy-2,3-dihydro-1H-indole-4,7-dione (91).}

4-(4-Benzylamino-but-1-ynyl)-4-hydroxy-2,3-diisopropoxy-cyclobut-2-enone (88) (221 $\mathrm{mg}, 0.618 \mathrm{mmol}$ ) was dissolved in $100 \mathrm{~mL}$ toluene and heated at reflux for 21 hours. The reaction was cooled to room temperature and the solvent was removed. The crude product was purified by chromatography $\left(\mathrm{SiO}_{2}\right.$, hexanes:EtOAc 8:2 then 1:1) to give 91 (113 $\mathrm{mg}, 0.32 \mathrm{mmol}, 51 \%$ ) as a blue oil. It was noticed that during the column the residue changed in color from a slow moving yellow to faster moving green and then finally to blue. ${ }^{1} \mathrm{H}$ NMR $(270$ 
$\mathrm{MHz}) \delta 7.32-7.22(\mathrm{~m}, 5 \mathrm{H}), 5.06$ (heptet, $1 \mathrm{H}, \mathrm{J}=6.2 \mathrm{~Hz}), 4.88(\mathrm{~s}, 2 \mathrm{H}), 4.47$

(heptet, $1 \mathrm{H}, \mathrm{J}=6.3 \mathrm{~Hz}$ ), $3.55(\mathrm{t}, 2 \mathrm{H}, \mathrm{J}=10.6 \mathrm{~Hz}), 2.80(\mathrm{t}, 2 \mathrm{H}, \mathrm{J}=10.5 \mathrm{~Hz}), 1.32$

(d, $6 \mathrm{H}, \mathrm{J}=8.3 \mathrm{~Hz}), 1.30(\mathrm{~d}, 6 \mathrm{H}, \mathrm{J}=8.3 \mathrm{~Hz}) ;{ }^{13} \mathrm{C} \mathrm{NMR}(150 \mathrm{MHz}) \delta 180.3(+)$,

$177.9(+), 149.0(+), 148.6(+), 136.6(+), 128.7(-), 128.5(-), 127.9(-), 127.7(+)$,

$112.9(+), 76.2(-), 75.5(-), 52.4(+), 51.5(+), 23.9(+), 22.8(-), 22.5(-)$; IR (neat)

$2975,1760,1617 \mathrm{~cm}^{-1}$.

\section{5,6-Diisopropoxy-2,3-dihydro-1H-indole-4,7-dione (93).}

1-Benzyl-5,6-diisopropoxy-2,3-dihydro-1H-indole-4,7-dione (91) (77 mg, 0.216 $\mathrm{mmol}$ ) was dissolved in $10 \mathrm{~mL}$ methanol. Ammonium formate pentahydrate (366 $\mathrm{mg}, 2.16 \mathrm{mmol}$ ) and a portion of $10 \% \mathrm{Pd} / \mathrm{C}(43 \mathrm{mg})$ were added to the flask and the reaction was heated to reflux for 2 hours. The opaque dark blue solution turned clear light blue in color after about 5 minutes into the heating. The reaction was allowed to cool to room temperature and filtered through a small pad of Celite with excess methanol. The methanol was removed and the residue was diluted with $100 \mathrm{~mL} \mathrm{CH} \mathrm{Cl}_{2}$ and washed with $50 \mathrm{~mL}$ of water. The organic layer was dried $\left(\mathrm{Na}_{2} \mathrm{SO}_{4}\right)$, filtered and concentrated. The residue was chromatographed on silica gel (hexanes:EtOAc 1:1) yielding 93 (16 mg, 0.060 mmol, $28 \%$ ) as a green-blue oil. ${ }^{1} \mathrm{H}$ NMR $\delta 4.99$ (heptet, $1 \mathrm{H}, \mathrm{J}=6.0 \mathrm{~Hz}$ ), 4.89 (br. s, 1H), 4.48 (heptet, 1H, J = 6.9 Hz), $3.71(\mathrm{t}, 2 \mathrm{H}, \mathrm{J}=10.2 \mathrm{~Hz}$ ), $2.93(\mathrm{t}, 2 \mathrm{H}, \mathrm{J}=$ $10.2 \mathrm{~Hz}), 1.30$ (d, 6H, J = 6.0 Hz), $1.26(\mathrm{~d}, 6 \mathrm{H}, \mathrm{J}=6.0 \mathrm{~Hz}) ;{ }^{13} \mathrm{C}$ NMR $\delta 197.6(+)$, $197.5(+), 179.0(+), 178.8(+), 173.6(+), 151.8(+), 149.7(+), 141.9\left(^{+}\right), 112.3$ 
(+), $76.4(-), 75.5(-), 46.8(+), 26.5(+), 22.8(-), 22.5(-)$; IR (neat) 3344 (br.), $2977,1664 \mathrm{~cm}^{-1}$.

\section{1-Benzyl-5,6-diisopropoxy-1H-indole-4,7-dione (94).}

1-Benzyl-5,6-diisopropoxy-2,3-dihydro-1H-indole-4,7-dione (91) (40 mg, 0.113 $\mathrm{mmol}$ ) and 2,3-dichloro-5,6-dicyanobenzoquinone (DDQ) (27 mg, $0.117 \mathrm{mmol})$ was dissolved in $5 \mathrm{~mL}$ benzene. The reaction was allowed to stir at room temperature for 22 hours and then was heated to reflux for 24 additional hours. The solvent was removed and the residue was chromatographed $\left(\mathrm{SiO}_{2}\right.$, hexanes:EtOAc 8:2) yielding $94(26 \mathrm{mg}, 0.073 \mathrm{mmol}, 65 \%)$ as a orange oil. ${ }^{1} \mathrm{H}$ NMR $\delta$ 7.34-7.24 (m, 5H), $6.84(\mathrm{~d}, 1 \mathrm{H}, \mathrm{J}=2.4 \mathrm{~Hz}), 6.56(\mathrm{~d}, 1 \mathrm{H}, \mathrm{J}=3.0 \mathrm{~Hz}), 5.53$ (s, 2H), 4.78 (heptet, 1H, J = 6.0 Hz), 7.73 (heptet, 1H, J = 6.0 Hz), $1.32(\mathrm{~d}, 6 \mathrm{H}, \mathrm{J}$ $=6.6 \mathrm{~Hz}), 1.31(\mathrm{~d}, 6 \mathrm{H}, \mathrm{J}=6.0 \mathrm{~Hz}) ;{ }^{13} \mathrm{C}$ NMR $\delta 180.1(+), 175.6(+), 146.9(+)$, $146.7(+), 136.2(+), 129.6(-), 128.9(-), 128.2(-), 127.7(-), 127.6(+), 125.7(+)$, $107.7(-), 76.1(-), 52.0(+), 22.7(-), 22.6(-) ; \quad I R$ (neat) 3112, 2976, $1648 \mathrm{~cm}^{-1}$.

tert-butyl benzyl-4-(1-hydroxy-2,3-diisopropoxy-4-oxocyclobut-2-enyl)but-3ynylcarbamate (89). tert-butyl benzylbut-3-ynylcarbamate ${ }^{57}$ (87) $(641 \mathrm{mg}, 2.47$ mmol) was dissolved in $5 \mathrm{~mL}$ THF and cooled to $-78{ }^{\circ} \mathrm{C}$. The $n$-BuLi $(2.0 \mathrm{M}$ in hexanes, $1.25 \mathrm{~mL}, 2.50 \mathrm{mmol}$ ) was added over a $15 \mathrm{~min}$. period and allowed to stir for 30 minutes. 27 was added $(5 \mathrm{~mL})$ THF was added via cannula and allowed to stir for 30 minutes. The reaction was quenched with $30 \mathrm{~mL}$ and extracted with $3 \times 50 \mathrm{~mL} \mathrm{Et} 2 \mathrm{O}$, dried $\left(\mathrm{MgSO}_{4}\right)$, filtered and concentrated. The 
residue was chromatographed on silica gel (hexanes:EtOAc 8:2) yielding 89 as a thick yellow oil (704 mg, $1.54 \mathrm{mmol}, 62 \%) .{ }^{1} \mathrm{H}$ NMR $\delta(270 \mathrm{MHz}) 7.31-7.16(\mathrm{~m}$, 5H), 4.97 (heptet, $1 \mathrm{H}, \mathrm{J}=6.2 \mathrm{~Hz}$ ), 4.84 (heptet, $1 \mathrm{H}, \mathrm{J}=6.2 \mathrm{~Hz}$ ), $4.51(\mathrm{~s}, 2 \mathrm{H}$ ), 4.30 (br. d, $1 \mathrm{H}, \mathrm{J}=11.1 \mathrm{~Hz}$ ), 3.38 (br. s, 1H), 3.26 (br. s, 1H), 2.45 (br. s, 2H), 1.41 (s overlapping with $\mathrm{d}$ at $1.40,9 \mathrm{H}), 1.40$ (d overlapping with $\mathrm{s}$ at $1.41,6 \mathrm{H}, \mathrm{J}=$ $6.3 \mathrm{~Hz}), 1.26(\mathrm{~d}, 6 \mathrm{H}, \mathrm{J}=5.2 \mathrm{~Hz}) .{ }^{13} \mathrm{C}$ NMR $\delta(67.5 \mathrm{MHz}) 181.1(+), 164.9(+)$, $155.3(+), 138.1(+), 137.9(+), 133.3(+), 128.2(-), 127.6(-), 126.9(-), 86.9\left(^{+}\right)$, $86.2(+), 79.9(-), 78.2(-), 77.5(-), 77.4(+), 76.2(-), 73.6(+), 51.2(-), 50.3(-)$, $45.4(-), 45.1(-), 30.7(+), 28.2(+), 22.5(+), 22.4(+), 22.3(+), 18.7(-), 18.5(-)$. IR (neat) 3340 br., 2990, 2930, 2106, 1767, 1686, $1094 \mathrm{~cm}^{-1}$.

\section{tert-butyl benzyl-2-(4,5-diisopropoxy-3,6-dioxocyclohexa-1,4-}

dienyl)ethylcarbamate (92). tert-butyl benzyl-4-(1-hydroxy-2,3-diisopropoxy-4oxocyclobut-2-enyl)but-3-ynylcarbamate (89) (560 mg, $1.22 \mathrm{mmol}$ ) was dissolved in $20 \mathrm{~mL} 1,2-\mathrm{DCE}$ and placed in a thick walled flask. The flask was sealed and heated to $100{ }^{\circ} \mathrm{C}$ for $22 \mathrm{~h}$. The reaction was cooled to room temperature and solvents were removed. The resulting residue was chromatographed on silica gel (hexanes:EtOAc; 8:2) yielding 92 as an orange oil (266 mg, $0.58 \mathrm{mmol}, 48 \%$ ) ${ }^{1} \mathrm{H}$ NMR $(270 \mathrm{MHz}) \delta 7.40-7.23(\mathrm{~m}, 5 \mathrm{H}), 6.26(\mathrm{~s}, 1 \mathrm{H}), 4.79$ (heptet, $2 \mathrm{H}, \mathrm{J}=5.8$ $\mathrm{Hz}), 4.45,(\mathrm{~s}, 2 \mathrm{H}), 3.40$ (br. s, 2H), $2.54(\mathrm{t}, 2 \mathrm{H}, \mathrm{J}=6.7 \mathrm{~Hz}), 1.43-1.27(\mathrm{~m}, 21 \mathrm{H})$. ${ }^{13}$ C NMR $\delta$ 184. $3(+), 155.6(+), 145.3(+), 131.3(+), 128.5(+), 128.3(-), 128.1$ $(-), 127.3(-), 80.0(+), 76.0(+), 75.9(+), 50.8(+), 45.5(+), 28.6(-), 28.3(-), 28.1$ (-), 22.9()$, 22.7(-), 22.6(-)$. IR (neat) 2977, 2933, 1686, 1654, $1095 \mathrm{~cm}^{-1}$. 
1-Benzyl-5,6-diisopropoxy-2,3-dihydro-1H-indole-4,7-dione (91). tert-butyl benzyl2-(4,5-diisopropoxy-3,6-dioxocyclohexa-1,4-dienyl)ethylcarbamate (92) (200 mg, $0.44 \mathrm{mmol}$ ) was dissolved in $\mathrm{CH}_{2} \mathrm{Cl}_{2}(20 \mathrm{~mL}$ ) was treated with $1.5 \mathrm{~mL}$ trifluoroacetic acid ${ }^{73}$ at $0{ }^{0} \mathrm{C}$ for $3 \mathrm{~h}$. The reaction was then warmed to $50{ }^{0} \mathrm{C}$ for 1h. The reaction was cooled to room temperature and the solvents were removed under reduced pressure. The resulting residue was neutralized with 30 $\mathrm{mL}$ aqueous saturated $\mathrm{NaHCO}_{3}$ and extracted with $3 \mathrm{X} 30 \mathrm{~mL}$ portions of $\mathrm{CH}_{2} \mathrm{Cl}_{2}$. The organic layer was dried $\left(\mathrm{MgSO}_{4}\right)$, filtered, and the solvent was removed under reduced pressure. The crude product was purified by chromatography $\left(\mathrm{SiO}_{2}\right.$, hexanes:EtOAc, 8:2) to give 91 (80 mg, $\left.0.22 \mathrm{mmol}, 51 \%\right)$ as a blue oil.

\section{[2-(3,4-Di(1-methylethoxy)-2,5-dioxo-3-cyclopenten-1-ylmethyl)phenyl]-} carbamic acid 1,1-dimethylethyl ester (33a). A solution of 28a (184 mg, 0.44 mmol) in $\mathrm{N}, \mathrm{N}$-dimethylformamide (DMF) (3 mL) was heated to $100{ }^{\circ} \mathrm{C}$ for $6 \mathrm{~h}$. The reaction was cooled to ambient temperature, diluted with $100 \mathrm{~mL} \mathrm{Et}_{2} \mathrm{O}$ and

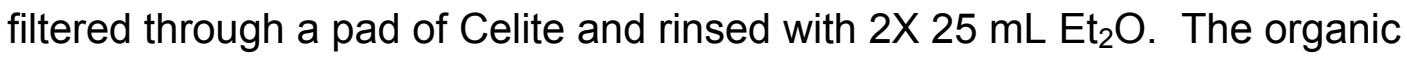
washings were combined and washed with $20 \mathrm{~mL}$ brine, dried $\left(\mathrm{Na}_{2} \mathrm{SO}_{4}\right)$ and concentrated. The solvent was then removed under reduced pressure and the residue was purified by chromatography $\left(\mathrm{SiO}_{2}\right.$, hexanes: EtOAc, 8:2) to give $\mathbf{3 3 a}$ (19 mg, $0.048 \mathrm{mmol}, 11 \%$ ) as an orange solid. mp 93-96 ${ }^{\circ} \mathrm{C} ;{ }^{1} \mathrm{H}$ NMR $(270 \mathrm{MHz})$ $\delta 7.91(\mathrm{dd}, 1 \mathrm{H}, \mathrm{J}=7.9$ and $1.6 \mathrm{~Hz}), 7.80(\mathrm{~d}, 1 \mathrm{H}, \mathrm{J}=8.1 \mathrm{~Hz}), 7.44(\mathrm{~s}, 1 \mathrm{H})$, 
overlapping $7.40(\mathrm{t}, 1 \mathrm{H}, \mathrm{J}=8.7 \mathrm{~Hz}), 7.13(\mathrm{t}, 1 \mathrm{H}, \mathrm{J}=7.5 \mathrm{~Hz}), 6.54(\mathrm{br} \mathrm{s}, 1 \mathrm{H}), 5.59$

(m, 2H), $1.51(\mathrm{~s}, 9 \mathrm{H}), 1.40(\mathrm{~d}, 6 \mathrm{H}, \mathrm{J}=6.3 \mathrm{~Hz}), 1.37(\mathrm{~d}, 6 \mathrm{H}, \mathrm{J}=6.1 \mathrm{~Hz})$.

This reaction was also repeated in several different temperatures and times and are summarized in Table 5.

Table 5: Copper Mediated Reaction Conditions for 28a

\begin{tabular}{|c|c|c|c|}
\hline Temp/Time/28a & Cul & 33a & Recovered 28a \\
\hline $\begin{array}{c}75^{\circ} \mathrm{C}, 24 \mathrm{~h}, \\
\mathbf{2 8 a} \begin{array}{c}120 \mathrm{mg}, 0.29 \\
\mathrm{mmol}\end{array}\end{array}$ & $\begin{array}{c}\text { Yes } \\
2 \text { eq }\end{array}$ & No Reaction & Not Calculated \\
\hline $\begin{array}{c}85^{\circ} \mathrm{C}, 24 \mathrm{~h}, \\
\mathbf{2 8 a}\left(\begin{array}{c}120 \mathrm{mg}, 0.29 \\
\mathrm{mmol})\end{array}\right.\end{array}$ & $\begin{array}{c}\text { Yes } \\
2 \text { eq }\end{array}$ & $10 \mathrm{mg}, 0.024 \mathrm{mmol}, 8 \%$ & $\begin{array}{c}29 \mathrm{mg}, 0.069 \mathrm{mmol}, \\
24 \%\end{array}$ \\
\hline $\begin{array}{c}100^{\circ} \mathrm{C}, 6 \mathrm{~h}, \\
\mathbf{2 8 a} 184 \mathrm{mg}, 0.44 \\
\mathrm{mmol}\end{array}$ & $\begin{array}{c}\text { Yes } \\
2 \text { eq }\end{array}$ & $19 \mathrm{mg}, 0.048 \mathrm{mmol}, 11 \%$ & Not recovered \\
\hline $\begin{array}{c}120^{\circ} \mathrm{C}, 1 \mathrm{~h}, \\
\mathbf{2 8 a ~} 212 \mathrm{mg}, 0.51 \\
\mathrm{mmol}\end{array}$ & $\begin{array}{c}\text { Yes } \\
2 \text { eq }\end{array}$ & $24 \mathrm{mg}, 0.057 \mathrm{mmol}, 11 \%$ & $\begin{array}{c}70 \mathrm{mg}, 0.17 \mathrm{mmol}, \\
32 \%\end{array}$ \\
\hline $\begin{array}{c}120^{\circ} \mathrm{C}, 1 \mathrm{~h}, \\
\mathbf{2 8 a} \begin{array}{c}166 \mathrm{mg}, 0.40 \\
\mathrm{mmol}\end{array}\end{array}$ & No & $38 \mathrm{mg}, 0.091 \mathrm{mmol}, 23 \%$ & $\begin{array}{c}13 \mathrm{mg}, 0.032 \mathrm{mmol}, \\
8 \%)\end{array}$ \\
\hline
\end{tabular}

\section{4-hydroxy-2,3-diisopropoxy-4-(2-(2-nitrophenyl)ethynyl)cyclobut-2-enone}

(51a). 4-Ethynyl-4-hydroxy-2,3-diisopropoxy-cyclobut-2-enone ${ }^{69} 39$ (370 mg,

$1.65 \mathrm{mmol}$ ), bis(triphenylphosphine)palladium dichloride (56 $\mathrm{mg}, 0.080 \mathrm{mmol}$ ), copper iodide (317 mg, $1.66 \mathrm{mmol}$ ) were slurried in $30 \mathrm{~mL} \mathrm{NEt}_{3}$.

lodonitrobenzene $(418 \mathrm{mg}, 1.68 \mathrm{mmol})$ was added after five minutes and the reaction was allowed to stir. After 24 hours the reaction was diluted with $50 \mathrm{~mL}$ water and extracted with diethyl ether $(3 \times 50 \mathrm{~mL})$. The combined organic layers 
were washed with $20 \mathrm{~mL} 10 \% \mathrm{NH}_{4} \mathrm{OH}$, dried $\left(\mathrm{MgSO}_{4}\right)$, filtered, and the solvents were removed under reduced pressure. The crude product was purified by chromatography $\left(\mathrm{SiO}_{2}\right.$, hexanes: EtOAc, 1:1) to give $51 \mathrm{a}(300 \mathrm{mg}, 0.57 \mathrm{mmol}$, $53 \%)$ as a yellow oil ${ }^{1} \mathrm{H}$ NMR $(270 \mathrm{MHz}) \delta 8.07(\mathrm{dd}, 1 \mathrm{H}, \mathrm{J}=1.8,8.3 \mathrm{~Hz}), 7.66$ $(\mathrm{dd}, 1 \mathrm{H}, \mathrm{J}=1.8,7.9 \mathrm{~Hz}), 7.59(\mathrm{dt}, 1 \mathrm{H}, \mathrm{J}=1.1,7.5 \mathrm{~Hz}), 7.49(\mathrm{dt}, 1 \mathrm{H}, \mathrm{J}=1.6,8.1$ Hz), 5.06 (heptet, 1H, J = 6.1 Hz), 4.91 (heptet, 1H, J = 6.1 Hz), 3.03 (br. s, 1H), $1.47(\mathrm{~d}, 6 \mathrm{H}, \mathrm{J}=6.1 \mathrm{~Hz}$ ), 1.34-1.31 (overlapping $\mathrm{d}, 6 \mathrm{H}, \mathrm{J}=6.2,6.1 \mathrm{~Hz}) .{ }^{13} \mathrm{C} \mathrm{NMR}$ (67.5 MHz) $\delta 179.6(+), 163.9(+), 149.4(+), 135.0(-), 134.2(+), 132.9(-), 129.3$ $(-), 124.6(-), 117.3(+), 91.3(+), 83.7(+), 79.1(+), 78.4(-), 74.3(-), 22.6(-), 22.5$ (-). IR (neat) 3348 br., 2980, 2934, 2368, 1774, 1609, $1319 \mathrm{~cm}^{-1}$.

\section{2-(2-nitrobenzylidene)-4,5-diisopropoxycyclopent-4-ene-1,3-dione (51d) and} 2,3-diisopropoxy-5-(2-nitrophenyl)cyclohexa-2,5-diene-1,4-dione (51c). 4hydroxy-2,3-diisopropoxy-4-(2-(2-nitrophenyl)ethynyl)cyclobut-2-enone 51a was dissolved in $200 \mathrm{~mL}$ toluene and heated to reflux for 5 hours. The reaction was allowed to cool to room temperature and the solvent was removed under reduced pressure. The residue was chromatographed $\left(\mathrm{SiO}_{2}\right.$, hexanes:EtOAc, 8:2)

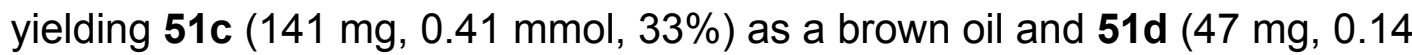
mmol, 11\%) Data for $51 \mathrm{c}{ }^{1} \mathrm{H}$ NMR $\delta 8.15(\mathrm{dd}, 1 \mathrm{H}, \mathrm{J}=1.2,8.4 \mathrm{~Hz}), 7.70(\mathrm{~s}, 1 \mathrm{H})$, $7.68(\mathrm{dd}, 1 \mathrm{H}, \mathrm{J}=1.2,7.2 \mathrm{~Hz}), 7.64(\mathrm{dt}, 1 \mathrm{H}, \mathrm{J}=1.2,7.2 \mathrm{~Hz}), 7.56(\mathrm{dt}, 1 \mathrm{H}, \mathrm{J}=1.2$, $6.0 \mathrm{~Hz}$ ), 5.64 (heptet, 1H, J = $6.0 \mathrm{~Hz}$ ), 4.95 (heptet, 1H, J = 6.0 Hz), 1.41 (d, 6H, $\mathrm{J}=6.0 \mathrm{~Hz}), 1.35(\mathrm{~d}, 6 \mathrm{H}, \mathrm{J}=6.0 \mathrm{~Hz}) \cdot{ }^{13} \mathrm{C}$ NMR $\delta 184.7(+), 183.8(+), 152.5(+)$, $150.7(+), 148.1(+), 132.8(-), 132.5(-), 131.2(-), 130.2(+), 129.1(+), 128.3(+)$, 
$124.6(-), 75.2(-), 75.1(-), 23.1(-), 22.9(-) . \quad$ IR (neat) 2990, 1732, 1673, 1655, $1340 \mathrm{~cm}^{-1}$. Data for 51d ${ }^{1} \mathrm{H}$ NMR $\delta$ 7.72-7.58 (br. d, 2H), 7.24 (d overlapping $\mathrm{CHCl}_{3}, 1 \mathrm{H}$ ), $7.10(\mathrm{t}, 1 \mathrm{H}, \mathrm{J}=7.3 \mathrm{~Hz}$ ), $6.47(\mathrm{~s}, 1 \mathrm{H}), 5.51$ (overlapping heptets, $2 \mathrm{H}$, $\mathrm{J}=6.1$ ), 1.41 (d overlapping $\mathrm{d}$ at $1.38,6 \mathrm{H}, \mathrm{J}=7.1 \mathrm{~Hz}$ ), 1.38 (d overlapping $\mathrm{d}$ at $1.41,6 \mathrm{H}, \mathrm{J}=6.5 \mathrm{~Hz})$ 
References and Notes

${ }^{1}$ (a) Wang, J.; Fan, X.; Zhang, X.; Han, L. Can. J. Chem, 2004, 82, 1192. (b) Huma, H. Z. S.; Halder, R.; Kalra, S.; Das, J.; Iqbal, J. Tetrahedron Lett., 2002, 43, 6485. (c) McLeod, C.; Austin, C. A.; Hamprecht, D. W.; Hartley, R. C. Tetrahedron Lett., 2004, 45, 8879.

${ }^{2}$ Yadav, J. S.; Reddy, B. V. S.; Rao, R. S.; Nagaiah, V. N. Synthesis, 2003, 10, 1610.

${ }^{3}$ Du, W. Tetrahedron, 2003, 59, 8649.

${ }^{4}$ Website: http://sres.anu.edu.au/associated/fpt/nwfp/quinine/Quinine.html,1110-2005.

${ }^{5}$ Jones, G. The Chemistry of Heterocyclic Compounds. Edited by Weissberger, A.; Taylor, E. C. Vol. 32, John Wiley \& Sons. 1977

${ }^{6}$ Skraup, Z, H. Ber. 1880, 13, 2086

${ }^{7}$ Badger, G. M.; Crocker, H. P.; Ennis, B. C.; Gayler, J. A.; Matthews, W. E.;

Raper, W. C. G.; Samuel, E. T.; Spotswood, M. T. Aust. J. Chem., 1963, 16, 814.

${ }^{8}$ Doebner, O.; von Miller, W. Ber. Dtsch. Chem. Ges. 1883, 16, 2464.

${ }^{9}$ Knorr, L. Ber., 1883, 16, 2593

${ }^{10} \mathrm{Li}, \mathrm{J}$. J. Name Reactions in Heterocyclic Chemistry. Editor: Corey, E. J. WileyIntersicence. John Wiley \& Sons 2005.

${ }^{11}$ Conrad, M.; Limpach, L. Ber., 1887, 20, 944.

${ }^{12}$ Hauser, C. R.; Reynolds, G. A. J. Am. Chem. Soc., 1948, 70, 2402.

${ }^{13}$ Friedländer, P. Chem. Ber. 1882, 15, 2572.

${ }^{14}$ Pfitzinger, J. J. Prakt. Chem. 1902, 66, 1902.

${ }^{15}$ Zemtsova, M. N.; Trakhtenberg, P. L.; Galkina, M. V. Russian Journal of Organic Chemistry, 2003, 39, 1803.

${ }^{16}$ Motokura, K.; Mizugaki, T.; Ebitani, K.; Kaneda, K. Tetrahedron Letters, 2004, 45, 6029 .

${ }^{17}$ Ohno, M.; Eguchi, Y. S. Synlett, 1998, 11, 1167.

${ }^{18}$ Foland, L. D.; Karlsson, O.; Perri, S. T.; Schwabe, R.; Xu, S. L.; Patil, S.; Moore, H. W. J. Am. Chem. Soc. 1989, 111, 975. 
${ }^{19}$ (a) Gayo, L. M.; Winters, M. P.; Moore, H. W. J. Org. Chem. 1992, 57, 6896. (b) Wipf, P.; Hopkins, C. R.; Phillips, E. O.; Lazo, J. S. Tetrahedron 2002, 58, 6367. (c) Boullais, C.; Rannou, C.; Reveillere, E.; Mioskowski, C. Europ. J. Org. Chem. 2000, 723. (d) Wipf, P.; Hopkins, C. R. J. Org. Chem. 1999, 64, 6881. (e) Hergueta, A. R.; Moore, H. W. J. Org. Chem. 1999, 64, 5979. (f) Xiong, Y.; Moore, H. W. J. Org. Chem. 1996, 61, 9168. (g) Taing, M.; Moore, H. W. J. Org. Chem. 1996, 61, 329 (h) Xiong, Y.; Xia, H.; Moore, H. W. J. Org. Chem. 1995, 60, 6460. (i) Sullivan, R. W.; Coghlan, V. M.; Munk, S. A.; Moore, H. W.; Reed, M. W. J. Org. Chem. 1994, 59, 2276. (j) Xia, H.; Moore, H. W. J. Org. Chem. 1992, 57, 3765. (k) Liebeskind, L. S.; Foster, B. S. J. Am. Chem. Soc. 1990, 112, 8612. (I) Karabelas, K.; Moore, H. W. J. Am. Chem. Soc. 1990, 112, 5372. (m) Foland, L. D.; Decker, O. H. W.; Moore, H. W. J. Am. Chem. Soc. 1989, 111, 989. (n) Perri, S. T.; Foland, L. D.; Decker, O. H. W.; Moore, H. W. J Org. Chem. 1986, 51, 3067.

${ }^{20}$ Enhsen, A.; Karabelas, K.; Heerding, J. M.; Moore, H. W. J. Org. Chem., 1990, $55,1177$.

${ }^{21}$ Pena-Cabrera, E.; Liebeskind, L. S., J. Org. Chem., 2002, 67, 1689.

22 Paquette, L. A.; Geng, F. Org. Lett., 2002, 4, 4547.

${ }^{23}$ General reference for BOC protection: Kelly, T.; McNeil, D. W. Tetrahedron Letters, 1994, 35, 9003.

${ }^{24}$ General reference for the Sonogashira reaction: Sakamoto, T.; Kondo, Y.; Yamanaka, H. Heterocycles, 1986, 24, 31.

${ }^{25}$ General reference for TMS cleavage from a propargyl alcohol: Lu, Y.-F.;

Fallis, A. G. Tetrahedron Letters, 1993, 34, 3370.

${ }^{26}$ a) Crous, R.; Dwyer, C.; Holzapfel, C. W. Heterocycles, 1999, 51, 721. b)

Turner, J. A. J. Org. Chem., 1983, 48, 3401. and Estel, L.; Marasais, F.;

Queguiner, G. J. Org. Chem., 1988, 53, 2740.

${ }^{27}$ Liebeskind, L. S. Tetrahedron, 1989, 45, 3060.

${ }^{28}$ Olah, G. A.; Narang, S. C. Tetrahedron, 1982, 38, 2225. 
${ }^{29}$ Foland, L. D.; Karlsson, O.; Perri, S. T.; Schwabe, R.; Xu, S. L.; Patil, S.; Moore, H. W. J. Am. Chem. Soc. 1989, 111, 975.

${ }^{30}$ Cary, J. M.; Moore, J. S. Organic Letters, 2002, 4, 4663.

${ }^{31}$ Gabriele, B.; Salerno, G.; Veltri, L.; Costa, M.; Massera, C. Eur. J. Org. Chem. $2001,4607$.

${ }^{32}$ Koradin, C.;Dohle, W.; Rodriguez, A. L.; Schmid, B.; Knochel, P. Tetrahedron, 2003, 59, 1571.

${ }^{33}$ Larock, R.; Yum, E. K. J .Am. Chem. Soc., 1991, 113, 6689.

${ }^{34}$ Ezquerra, J.; Pedregal, C.; Lamas, C.; Barluenga, J.; Pérez, M.; García-Martín, M. A.; González, J. M. J. Org. Chem., 1996, 61, 5804.

${ }^{35}$ (a) Koradin, C.;Dohle, W.; Rodriguez, A. L.; Schmid, B.; Knochel, P. Tetrahedron, 2003, 59, 1571. (b) Kondo, Y.; Kojima, S.; Sakamoto, T. J. Org. Chem., 1997, 62, 6507.

${ }^{36}$ Larock, R.; Yum, E. K. J .Am. Chem. Soc., 1991, 113, 6689. (c) Hiroya, K.; Itoh, S.; Sakamoto, T. J. Org. Chem., 2004, 69, 1126.

${ }^{37}$ Yamamoto, Y.; Ohno, M.; Eguchi, S. Tetrahedron Letters, 1995, 36, 5539.

${ }^{38}$ Söderberg, B. C. G., Dantale, S. W. (unpublished results)

${ }^{39}$ Liu, F.; Liebeskind, L.S. J. Org. Chem. 1998, 63, 2835.

${ }^{40}$ Sakamoto, T.; Kondo, Y.; Yamanaka, H. Heterocycles, 1986, 24, 31.

${ }^{41}$ Kondo, Y.; Kojima, S.; Sakamoto, T. J. Org. Chem. 1997, 62, 6507

${ }^{42}$ Castro, C. E.; Gaughan, E. J.; Owsley, D. C. J. Org. Chem., 1966, 31, 4071.

${ }^{43}$ Reboredo, F. J.; Treus, M.; Estevez, J. C.; Castedo, L.; Estevez, R. J. Synlett, 2003, 11, 1603.

${ }^{44}$ Hiroya, K.; Itoh, S.; Sakamoto, T. J. Org. Chem., 2004, 69, 1126.

${ }^{45}$ Hegedus, L. S. Transition Metals in the Synthesis of Complex Organic Molecules. Edited by Douville, J. A., $2^{\text {nd }}$ edition. University Science Books, 1999. ${ }^{46}$ Fujii, N.; Haresco, J. J.; Novak, K. A. P.; Stokoe, D.; Kuntz, I. D.; Guy, R. K. J. Am. Chem. Soc. 2003, 125, 12074.

${ }^{47}$ Yamamoto, Y.; Ohno, M.; Eguchi, S. Tetrahedron Letters, 1995, 36, 5539.

48 Söderberg, B. C. G., Dantale, S. W. (unpublished results) 
${ }^{49}$ Liebeskind, L. S.; Mitchell, D.; Foster, B. S. J. Am. Chem. Soc., 1987, 109, 7908.

${ }^{50}$ Reed, M. W.; Pollart, D. J.; Perri, S. T.; Foland, L. D.; Moore, H. W. J. Org. Chem. 1988, 53, 2477.

${ }^{51}$ Saá, J. M.; Martí, C.; García-Raso, A. J. Org. Chem., 1992, 57, 589.

52 (a) Skibo, E. B.; Xing, C.; Dorr, R. T. J. Med. Chem. 2001, 44, 3545.), (b) Xing, C.; Wu, P.; Skibo, E. B.; Dorr, R. T. J. Med. Chem. 2000, 43, 457.

${ }^{53}$ (a) Allen, G. A.; Poletto, J. F.; Weiss, M. J. J. Am. Chem. Soc. 1964, 86, 3878. (b) Allen, G. R.; Binovi, L. J.; Weiss, M. J. J. Med. Chem., 1967, 10, 7. c) Gould, S. J., Chem. Rev., 1997, 97, 2499.

${ }^{54}$ Sun, H. H.; Sakemi, S.; Burres, N.; McCarthy, P., J. Org. Chem., 1990, 55, 4964.

${ }^{55}$ Murakami, Y.; Yokoo, H.; Watanabe, T., Heterocycles 1998, 49, 127.

${ }^{56}$ Fukuyama, Y.; Iwatsuki, C.; Kodama, M.; Ochi, M.; Kataoka, K.; Shibata, K. Tetrahedron, 1998, 54, 10007.

${ }^{57}$ Hirai, Y.; Terada, T.; Yamazaki, T.; Momose, T. J. Chem. Soc. Perkin Trans. 1, 1992, 509.

${ }^{58}$ Iyer, S.; Liebeskind, L. S. J. Am. Chem. Soc., 1987, 109, 2759.

${ }^{59}$ Kiguchi, T.; Kuninobu, N.; Takahashi, Y.; Yoshida, Y.; Naito, T.; Ninomiya, I. Synthesis, 1989, 778.

${ }^{60}$ Flitsch, W.; Pandl, K.; Rußkamp, P., Liebigs Ann. Chem., 1983, 529.

${ }^{61}$ Somei, M.; Yamada, F.; Kato, J.; Suzuki, Y.; Ueda, Y. Heterocycles, 2002, 56, 81.

62 Sakamoto, T., Kondo, Y., Uchiyama, M., Yamanaka, H. J. Chem. Soc. Perkin Trans. I, 1993, 1941-1942.

${ }^{63}$ Fisher, T. H., Meierhoefer, A. W. J. Org. Chem., 1978, 43, 220-224.

${ }^{64}$ Crous, R.; Dwyer, C.; Holzapfel, C. W. Heterocycles 1999, 51, 721.

${ }^{65}$ General references for $\mathrm{NaOH}$ cleavage of ethynyl-TMS: a) Osuka, A., Fujikane, D., Shinmori, H., Kobatake, S., Irie, M. J. Org. Chem., 2001, 66, 3913- 
3923. b) Lavastre, O., Cabioch, S., Dixneuf, P. H. Tetrahedron, 1997, 53, 75957604. c) Lu, Y-F., Fallis, A. G. Tetrahedron Letters, 1993, 34, 3367-3370.

${ }^{66}$ (a) McDonald, F. E.; Chatterjee, A. K. Tetrahedron Lett. 1997, 38, 7687.

(b) Ishizaki, M.; Zyo, M.; Kasama, Y.; Niimi, Y.; Hoshino, O.; Nishitani, K.; Hara, H. Heterocycles 2003, 60, 2259-2271.

${ }^{67}$ General reference for Boc cleavage 3N HCl:EtOAc : Stahl, G. L., Walter, R., Smith, C. W. J. Org. Chem. 1978, 43, 2285-2286.

${ }^{68}$ General reference for N-Boc cleavage with TFA: Luo, Q-L., Li, J-Y., Liu, Z-Y., Chen, L-L., Li, J., Qian, Z., Shen, Q., Li, Y., Lushington, G. H., Ye, Q-Z., Nan, FJ. J. Med. Chem. 2003, 46, 2631-2640.

${ }^{69}$ Liebeskind, L. S., Fengl, R. W., Wirtz, K. R., Shawe, T. T, J. Org. Chem. 1988, 53, 2482.

${ }^{70}$ Switched to 1,2-dichloro based on: Söderberg, B. C. G., Dantale, S. W. (unpublished results)

${ }^{71}$ Ezquerra, J.; Pedregal, C; Lamas, C. J. Org. Chem., 1996, 61, 5804-5812.

72 (a) Lizos, D. E.; Murphy, J. A.. Org. Biomol. Chem., 2003, 1, 117. (b) Fielding, M. R.; Grigg, R.; Urch, C. J. Chem. Commun., 2000, 2239.

${ }^{73}$ General reference for N-Boc cleavage with TFA: Luo, Q-L., Li, J-Y., Liu, Z-Y., Chen, L-L., Li, J., Qian, Z., Shen, Q., Li, Y., Lushington, G. H., Ye, Q-Z., Nan, FJ. J. Med. Chem. 2003, 46, 2631-2640. 


\section{Appendix}




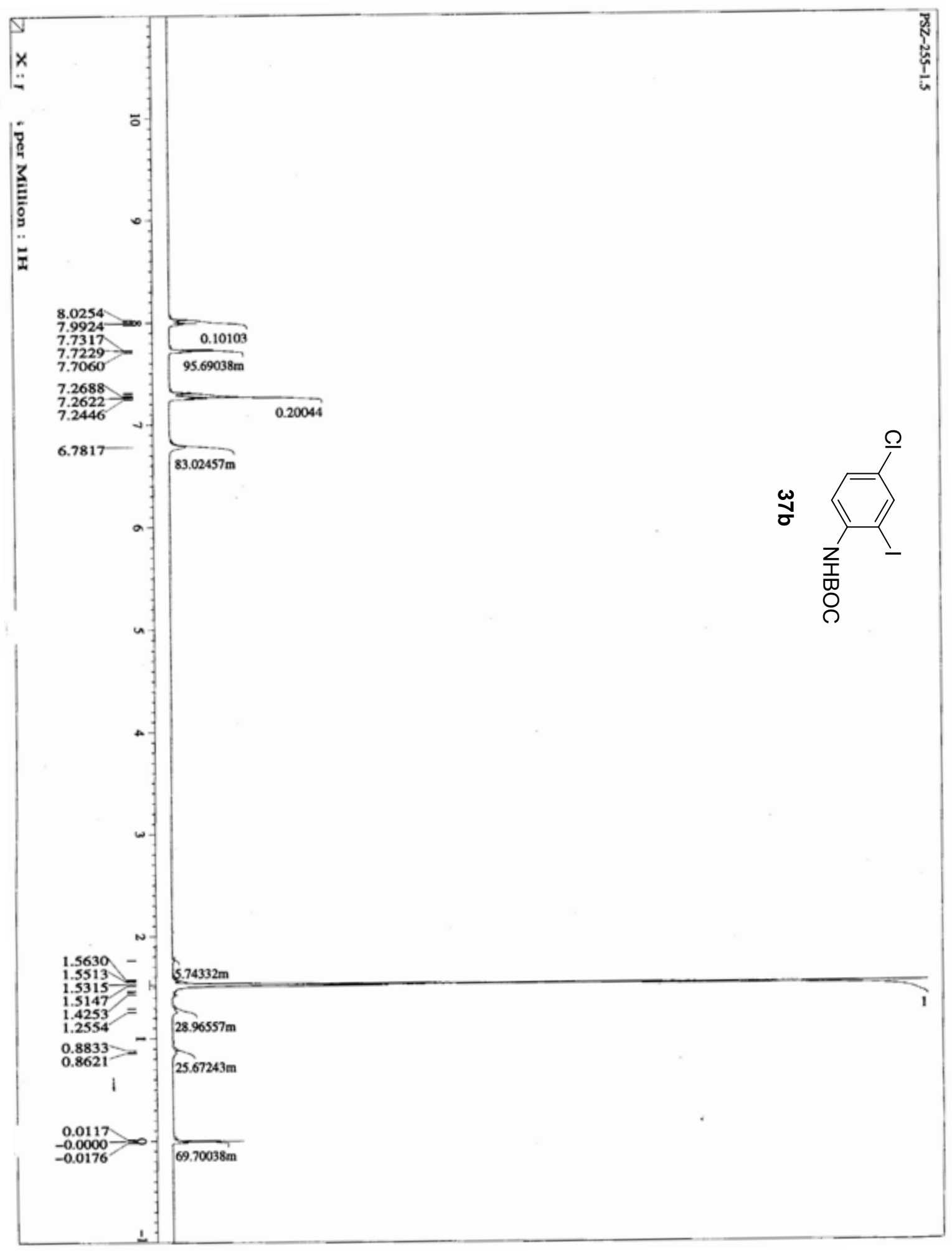

Figure 4: ${ }^{1} \mathrm{H}$ Spectrum of (4-Chloro-2-iodophenyl)-carbamic acid 1,1dimethylethyl ester $\mathbf{3 7 b}$ 


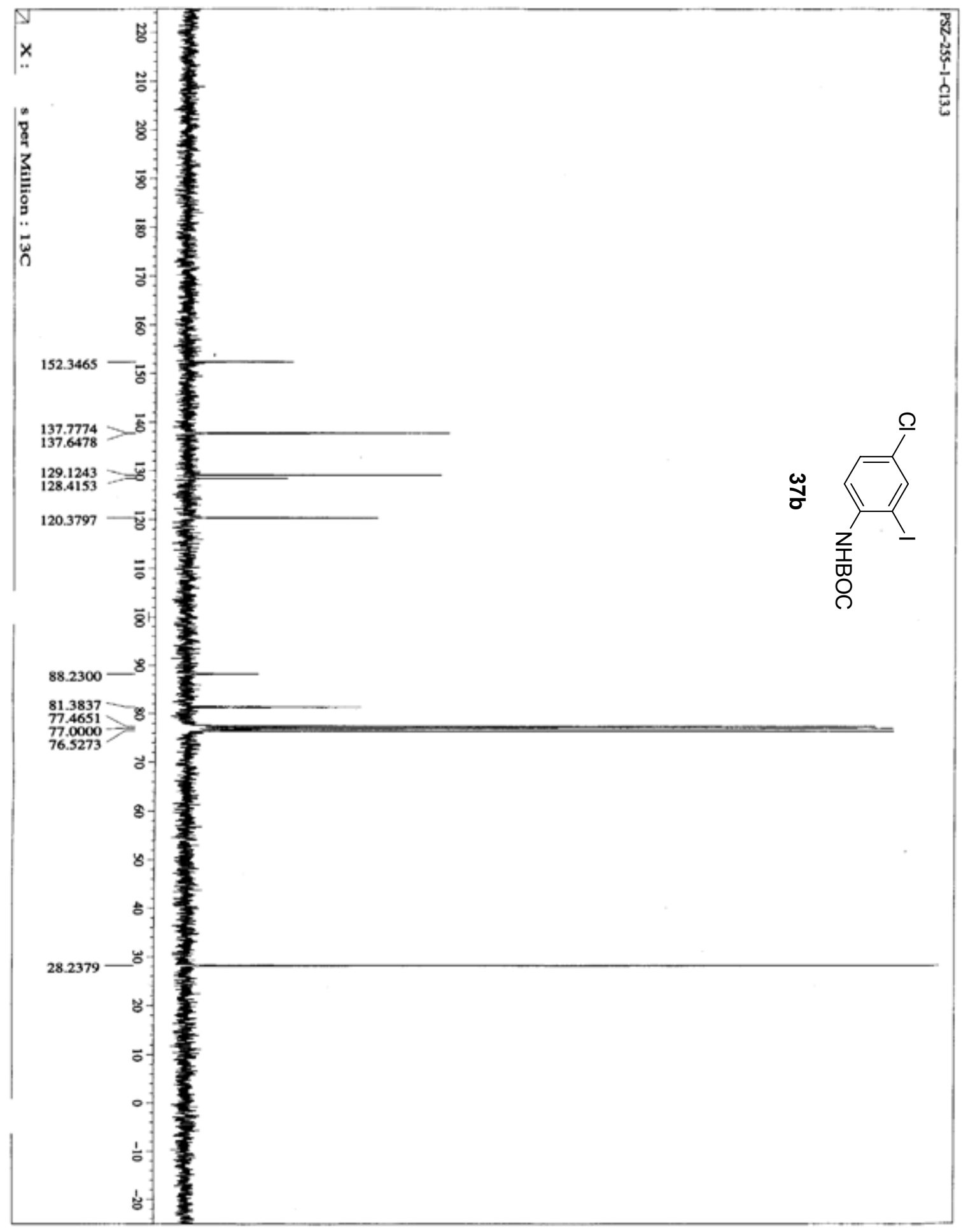

Figure 5: ${ }^{13} \mathrm{C}$ Spectrum of (4-Chloro-2-iodophenyl)-carbamic acid 1,1dimethylethyl ester $\mathbf{3 7 b}$ 


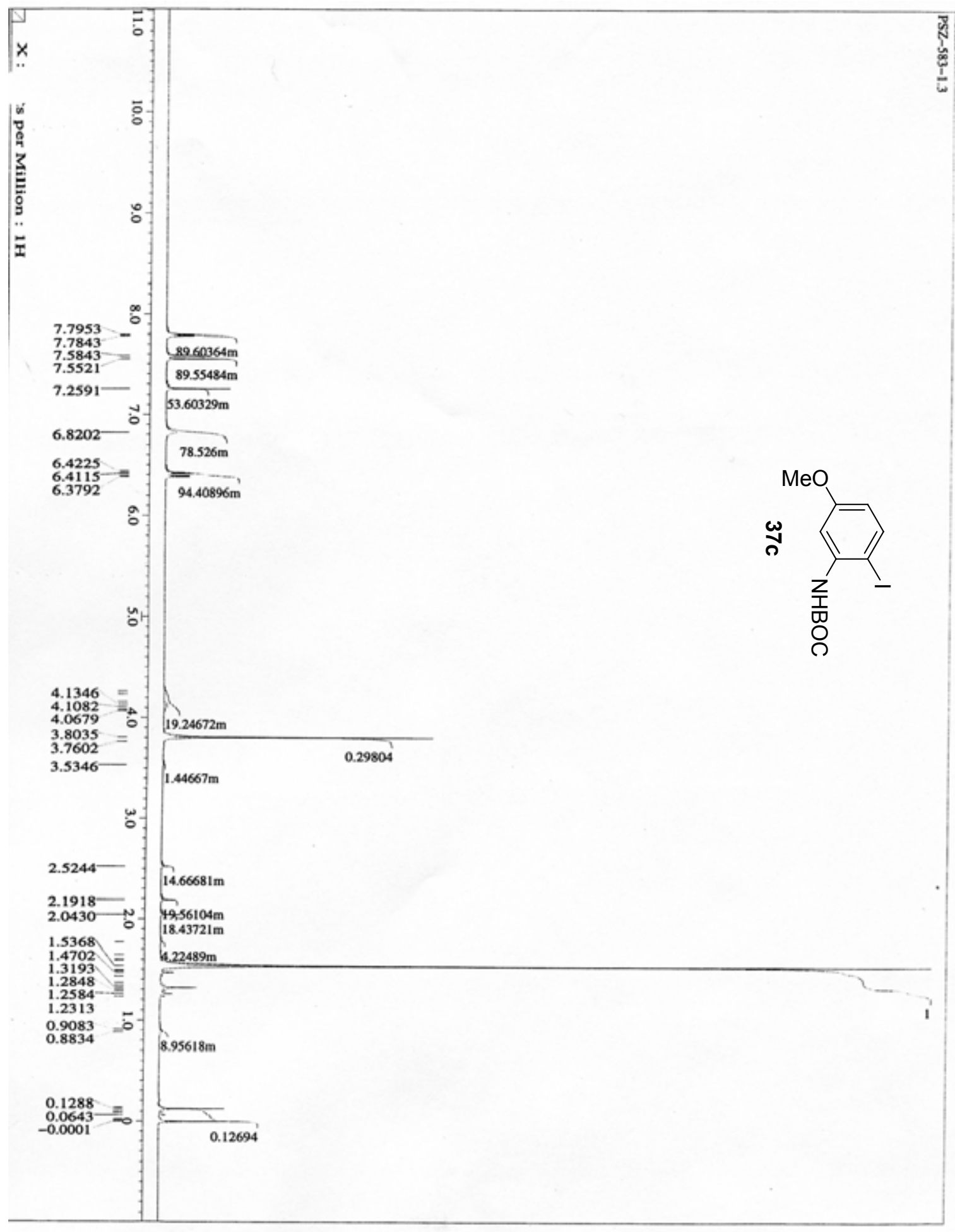

Figure 6: ${ }^{1} \mathrm{H}$ Spectrum of (2-lodo-5-methoxy-phenyl)-carbamic acid 1,1dimethylethyl ester 37c 


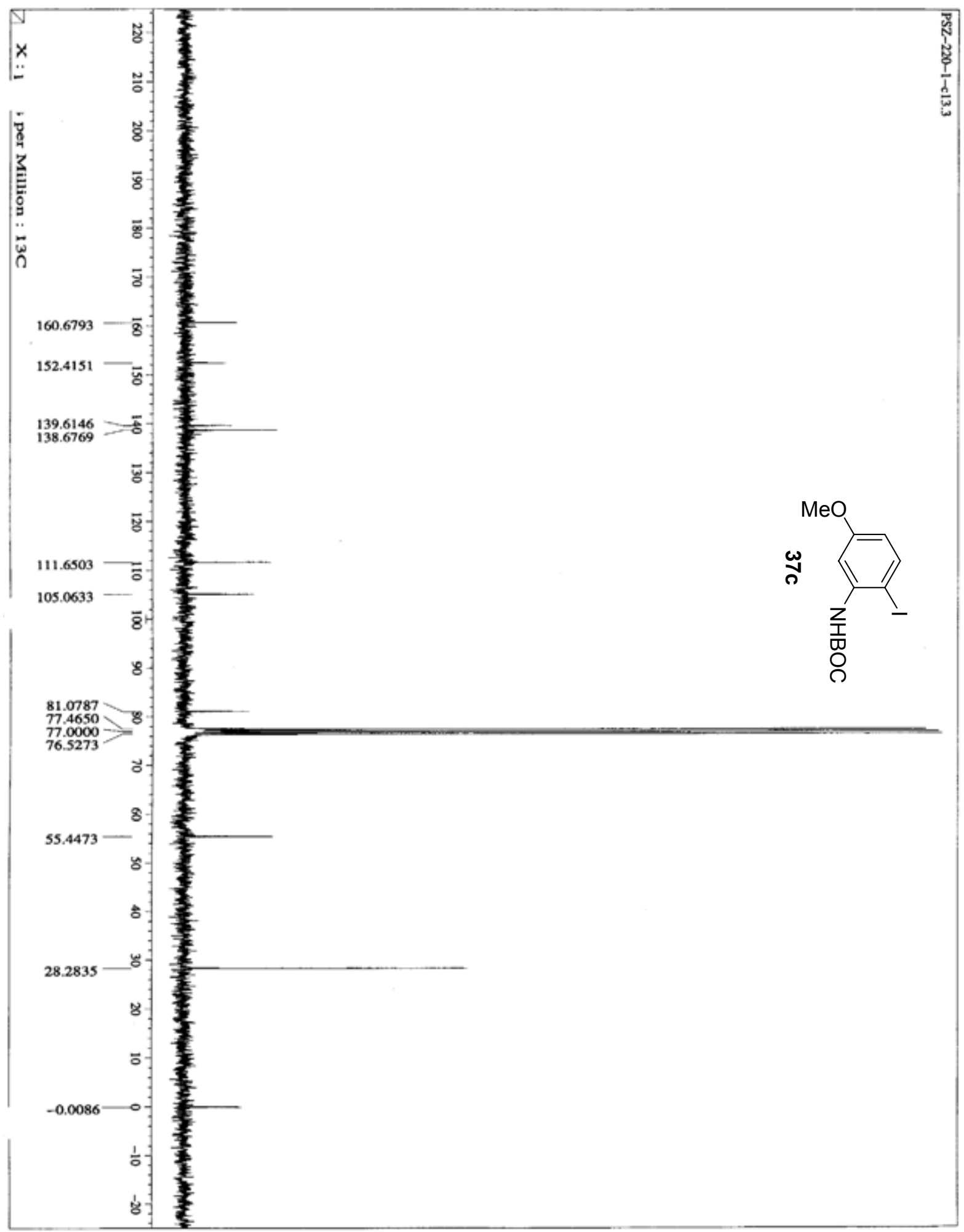

Figure 7: ${ }^{13} \mathrm{C}$ Spectrum of (2-lodo-5-methoxy-phenyl)-carbamic acid 1,1dimethylethyl ester 37c 


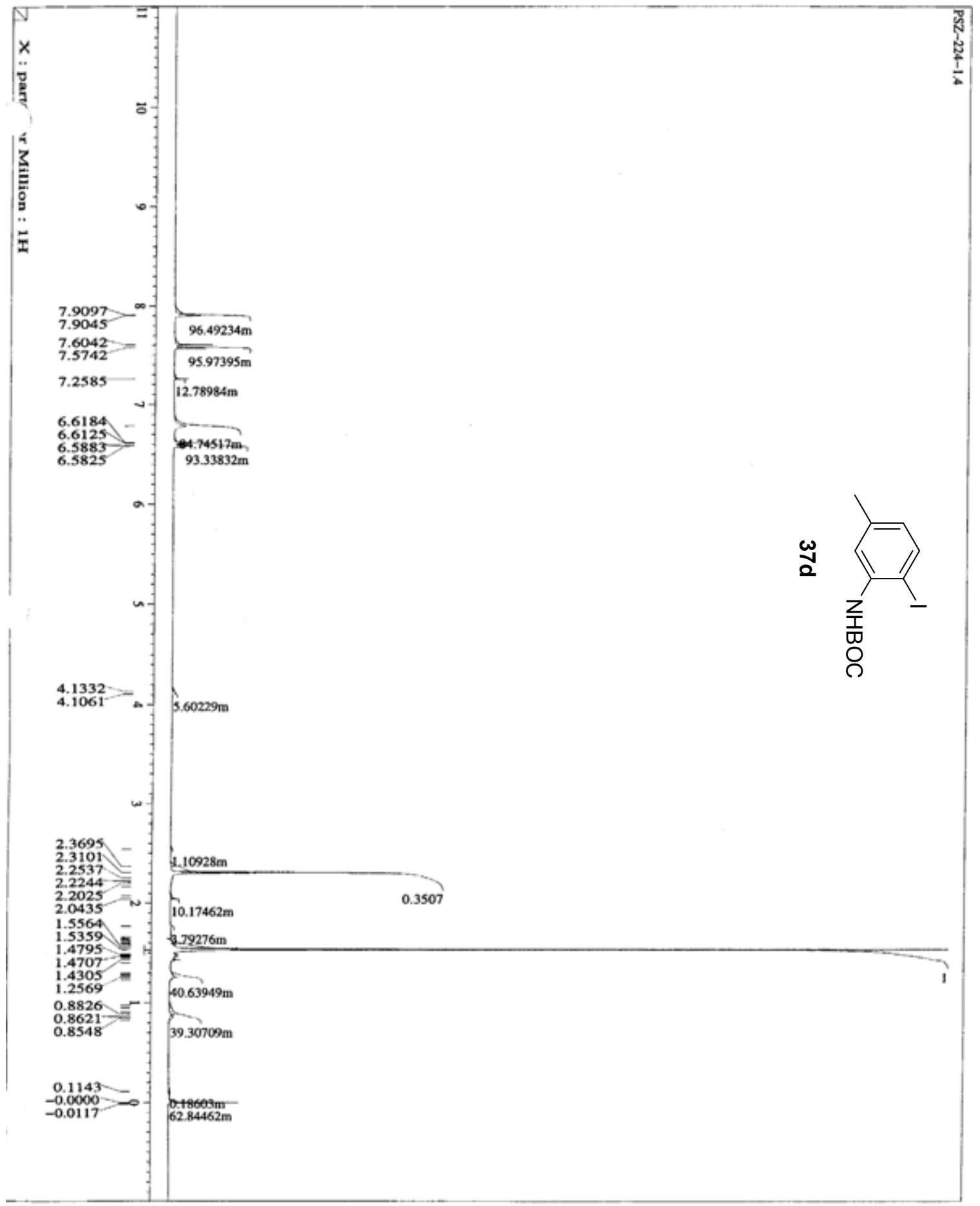

Figure 8: ${ }^{1} \mathrm{H}$ Spectrum of (2-lodo-5-methylphenyl)-carbamic acid 1,1dimethylethyl ester $\mathbf{3 7 d}$ 


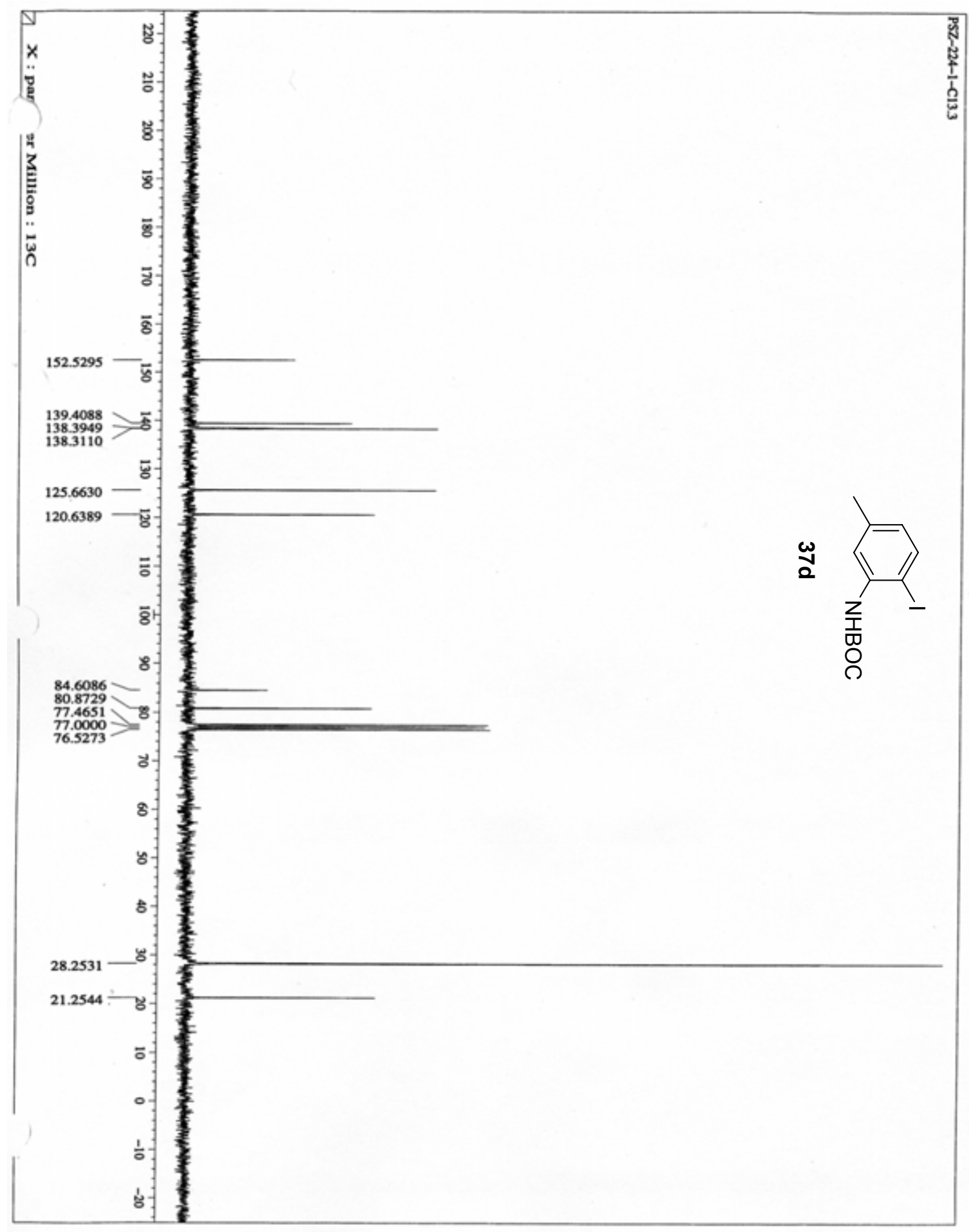

Figure 9: ${ }^{13} \mathrm{C}$ Spectrum of (2-lodo-5-methylphenyl)-carbamic acid 1,1dimethylethyl ester $\mathbf{3 7 d}$ 


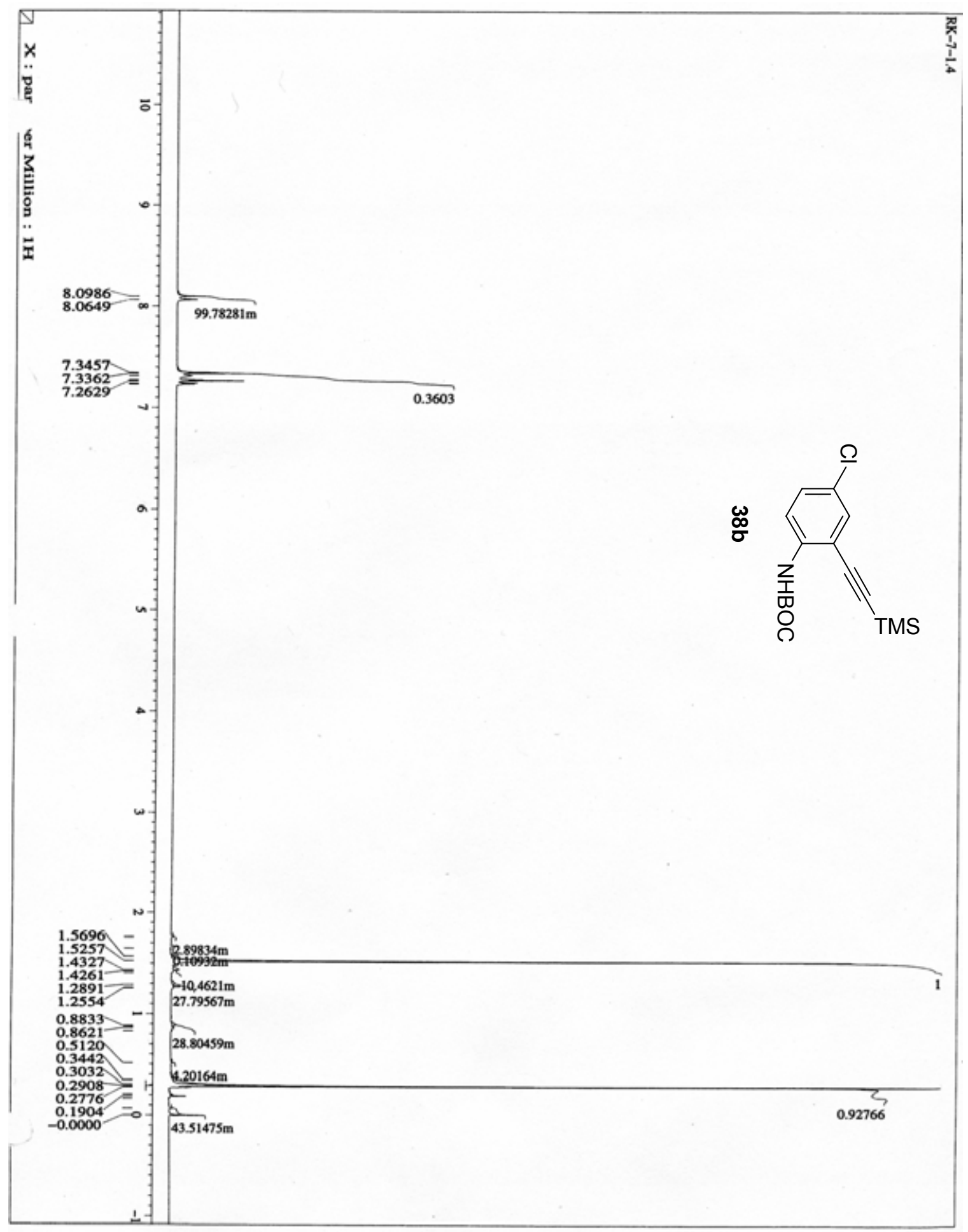

Figure 10: ${ }^{1} \mathrm{H}$ Spectrum of (4-Chloro-2-(trimethylsilylethynyl)phenyl)-carbamic acid 1,1-dimethylethyl ester $\mathbf{3 8 b}$ 


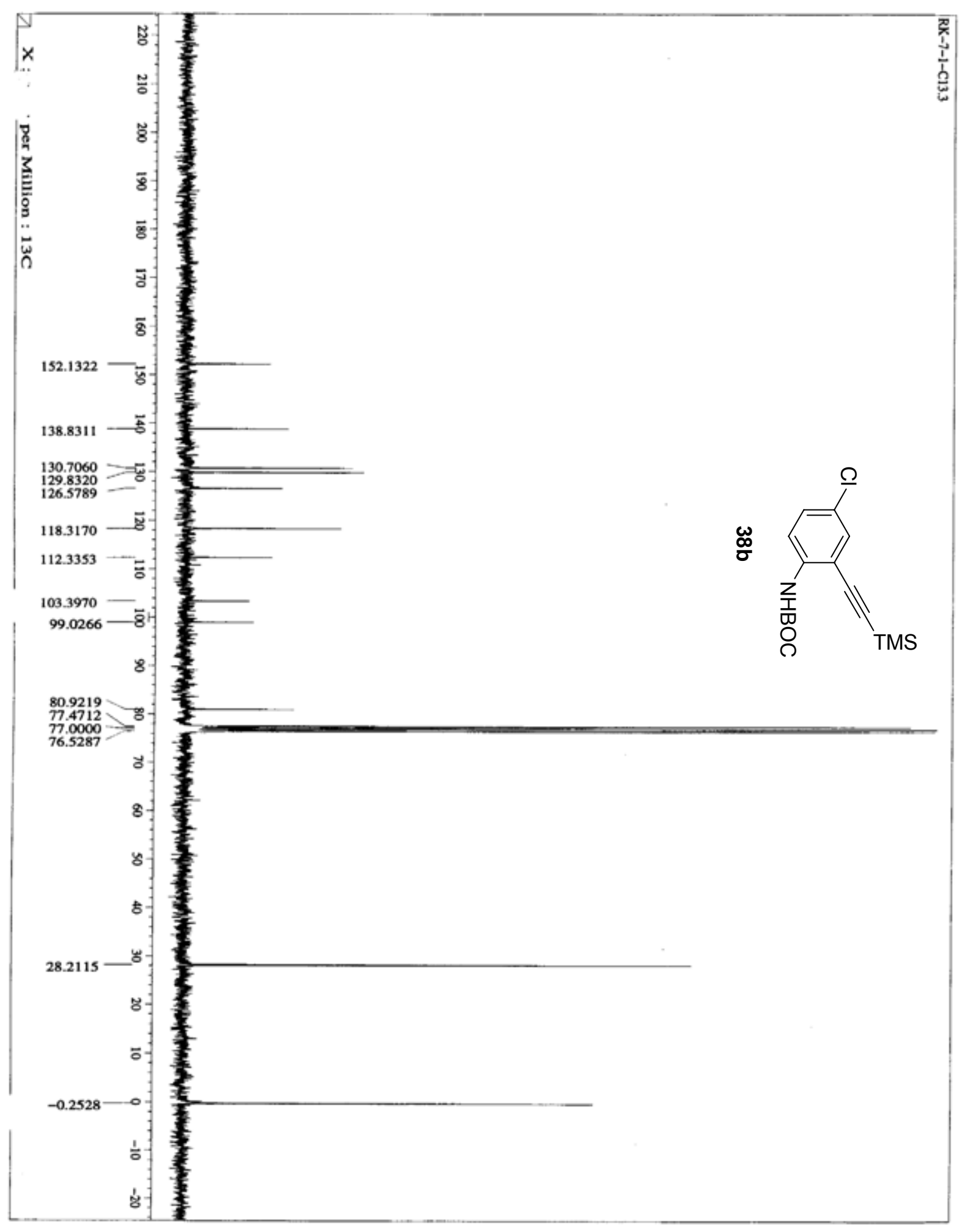

Figure $11:{ }^{13} \mathrm{C}$ Spectrum of (4-Chloro-2-(trimethylsilylethynyl)phenyl)-carbamic acid 1,1-dimethylethyl ester $\mathbf{3 8 b}$ 


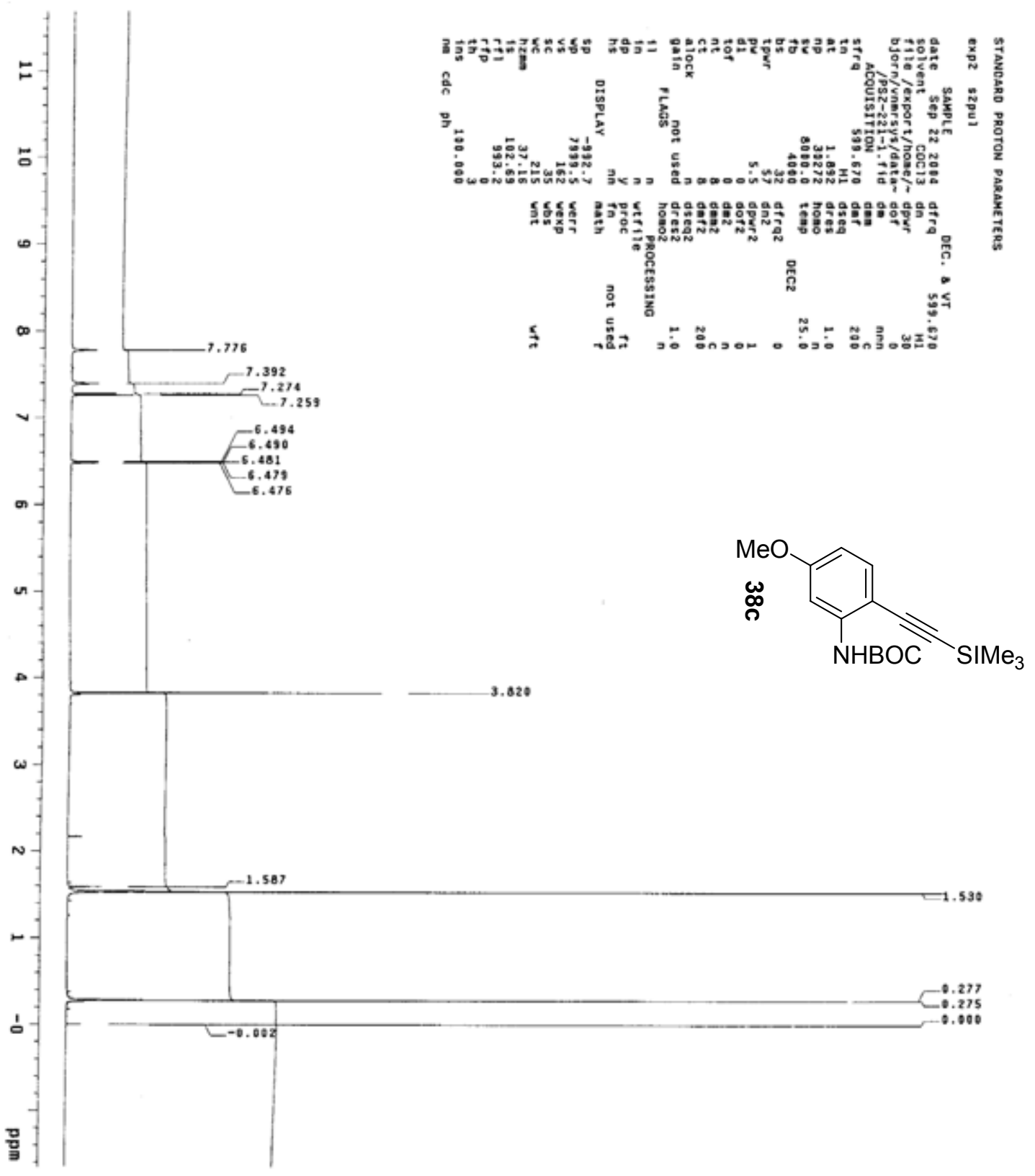

Figure 12: ${ }^{1} \mathrm{H}$ Spectrum of (5-Methoxy-2-trimethylsilylethynylphenyl)-carbamic acid 1,1-dimethylethyl ester 38c 


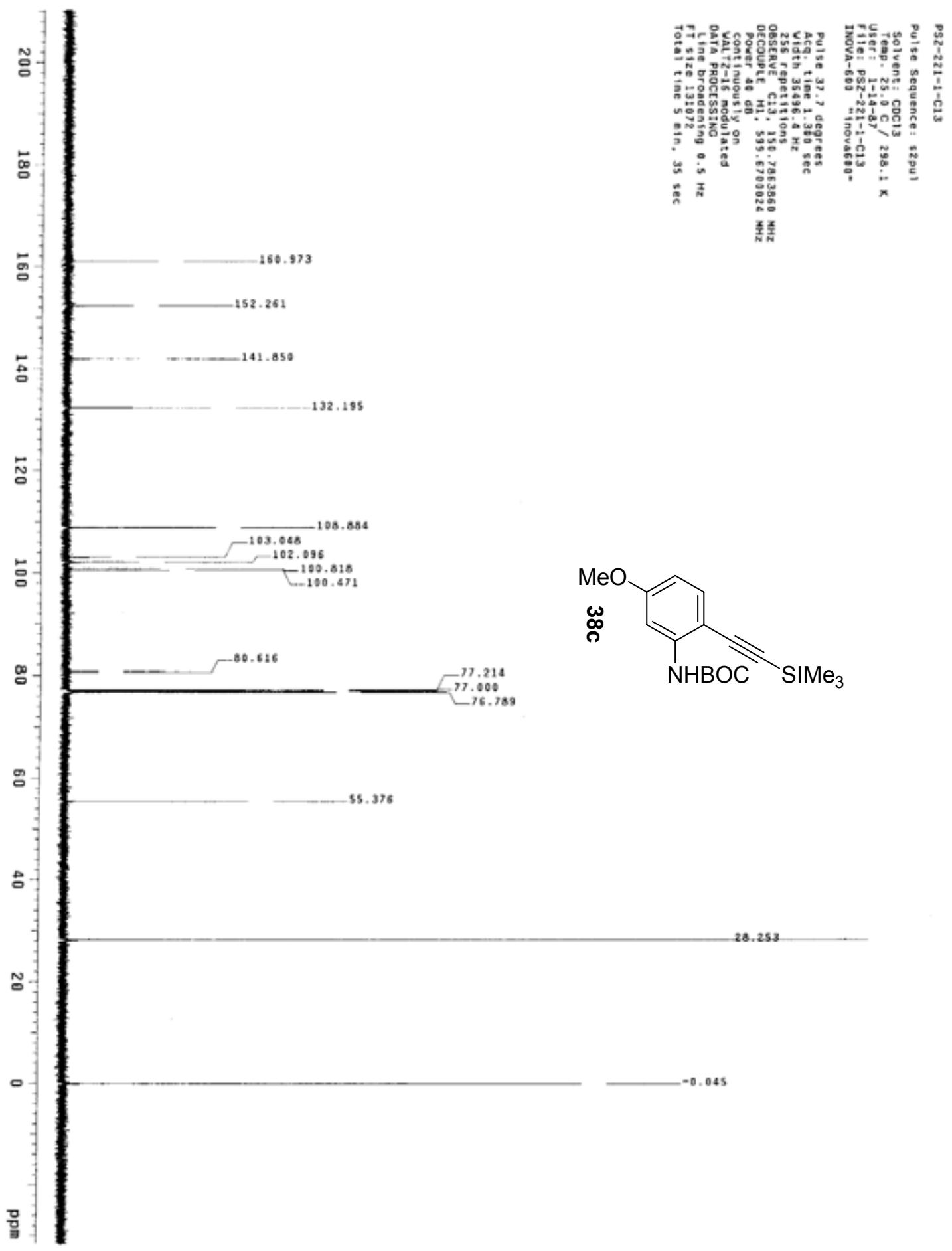

Figure 13: ${ }^{13} \mathrm{C}$ Spectrum of (5-Methoxy-2-trimethylsilylethynylphenyl)-carbamic acid 1,1-dimethylethyl ester 38c 


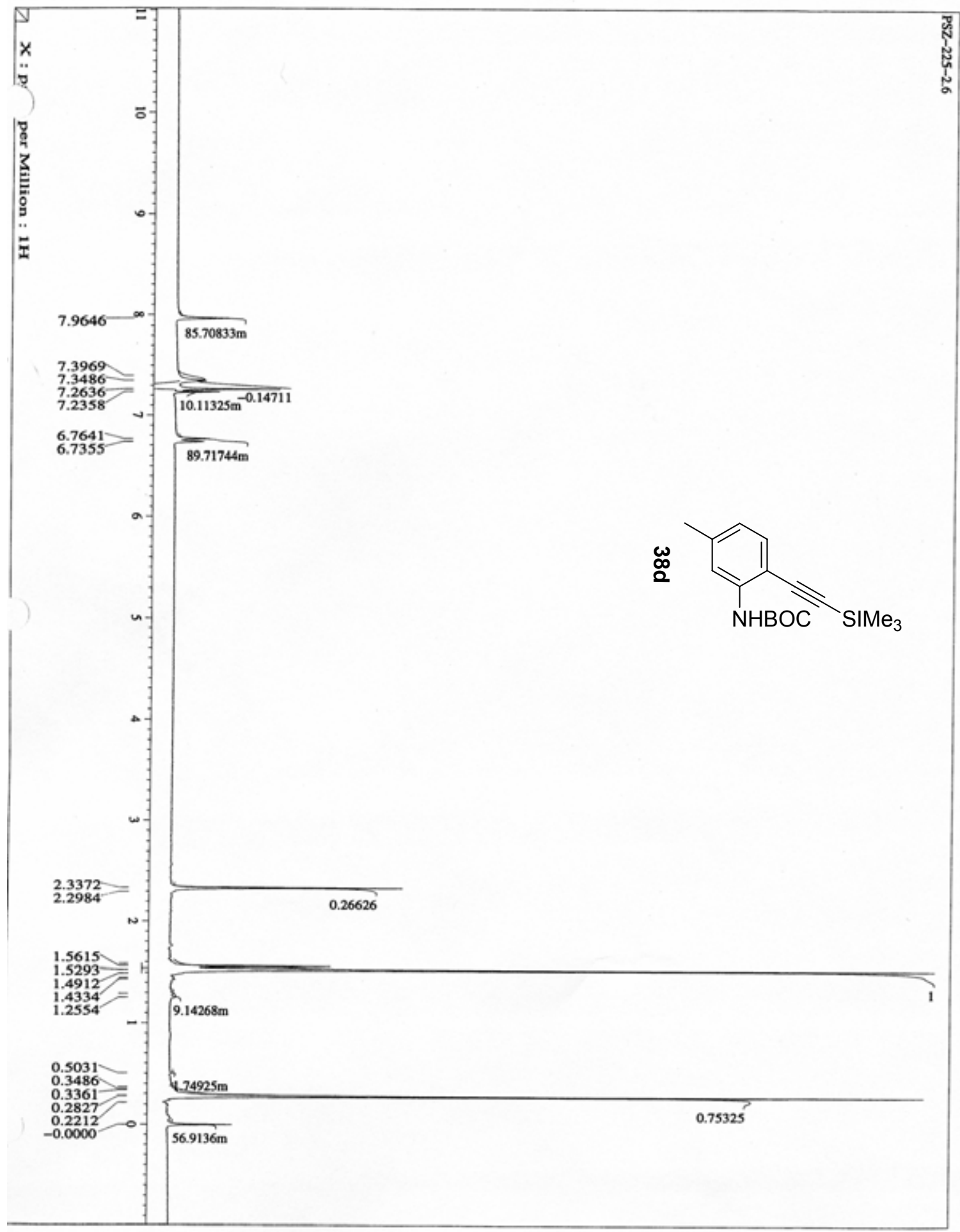

Figure 14: ${ }^{1} \mathrm{H}$ Spectrum of (5-Methyl-2-trimethylsilylethynylphenyl)-carbamic acid 1,1-dimethylethyl ester 38d 


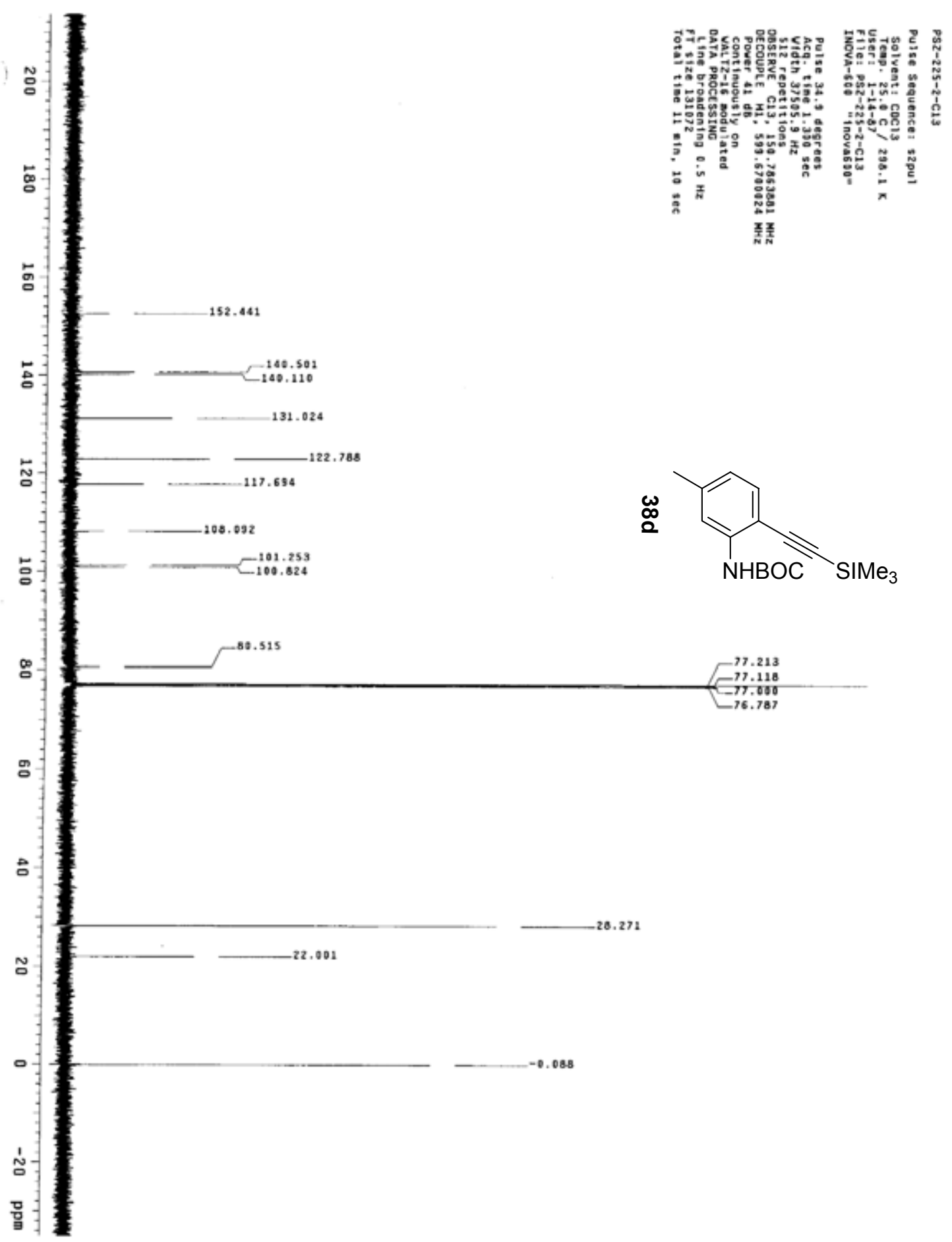

Figure 15: ${ }^{13} \mathrm{C}$ Spectrum of (5-Methyl-2-trimethylsilylethynylphenyl)-carbamic acid 1,1-dimethylethyl ester $\mathbf{3 8 d}$ 


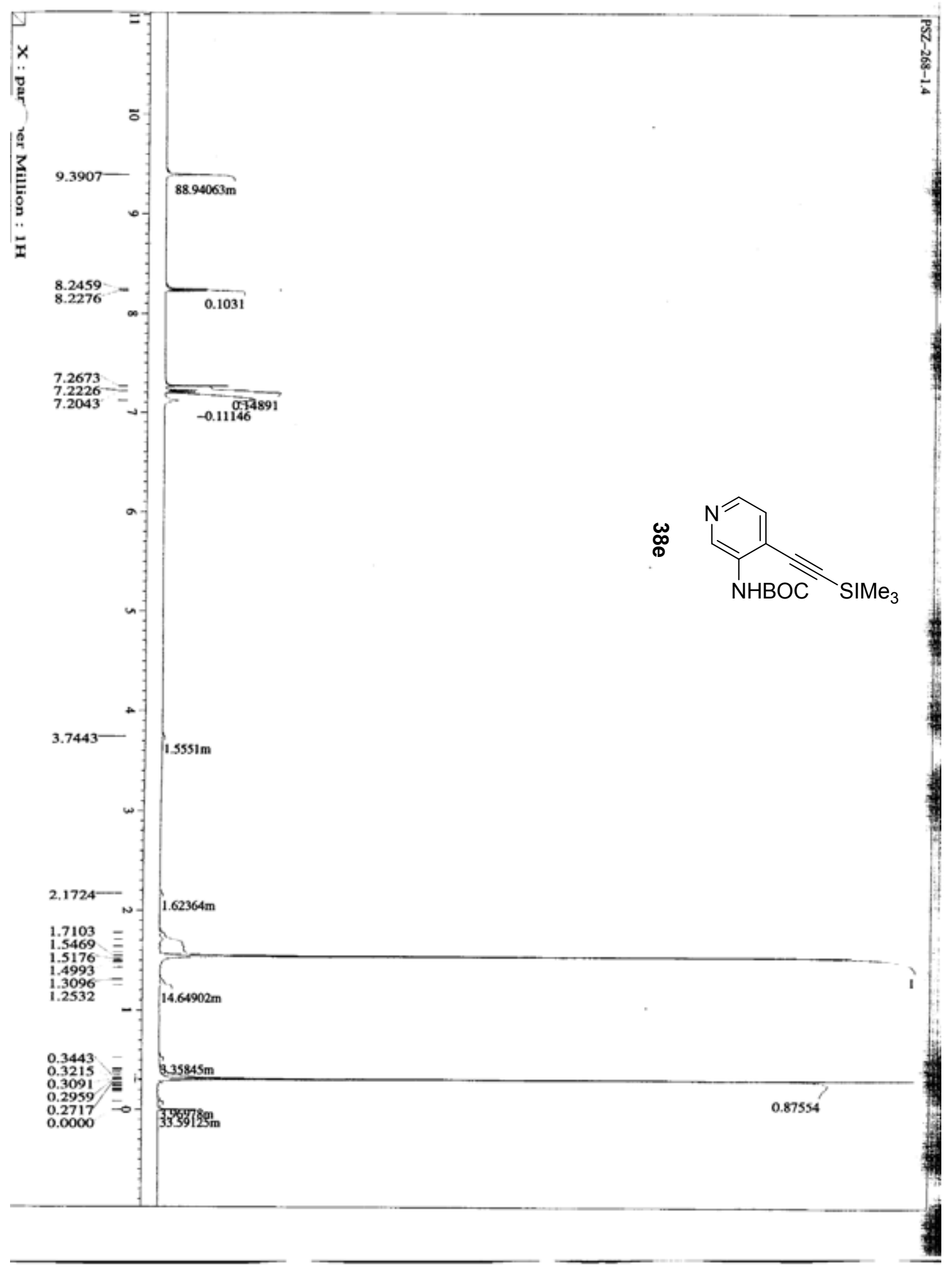

Figure 16: ${ }^{1} \mathrm{H}$ Spectrum of (4-trimethylsilylethynyl-3-pyridinyl)-carbamic acid 1,1dimethylethyl ester 38e 


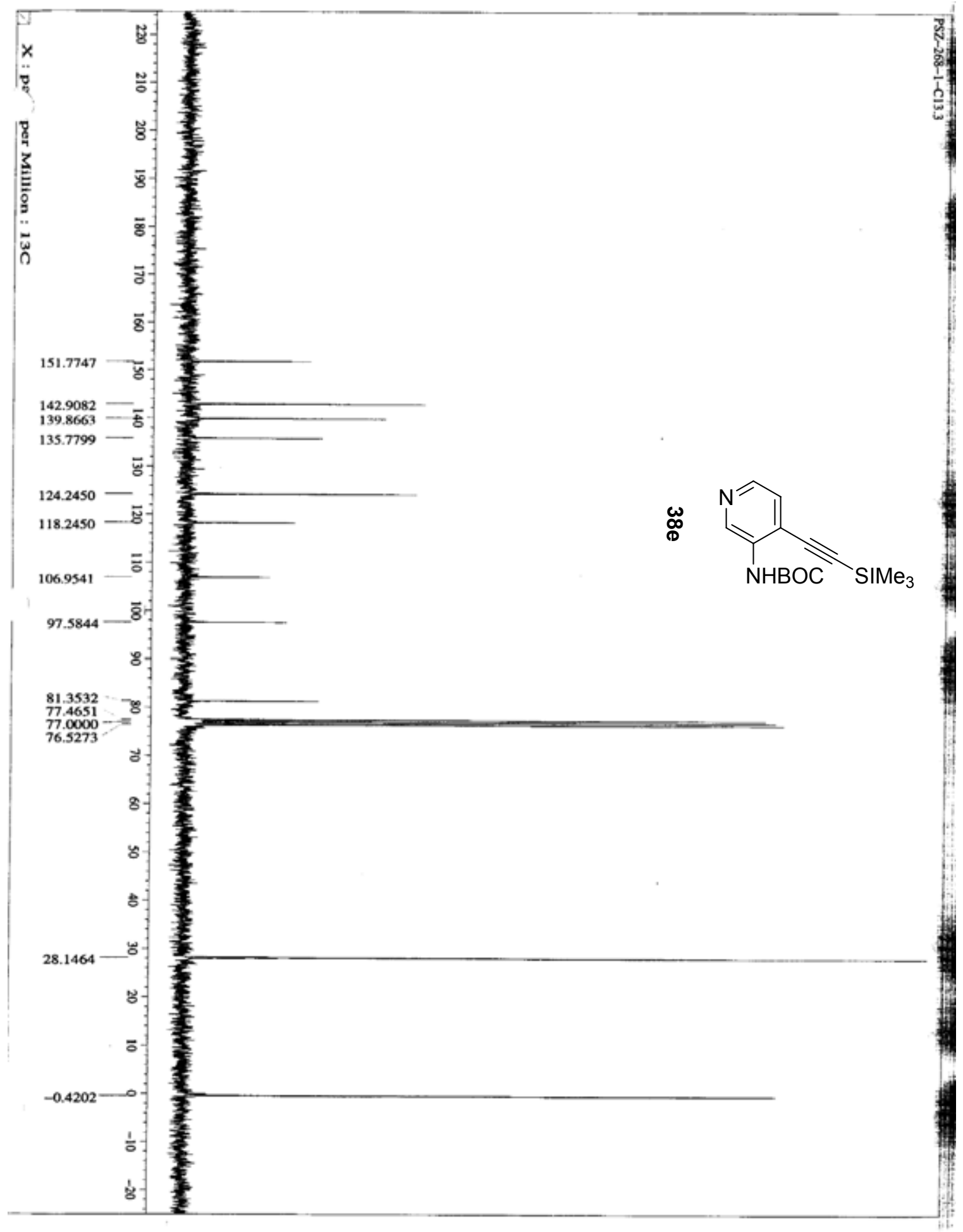

Figure $17:{ }^{13} \mathrm{C}$ Spectrum of (4-trimethylsilylethynyl-3-pyridinyl)-carbamic acid 1,1dimethylethyl ester $\mathbf{3 8 e}$ 


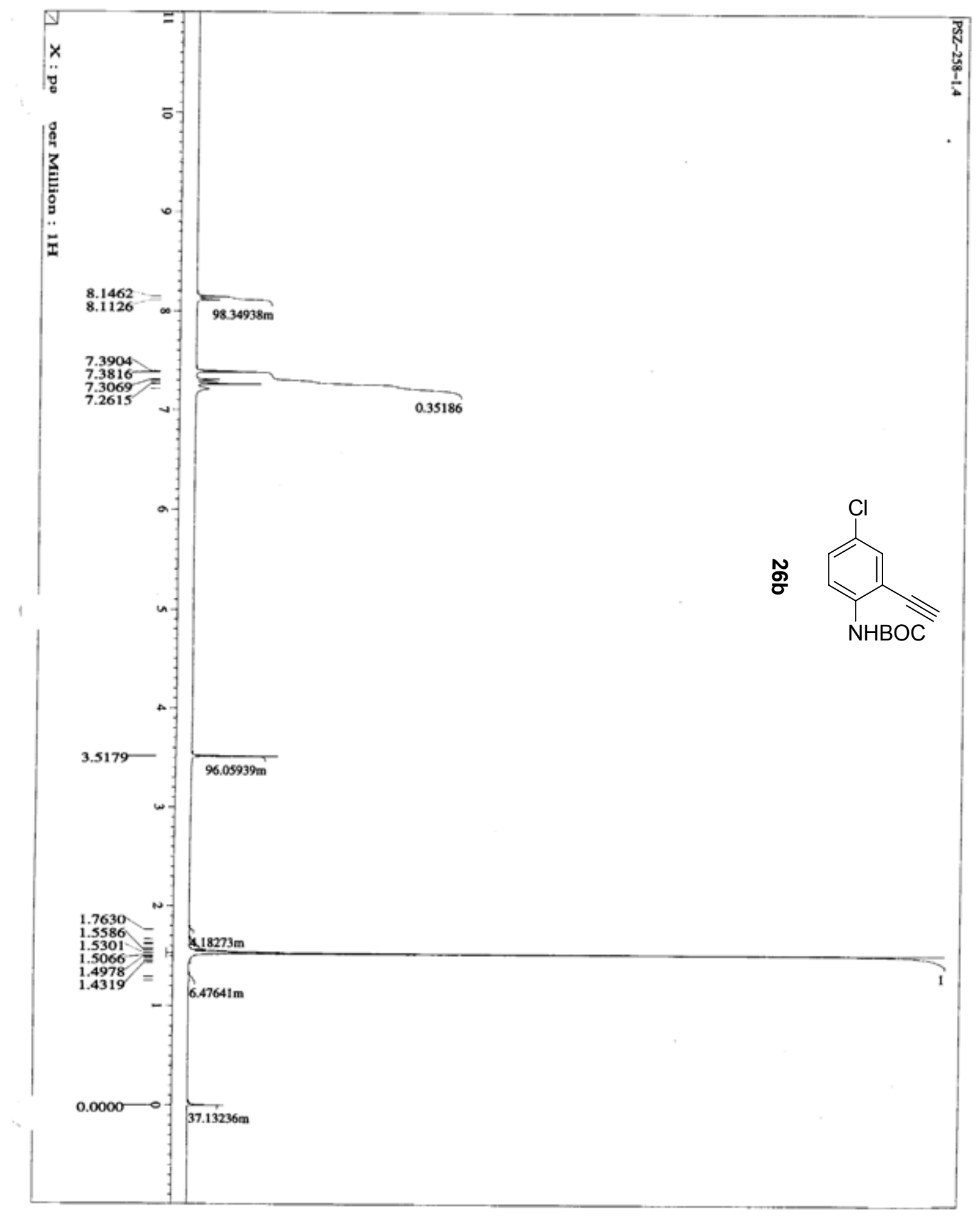

Figure 18: ${ }^{1} \mathrm{H}$ Spectrum of (4-Chloro-2-ethynylphenyl)-carbamic acid 1,1dimethylethyl ester 26b 


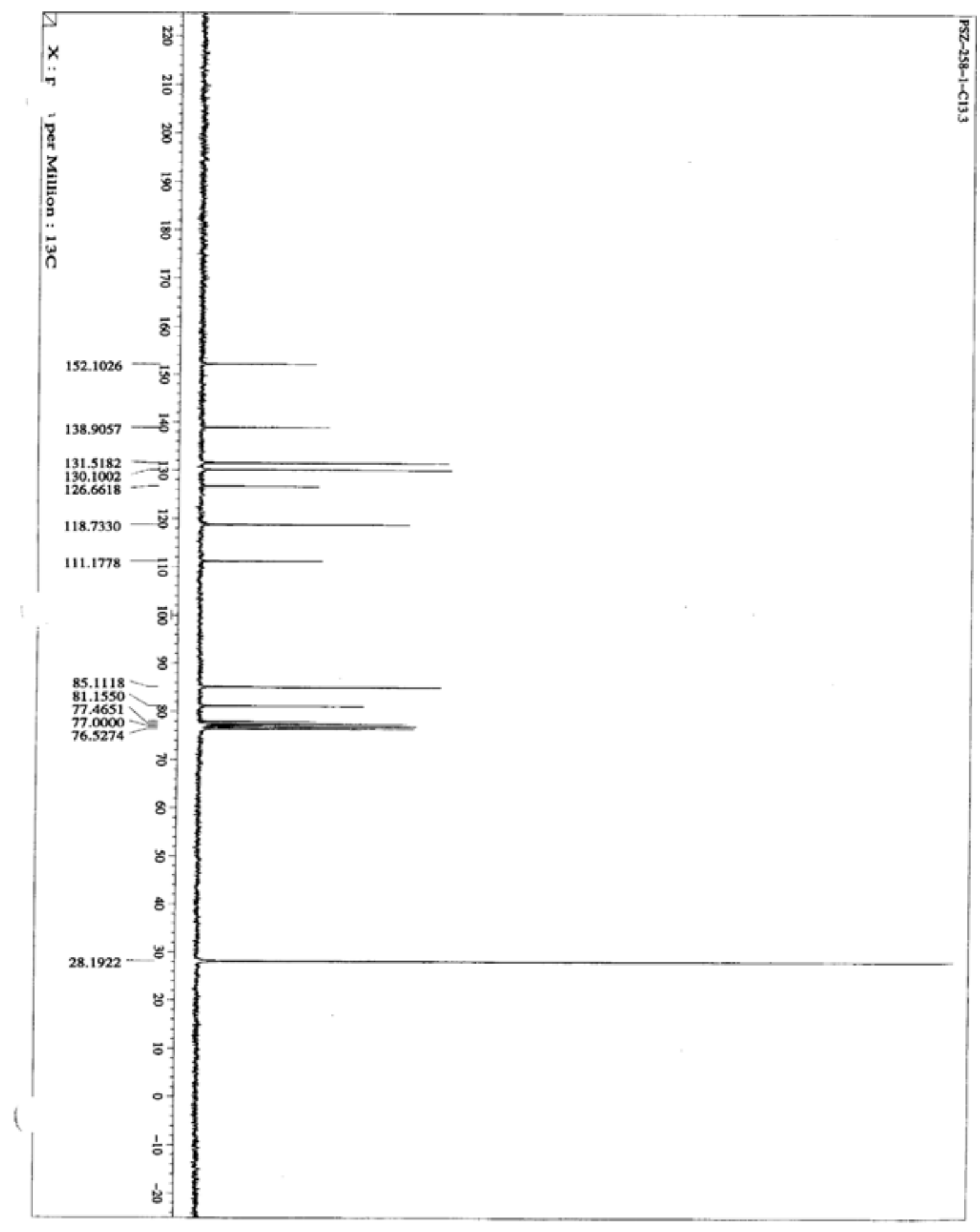

Figure 19: ${ }^{13} \mathrm{C}$ Spectrum of (4-Chloro-2-ethynylphenyl)-carbamic acid 1,1dimethylethyl ester 26b 


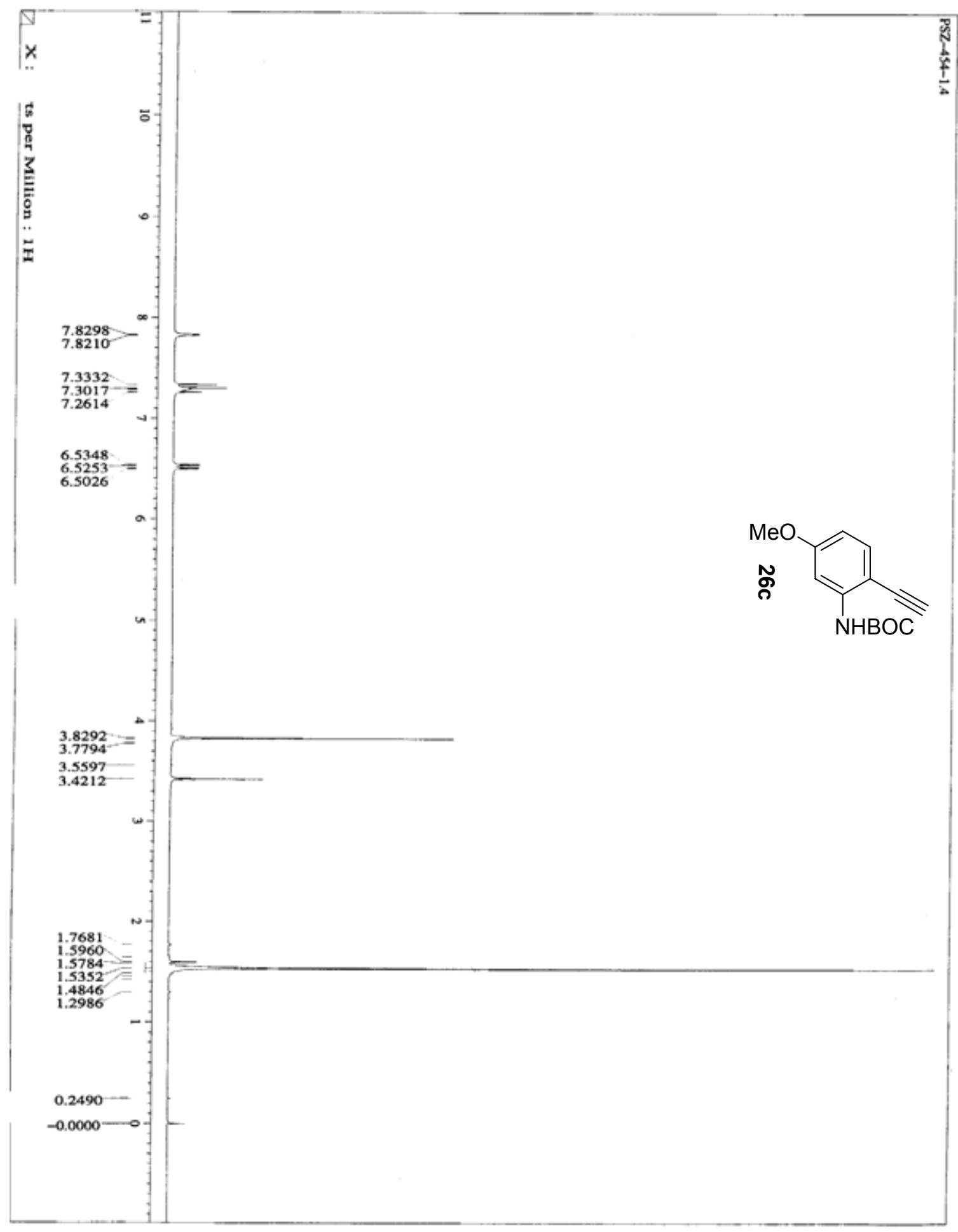

Figure 20: ${ }^{1} \mathrm{H}$ Spectrum of (2-Ethynyl-5-methoxyphenyl)-carbamic acid 1,1dimethylethyl ester 26c 


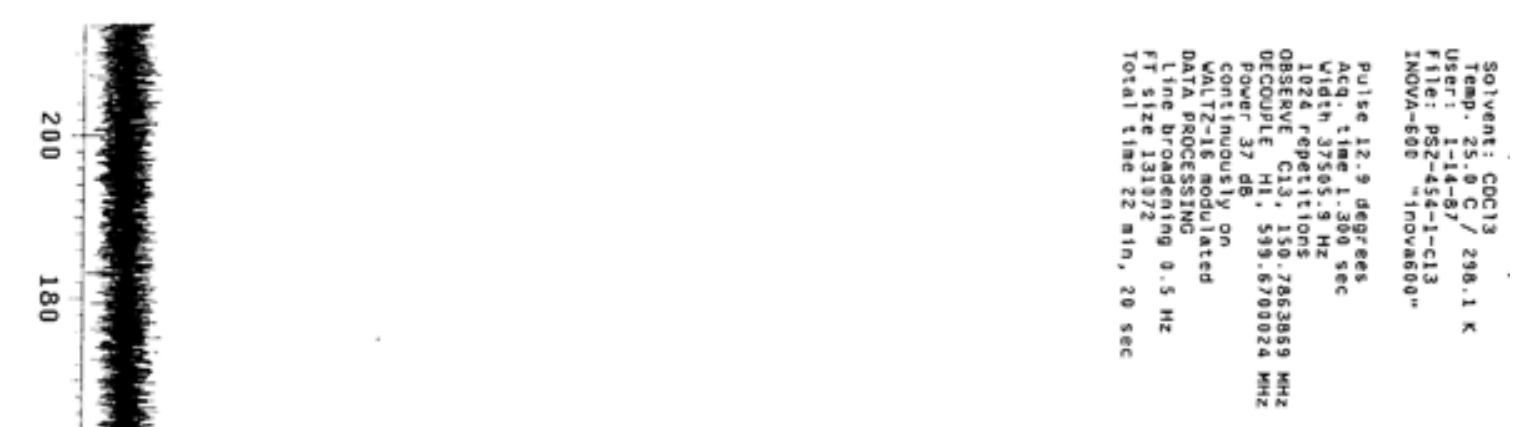
$-133.111$

$\stackrel{n}{\circ}$

$\stackrel{\infty}{\circ}$

:

它

N.

.141 .848

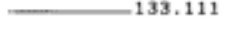

$-109.056$

เ

102.44
-101.841
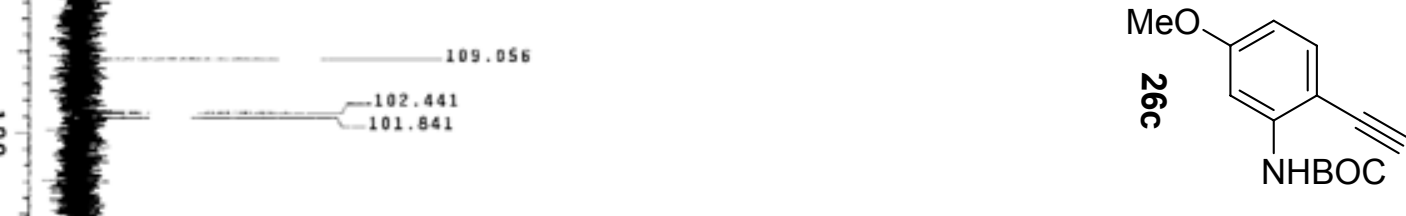

‥

$\circ$

$\stackrel{1}{\mathfrak{d}}$

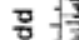

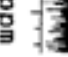

Figure 21: ${ }^{13} \mathrm{C}$ Spectrum of (2-Ethynyl-5-methoxyphenyl)-carbamic acid 1,1dimethylethyl ester 26c 


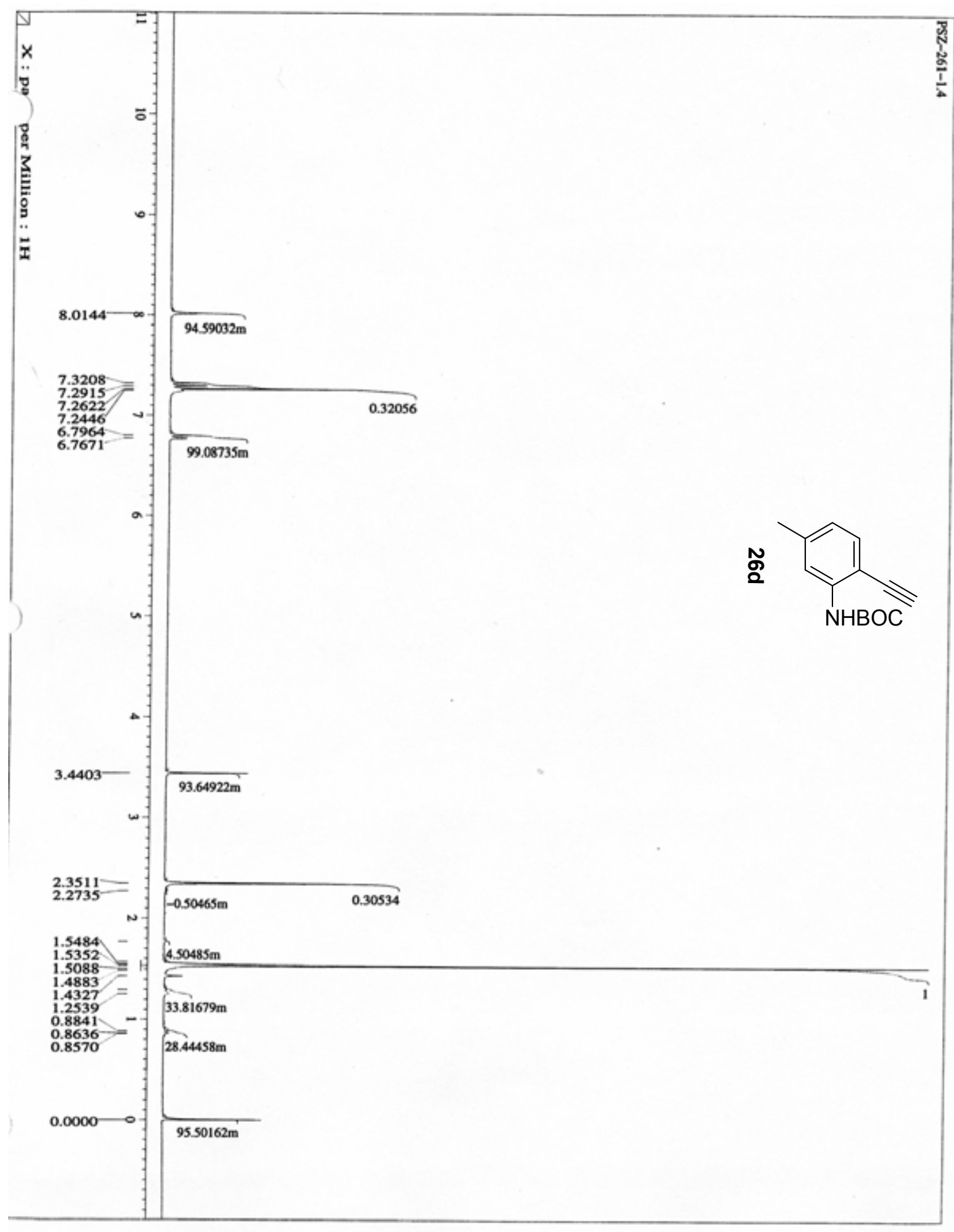

Figure 22: ${ }^{1} \mathrm{H}$ Spectrum of (2-Ethynyl-5-methylphenyl)-carbamic acid 1,1dimethylethyl ester 26d 


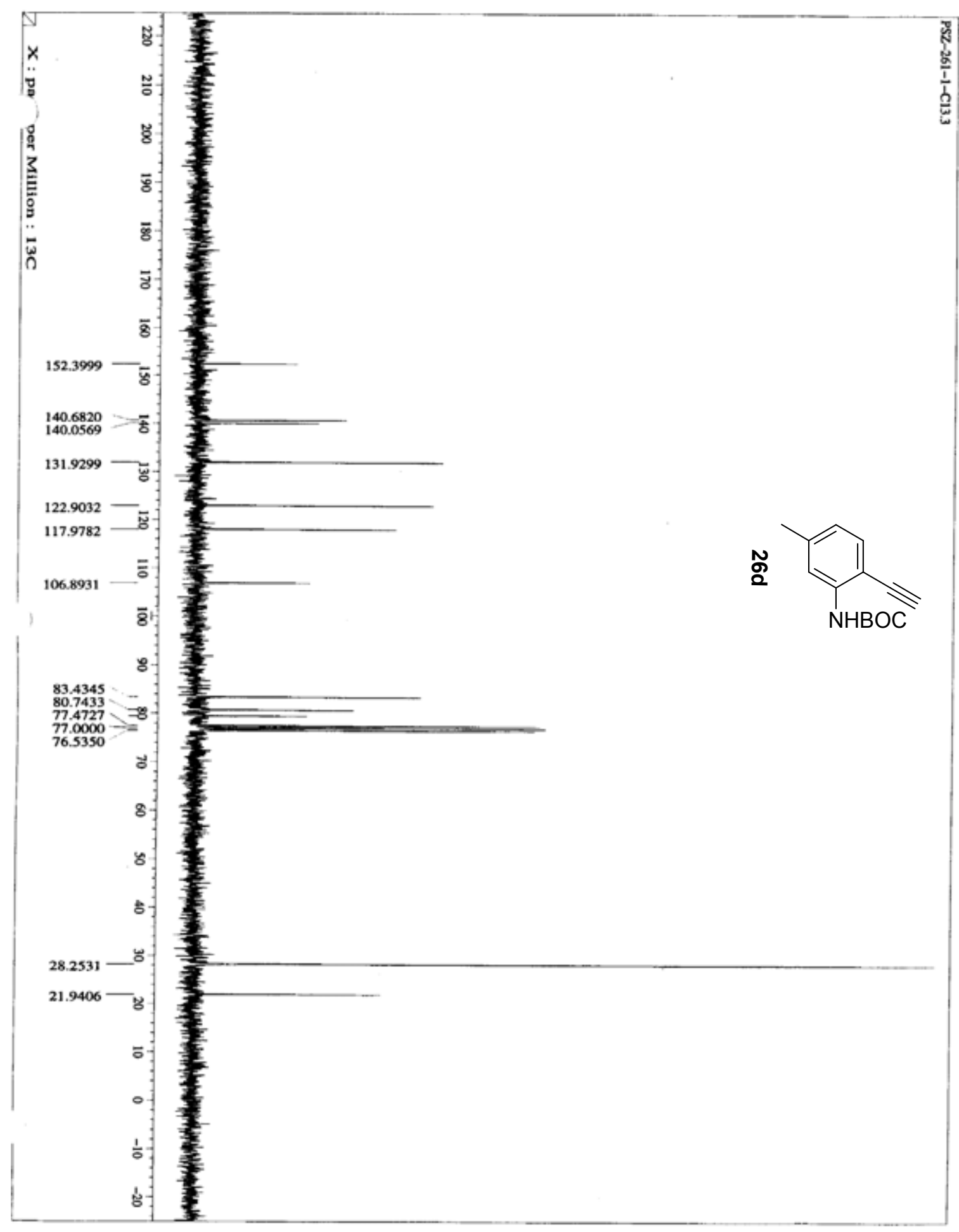

Figure 23: ${ }^{13} \mathrm{C}$ Spectrum of (2-Ethynyl-5-methylphenyl)-carbamic acid 1,1dimethylethyl ester $\mathbf{2 6 d}$ 


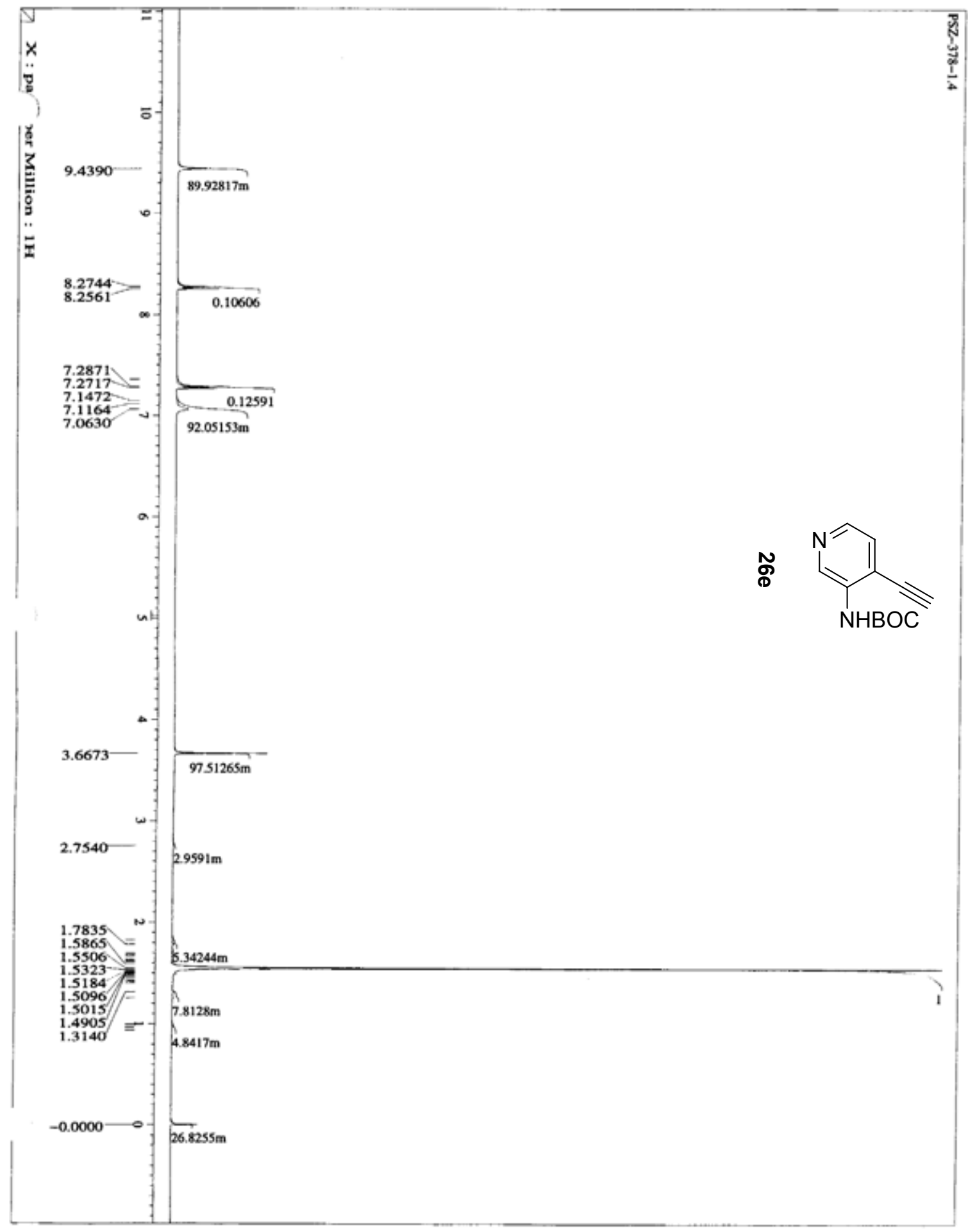

Figure 24: ${ }^{1} \mathrm{H}$ Spectrum of (4-Ethynyl-3-pyridinyl)-carbamic acid 1,1dimethylethyl ester 26e 


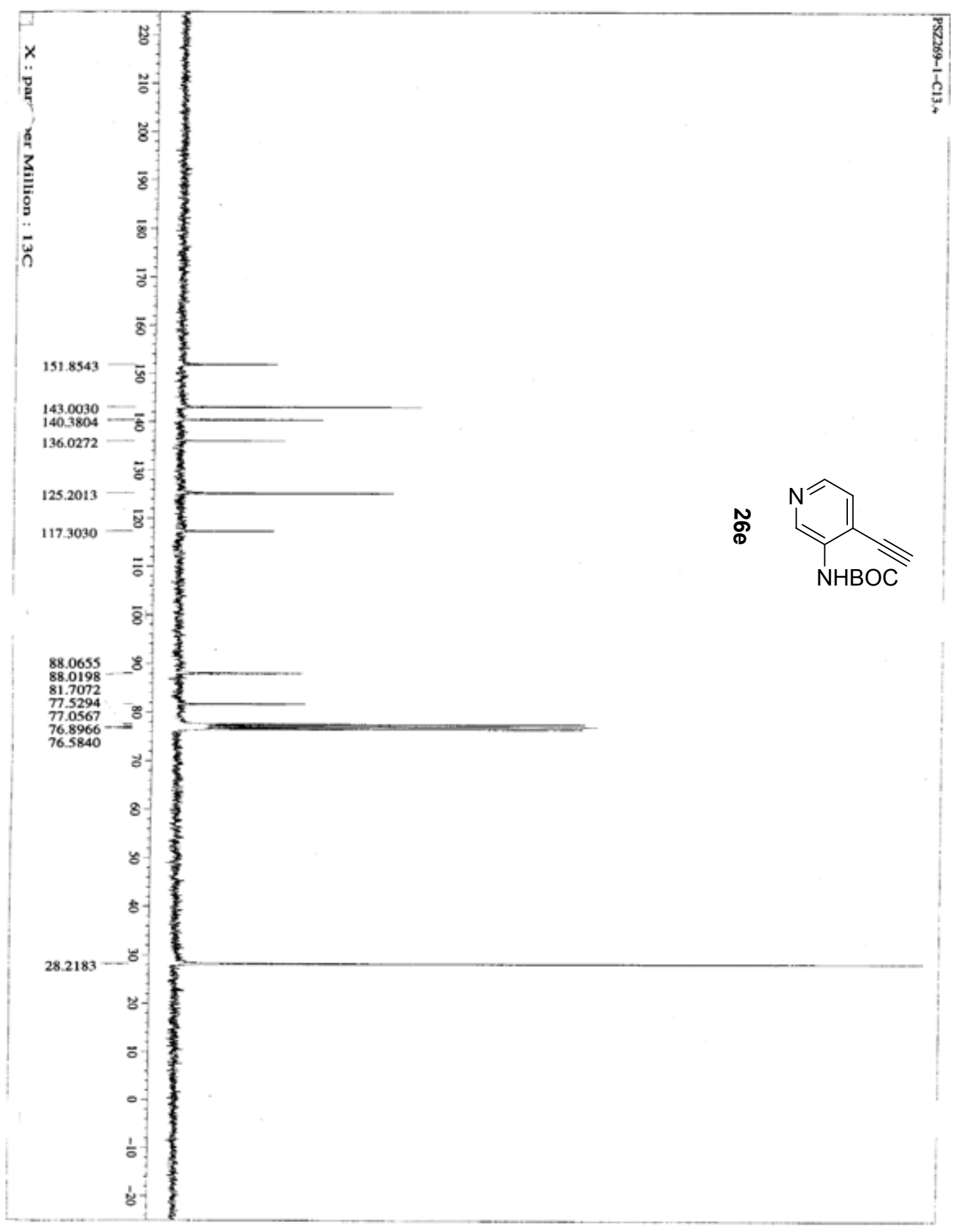

Figure $25:{ }^{13} \mathrm{C}$ Spectrum of (4-Ethynyl-3-pyridinyl)-carbamic acid 1,1dimethylethyl ester 26e 


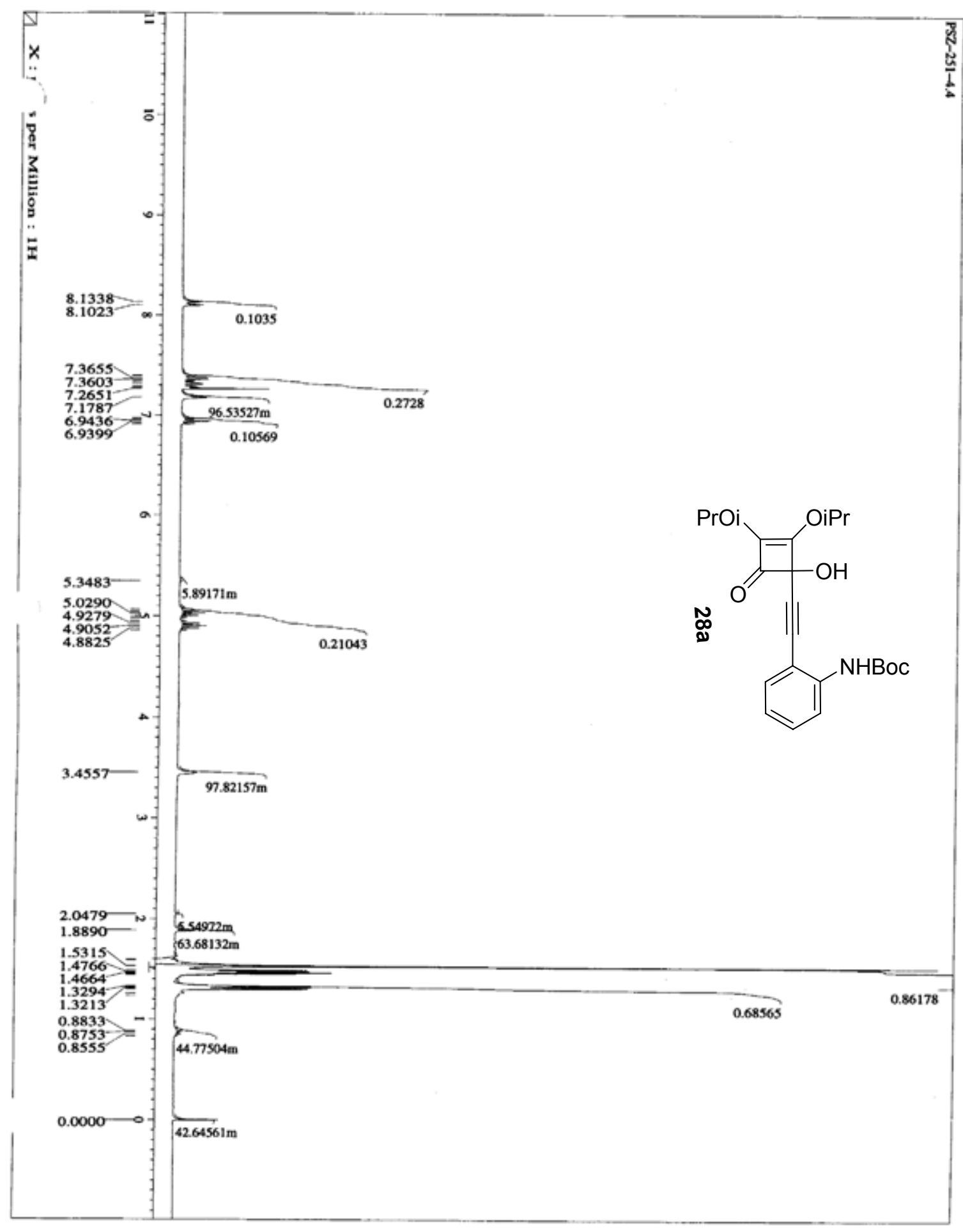

Figure 26: ${ }^{1} \mathrm{H}$ Spectrum of [2-(1-Hydroxy-2,3-bis(1-methylethoxy)-4-oxocyclobut-2-enylethynyl)phenyl]-carbamic acid 1,1-dimethylethyl ester 28a 


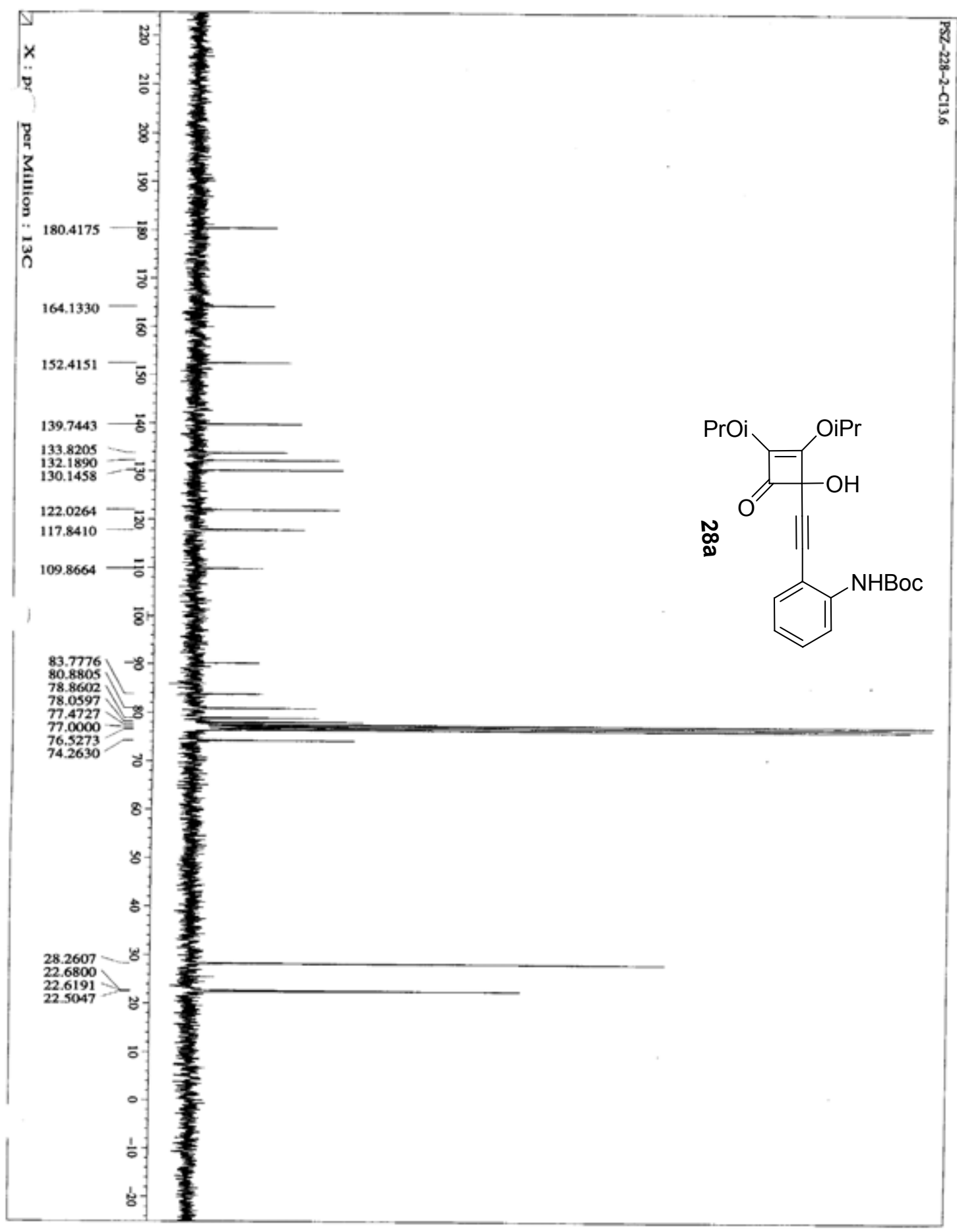

Figure 27: ${ }^{13} \mathrm{C}$ Spectrum of [2-(1-Hydroxy-2,3-bis(1-methylethoxy)-4-oxocyclobut-2-enylethynyl)phenyl]-carbamic acid 1,1-dimethylethyl ester 28a 


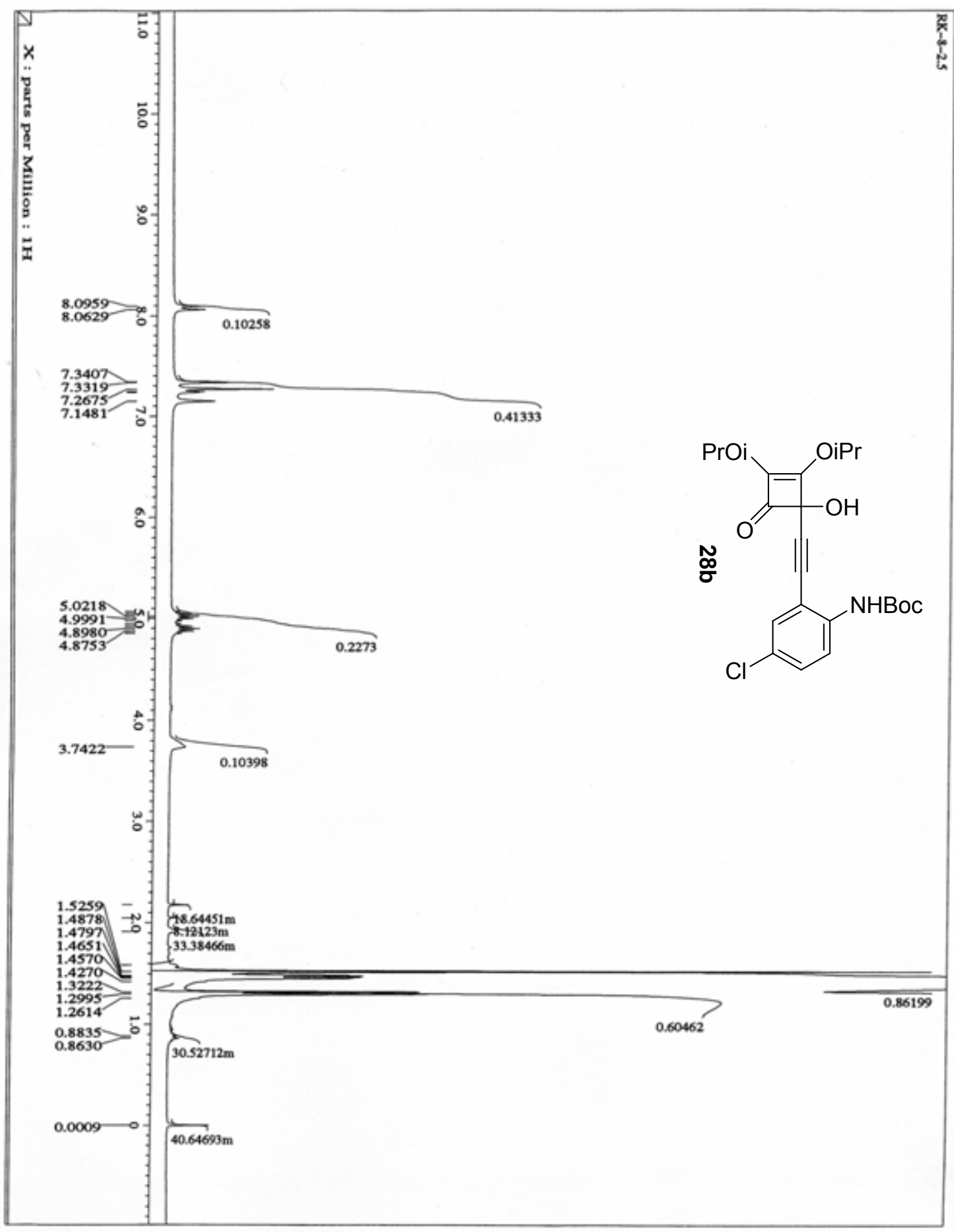

Figure 28: ${ }^{1} \mathrm{H}$ Spectrum of [4-Chloro-2-(1-hydroxy-2,3-di(1-methylethoxy)-4-oxocyclobut-2-enylethynyl)phenyl]-carbamic acid 1,1-dimethylethyl ester 28b 


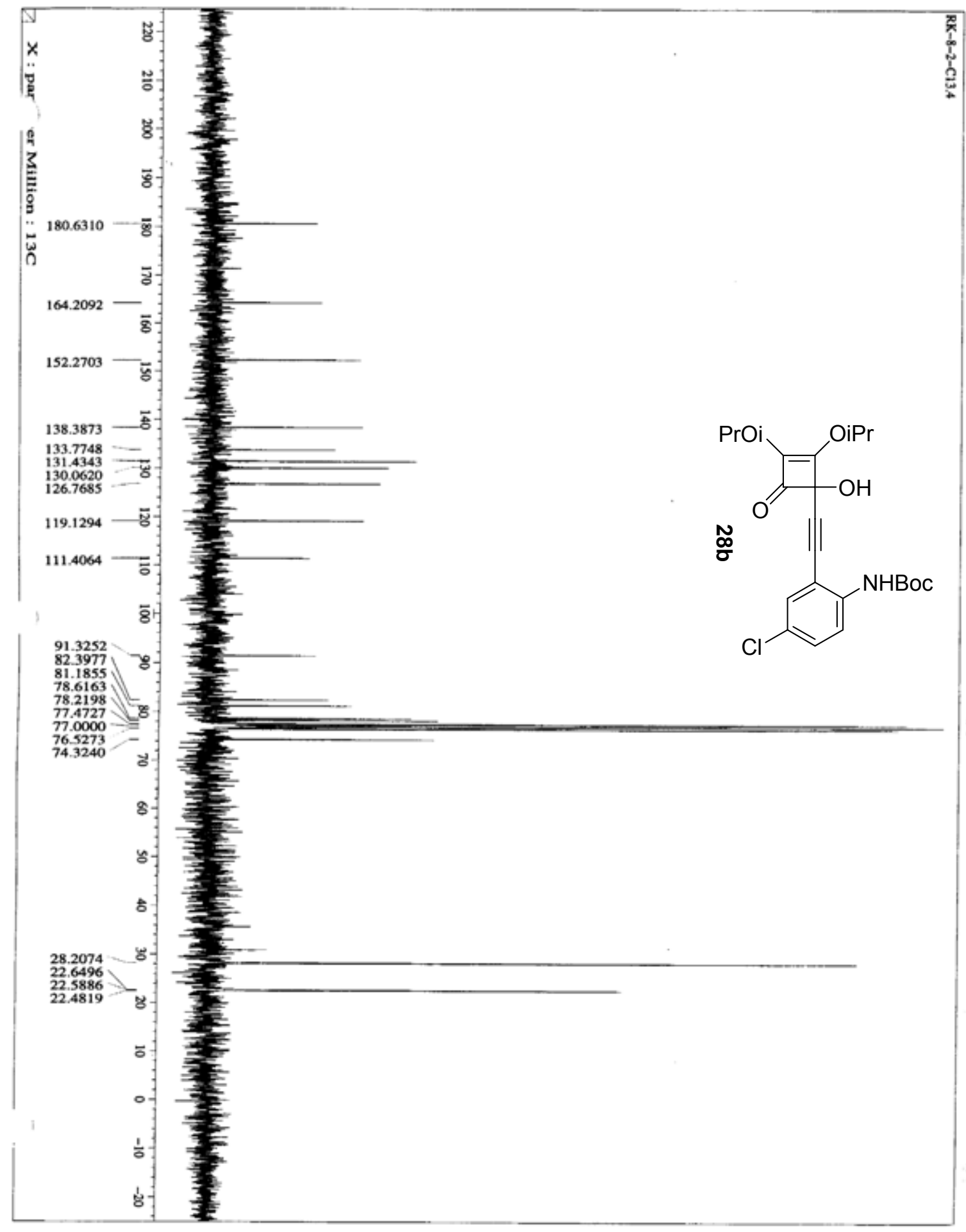

Figure $29:{ }^{13} \mathrm{C}$ Spectrum of [4-Chloro-2-(1-hydroxy-2,3-di(1-methylethoxy)-4-oxocyclobut-2-enylethynyl)phenyl]-carbamic acid 1,1-dimethylethyl ester $\mathbf{2 8 b}$ 


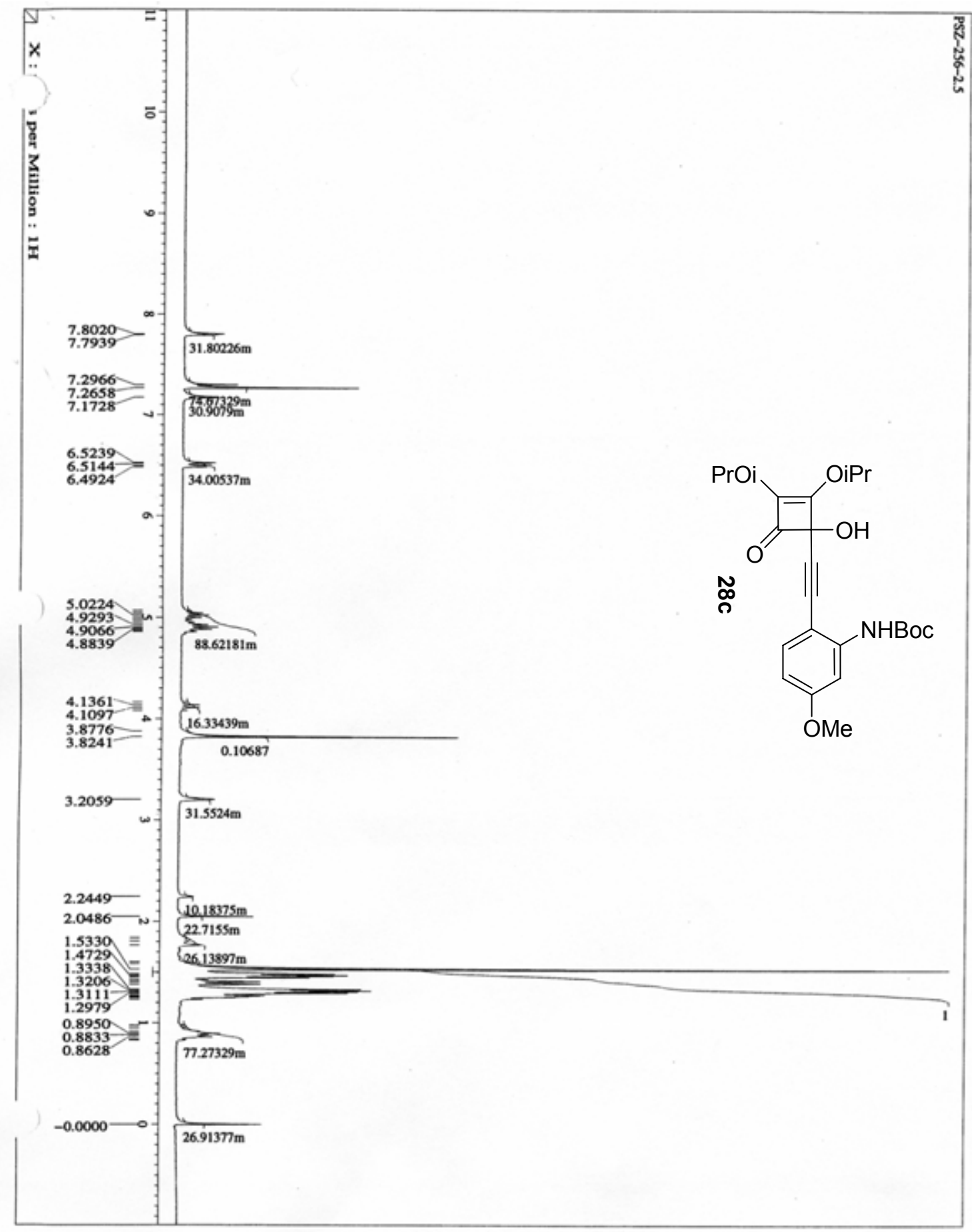

Figure 30: ${ }^{1} \mathrm{H}$ Spectrum of [2-(1-Hydroxy-2,3-di(1-methylethoxy)-4-oxo-cyclobut2-enylethynyl)-5-methoxyphenyl]-carbamic acid 1,1-dimethylethyl ester 28c and butyl addition product of diisopropyl squarate 


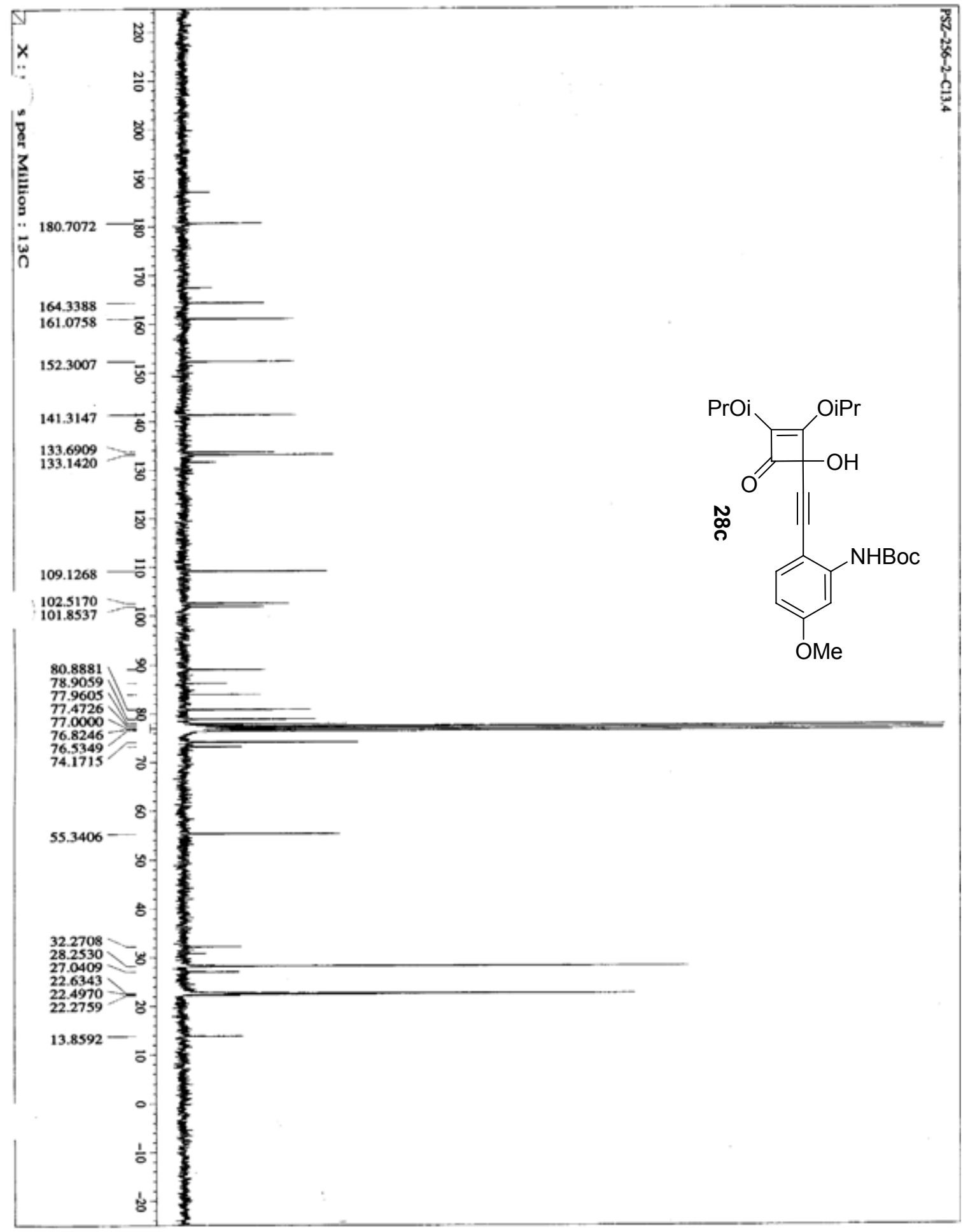

Figure 31: ${ }^{13} \mathrm{C}$ Spectrum of [2-(1-Hydroxy-2,3-di(1-methylethoxy)-4-oxo-cyclobut2-enylethynyl)-5-methoxyphenyl]-carbamic acid 1,1-dimethylethyl ester 28c and butyl addition product of diisopropyl squarate 


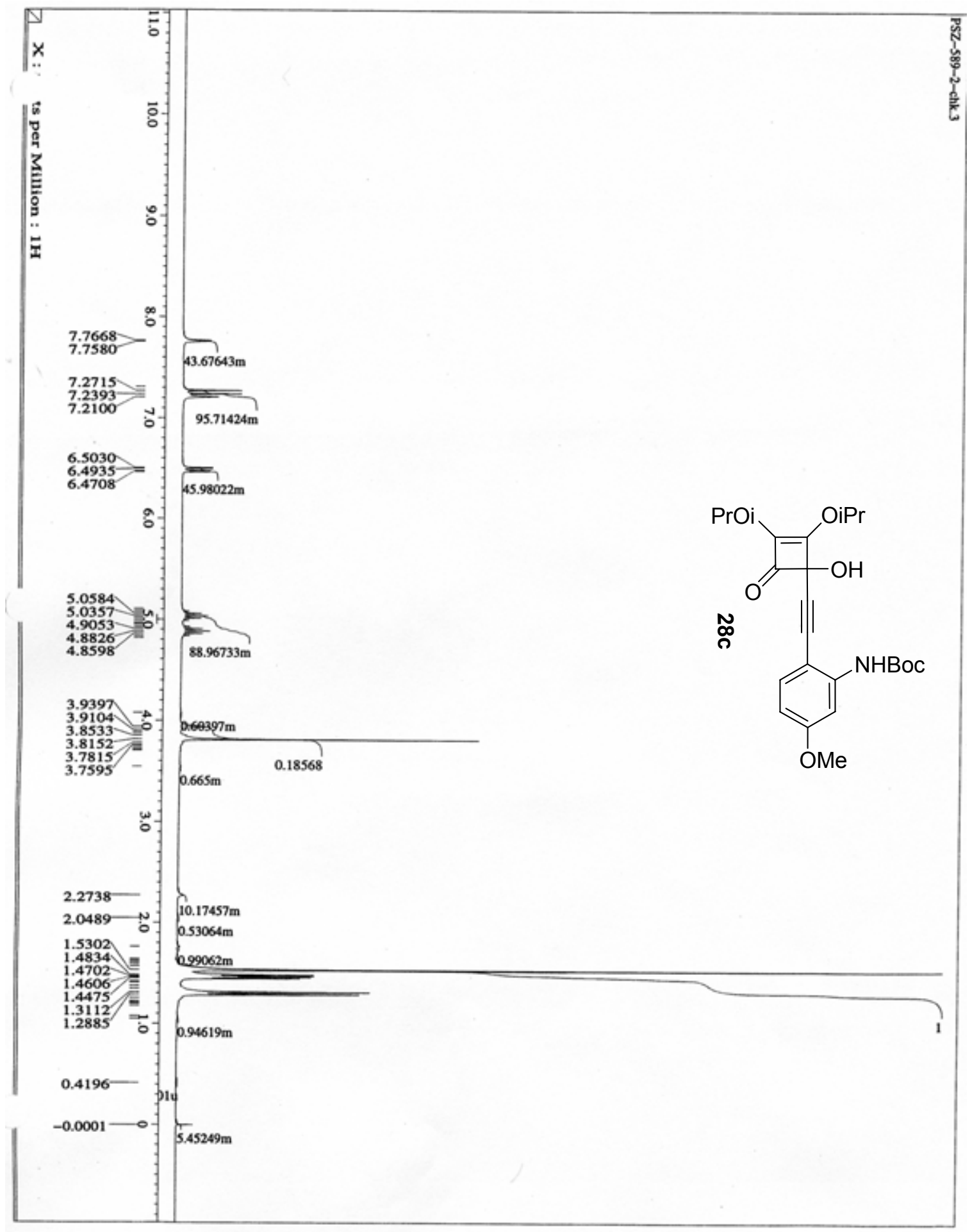

Figure 32: ${ }^{1} \mathrm{H}$ Spectrum of [2-(1-Hydroxy-2,3-di(1-methylethoxy)-4-oxo-cyclobut2-enylethynyl)-5-methoxyphenyl]-carbamic acid 1,1-dimethylethyl ester 28c 


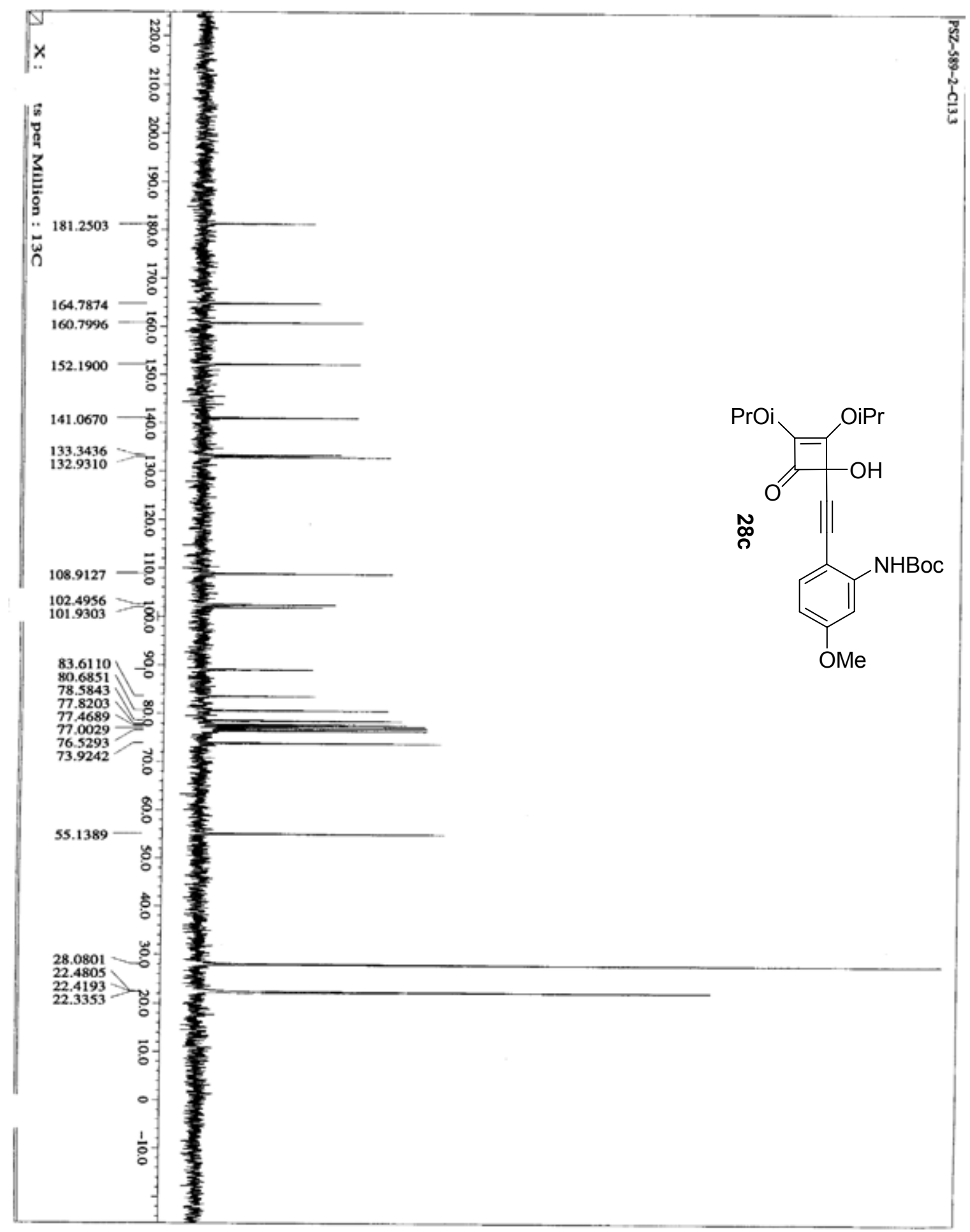

Figure 33: ${ }^{13} \mathrm{C}$ Spectrum of [2-(1-Hydroxy-2,3-di(1-methylethoxy)-4-oxo-cyclobut2-enylethynyl)-5-methoxyphenyl]-carbamic acid 1,1-dimethylethyl ester 28c 


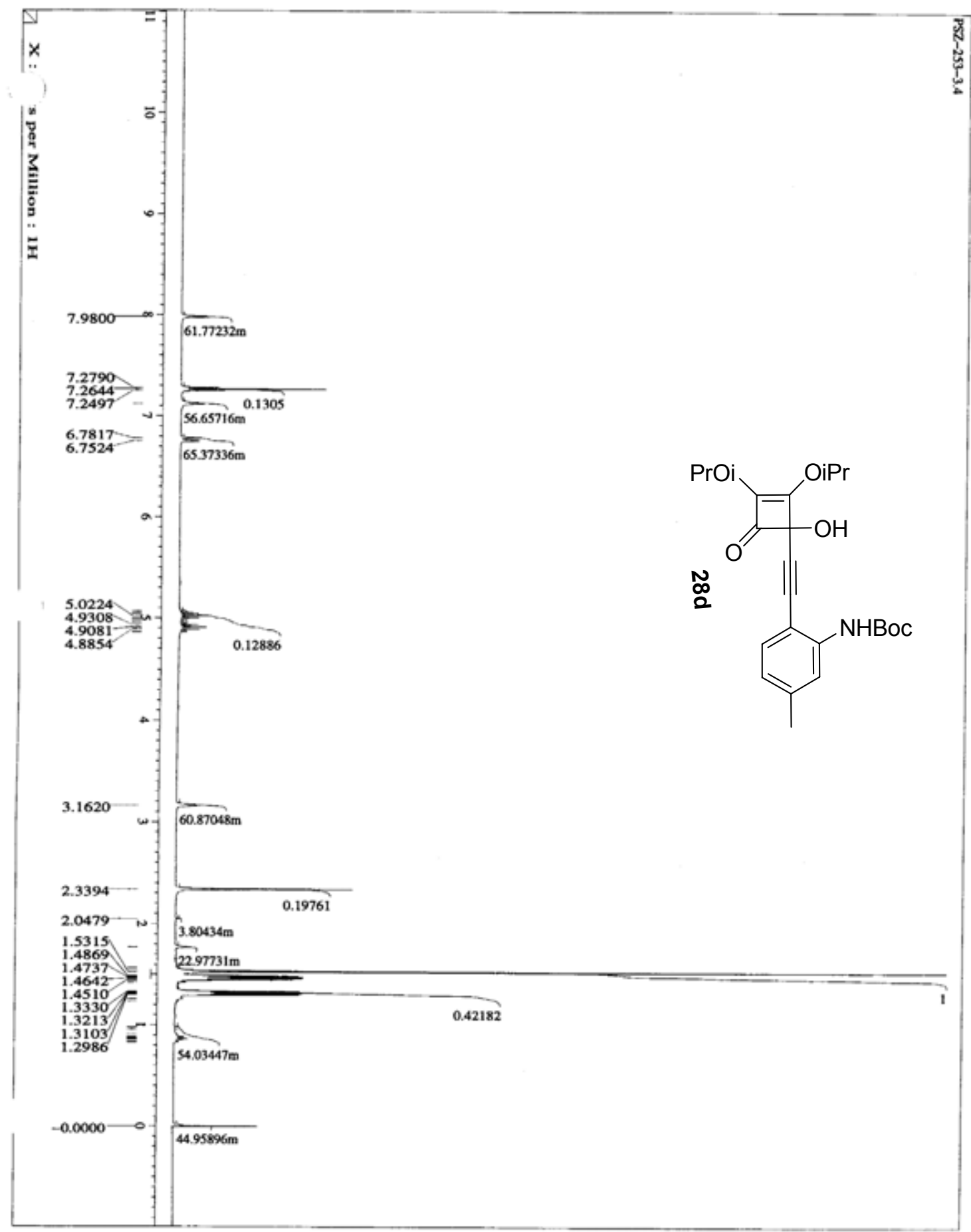

Figure 34: ${ }^{1} \mathrm{H}$ Spectrum of [2-(1-Hydroxy-2,3-di(1-methylethoxy)-4-oxo-cyclobut2-enylethynyl)-5-methylphenyl]-carbamic acid 1,1-dimethylethyl ester 28d 


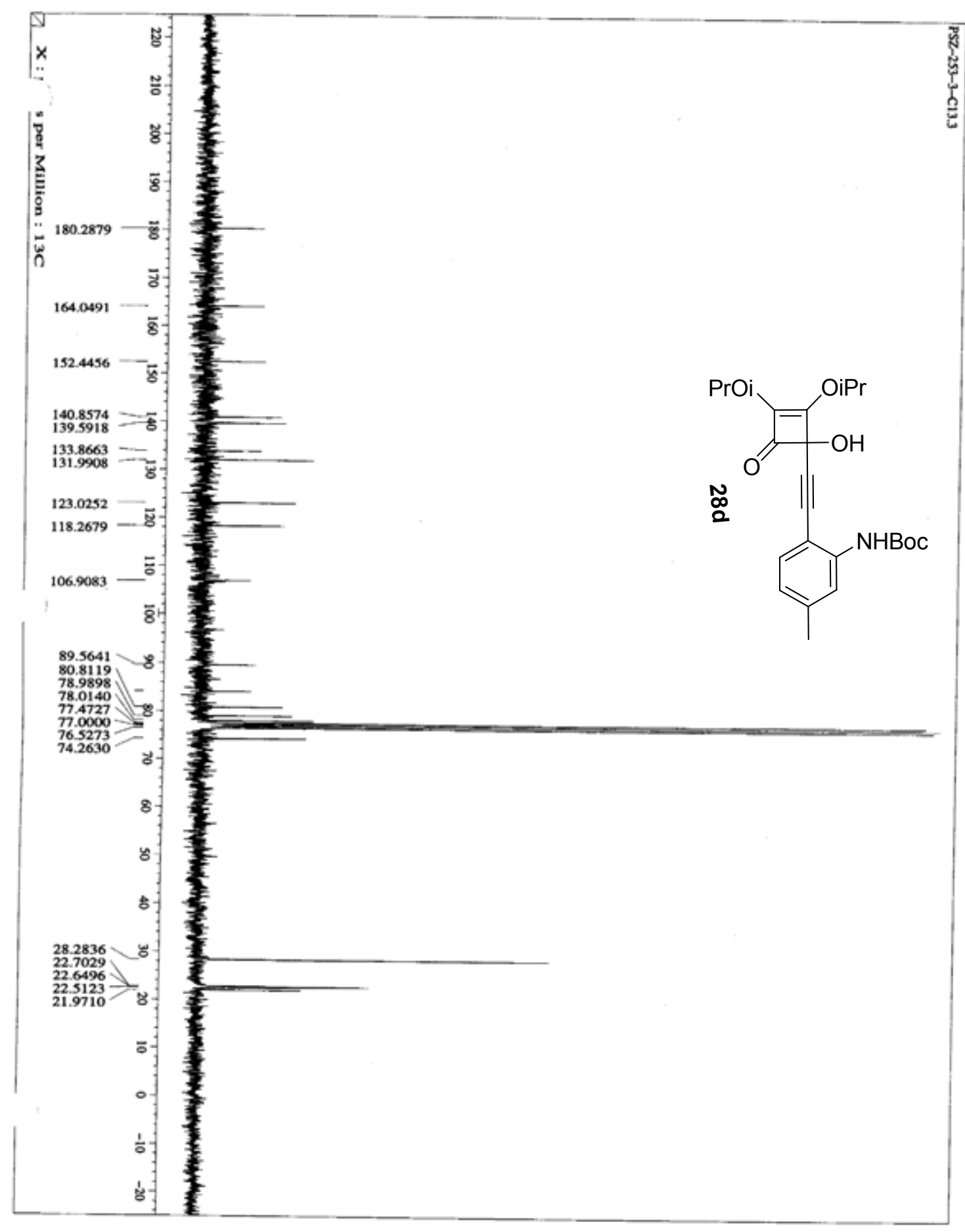

Figure 35: ${ }^{13} \mathrm{C}$ Spectrum of [2-(1-Hydroxy-2,3-di(1-methylethoxy)-4-oxo-cyclobut2-enylethynyl)-5-methylphenyl]-carbamic acid 1,1-dimethylethyl ester 28d 


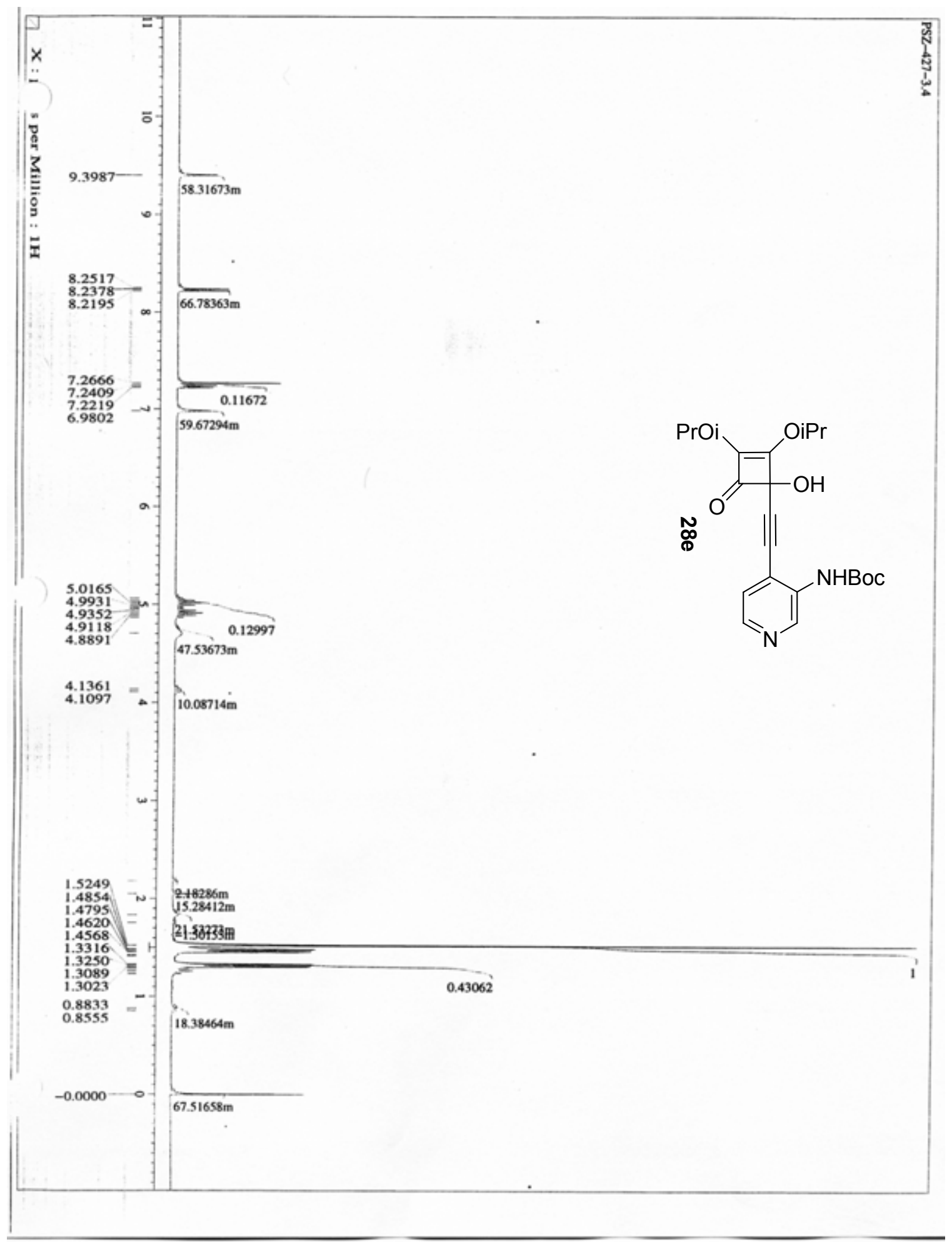

Figure 36: ${ }^{1} \mathrm{H}$ Spectrum of [4-(1-Hydroxy-2,3-di(1-methylethoxy)-4-oxo-cyclobut2-enylethynyl)-pyridin-3-yl]-carbamic acid 1,1-dimethylethyl ester 28e 


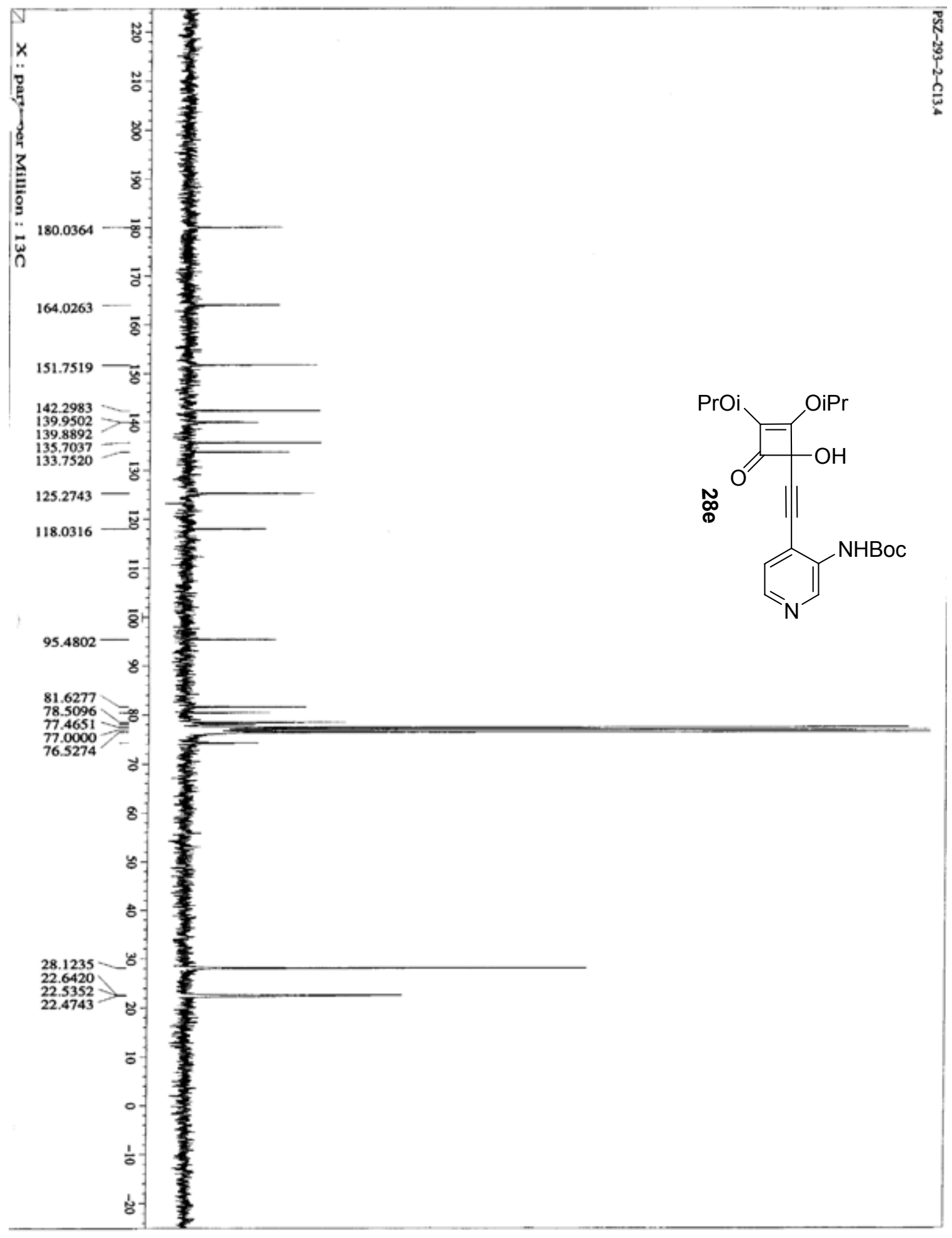

Figure $37:{ }^{13} \mathrm{C}$ Spectrum of [4-(1-Hydroxy-2,3-di(1-methylethoxy)-4-oxo-cyclobut2-enylethynyl)-pyridin-3-yl]-carbamic acid 1,1-dimethylethyl ester 28e 


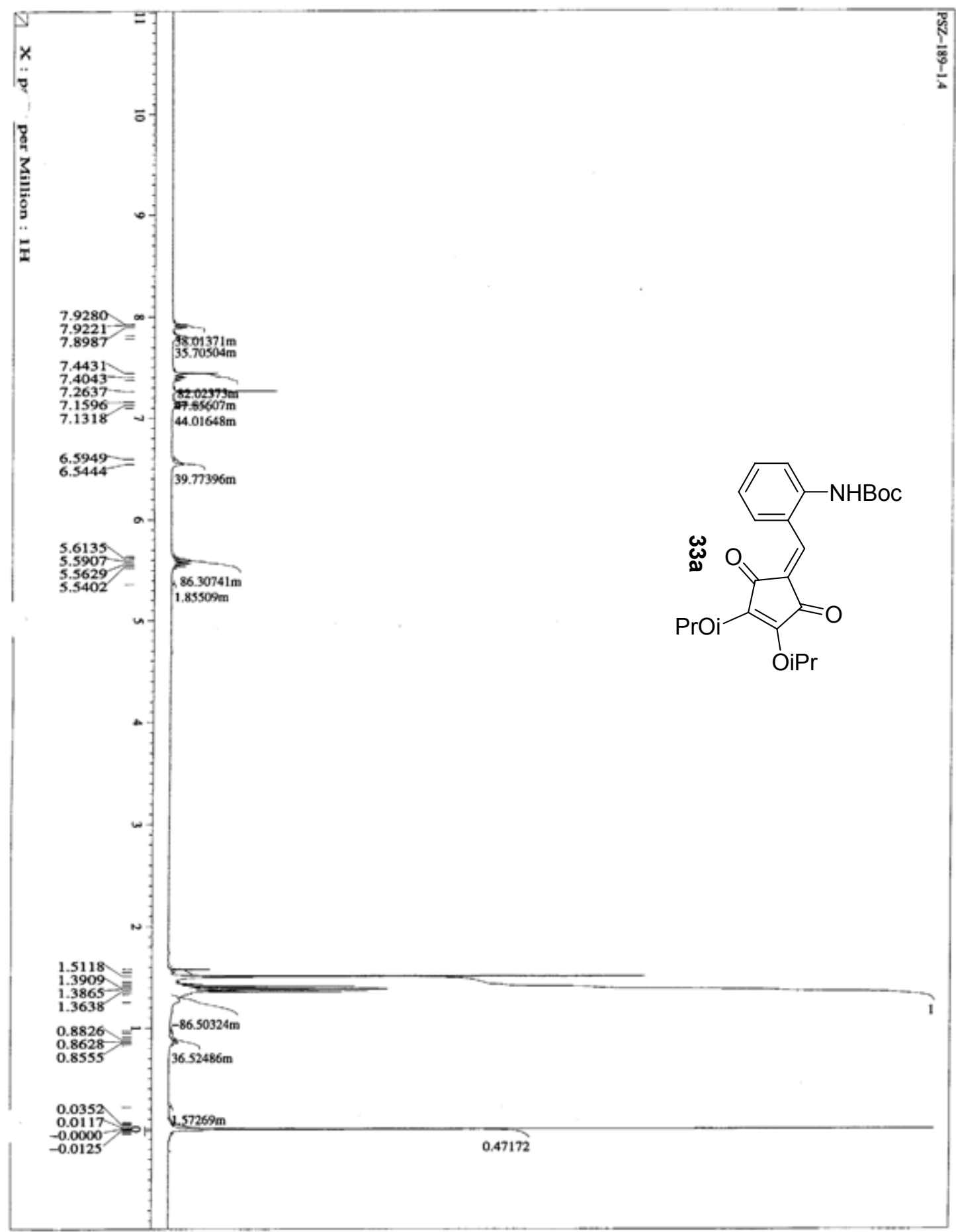

Figure 38: ${ }^{1} \mathrm{H}$ Spectrum of [2-(3,4-Di(1-methylethoxy)-2,5-dioxo-3-cyclopenten-1ylmethyl)phenyl]-carbamic acid 1,1-dimethylethyl ester 33a 


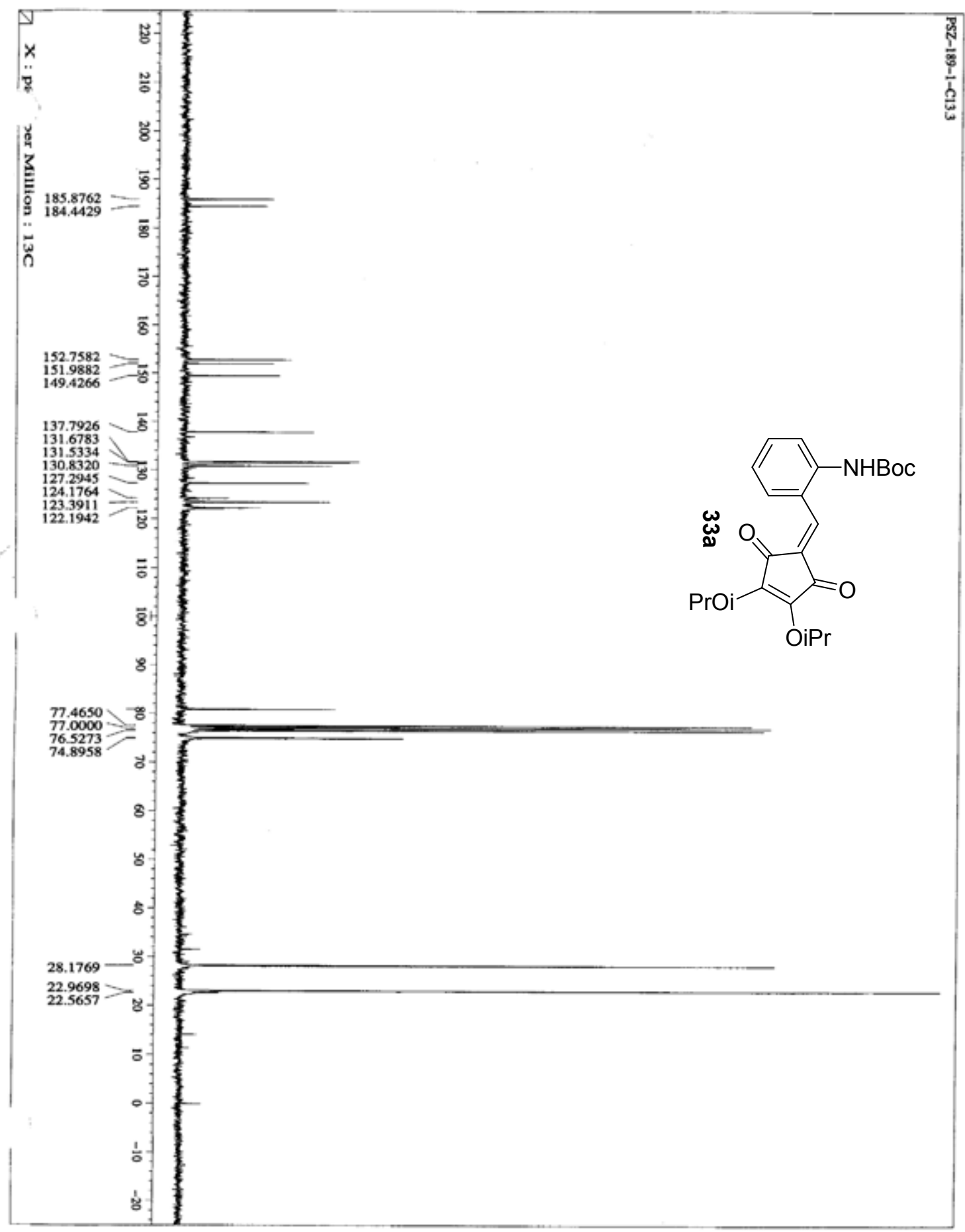

Figure 39: ${ }^{13} \mathrm{C}$ Spectrum of [2-(3,4-Di(1-methylethoxy)-2,5-dioxo-3-cyclopenten1-ylmethyl)phenyl]-carbamic acid 1,1-dimethylethyl ester 33a 


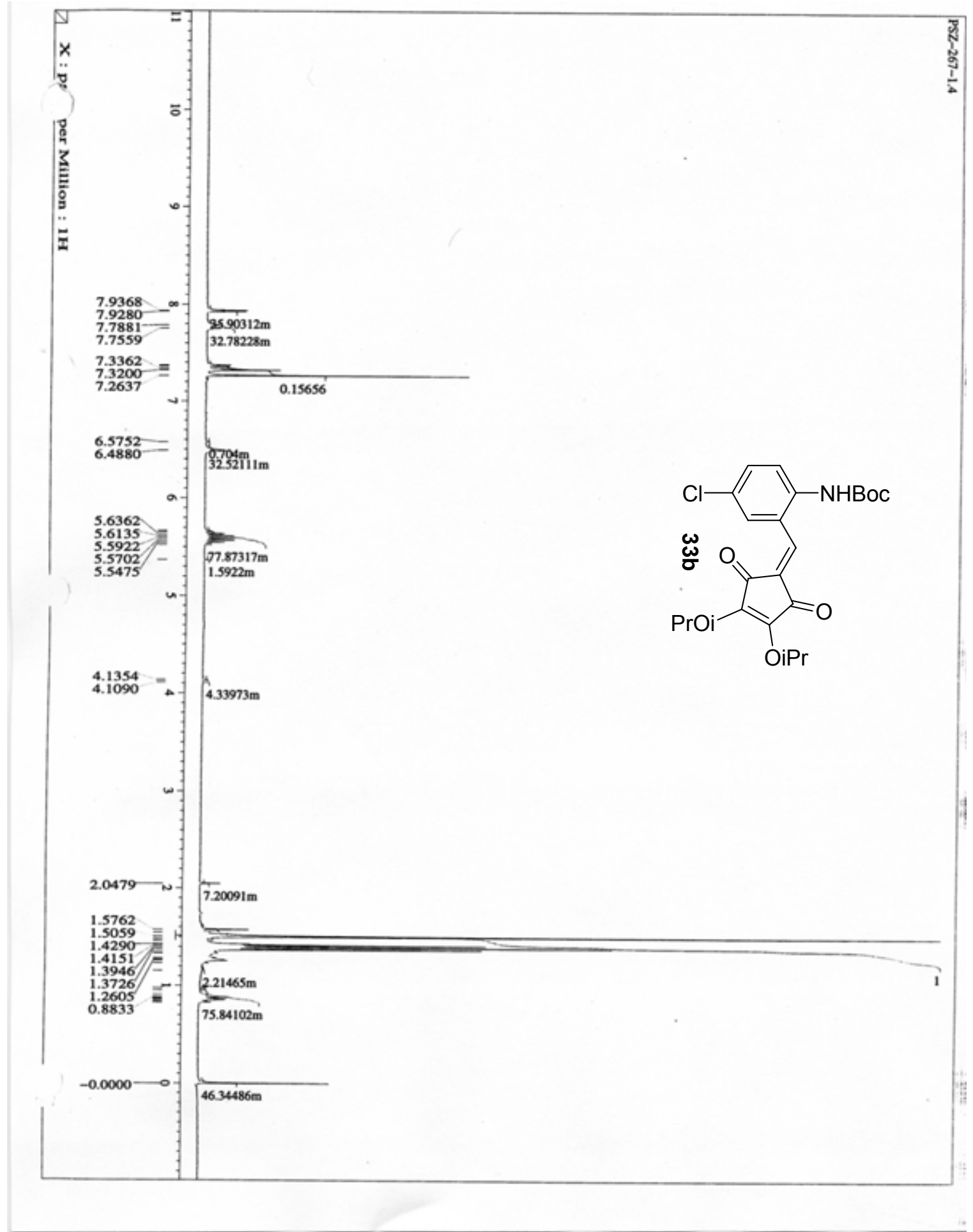

Figure 40: ${ }^{1} \mathrm{H}$ Spectrum of [4-Chloro-2-(3,4-di(1-methylethoxy)-2,5-dioxo-3cyclopenten-1-ylmethyl)phenyl]-carbamic acid 1,1-dimethylethyl ester 33b 


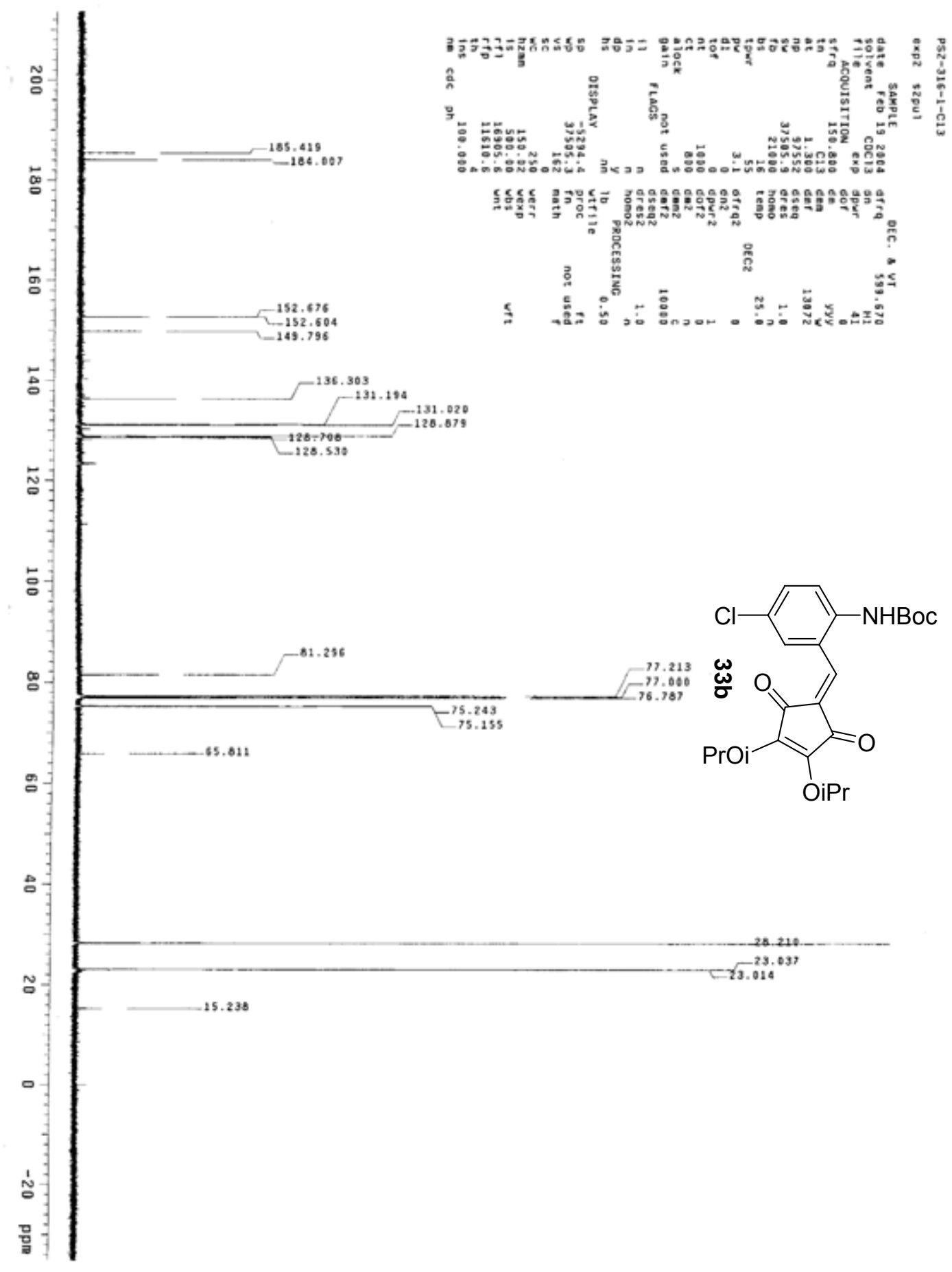

Figure 41: ${ }^{13} \mathrm{C}$ Spectrum of [4-Chloro-2-(3,4-di(1-methylethoxy)-2,5-dioxo-3cyclopenten-1-ylmethyl)phenyl]-carbamic acid 1,1-dimethylethyl ester 33b 


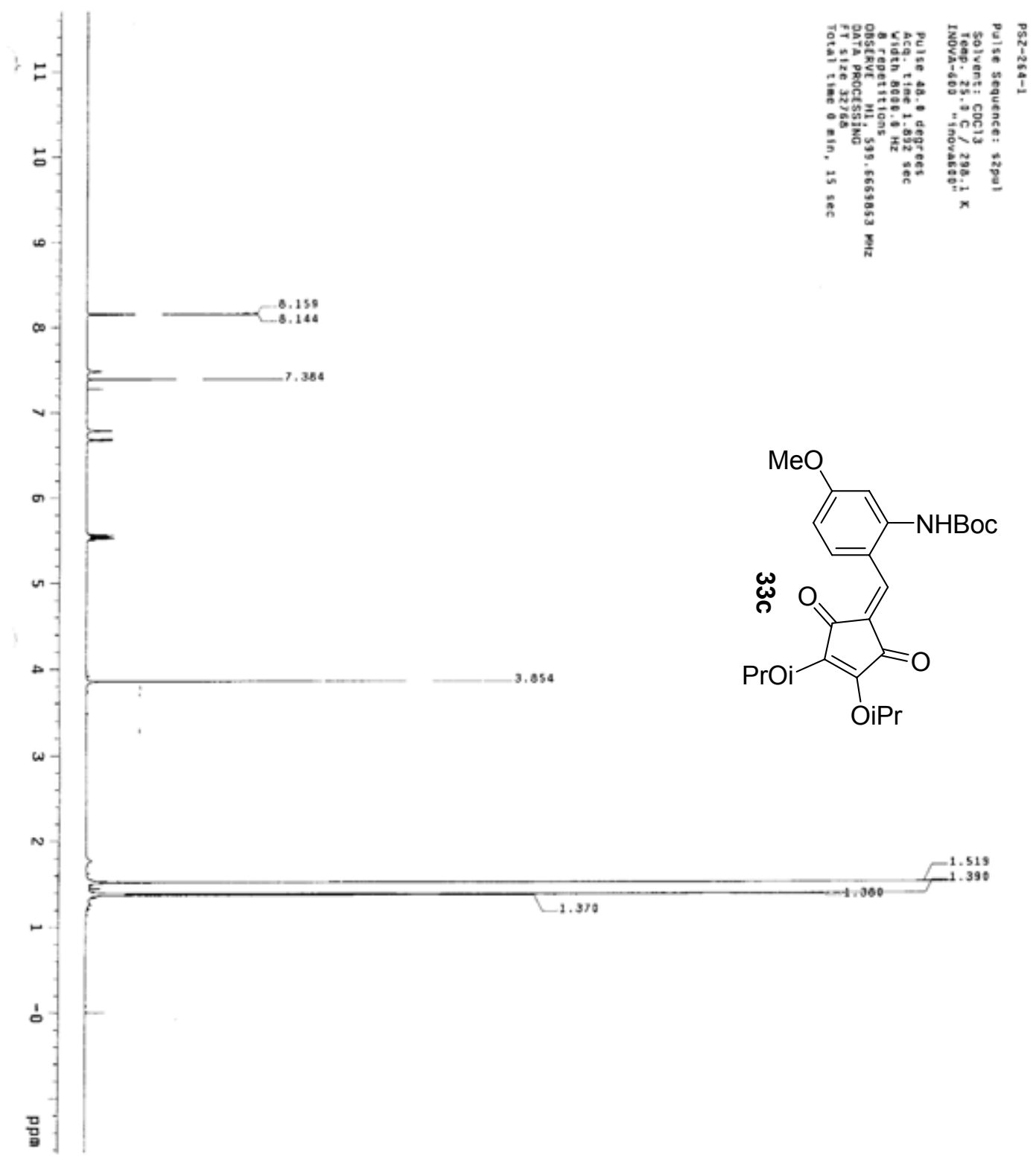

Figure 42: ${ }^{1} \mathrm{H}$ Spectrum of [2-(3,4-di(1-methylethoxy)-2,5-dioxo-3-cyclopenten-1ylmethyl)-5-methoxy-phenyl]-carbamic acid 1,1-dimethylethyl ester 33c 


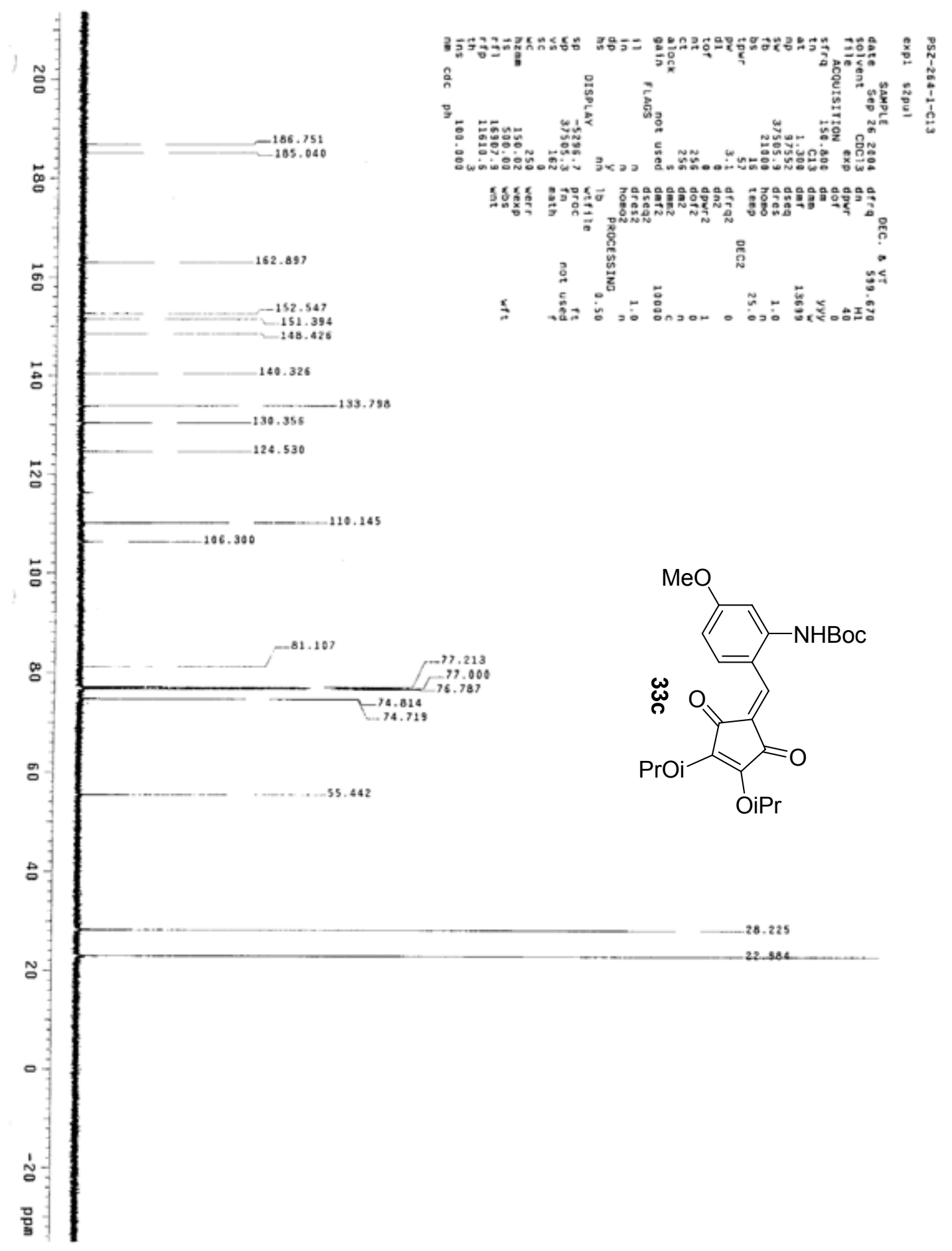

Figure 43: ${ }^{13} \mathrm{C}$ Spectrum of [2-(3,4-di(1-methylethoxy)-2,5-dioxo-3-cyclopenten1-ylmethyl)-5-methoxy-phenyl]-carbamic acid 1,1-dimethylethyl ester 33c 


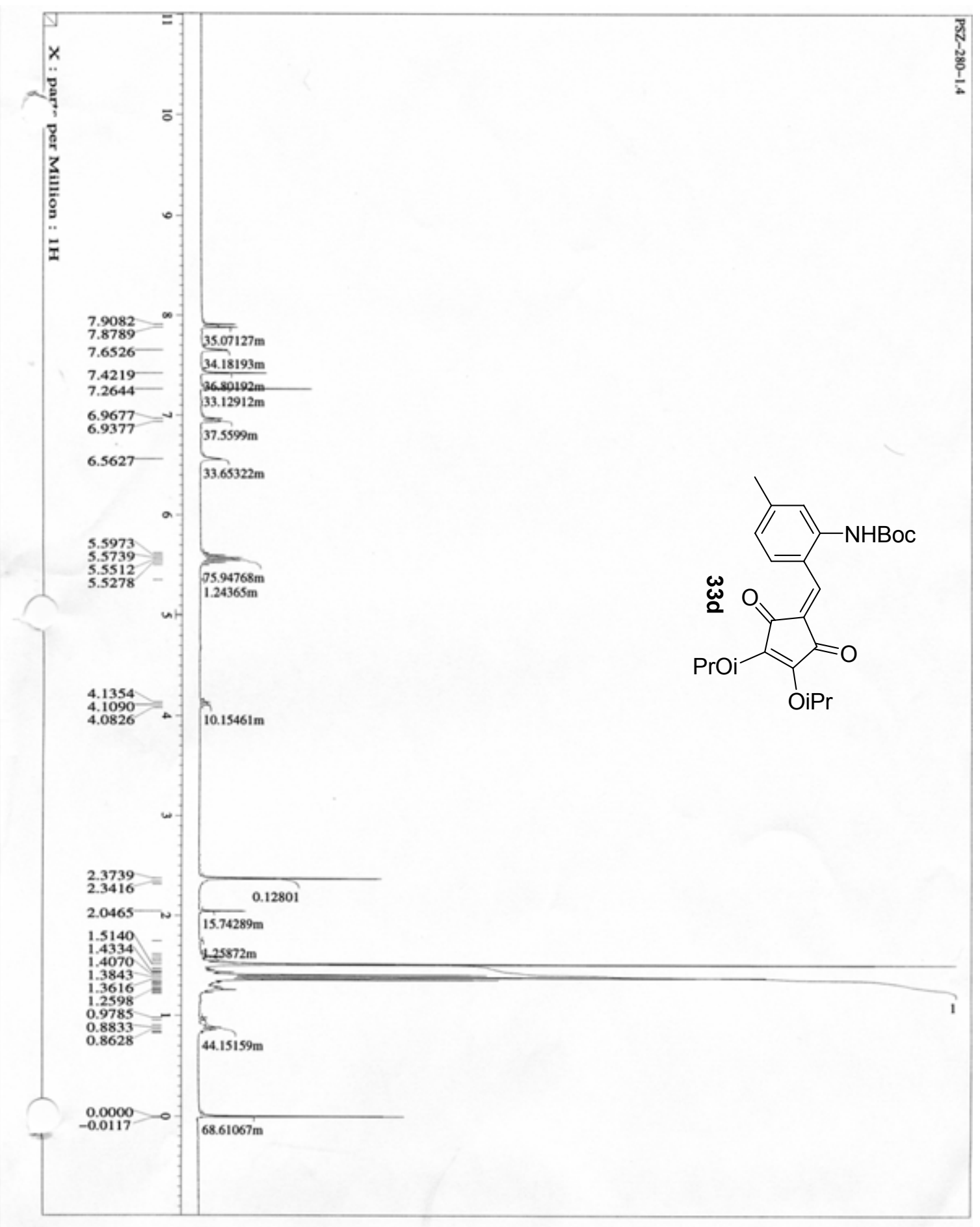

Figure 44: ${ }^{1} \mathrm{H}$ Spectrum of [2-(3,4-di(1-methylethoxy)-2,5-dioxo-3-cyclopenten-1methylidene)-5-methyl-phenyl]-carbamic acid 1,1-dimethylethyl ester 33d 


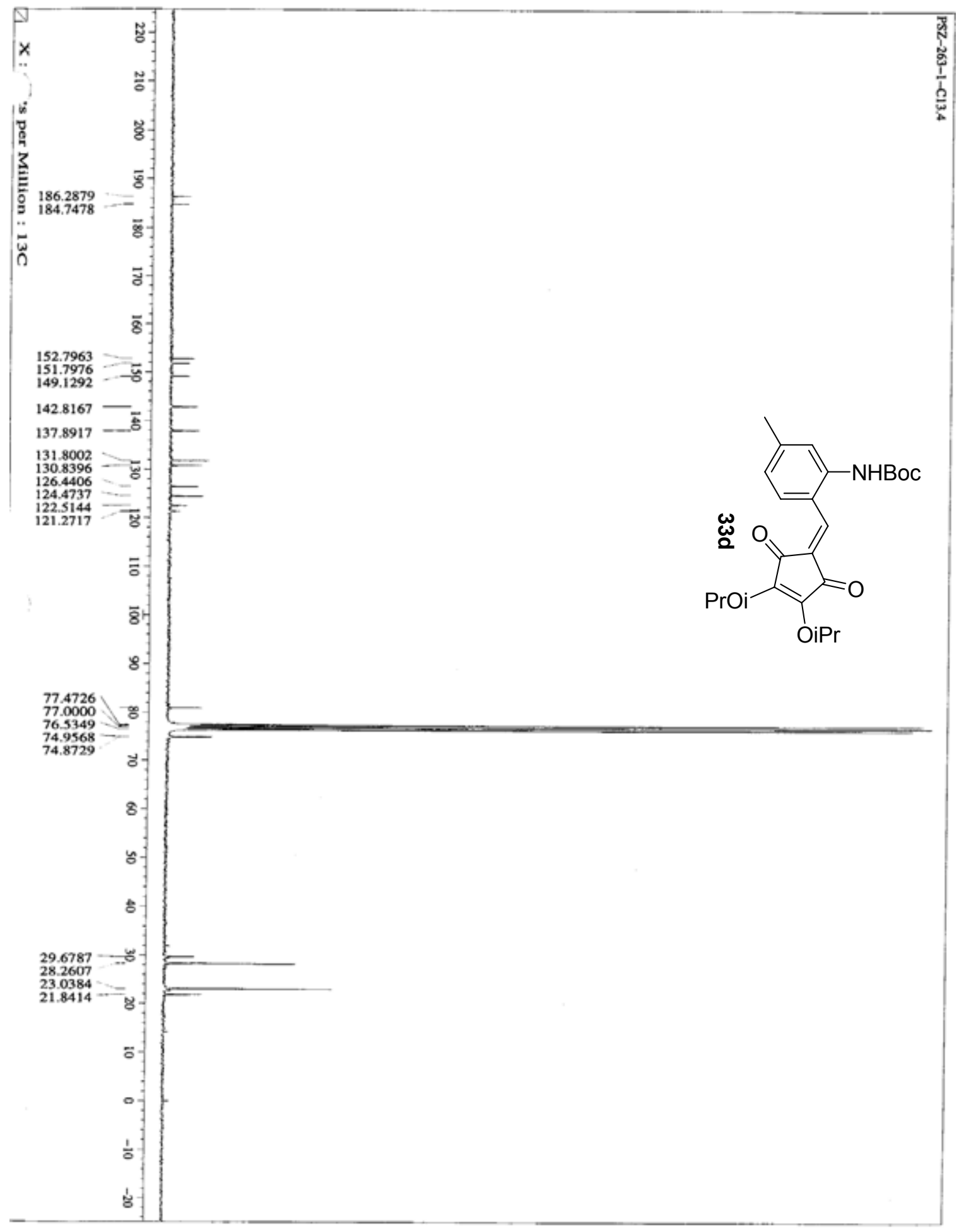

Figure 45: ${ }^{13} \mathrm{C}$ Spectrum of [2-(3,4-di(1-methylethoxy)-2,5-dioxo-3-cyclopenten1-methylidene)-5-methyl-phenyl]-carbamic acid 1,1-dimethylethyl ester 33d 


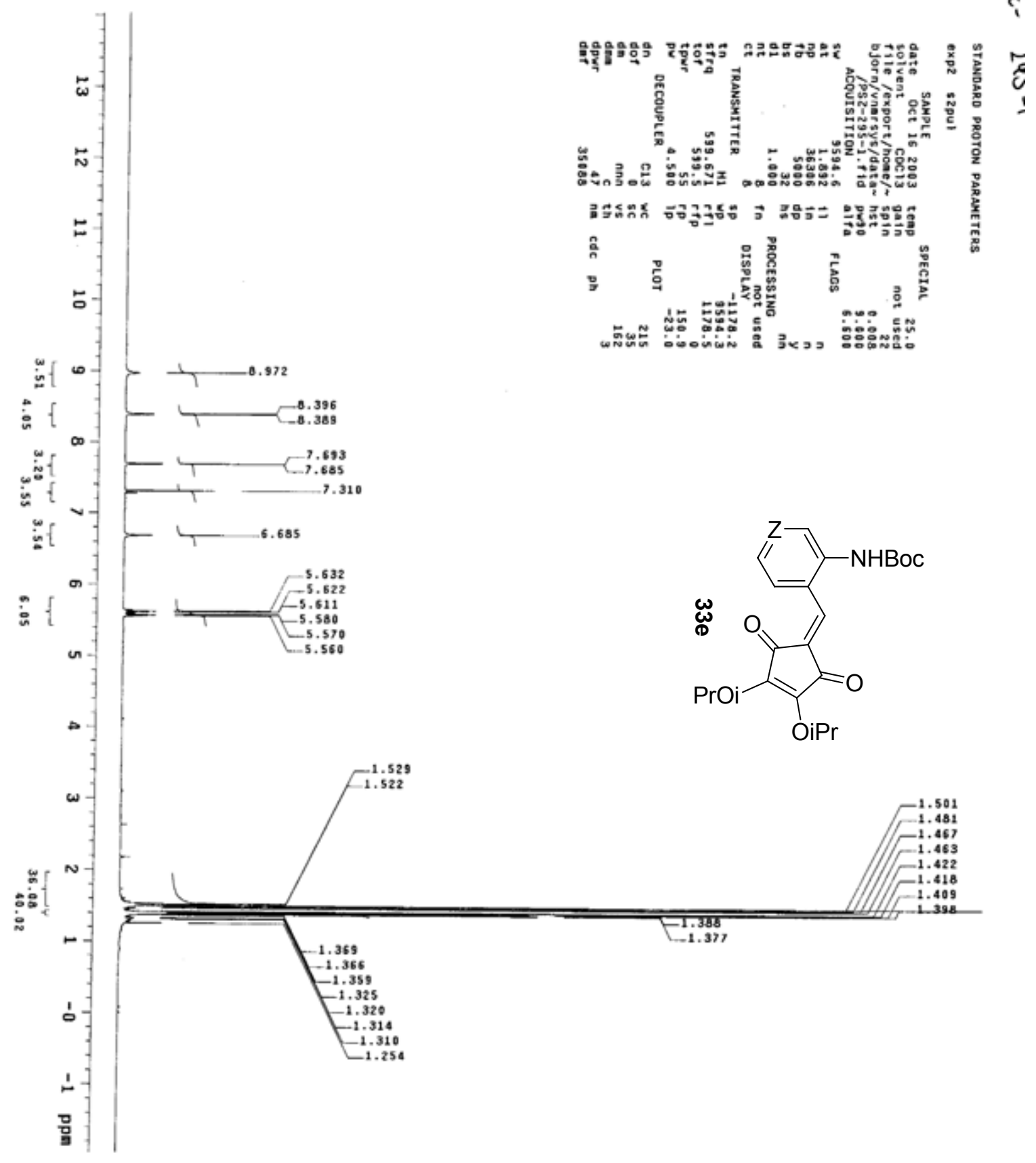

Figure 46: ${ }^{1} \mathrm{H}$ Spectrum of [4-(3,4-Di(1-methylethoxy)-2,5-dioxo-3-cyclopenten-1ylmethyl)-3-pyridinyl]-carbamic acid 1,1-dimethylethyl ester 33e 


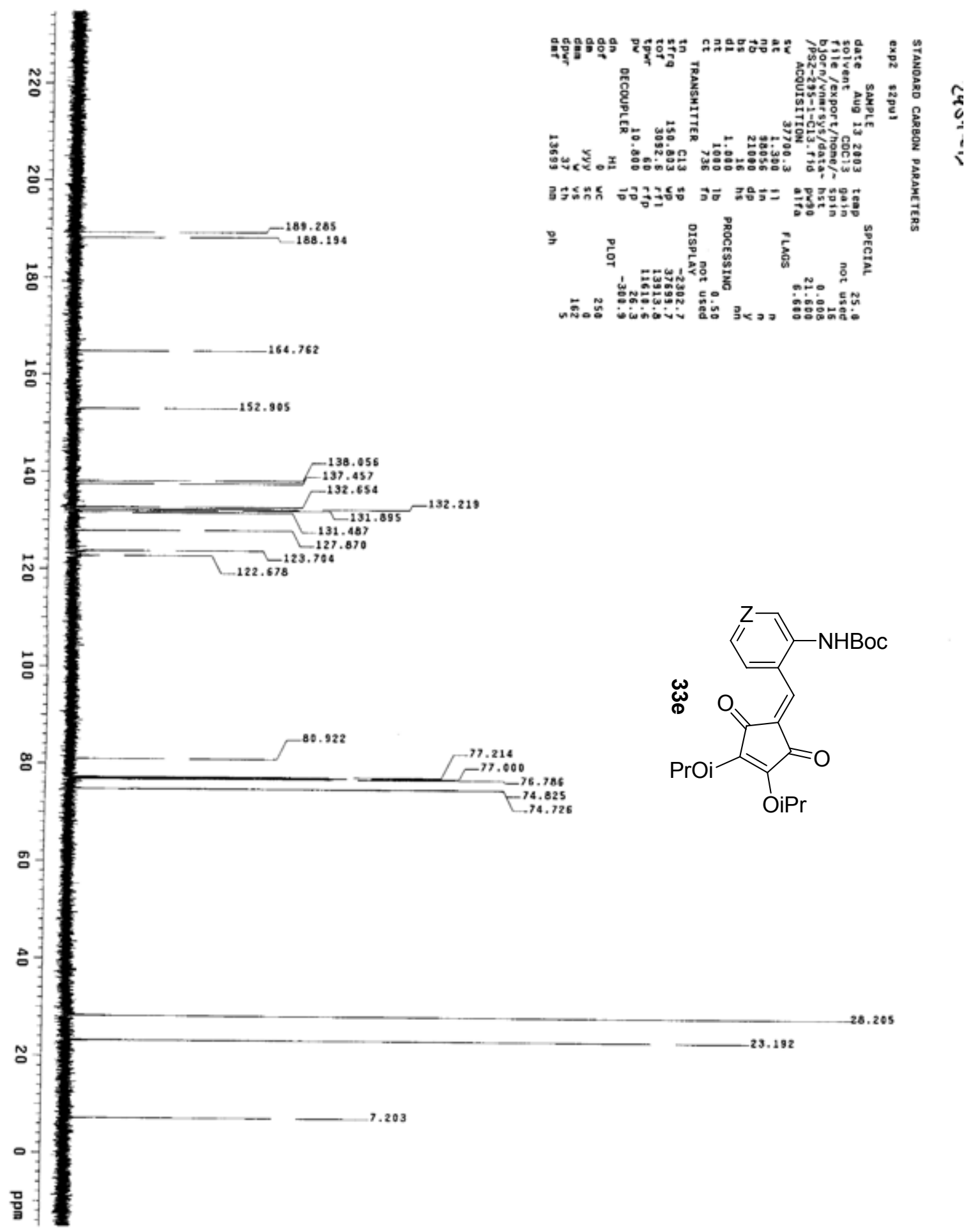

Figure 47: ${ }^{13} \mathrm{C}$ Spectrum of $[4-(3,4-\mathrm{Di}(1-$ methylethoxy)-2,5-dioxo-3-cyclopenten1-ylmethyl)-3-pyridinyl]-carbamic acid 1,1-dimethylethyl ester 33e 


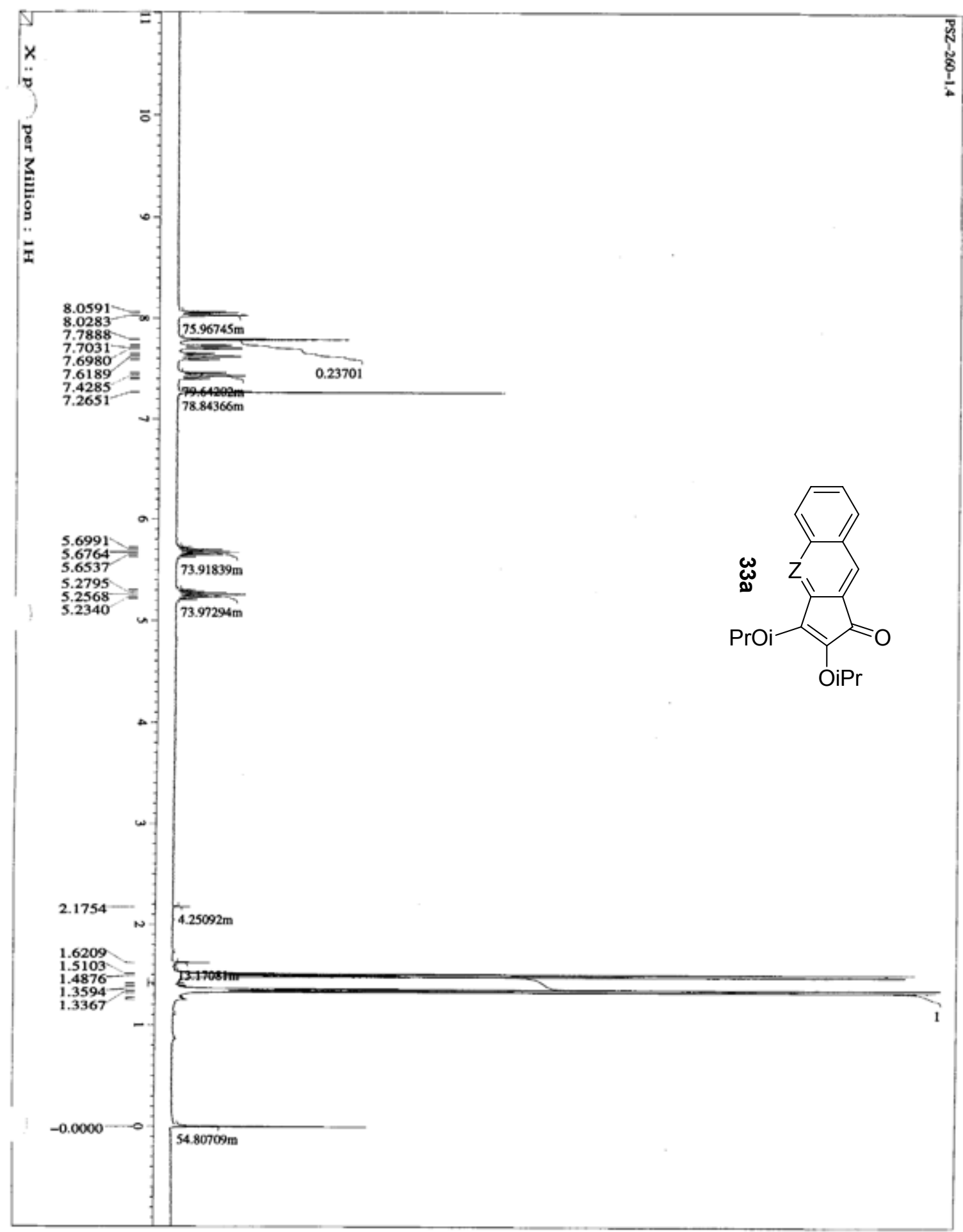

Figure 48: ${ }^{1} \mathrm{H}$ Spectrum of 2,3-Di(1-methylethoxy)cyclopenta[b]quinolin-1-one 34a 


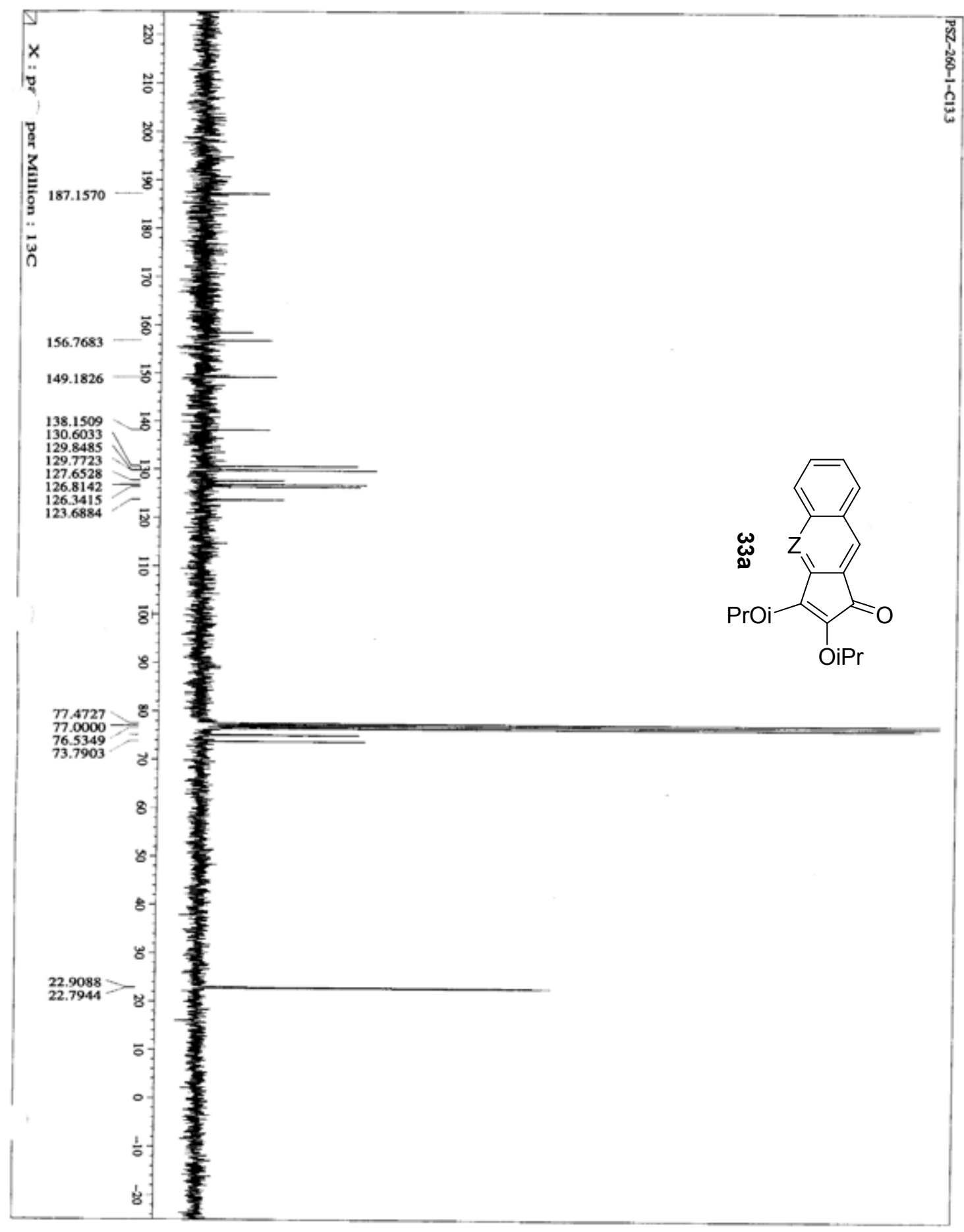

Figure 49: ${ }^{13} \mathrm{C}$ Spectrum of 2,3-Di(1-methylethoxy)cyclopenta[b]quinolin-1-one 34a 


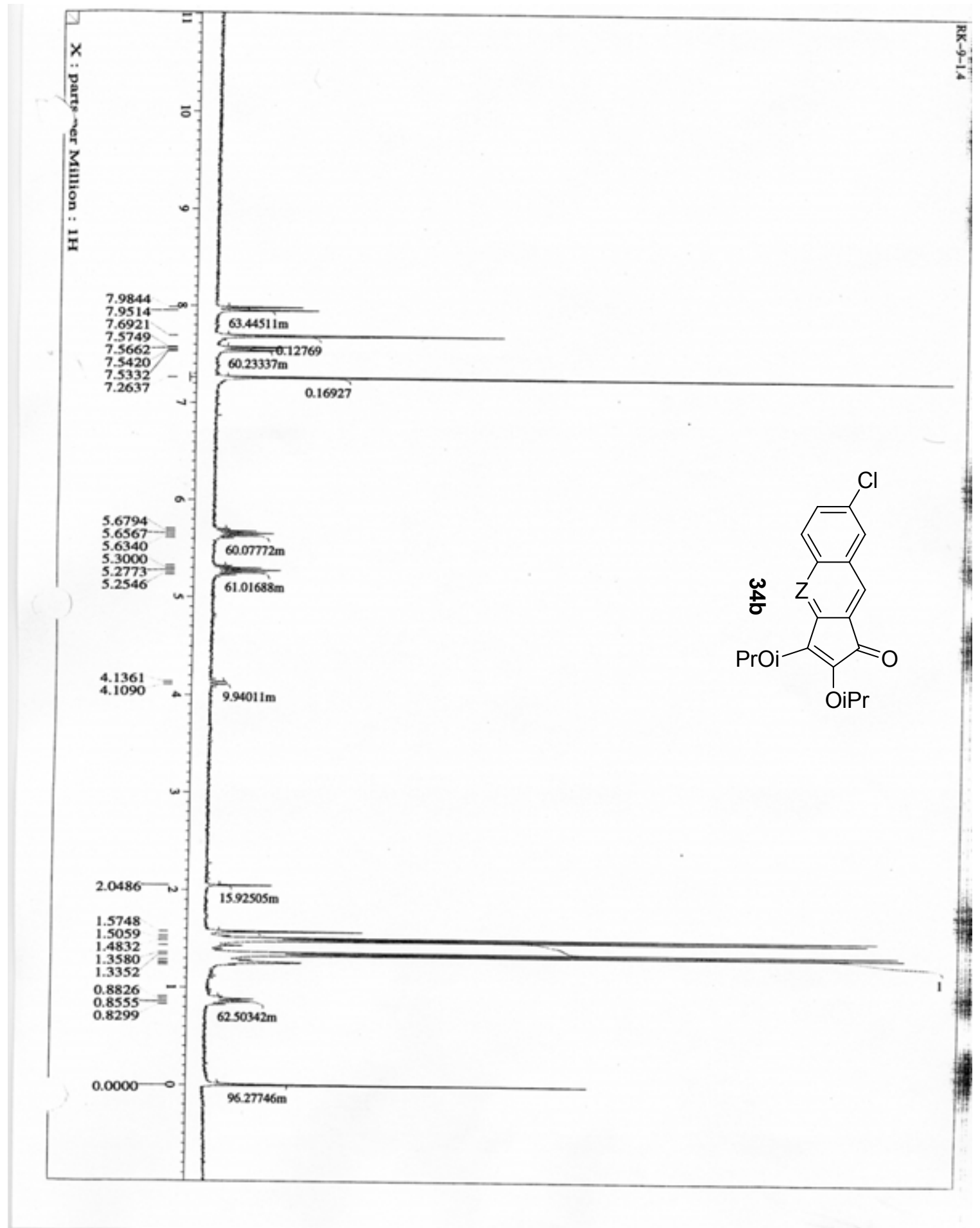

Figure 50: ${ }^{1} \mathrm{H}$ Spectrum of 7-Chloro-2,3-di(1-methylethoxy)cyclopenta[b]quinolin1-one 34b 


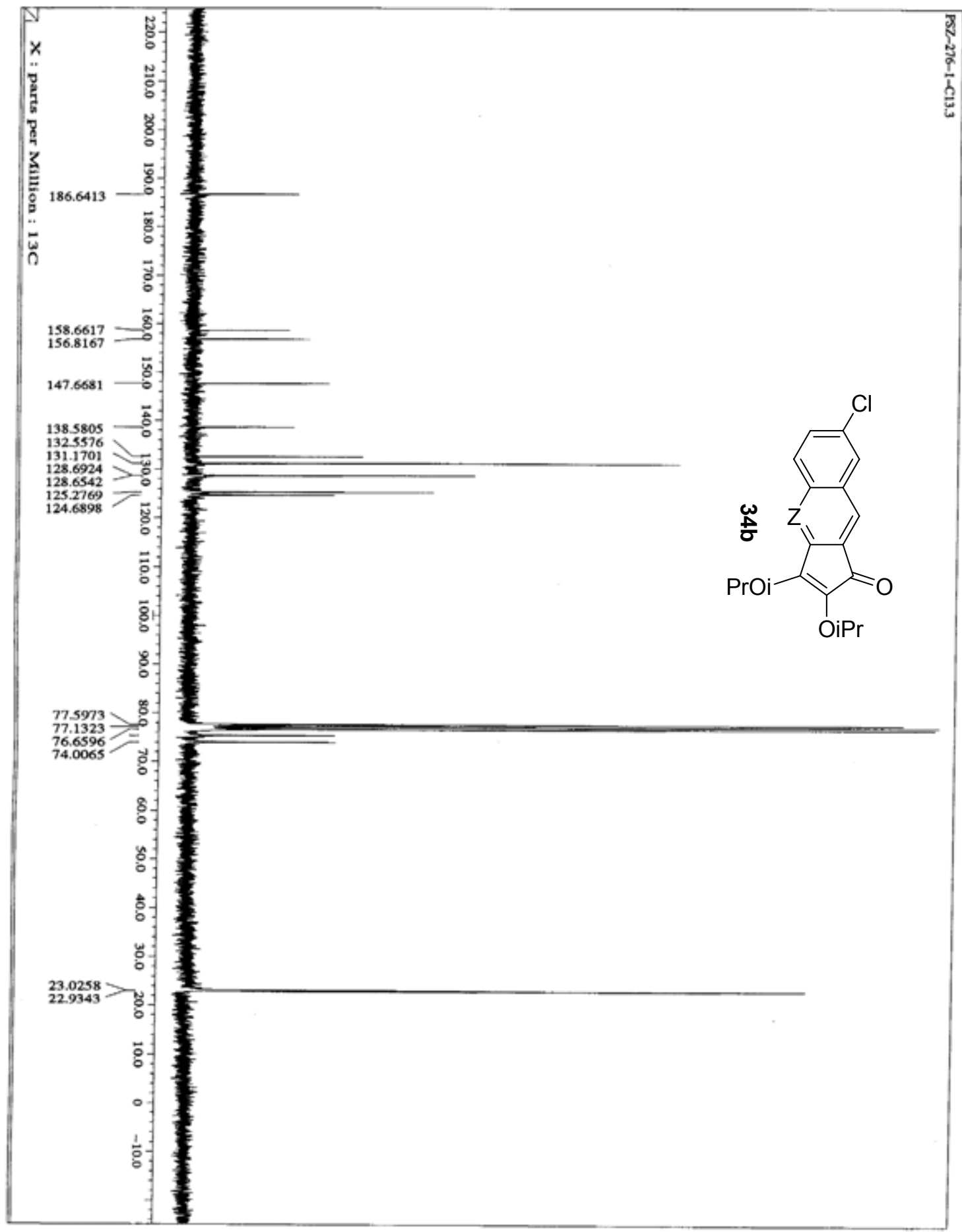

Figure $51:{ }^{13} \mathrm{C}$ Spectrum of 7-Chloro-2,3-di(1methylethoxy)cyclopenta[b]quinolin-1-one 34b 


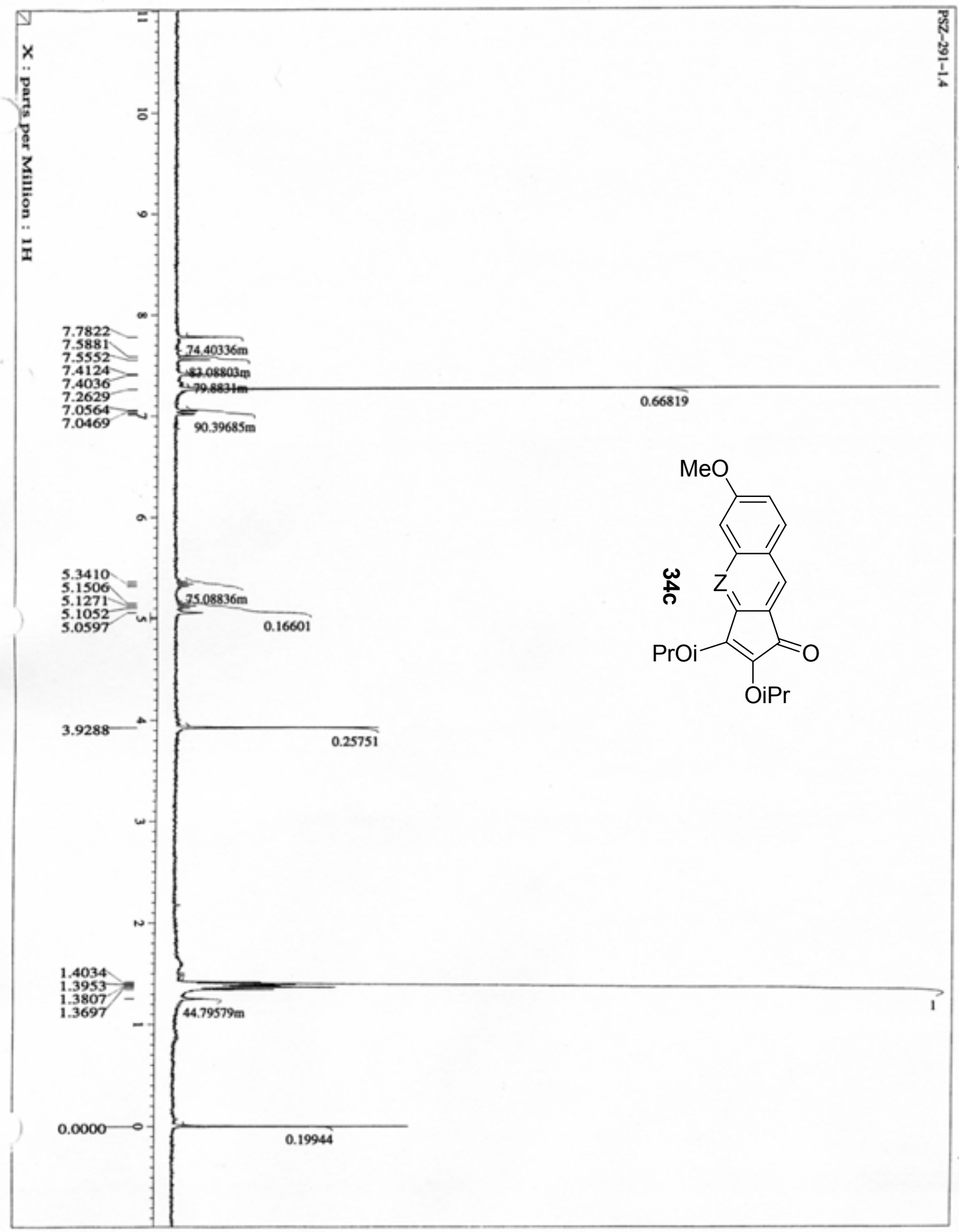

Figure 52: ${ }^{1} \mathrm{H}$ Spectrum of 2,3-Di(1-methylethoxy)-6methoxycyclopenta[b]quinolin-1-one 34c 


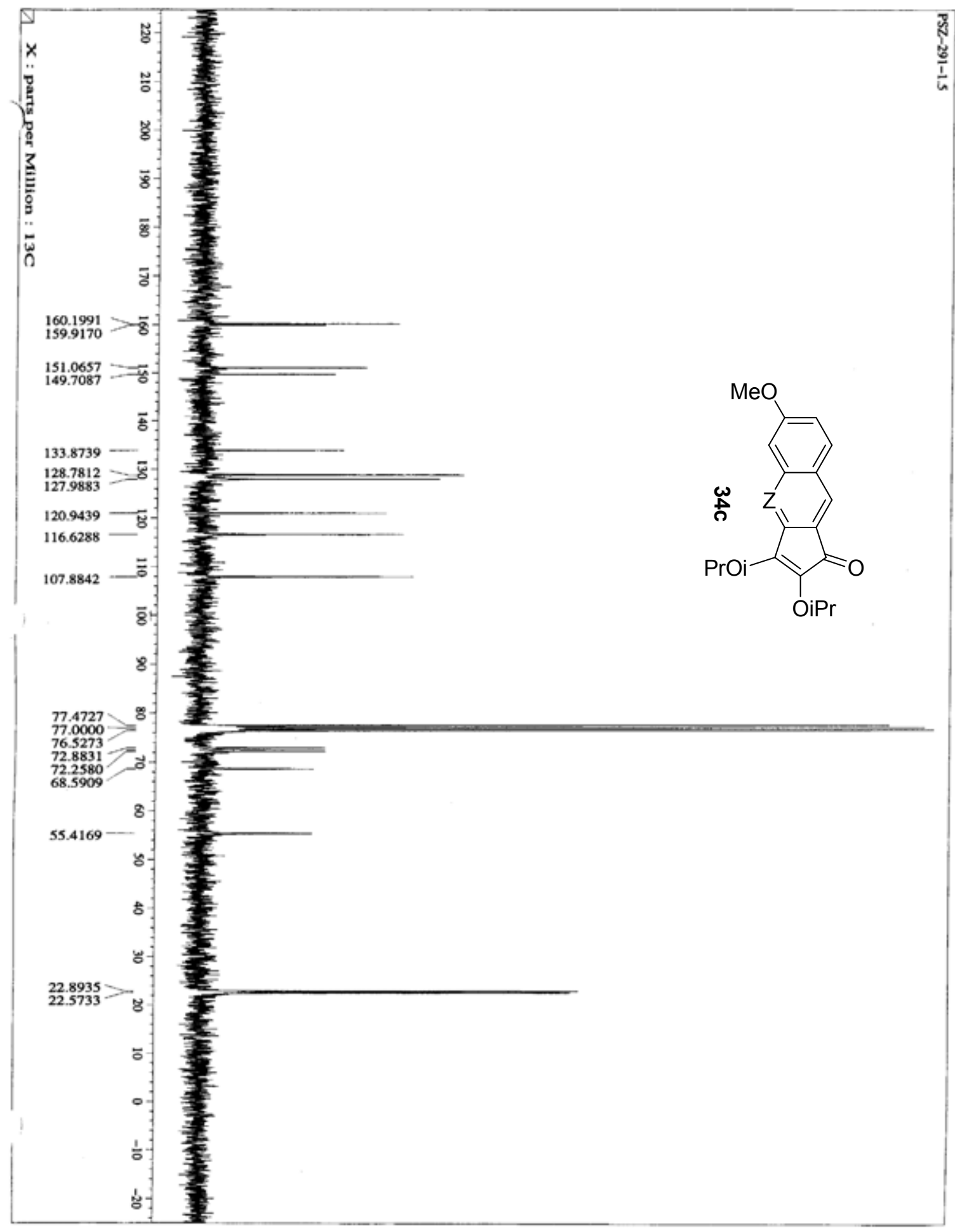

Figure 53: ${ }^{13} \mathrm{C}$ Spectrum of 2,3-Di(1-methylethoxy)-6methoxycyclopenta[b]quinolin-1-one 34c 


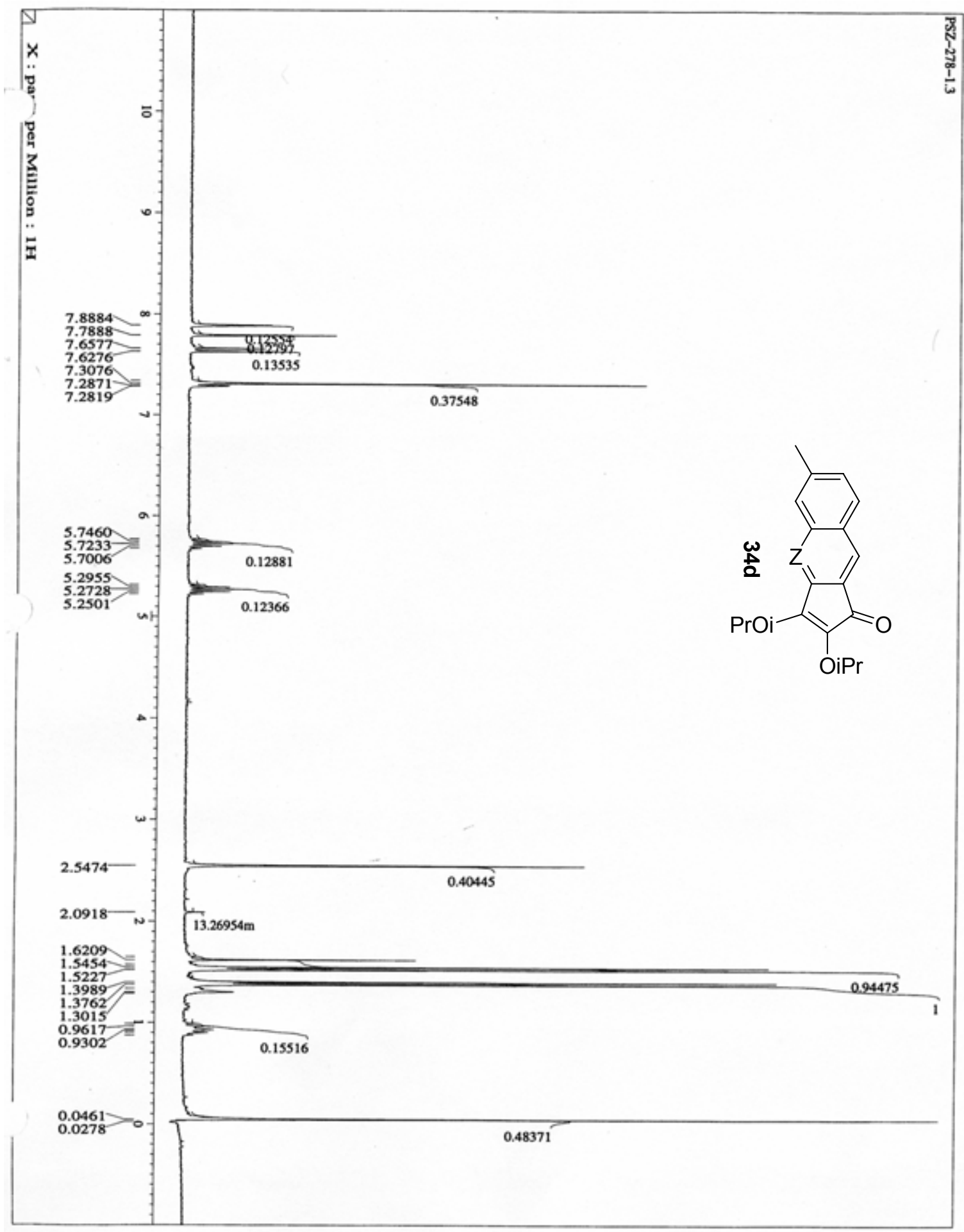

Figure 54: ${ }^{1} \mathrm{H}$ Spectrum of 2,3-Di(1-methylethoxy)-6-methylcyclopenta[b]quinolin1-one 34d 


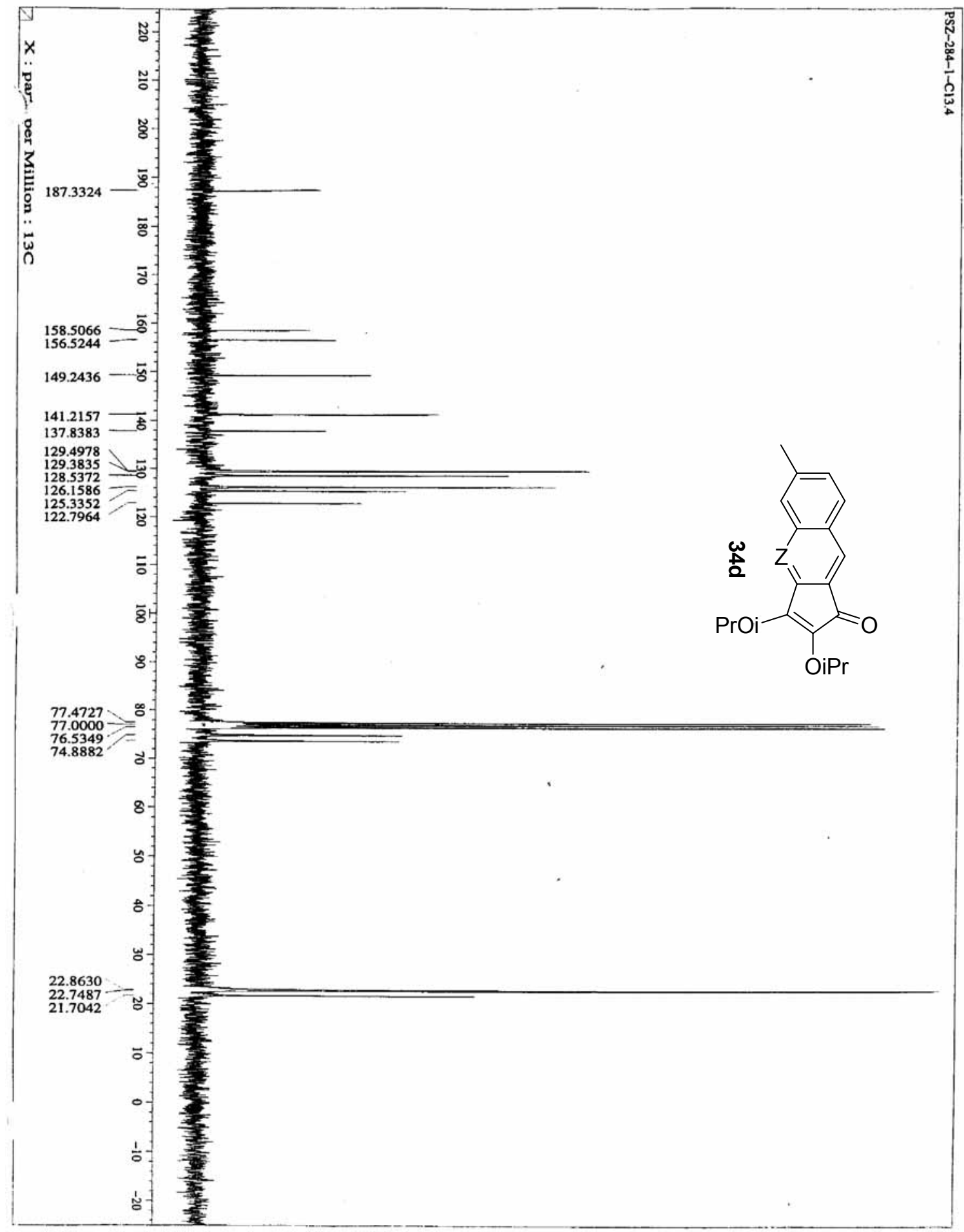

Figure 55: ${ }^{13} \mathrm{C}$ Spectrum of 2,3-Di(1-methylethoxy)-6methylcyclopenta[b]quinolin-1-one $\mathbf{3 4 d}$ 


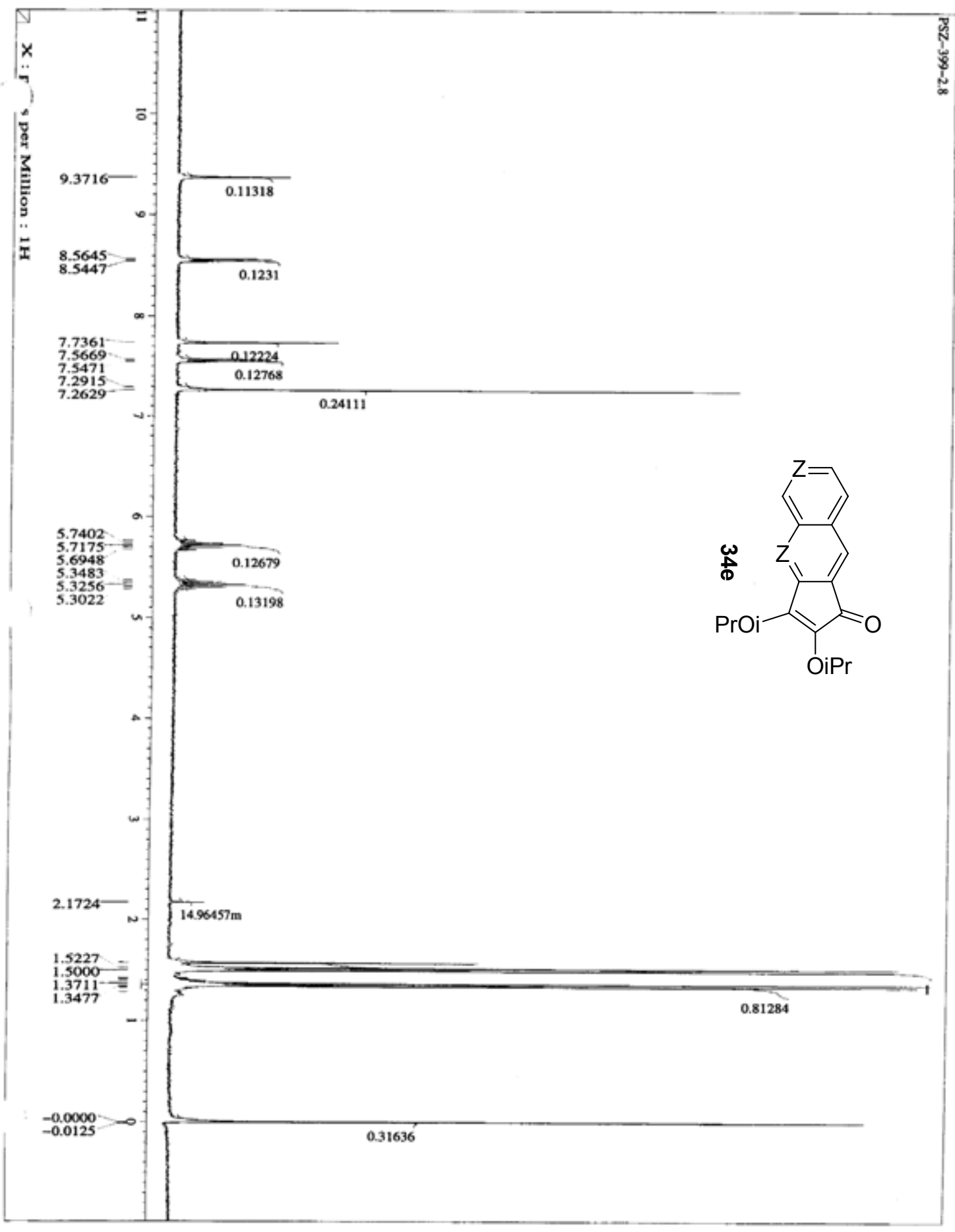

Figure 56: ${ }^{1} \mathrm{H}$ Spectrum of 2,3-Di(1-methylethoxy)-6-aza-cyclopenta[b]quinolin-1one $34 \mathrm{e}$ 


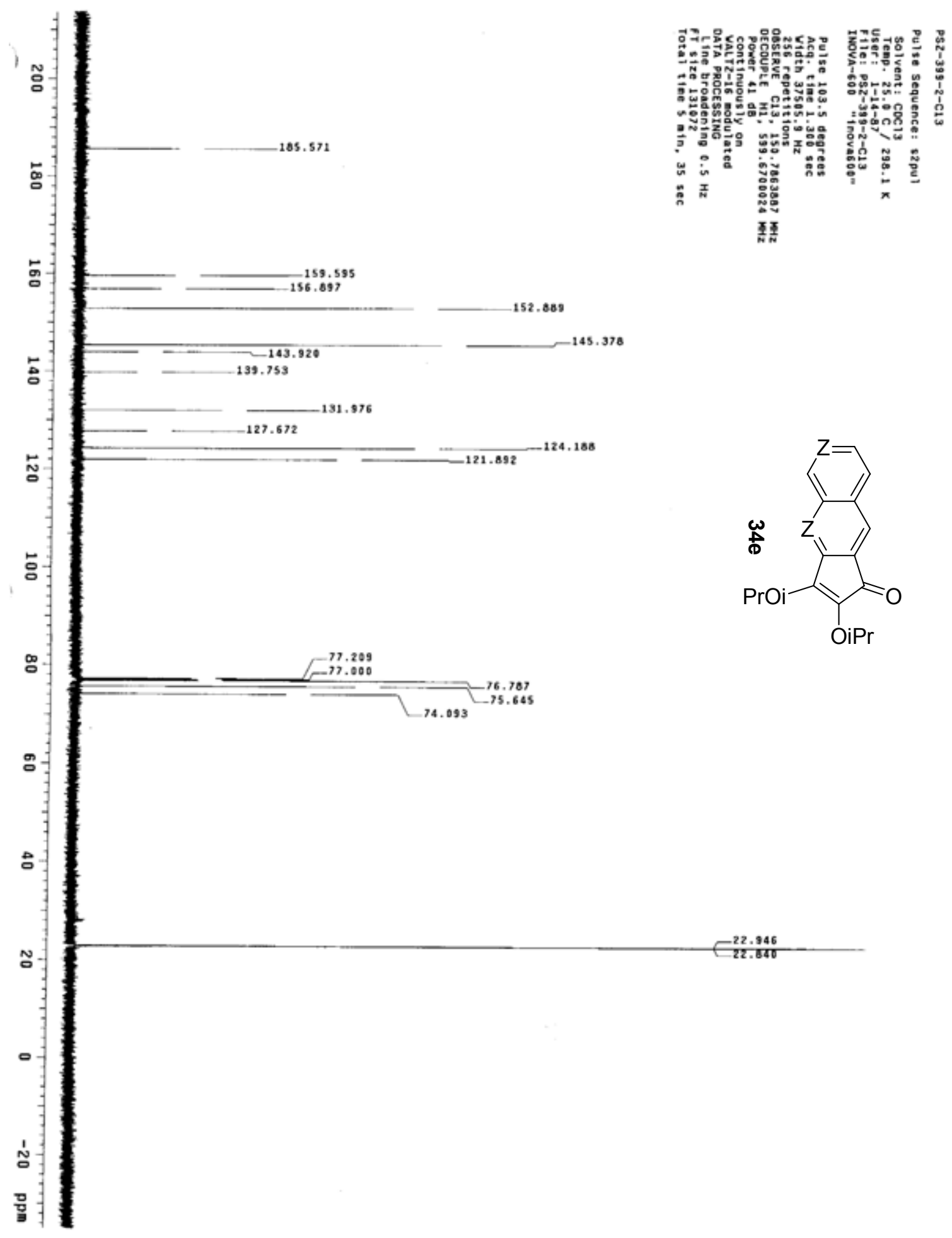

Figure 57: ${ }^{13} \mathrm{C}$ Spectrum of 2,3-Di(1-methylethoxy)-6-aza-cyclopenta[b]quinolin1-one 34e 


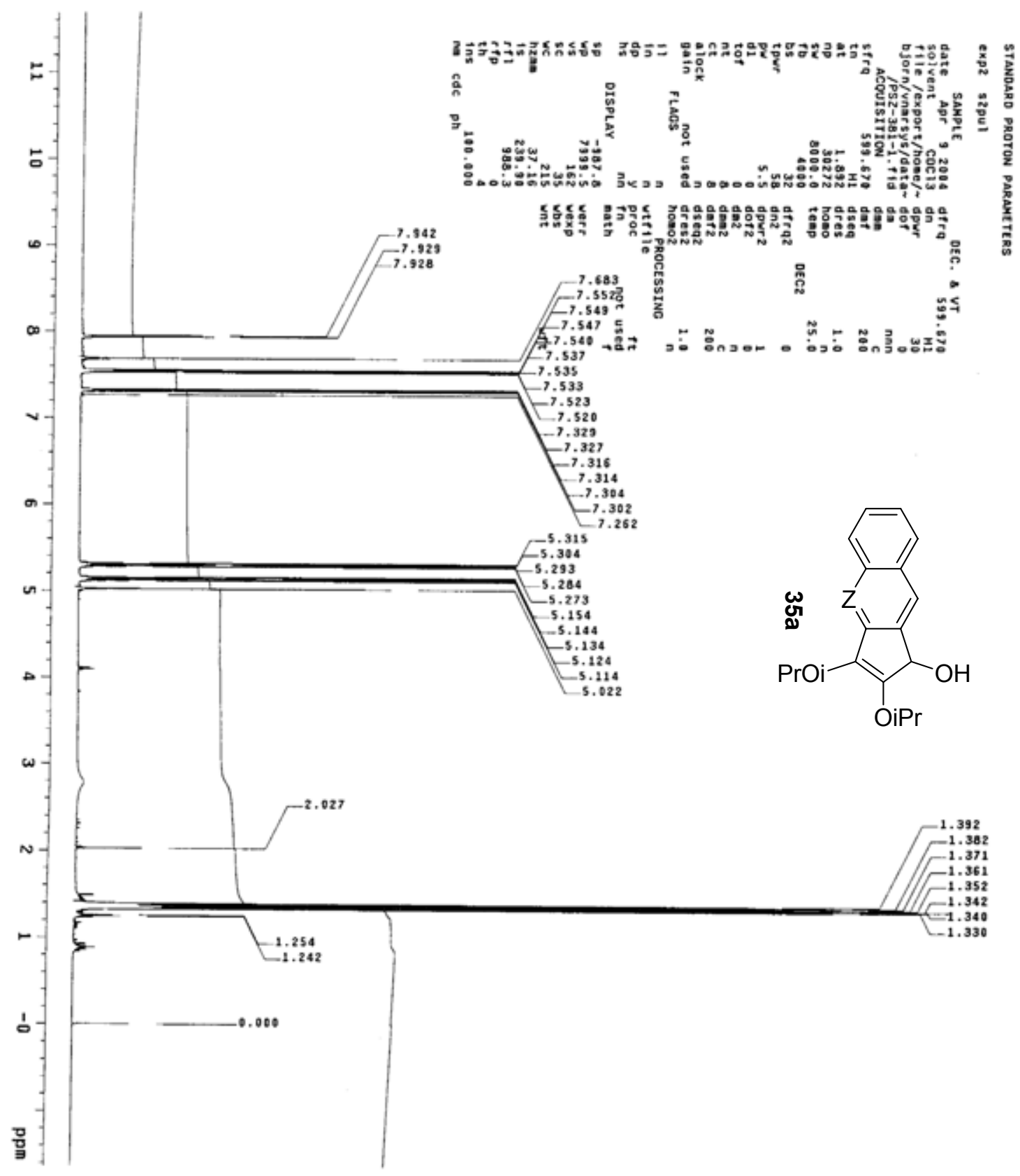

Figure 58: ${ }^{1} \mathrm{H}$ Spectrum of 2,3-Di(1-methylethoxy)cyclopenta[b]quinolin-1-ol $\overline{35 a}$ 

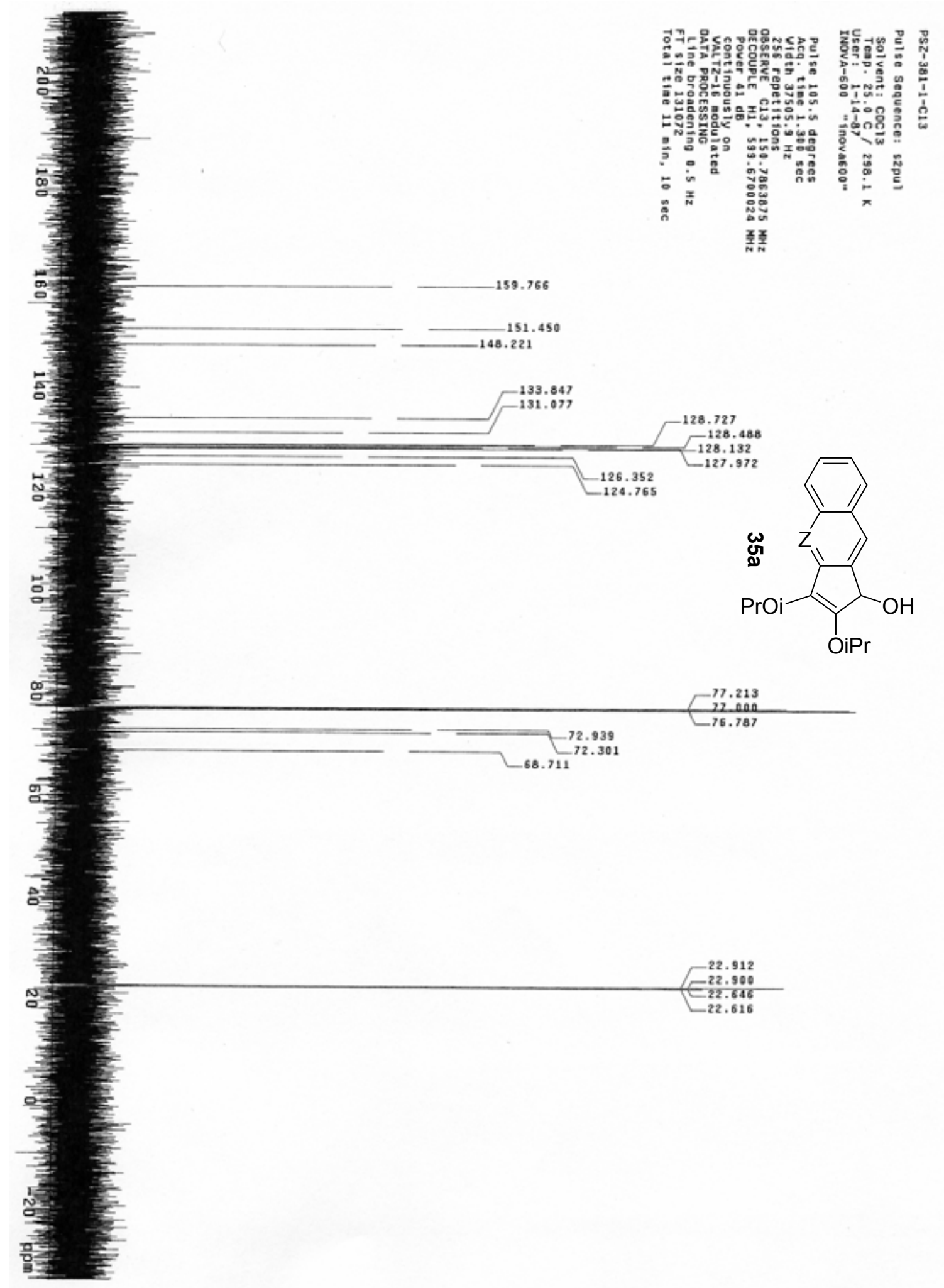

Figure 59: ${ }^{13} \mathrm{C}$ Spectrum of 2,3-Di(1-methylethoxy)cyclopenta[b]quinolin-1-ol 35a 


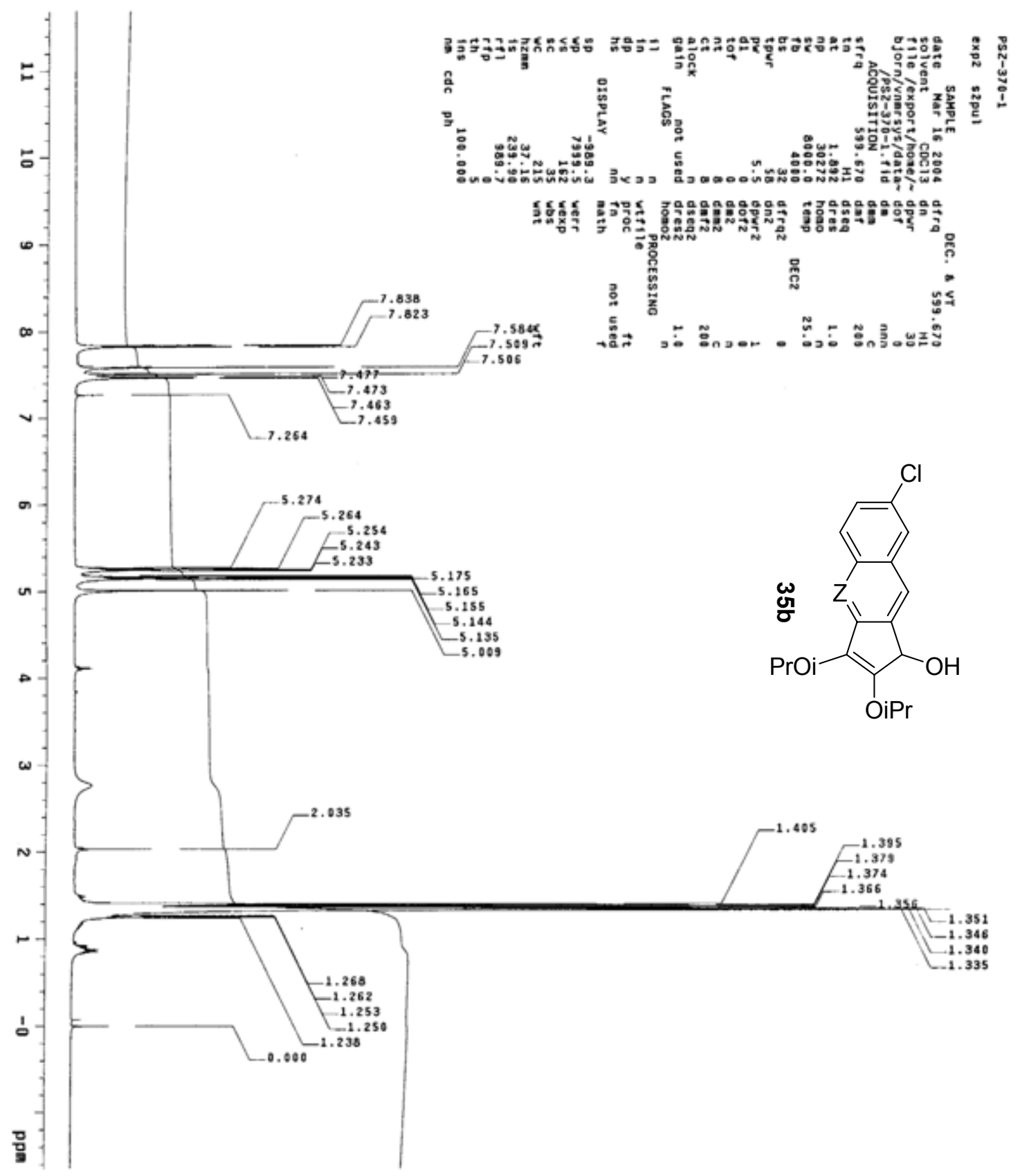

Figure 60: ${ }^{1} \mathrm{H}$ Spectrum of 7-Chloro-2,3-di(1-methylethoxy)cyclopenta[b]quinolin1-ol 35b 


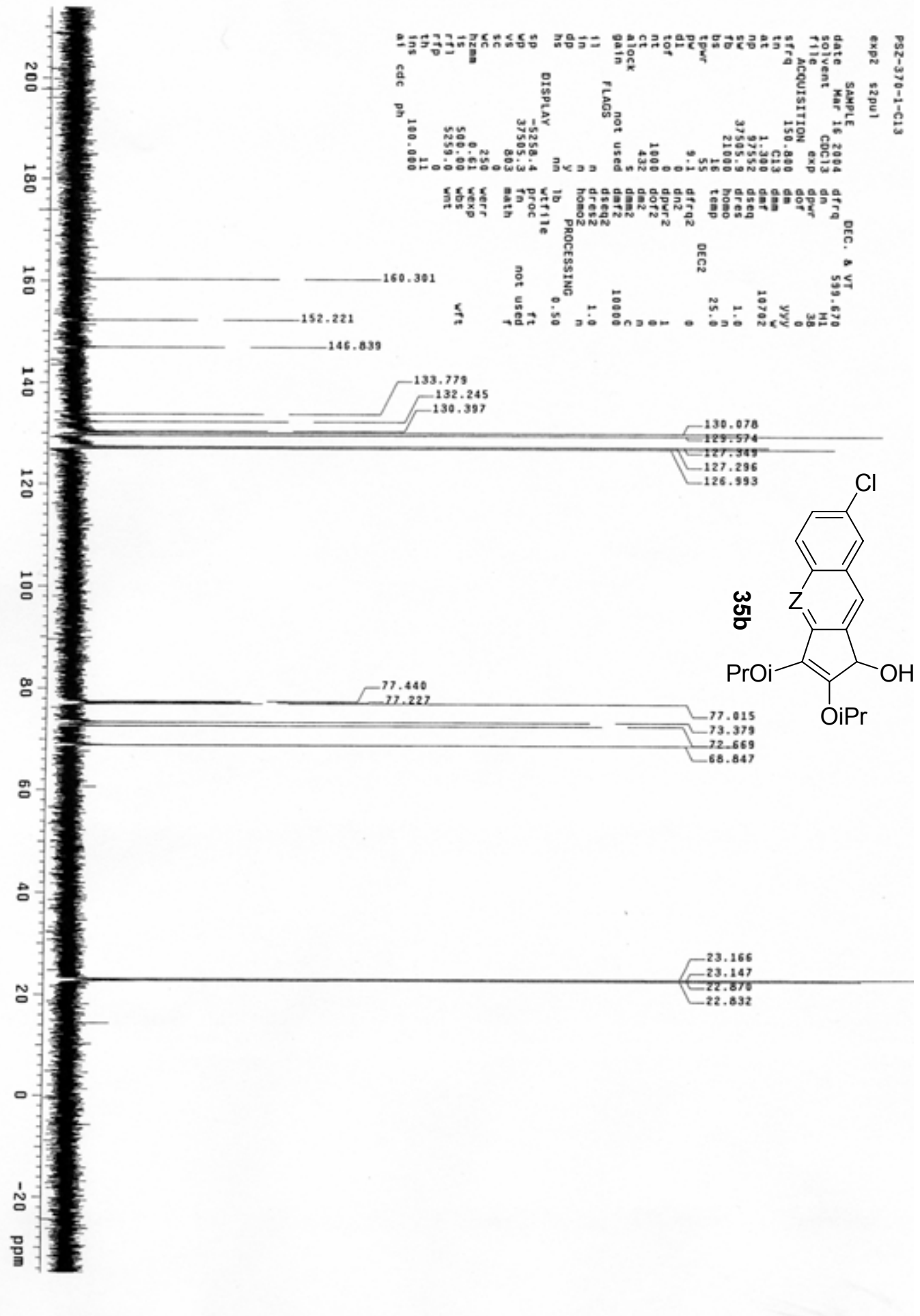

Figure 61: ${ }^{13} \mathrm{C}$ Spectrum of 7-Chloro-2,3-di(1methylethoxy)cyclopenta[b]quinolin-1-ol 35b 


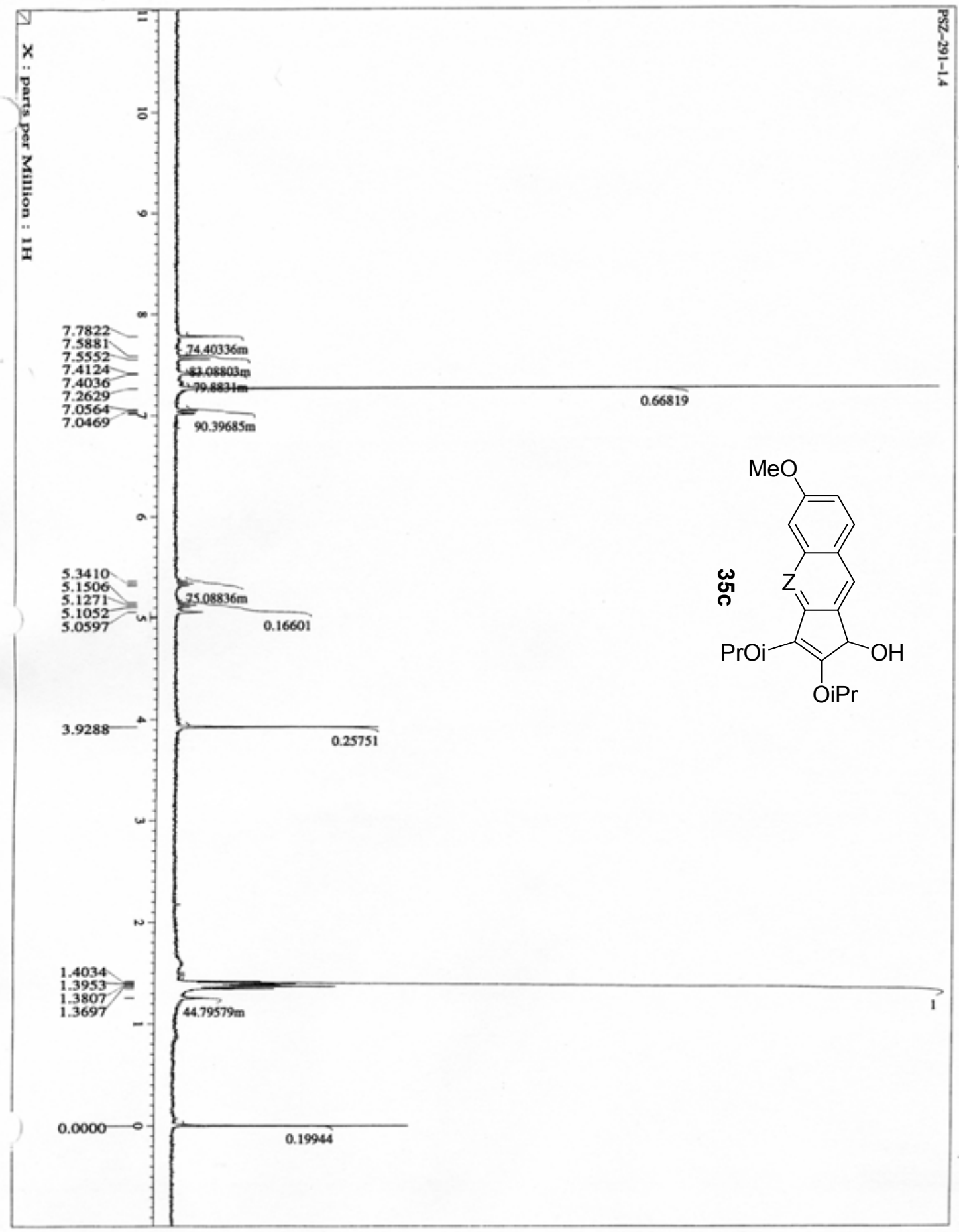

Figure 62: ${ }^{1} \mathrm{H}$ Spectrum of 2,3-Di(1-methylethoxy)-6methoxycyclopenta[b]quinolin-1-ol 35c 


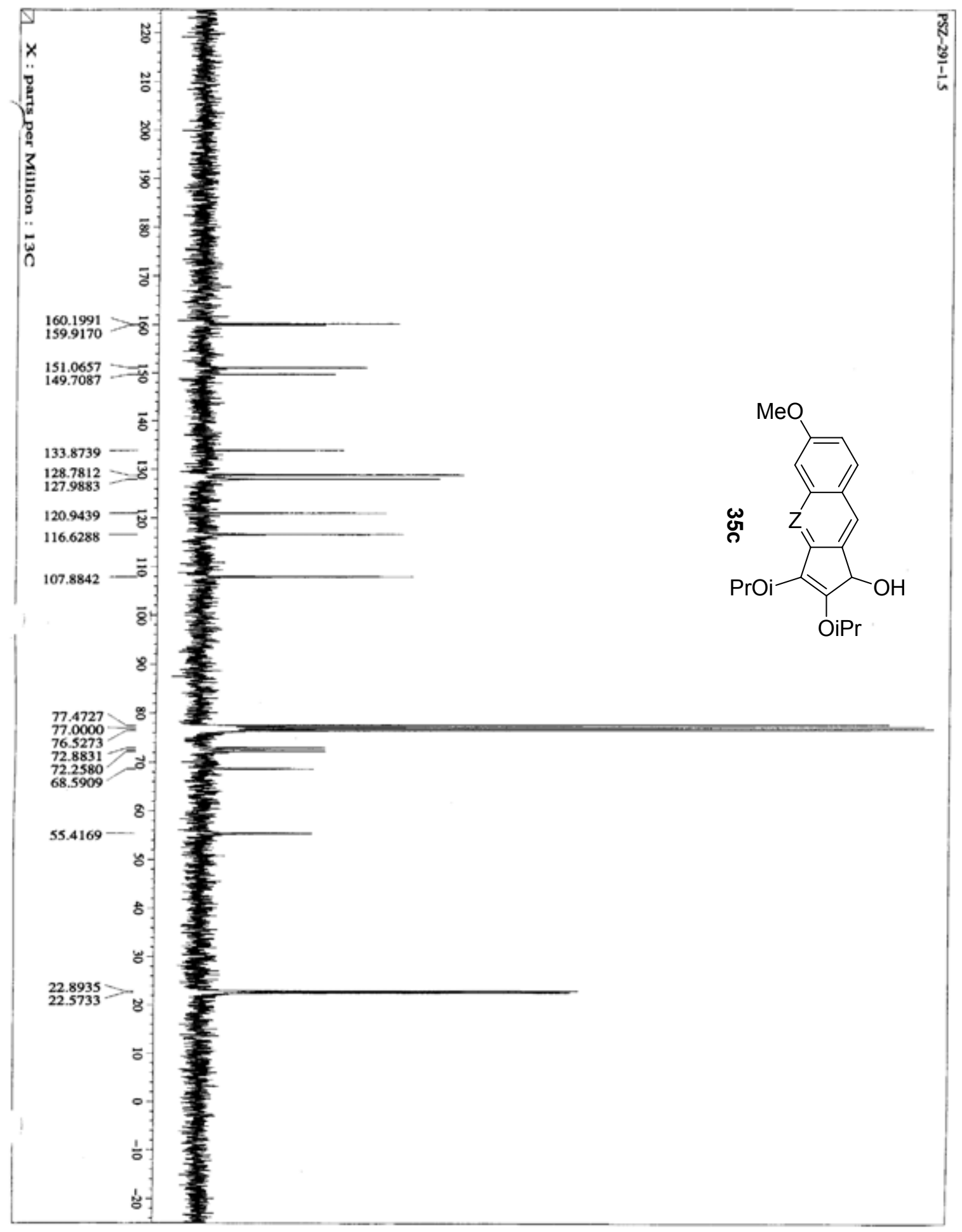

Figure $63:{ }^{13} \mathrm{C}$ Spectrum of 2,3-Di(1-methylethoxy)-6methoxycyclopenta[b]quinolin-1-ol 35c 


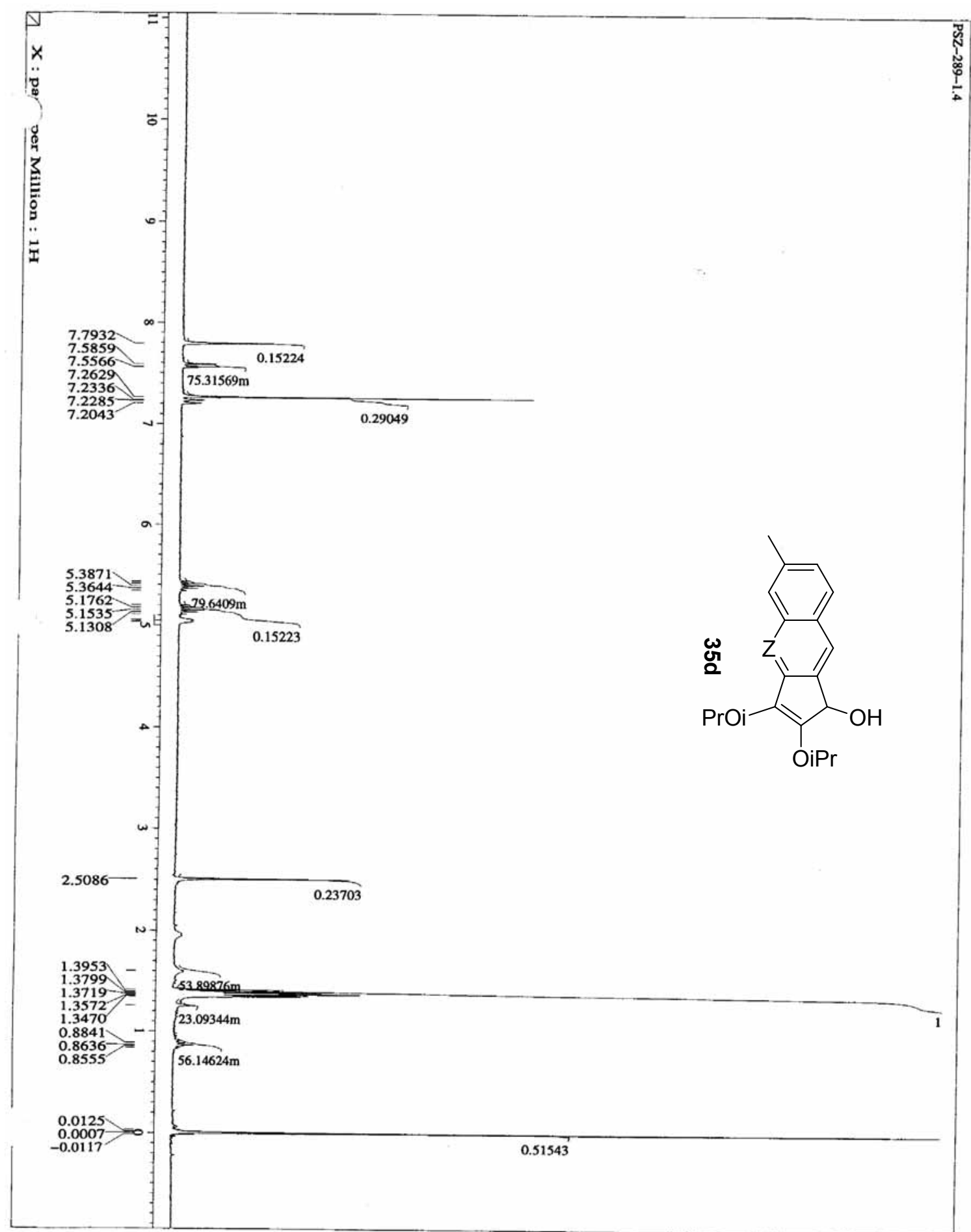

Figure 64: ${ }^{1} \mathrm{H}$ Spectrum of 2,3-Di(1-methylethoxy)-6-methylcyclopenta[b]quinolin$1-\mathrm{ol}$ 35d 


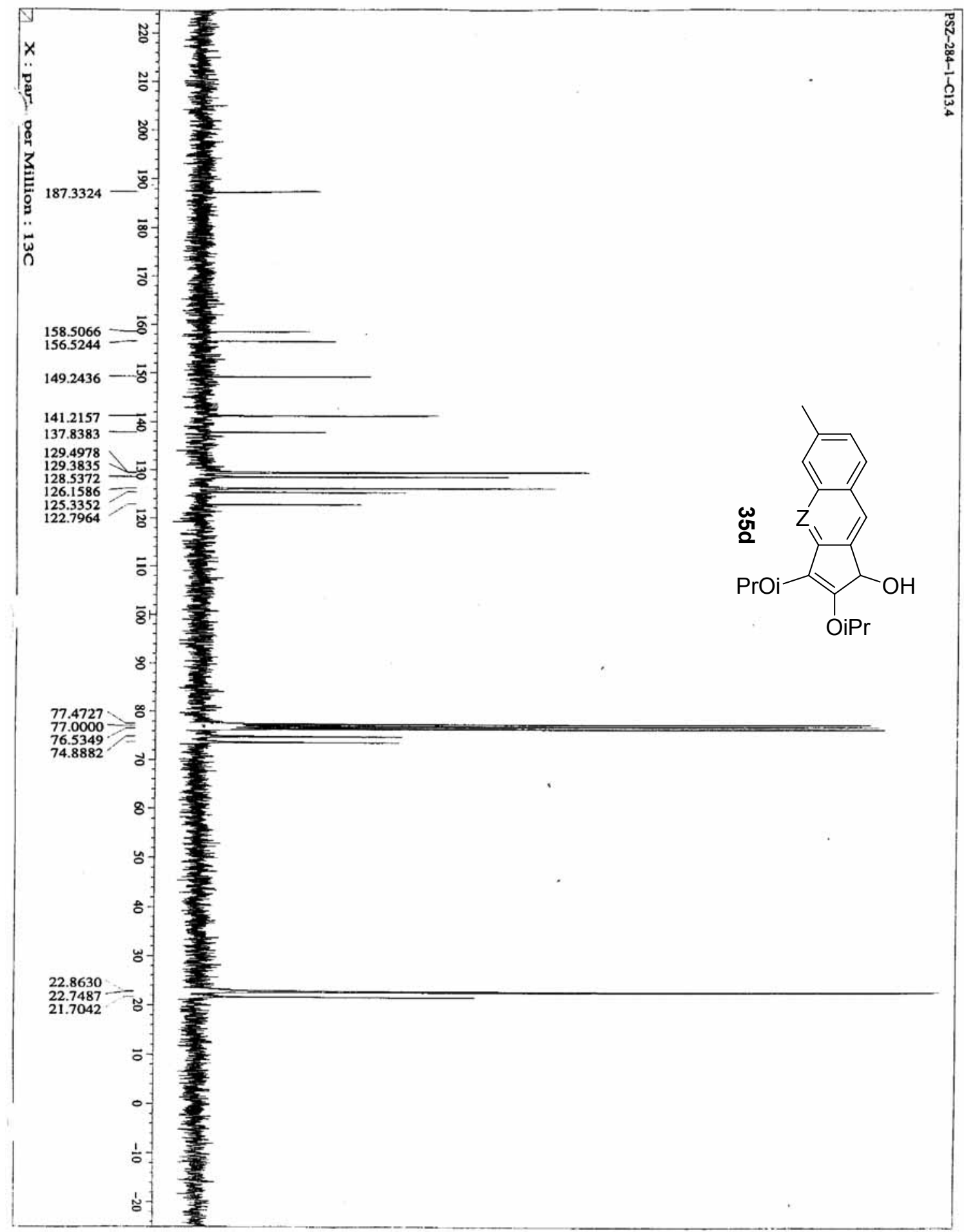

Figure 65: ${ }^{13} \mathrm{C}$ Spectrum of 2,3-Di(1-methylethoxy)-6methylcyclopenta[b]quinolin-1-ol 35d 


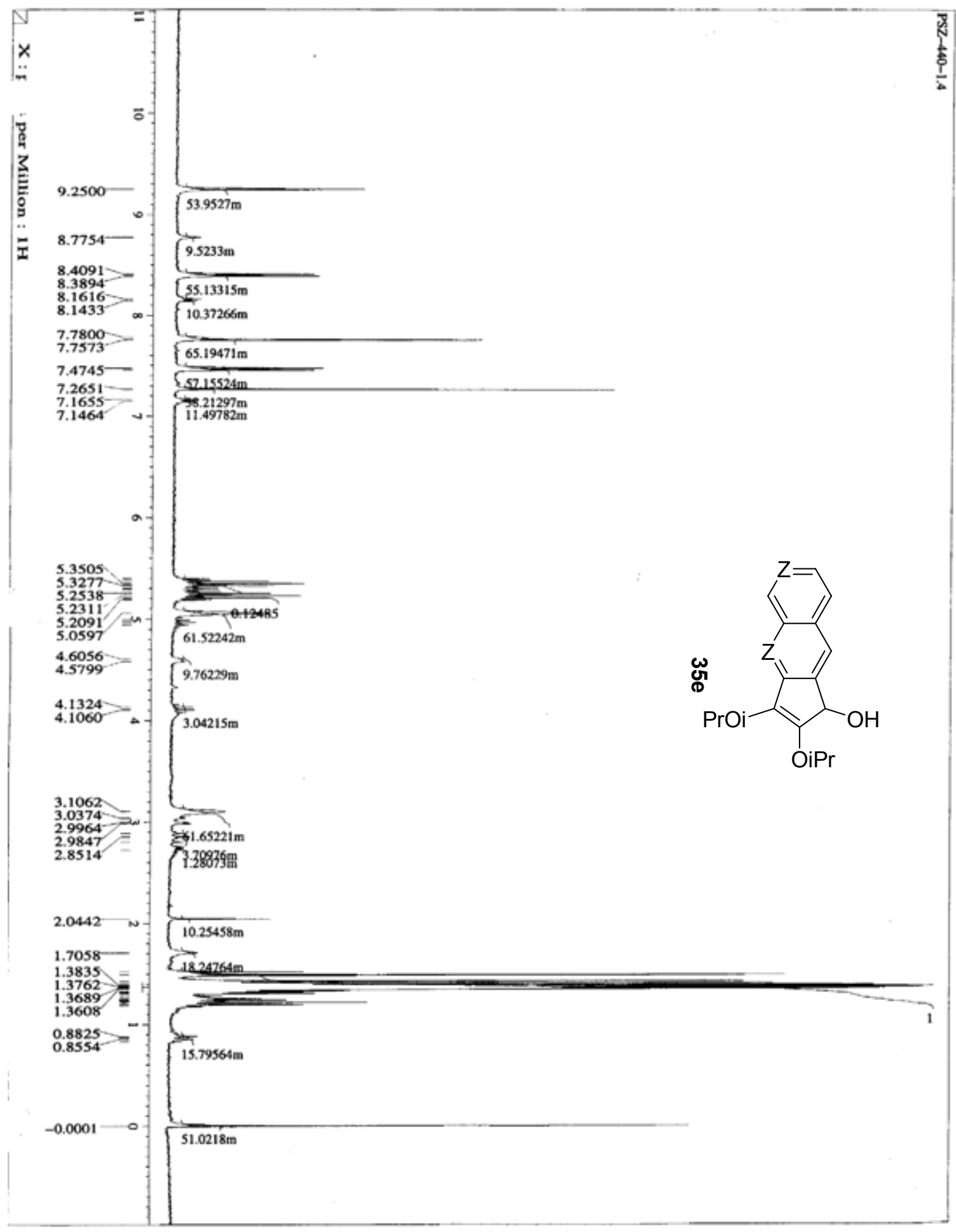

Figure 66: ${ }^{1} \mathrm{H}$ Spectrum of 2,3-Di(1-methylethoxy)-6-azacyclopenta[b]quinolin-1ol 35 e 


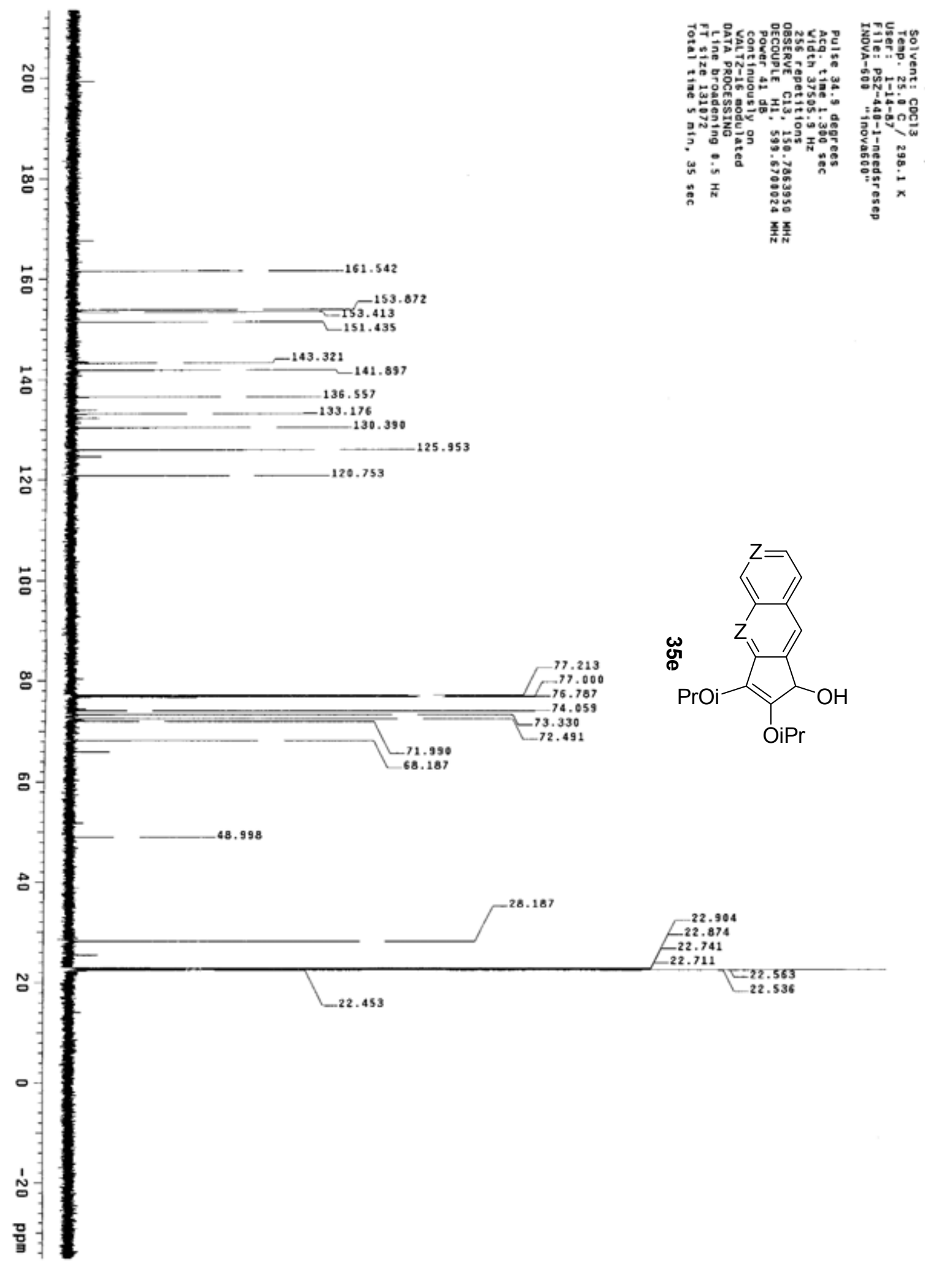

Figure $67:{ }^{13} \mathrm{C}$ Spectrum of 2,3-Di(1-methylethoxy)-6-azacyclopenta[b]quinolin-1ol $35 \mathrm{e}$ 


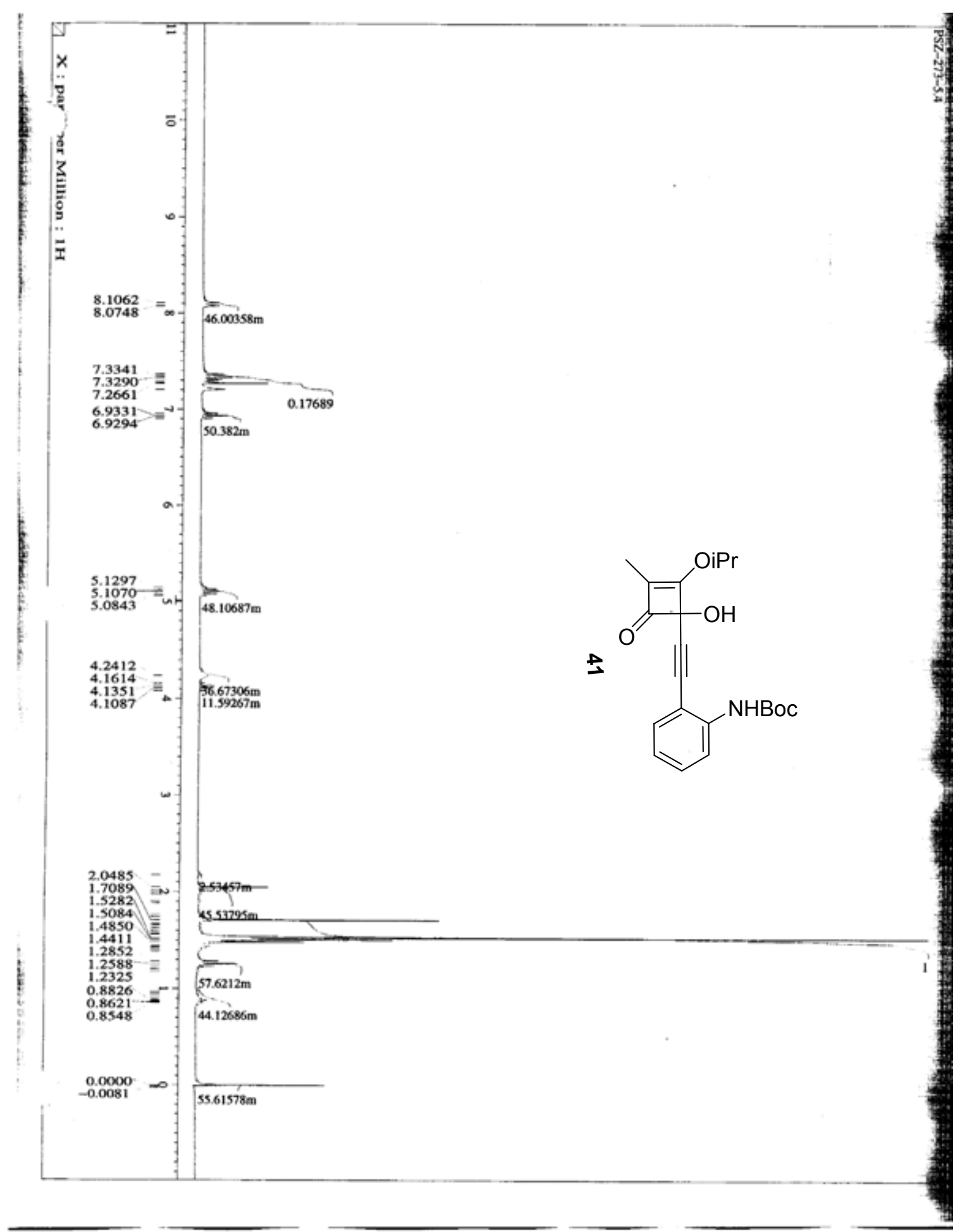

Figure 68: ${ }^{1} \mathrm{H}$ Spectrum of [2-(1-Hydroxy-2-(1-methylethoxy)-3-methyl-4-oxocyclobut-2-enylethynyl)-phenyl]-carbamic acid 1,1-dimethylethyl ester 41 


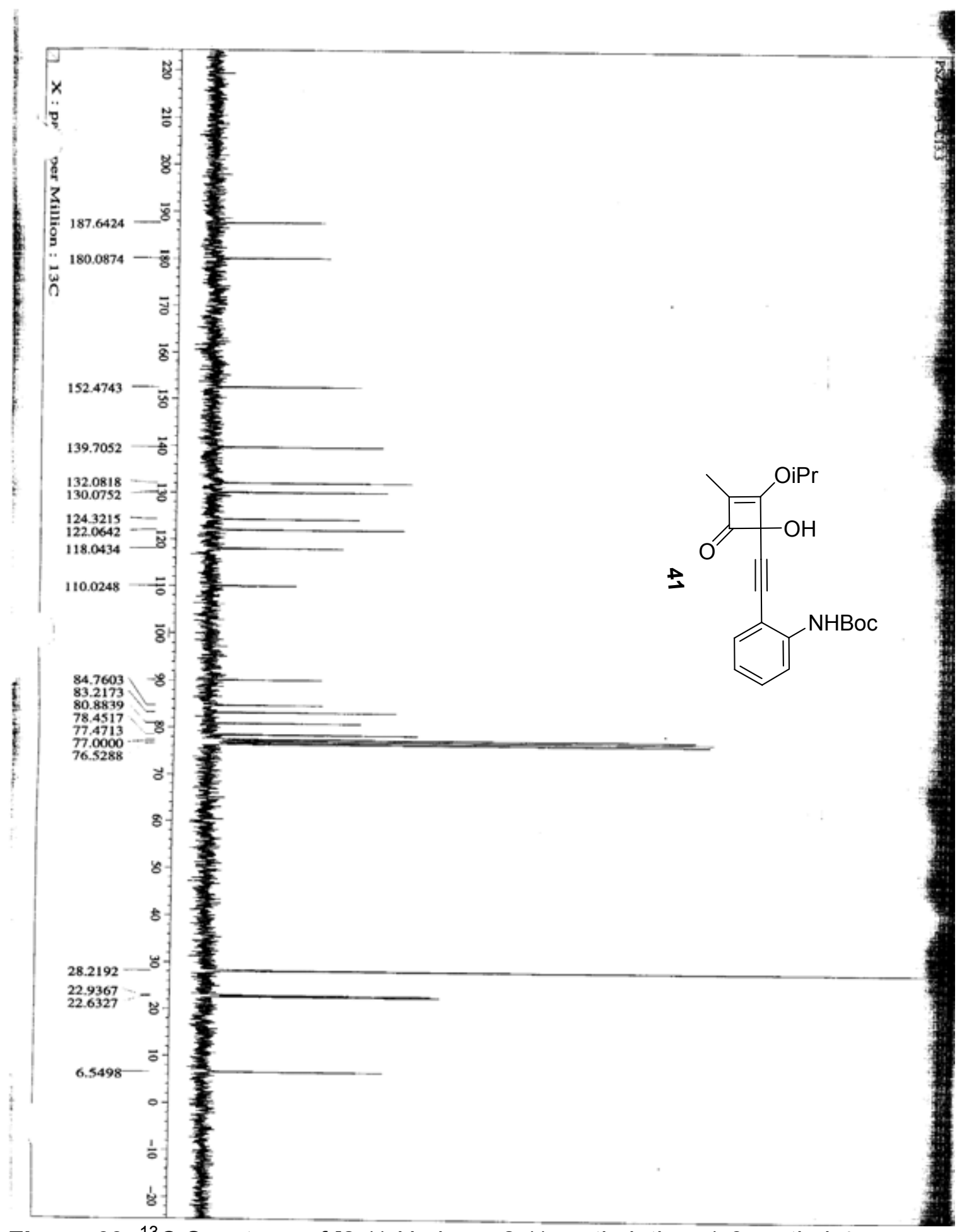

Figure 69: ${ }^{13} \mathrm{C}$ Spectrum of [2-(1-Hydroxy-2-(1-methylethoxy)-3-methyl-4-oxocyclobut-2-enylethynyl)-phenyl]-carbamic acid 1,1-dimethylethyl ester 41 


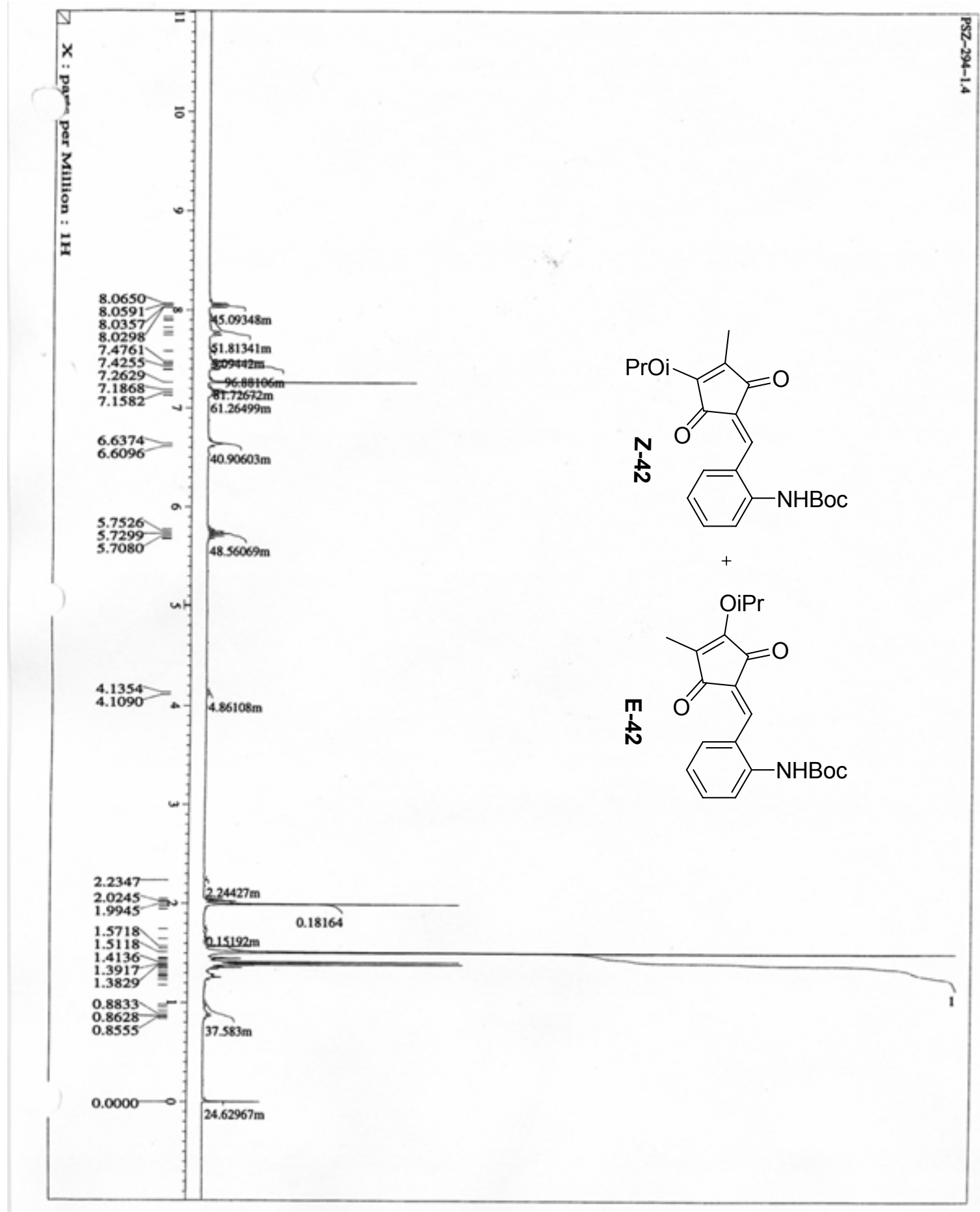

Figure 70: ${ }^{1} \mathrm{H}$ Spectrum of E- and Z-[2-(3-(1-methylethoxy)-4-methyl-2,5-dioxo-3cyclopenten-1-ylmethyl)phenyl]-carbamic acid 1,1-dimethylethyl ester $\mathbf{4 2}$ 


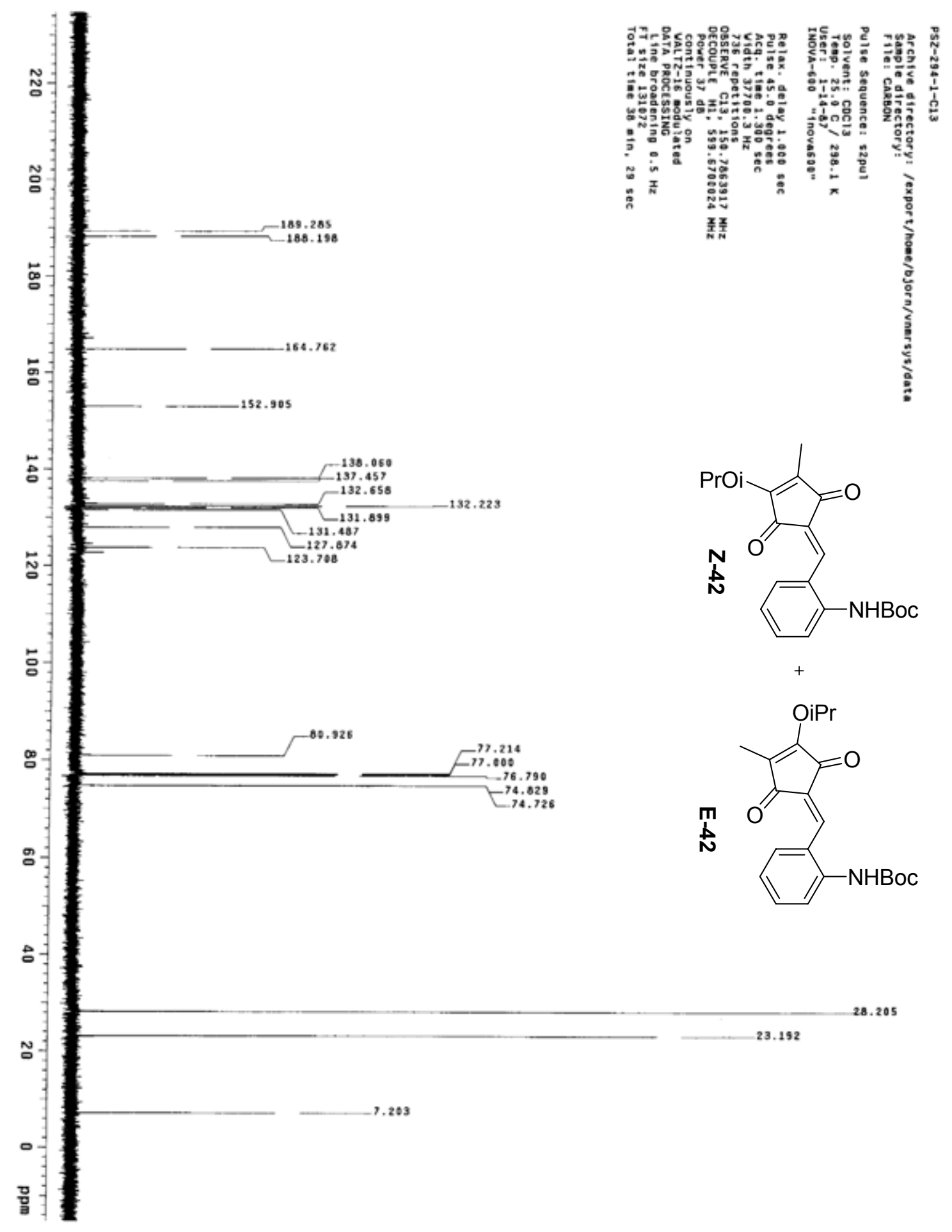

Figure 71: ${ }^{13} \mathrm{C}$ Spectrum of E- and Z-[2-(3-(1-methylethoxy)-4-methyl-2,5-dioxo3-cyclopenten-1-ylmethyl)phenyl]-carbamic acid 1,1-dimethylethyl ester 42 


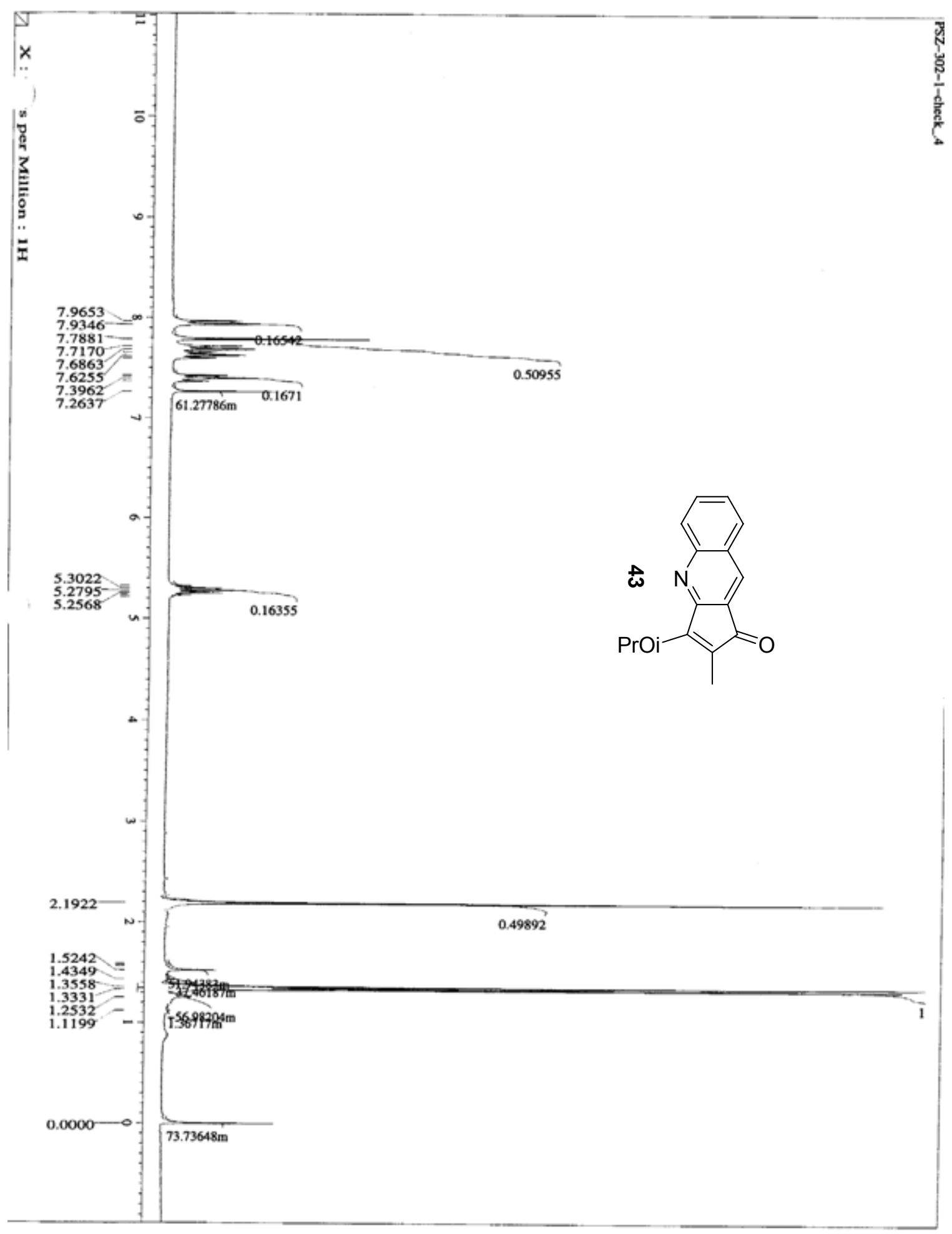

Figure 72: ${ }^{1} \mathrm{H}$ Spectrum of 2-(1-Methylethoxy)-3-methylcyclopenta[b]quinolin-1one 43 


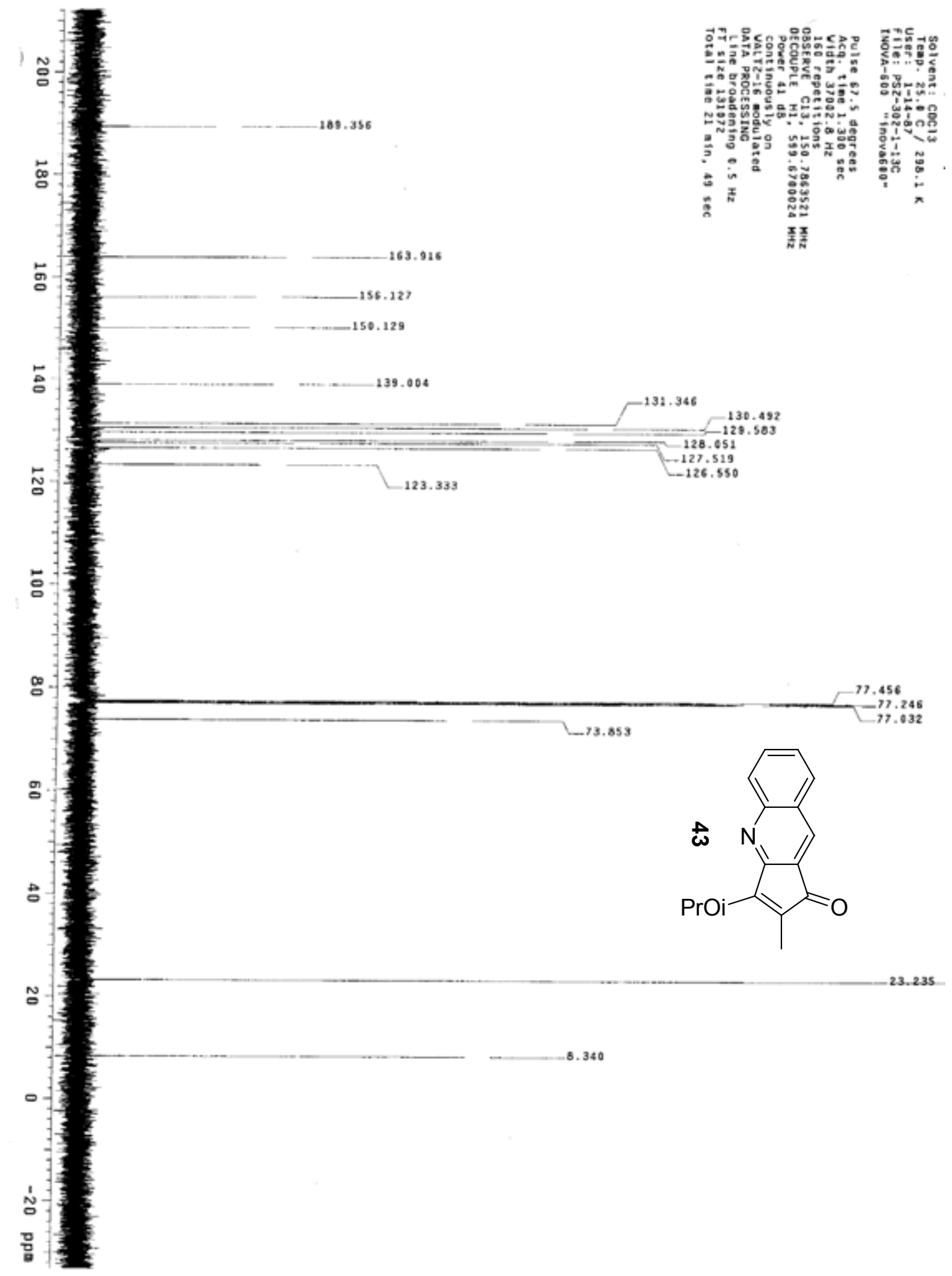

Figure $73:{ }^{13} \mathrm{C}$ Spectrum of 2-(1-Methylethoxy)-3-methylcyclopenta[b]quinolin-1one 43 


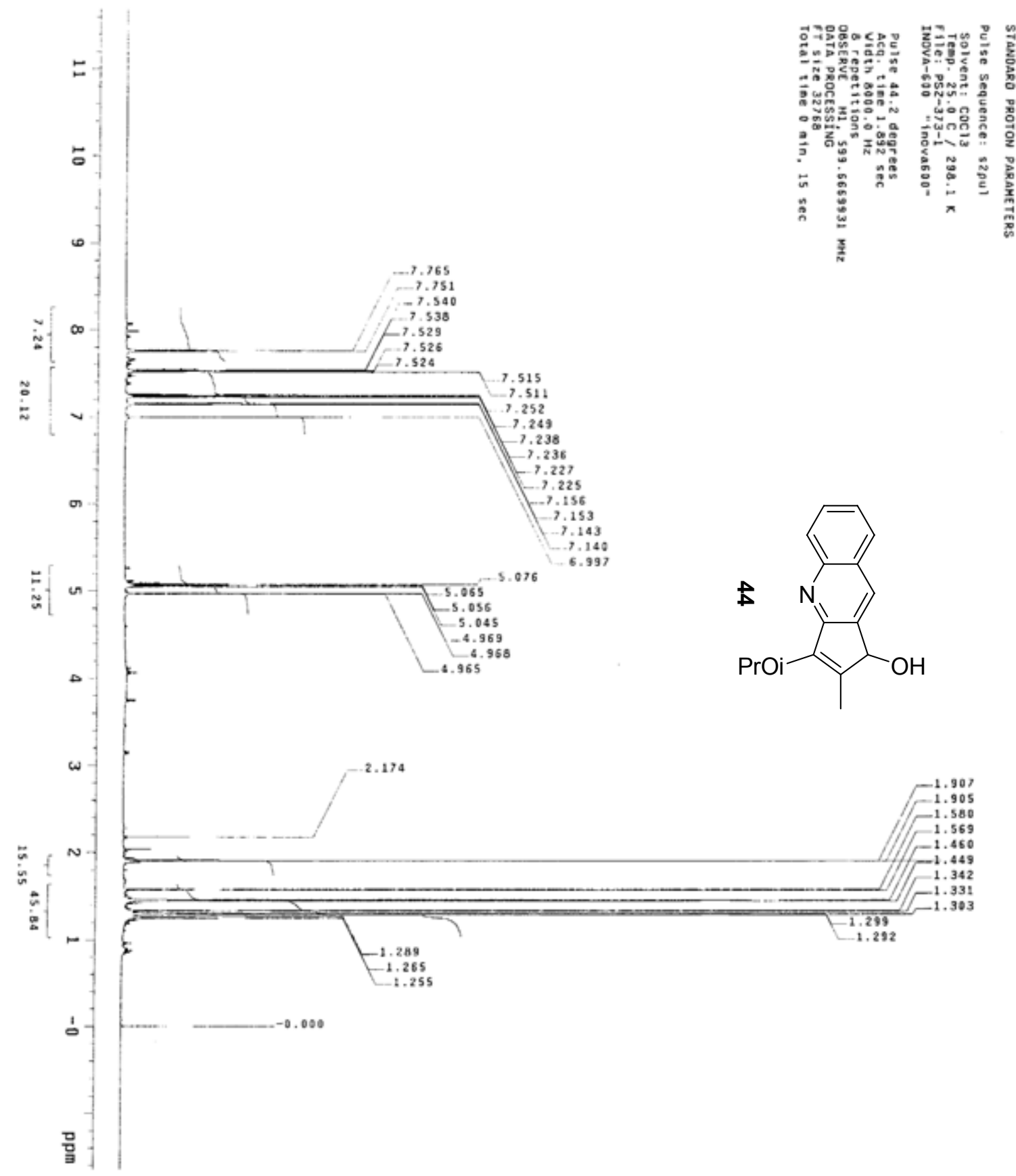

Figure 74: ${ }^{1} \mathrm{H}$ Spectrum of 2-(1-methylethoxy)-3-methylcyclopenta[b]quinolin-1-ol 44 


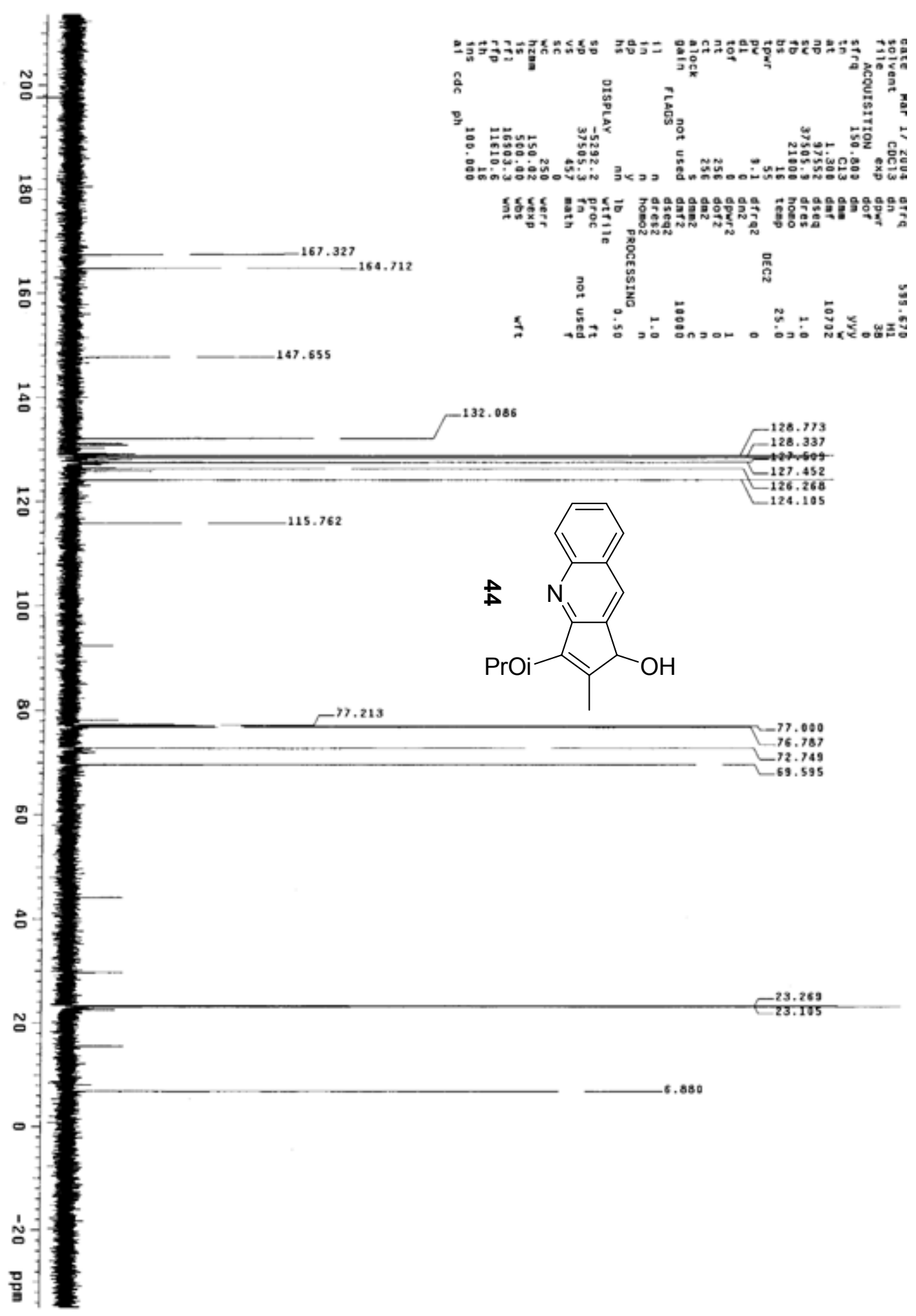

Figure $75:{ }^{13} \mathrm{C}$ Spectrum of 2-(1-methylethoxy)-3-methylcyclopenta[b]quinolin-1ol 44 


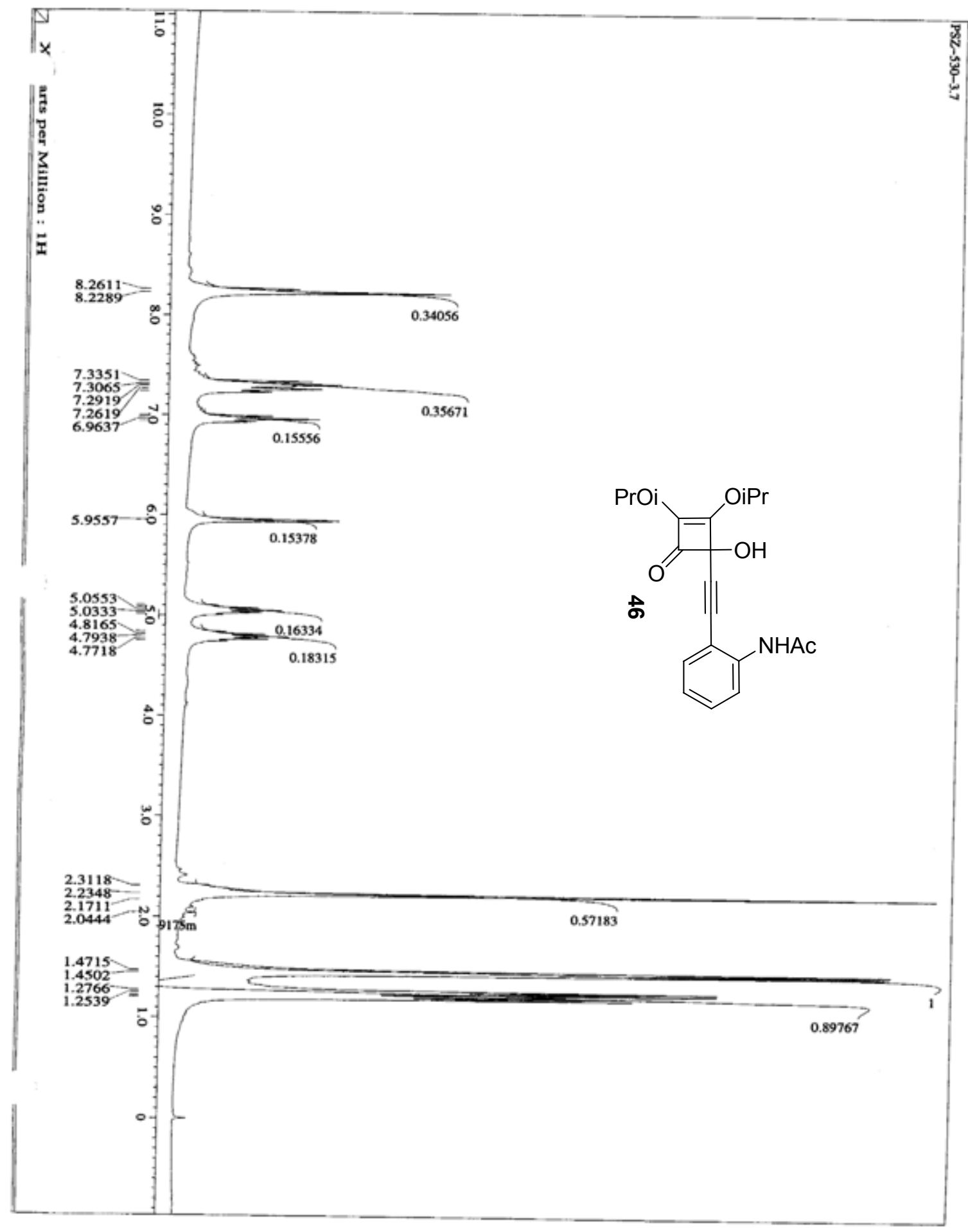

Figure 76: ${ }^{1} \mathrm{H}$ Spectrum of $\mathrm{N}-[2-(1-H y d r o x y-2,3-d i i s o p r o p o x y-4-o x o-c y c l o b u t-2-$ enylethynyl)-phenyl]-acetamide. 46 


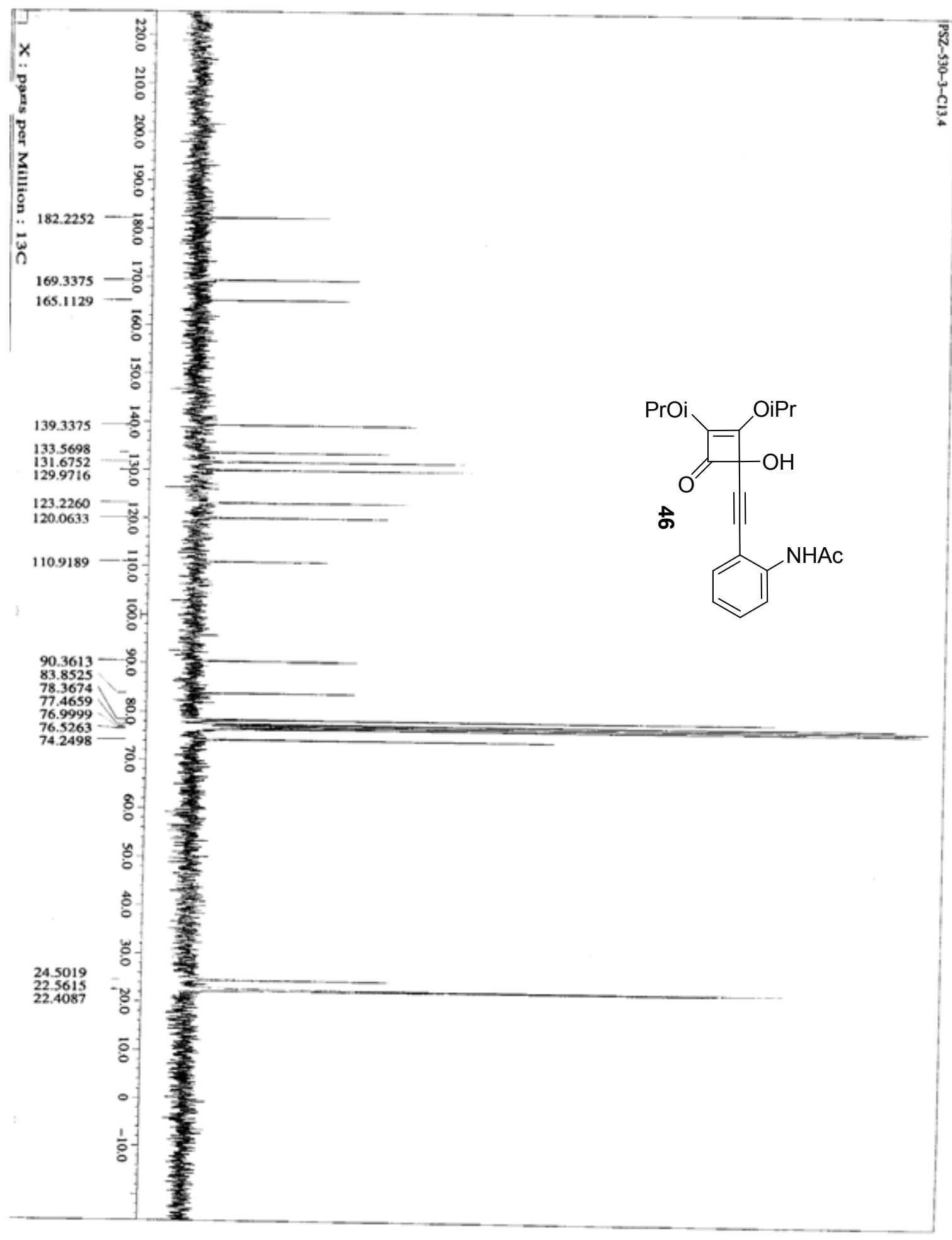

Figure 77: ${ }^{13} \mathrm{C}$ Spectrum of $\mathrm{N}$-[2-(1-Hydroxy-2,3-diisopropoxy-4-oxo-cyclobut-2enylethynyl)-phenyl]-acetamide 46 


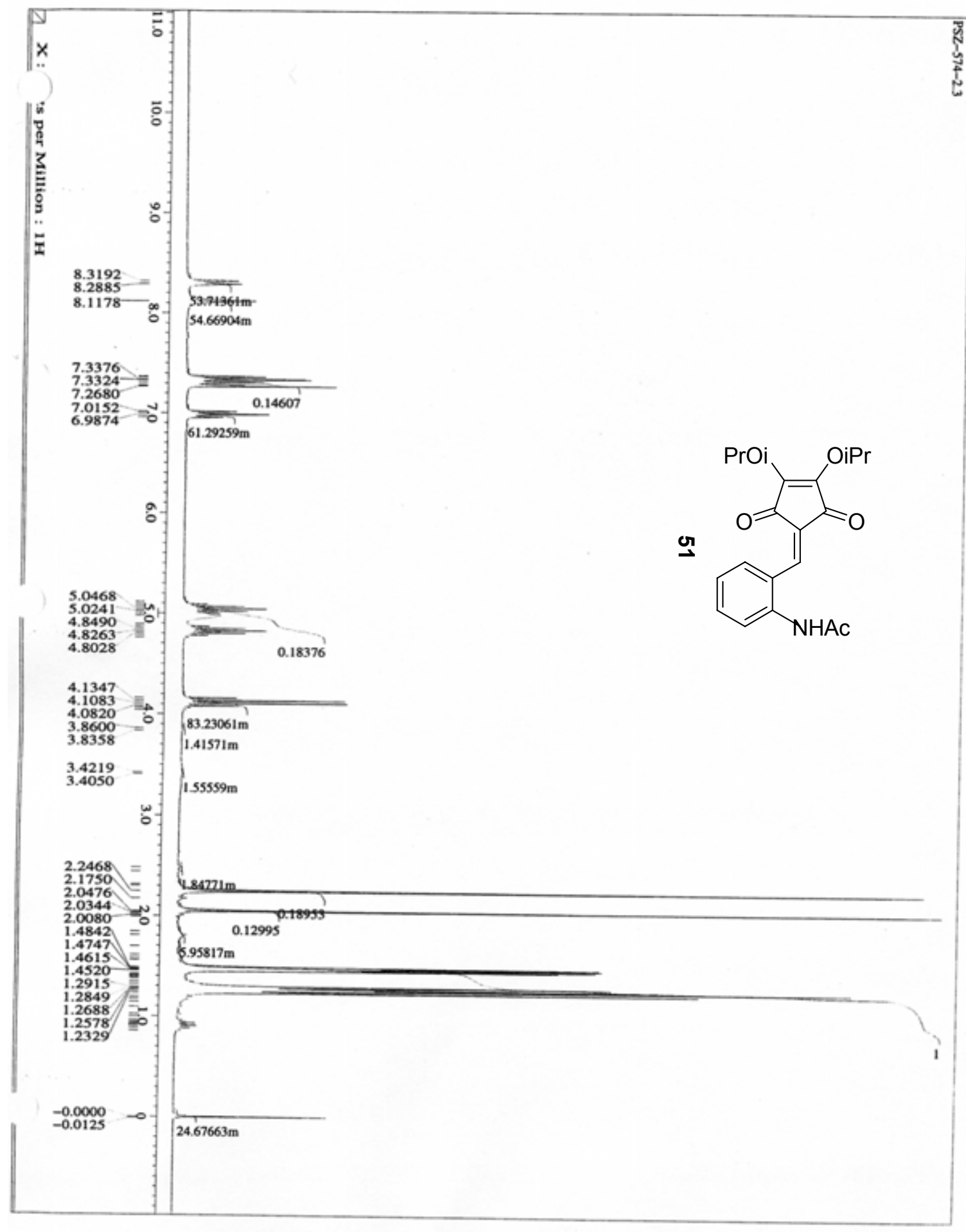

Figure 78: ${ }^{1} \mathrm{H}$ Spectrum of $\mathrm{N}$-[2-(3,4-Diisopropoxy-2,5-dioxo-cyclopent-3enylidenemethyl)-phenyl]-acetamide 51 


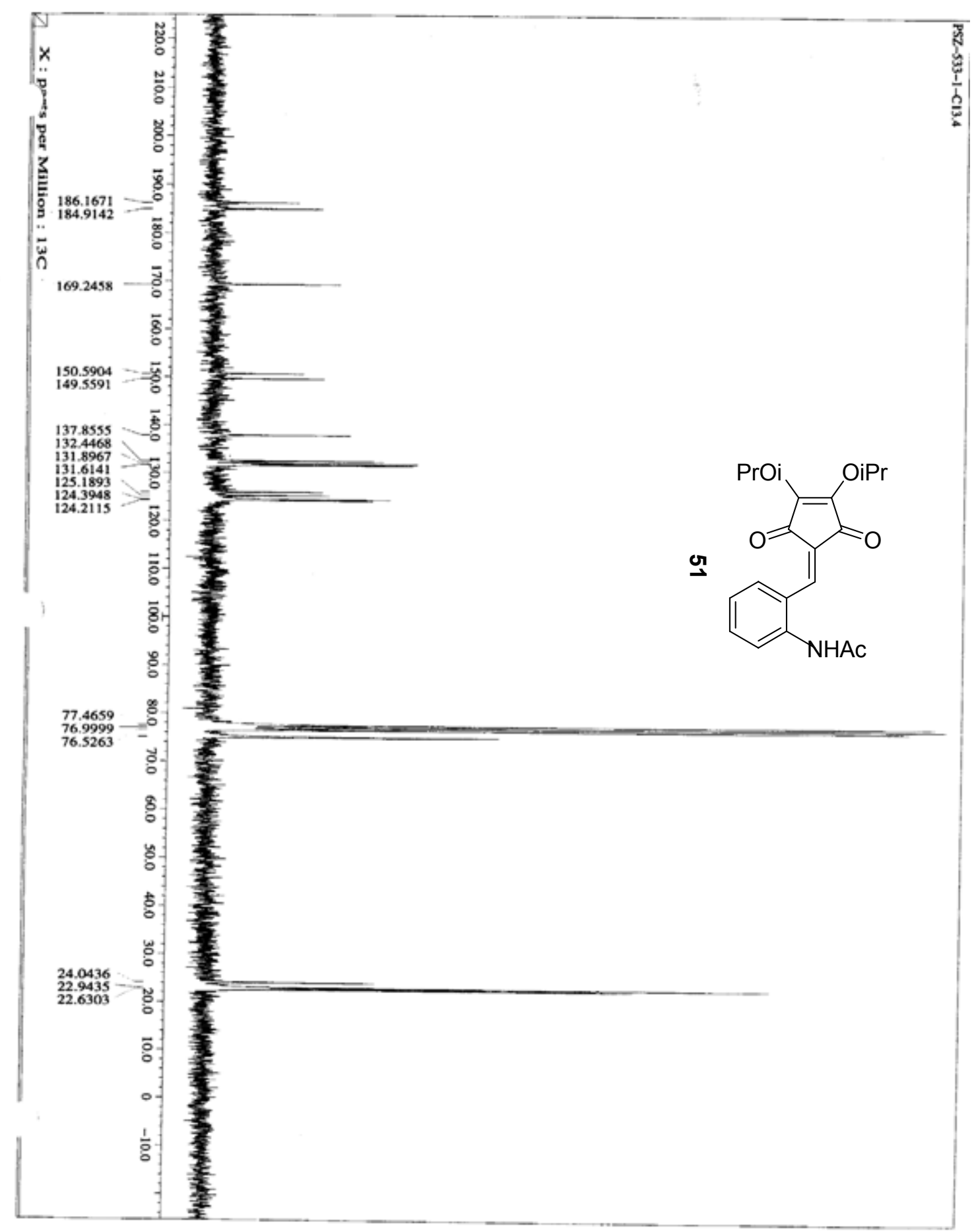

Figure 79: ${ }^{13} \mathrm{C}$ Spectrum of N-[2-(3,4-Diisopropoxy-2,5-dioxo-cyclopent-3enylidenemethyl)-phenyl]-acetamide 51 


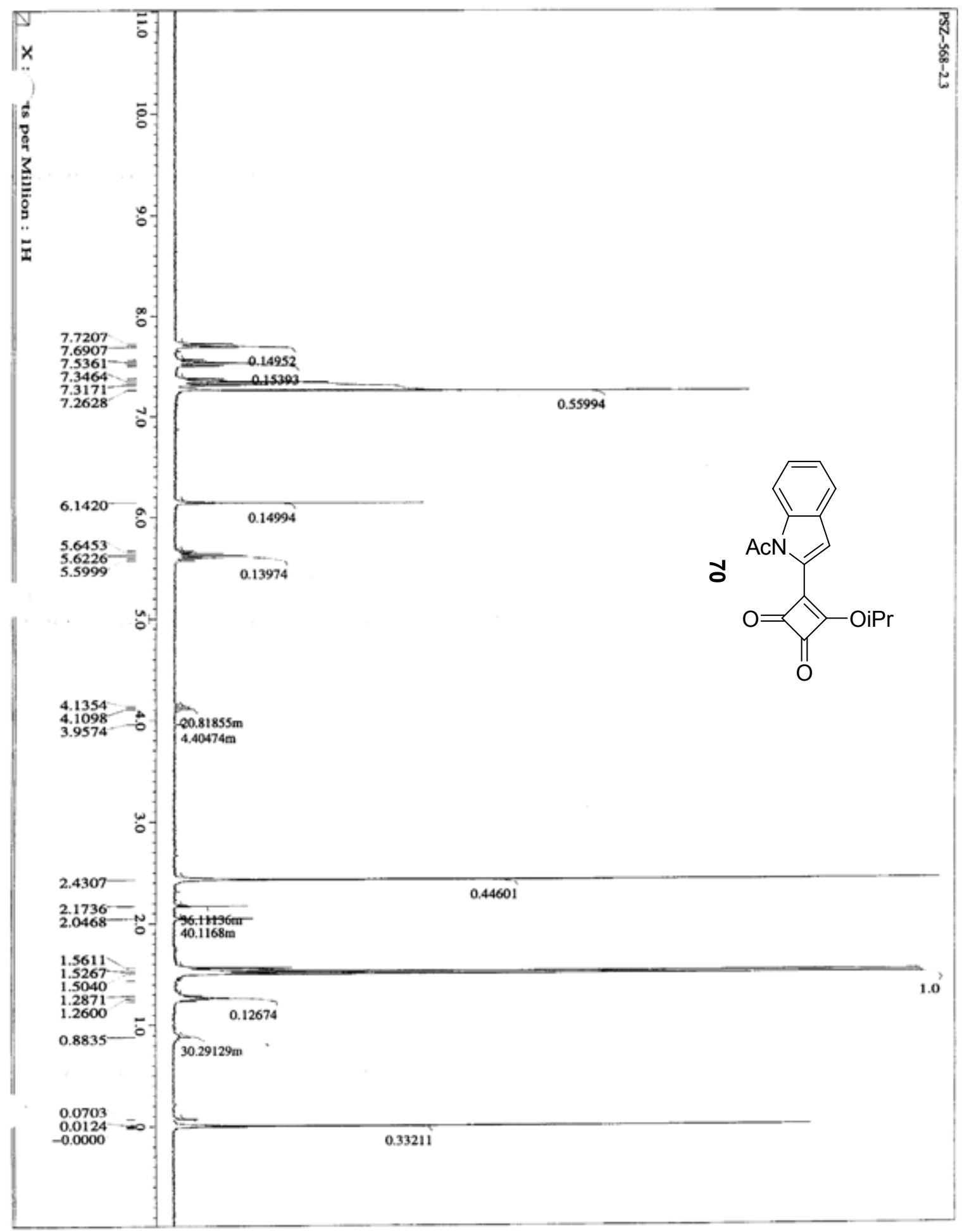

Figure 80: ${ }^{1} \mathrm{H}$ Spectrum of 3-(1-Acetyl-1H-indol-3-yl)-4-isopropoxy-cyclobut-3ene-1,2-dione. 70 


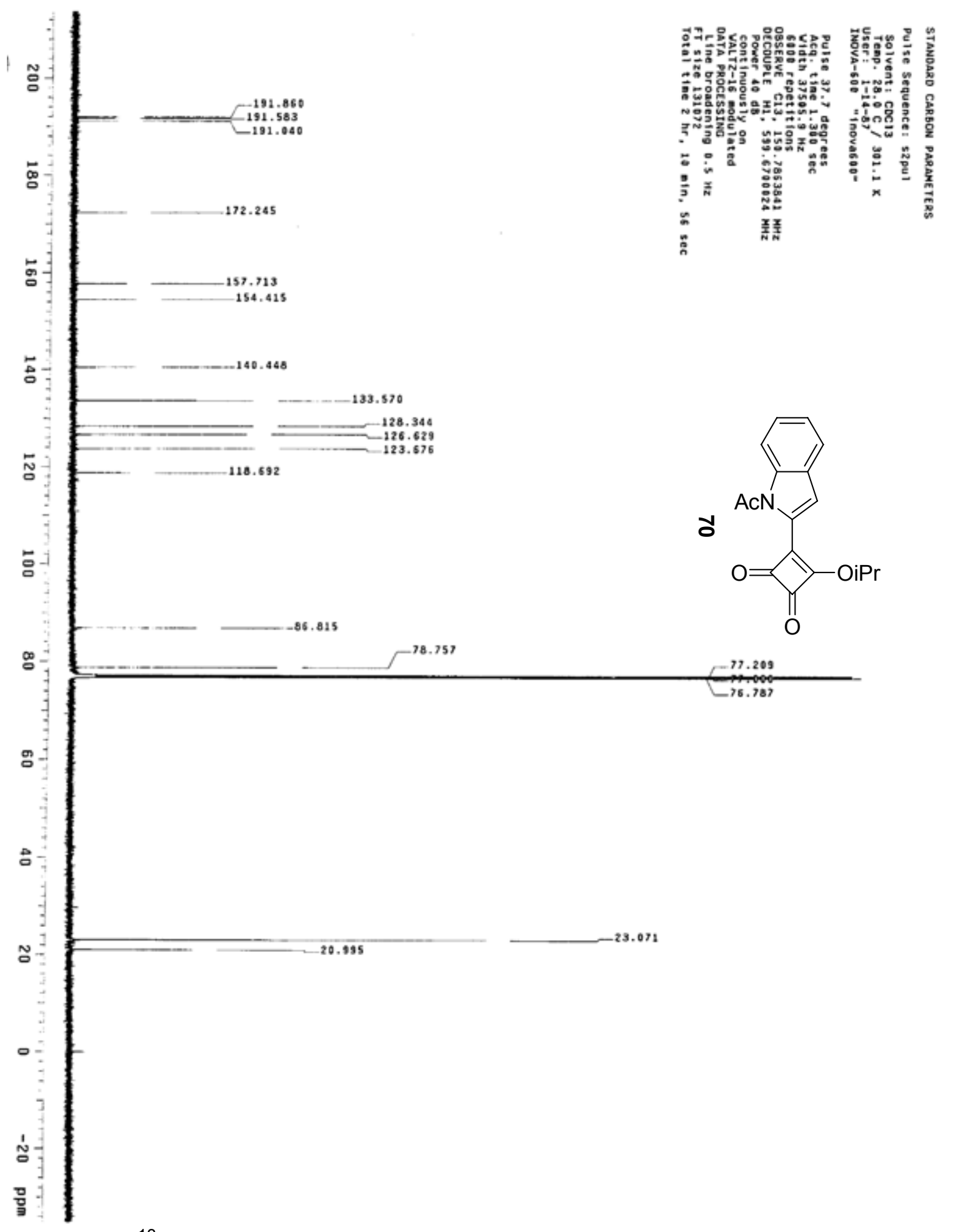

Figure 81: ${ }^{13} \mathrm{C}$ Spectrum of 3-(1-Acetyl-1H-indol-3-yl)-4-isopropoxy-cyclobut-3ene-1,2-dione. 70 


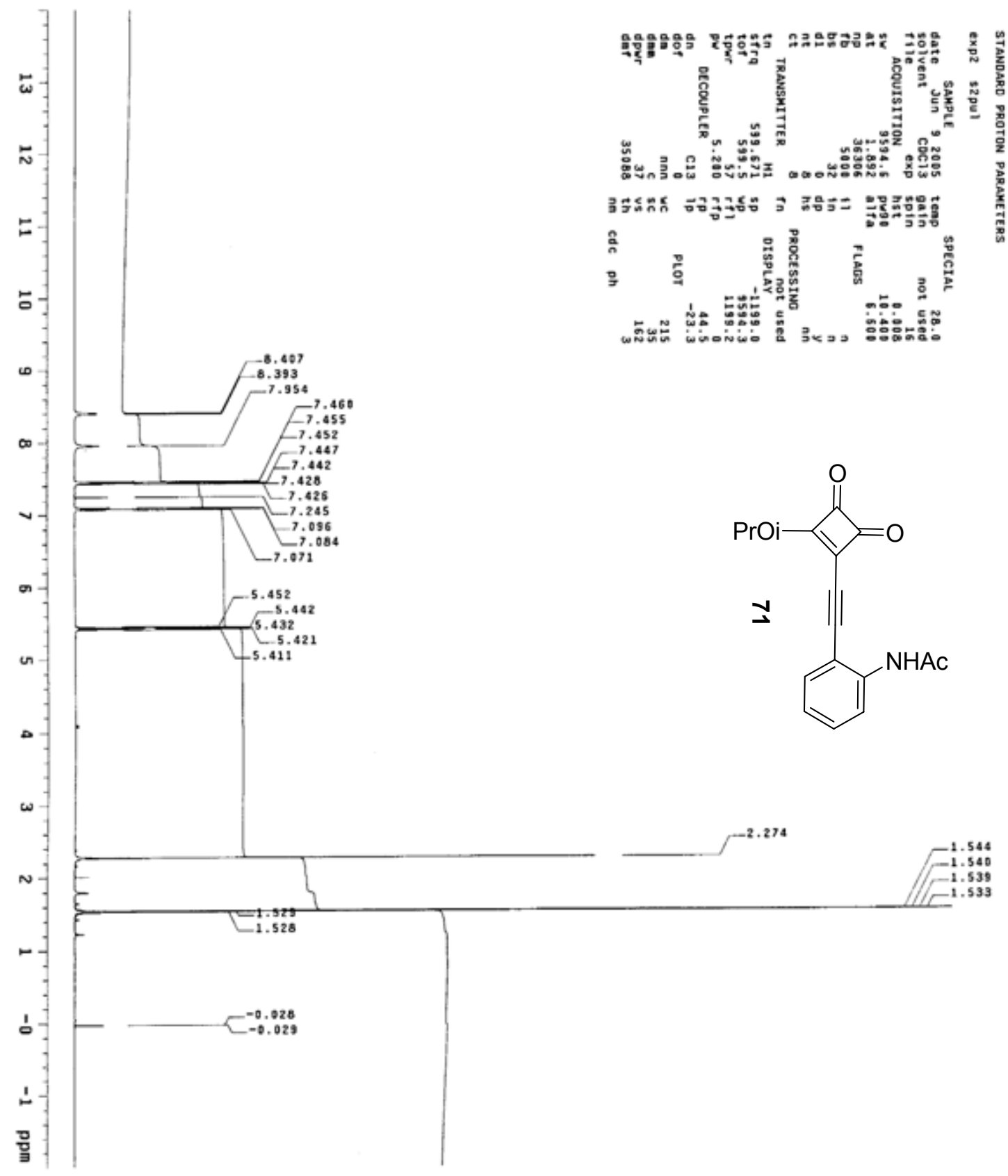

Figure 82: ${ }^{1} \mathrm{H}$ Spectrum of $\mathrm{N}$-[2-(2-Isopropoxy-3,4-dioxo-cyclobut-1-enylethynyl)phenyl]-acetamide $\mathbf{7 1}$ 


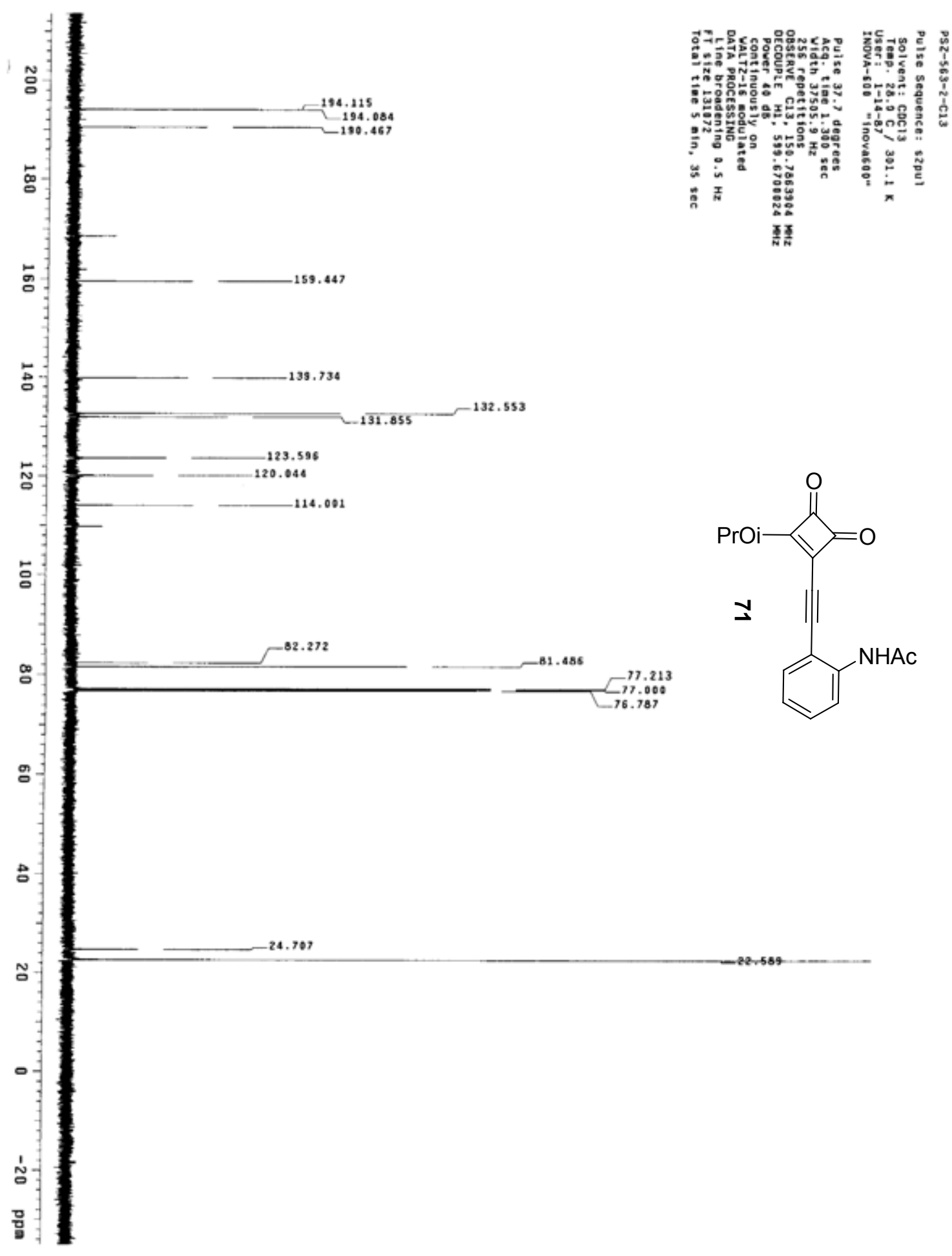

Figure 83: ${ }^{13} \mathrm{C}$ Spectrum of N-[2-(2-Isopropoxy-3,4-dioxo-cyclobut-1enylethynyl)-phenyl]-acetamide 71 


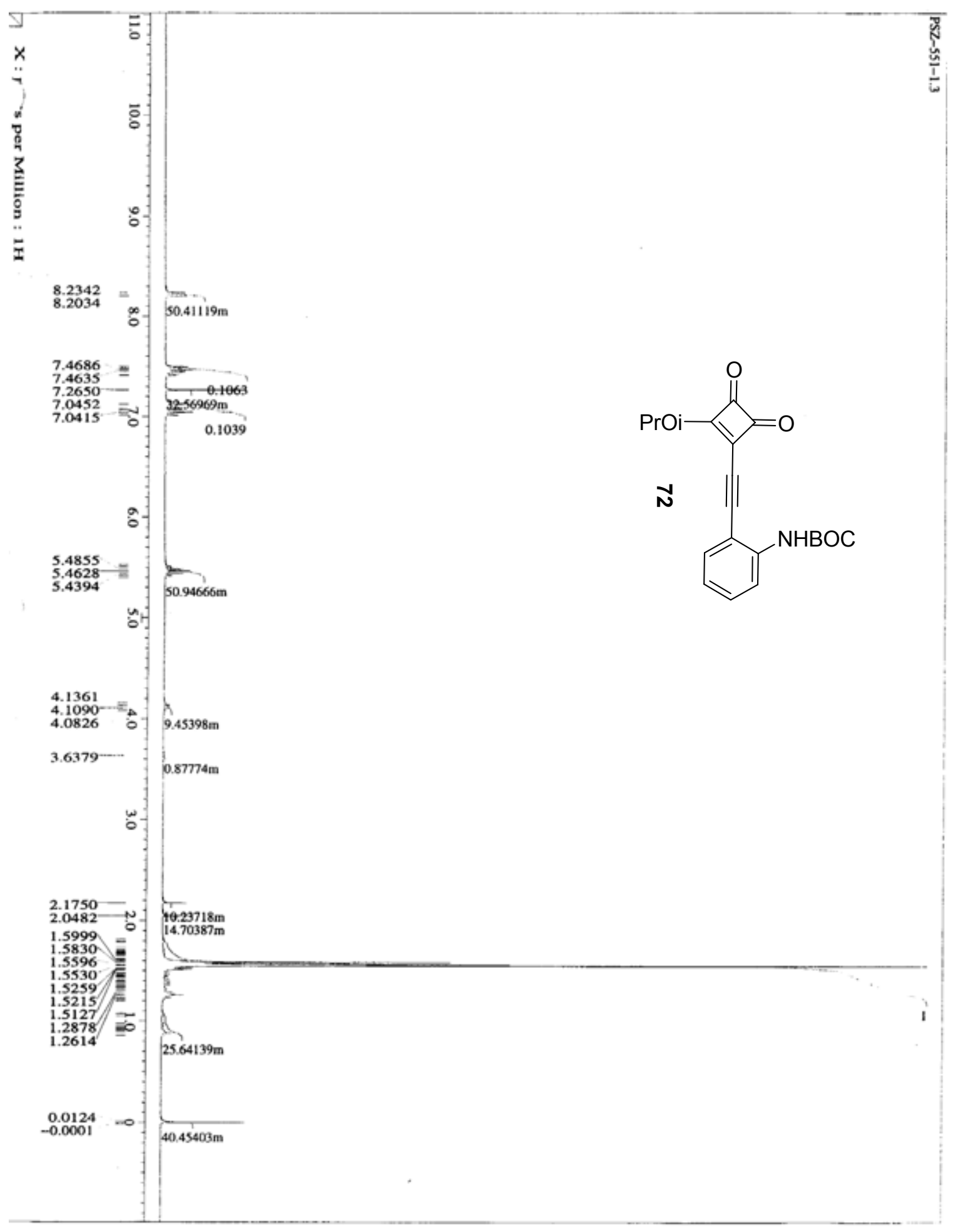

Figure 84: ${ }^{1} \mathrm{H}$ Spectrum of tert-butyl $2-(2-\overline{2-i s o p r o p o x y-3,4-d i o x o c y c l o b u t-1-~}$ enyl)ethynyl)phenylcarbamate $\mathbf{7 2}$ 

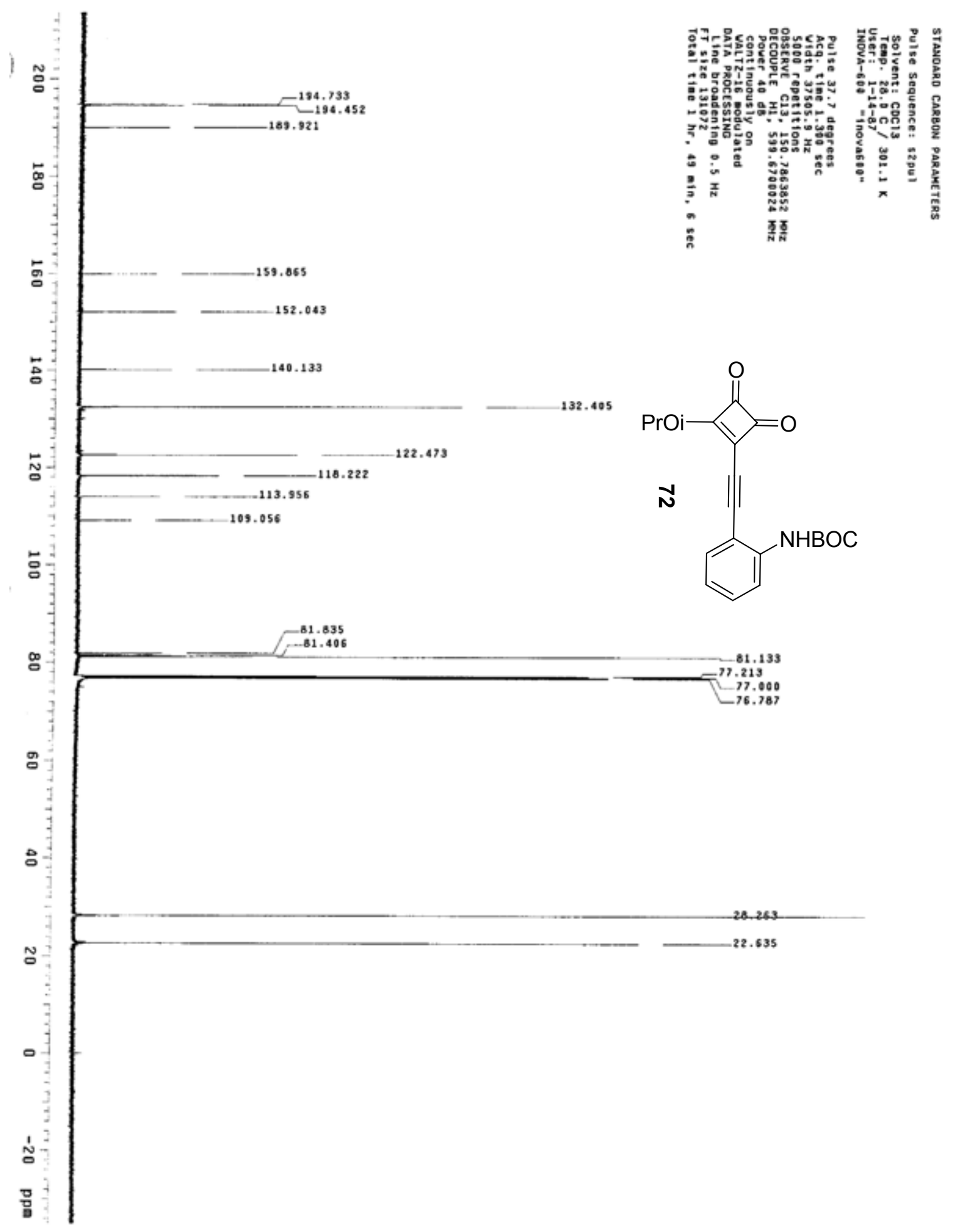

Figure $85:{ }^{13} \mathrm{C}$ Spectrum of tert-butyl 2-(2-(2-isopropoxy-3,4-dioxocyclobut-1enyl)ethynyl)phenylcarbamate $\mathbf{7 2}$ 


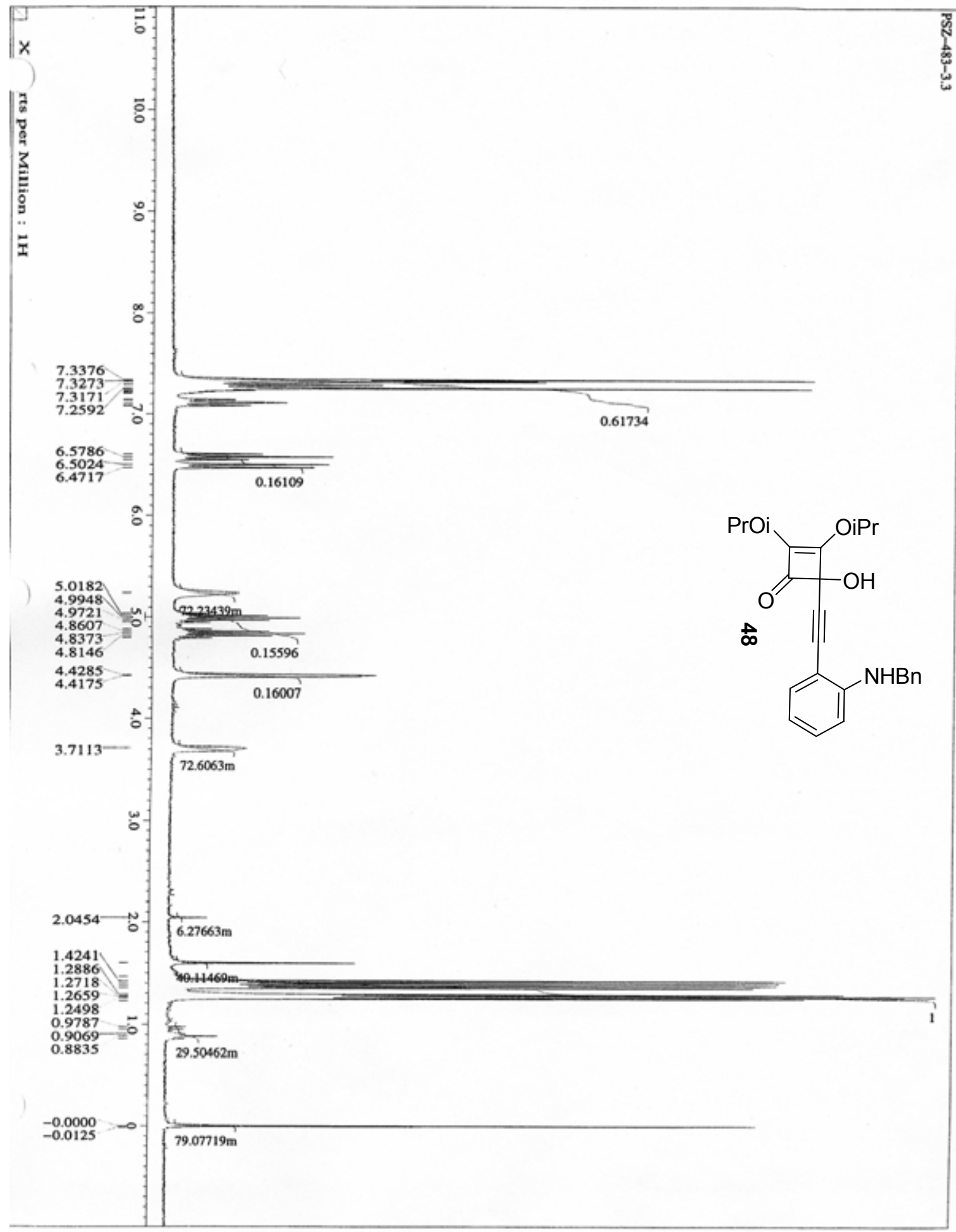

Figure 86: ${ }^{1} \mathrm{H}$ Spectrum of 4-(2-Benzylamino-phenylethynyl)-4-hydroxy-2,3diisopropoxy-cyclobut-2-enone 48 


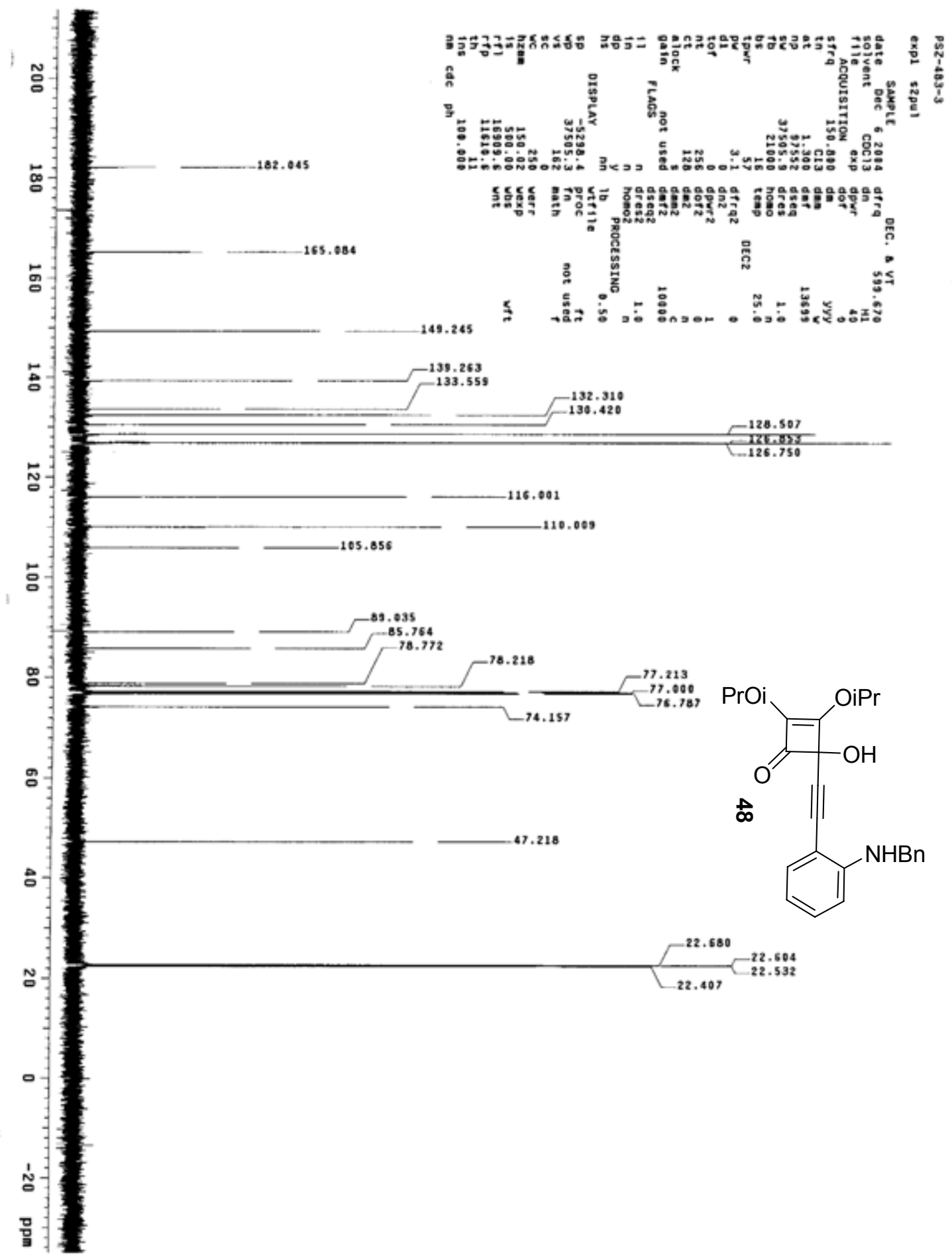

Figure 87: ${ }^{13} \mathrm{C}$ Spectrum of 4-(2-Benzylamino-phenylethynyl)-4-hydroxy-2,3diisopropoxy-cyclobut-2-enone 48 


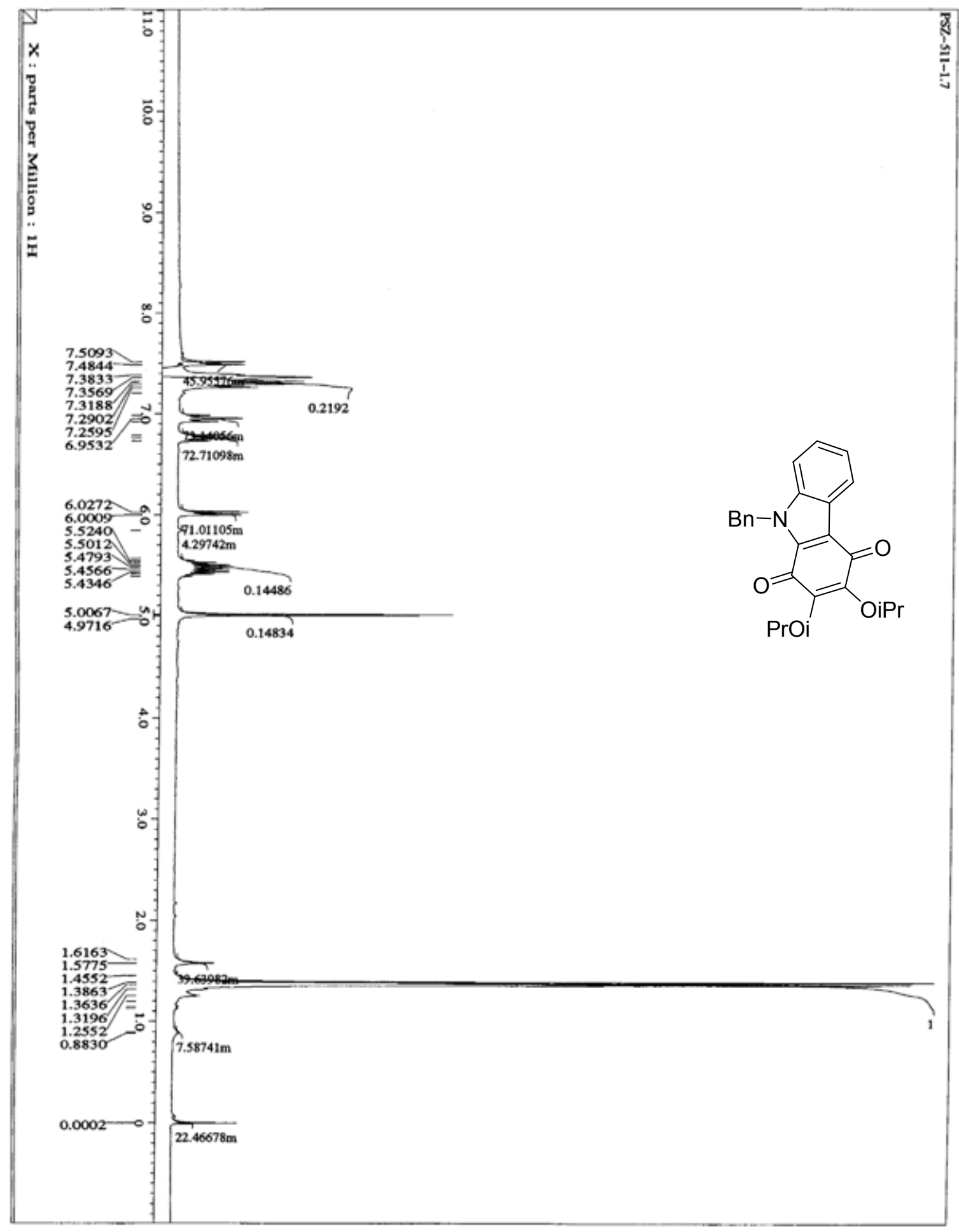

Figure 88: ${ }^{1} \mathrm{H}$ Spectrum of 9-Benzyl-2,3-diisopropoxy-9H-carbazole-1,4-dione 69 


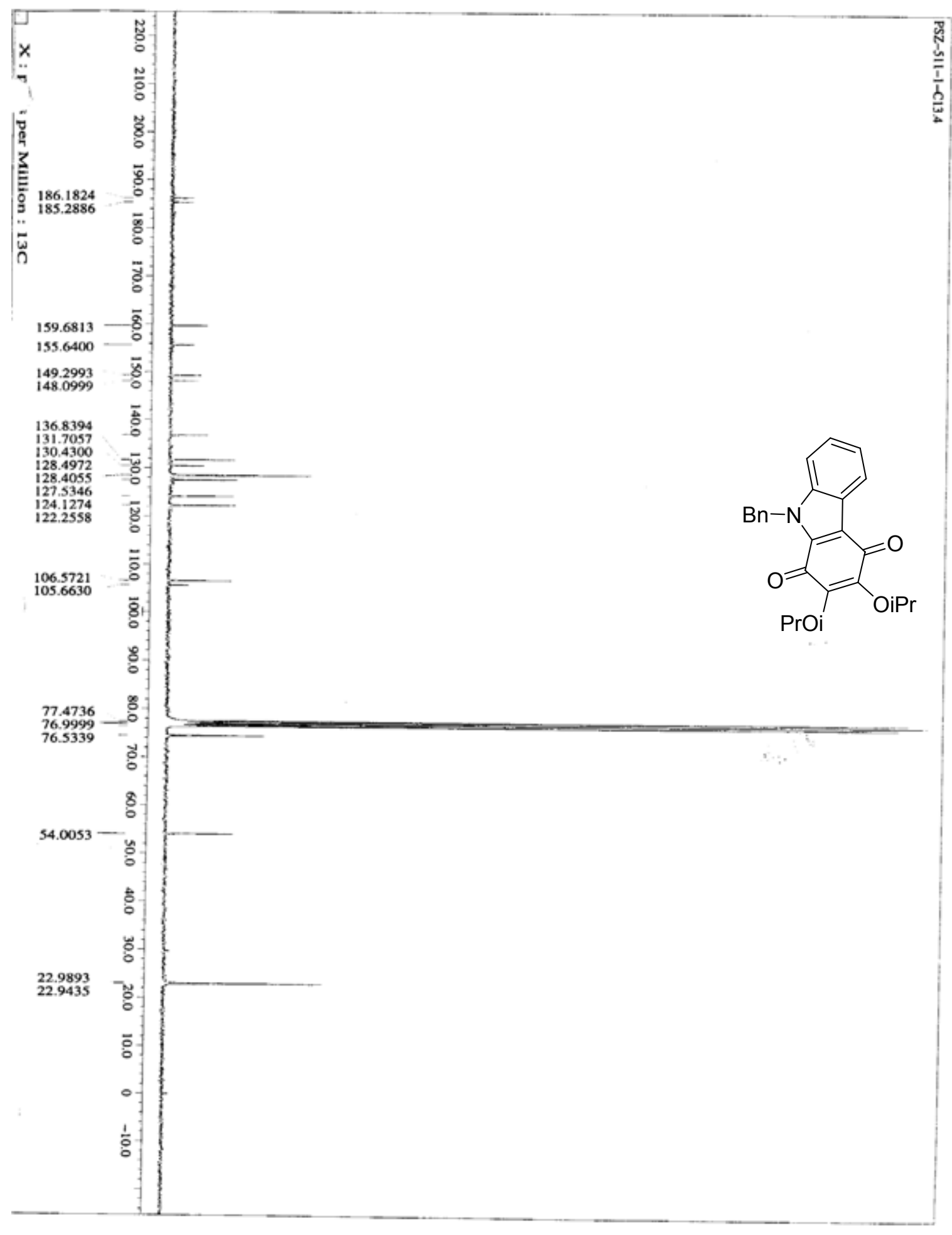

Figure 89: ${ }^{13} \mathrm{C}$ Spectrum of 9-Benzyl-2,3-diisopropoxy-9H-carbazole-1,4-dione 69 


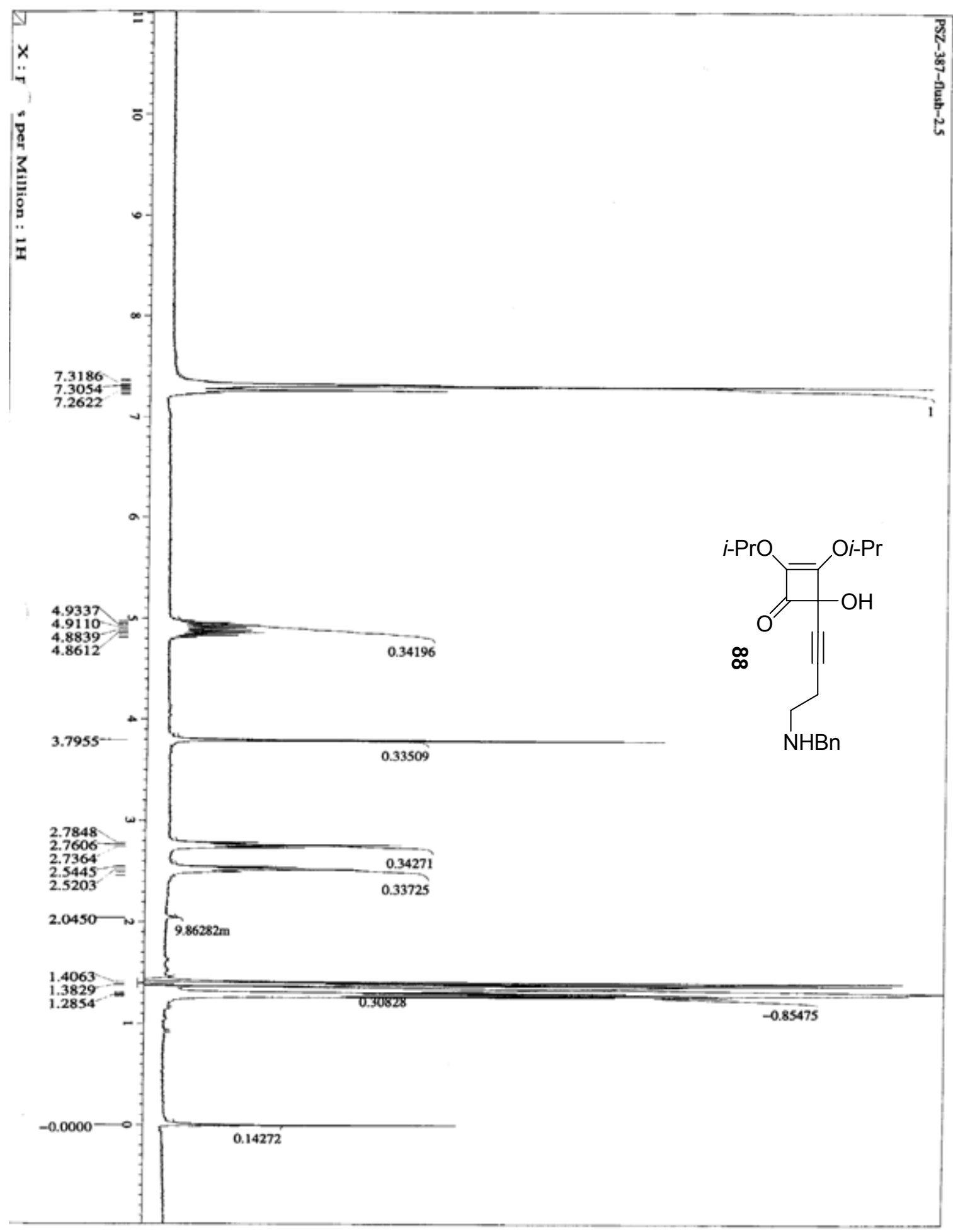

Figure 90: ${ }^{1} \mathrm{H}$ Spectrum of 4-(4-Benzylamino-but-1-ynyl)-4-hydroxy-2,3diisopropoxy-cyclobut-2-enone 88 


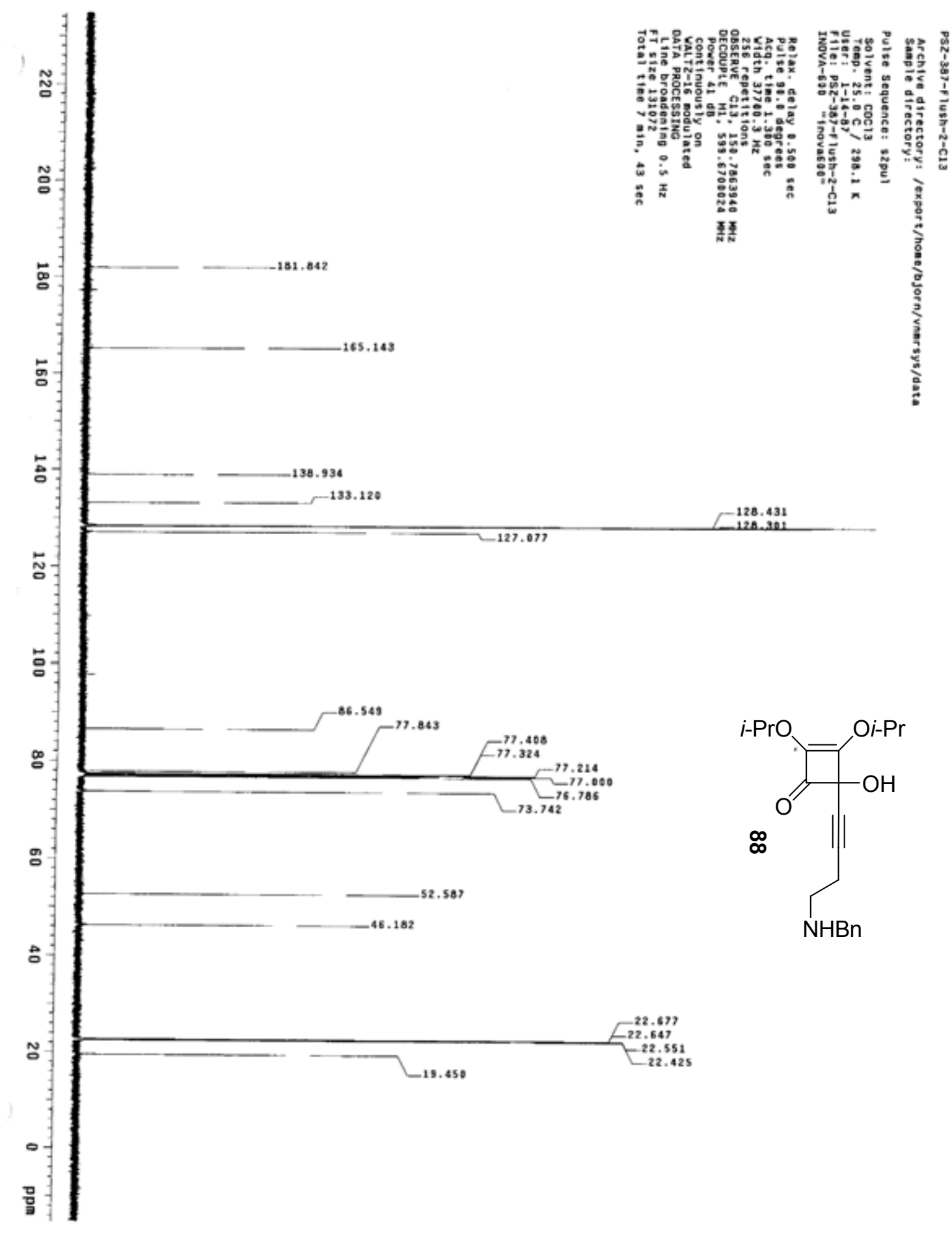

Figure 91: ${ }^{13} \mathrm{C}$ Spectrum of 4-(4-Benzylamino-but-1-ynyl)-4-hydroxy-2,3diisopropoxy-cyclobut-2-enone $\mathbf{8 8}$ 


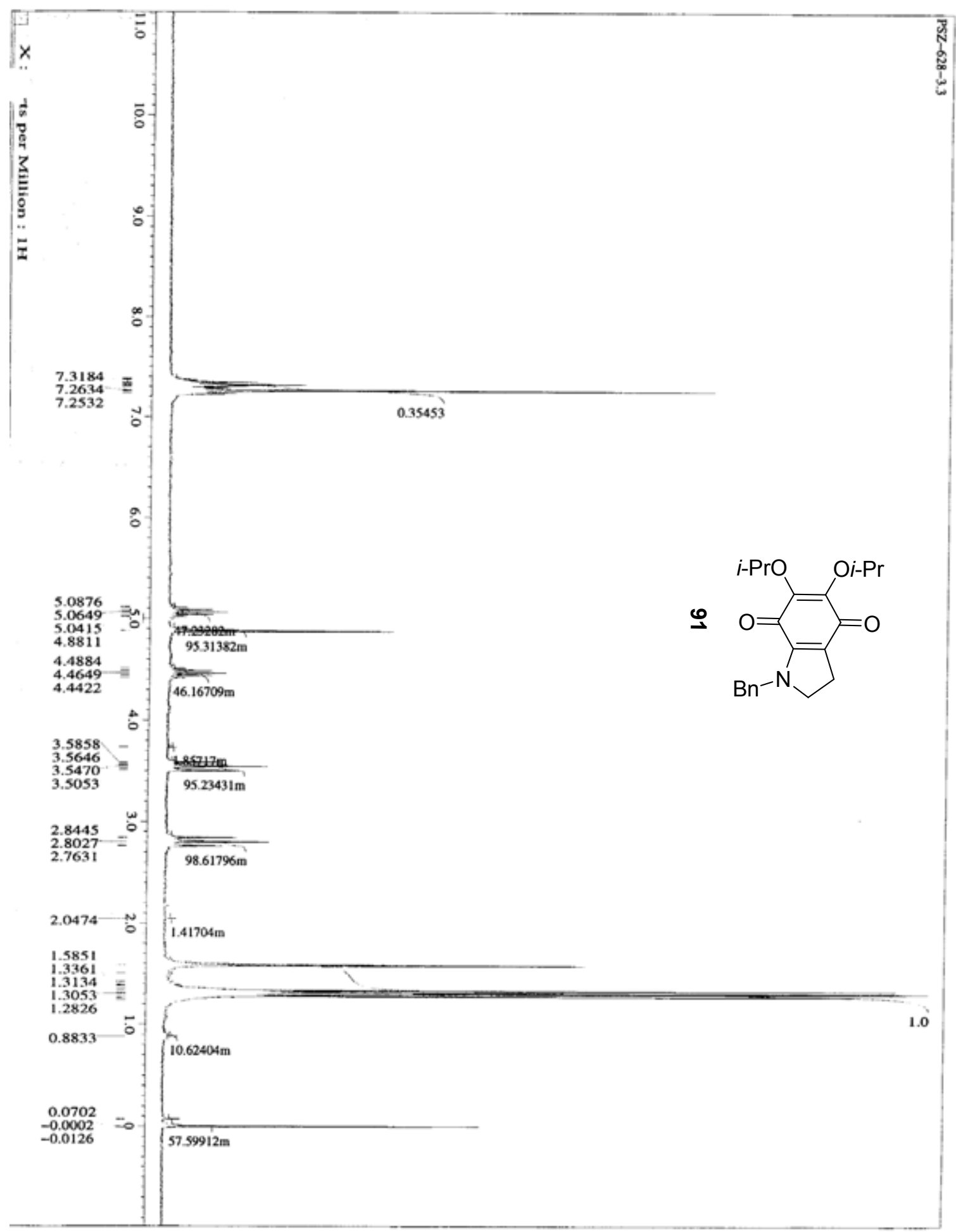

Figure 92: ${ }^{1} \mathrm{H}$ Spectrum of 1-Benzyl-5,6-diisopropoxy-2,3-dihydro-1H-indole-4,7dione 91 


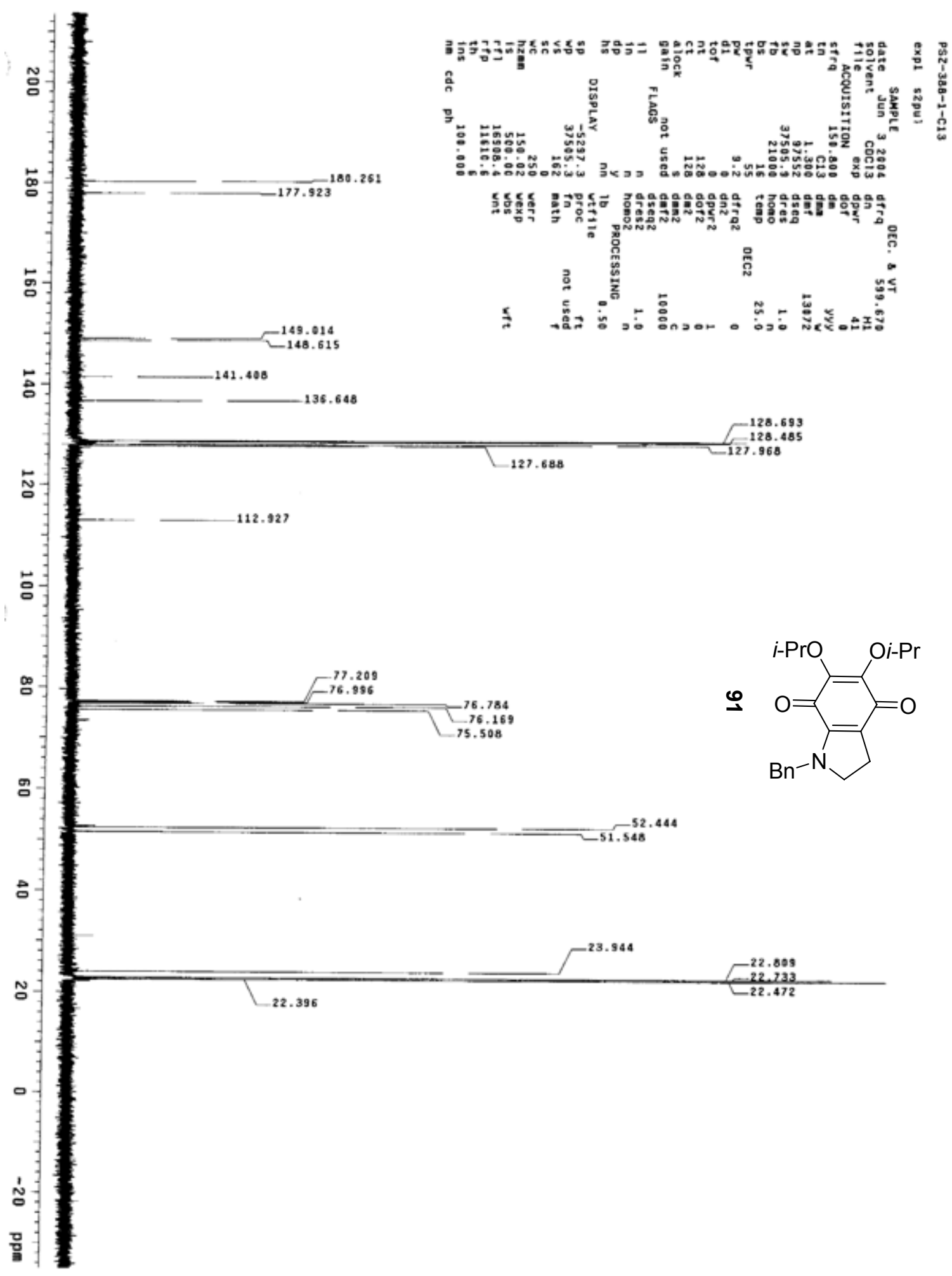

Figure 93: ${ }^{13} \mathrm{C}$ Spectrum of 1-Benzyl-5,6-diisopropoxy-2,3-dihydro-1H-indole-4,7dione 91 


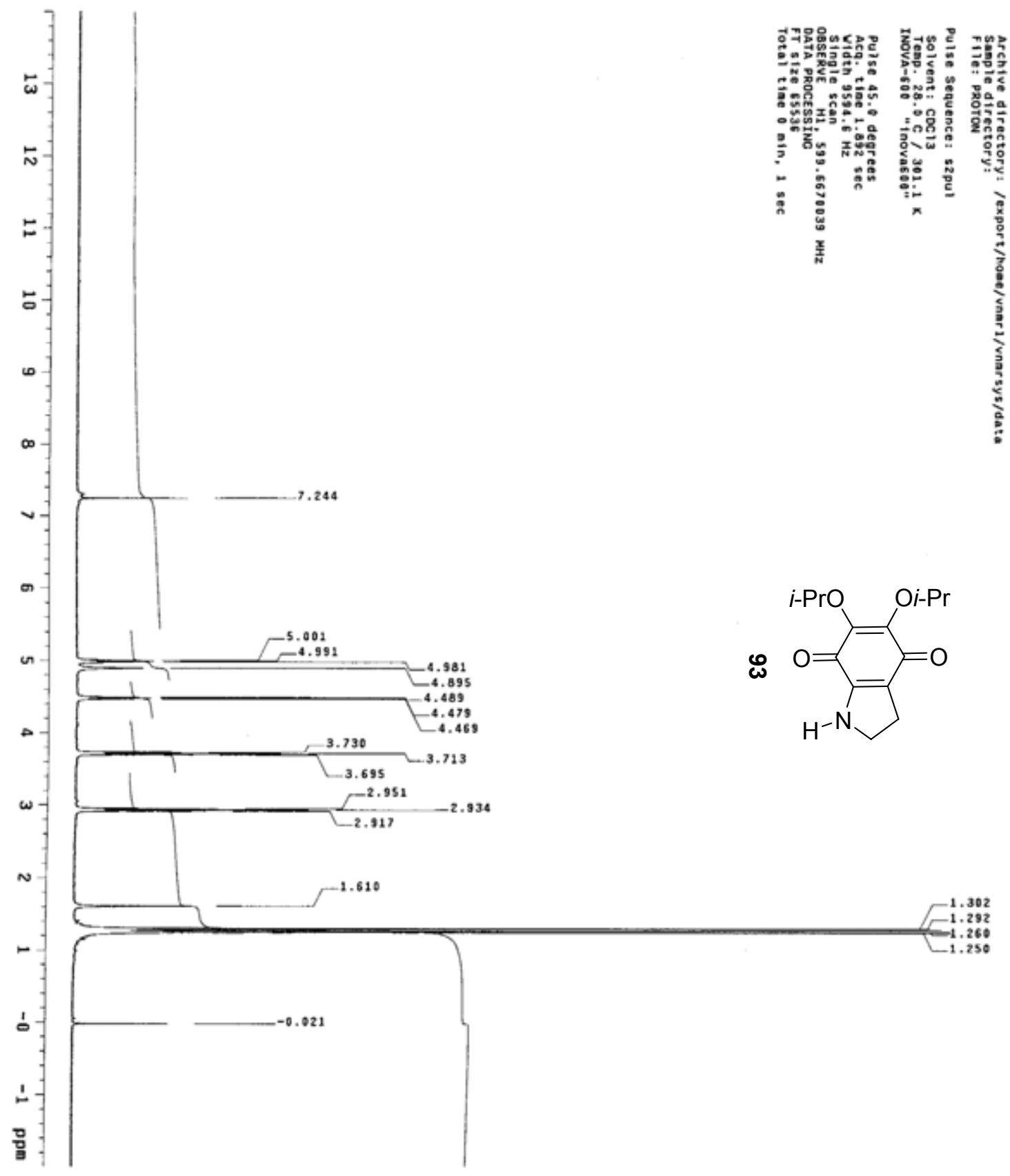

Figure 94: ${ }^{1} \mathrm{H}$ Spectrum of 5,6-Diisopropoxy-2,3-dihydro-1H-indole-4,7-dione 93 


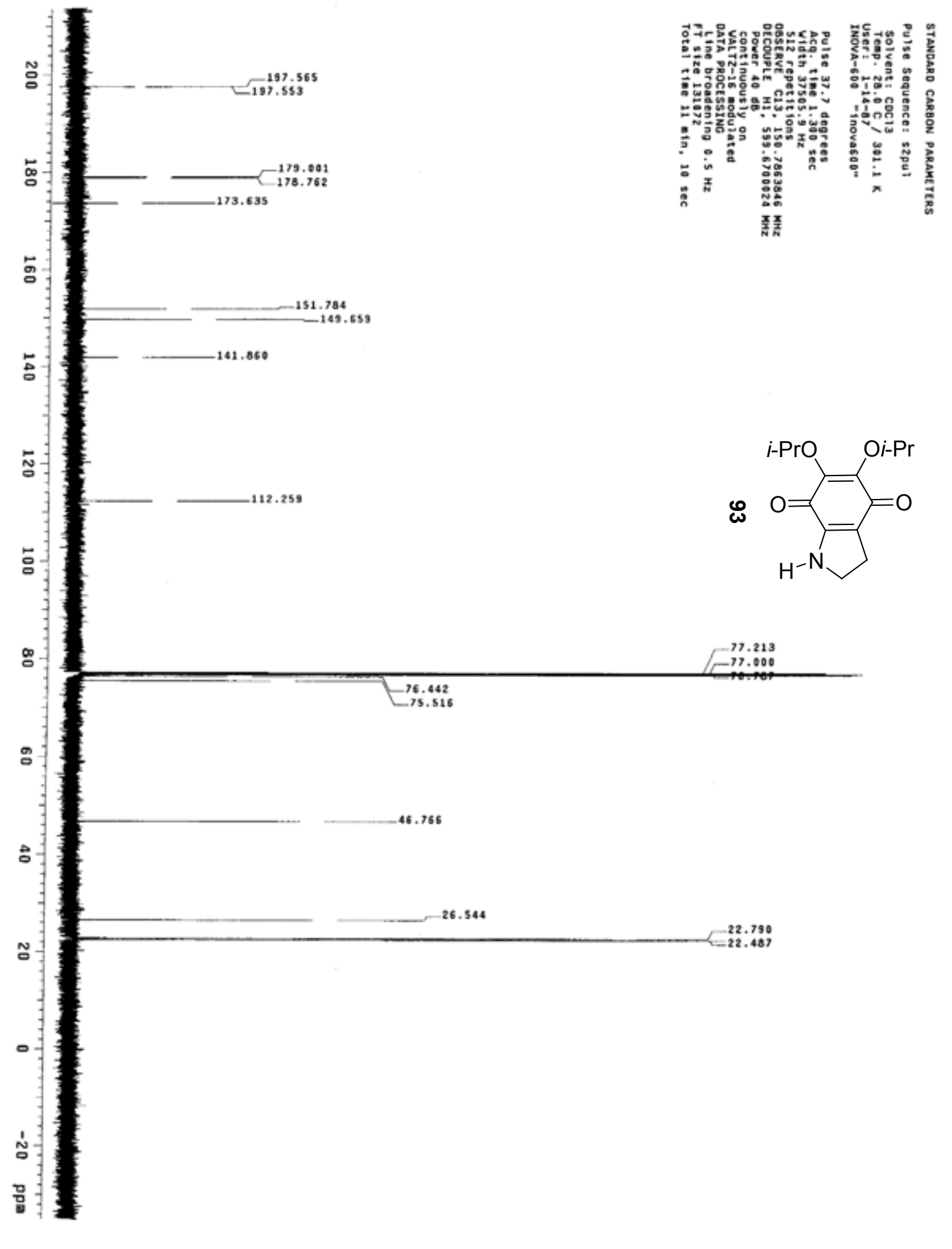

Figure $95:{ }^{13} \mathrm{C}$ Spectrum of 5,6-Diisopropoxy-2,3-dihydro-1H-indole-4,7-dione 93 


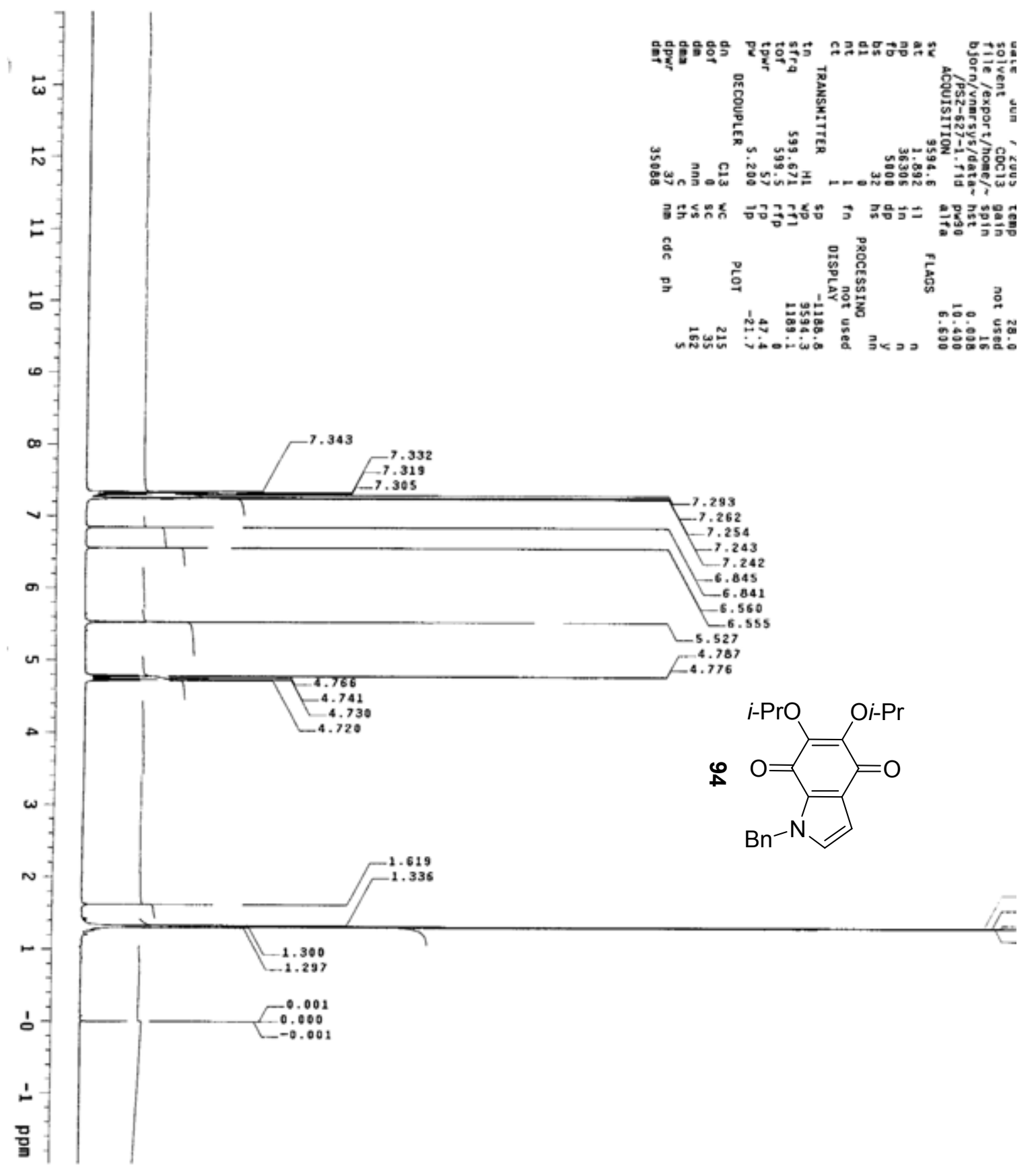

Figure 96: ${ }^{1} \mathrm{H}$ Spectrum of 1-Benzyl-5,6-diisopropoxy-1H-indole-4,7-dione 94 


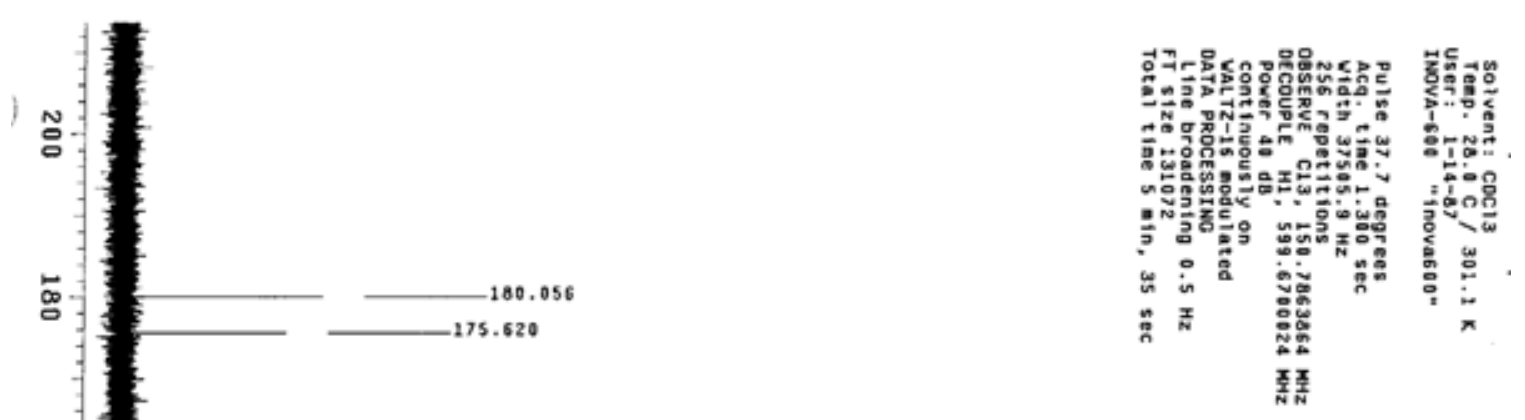

占
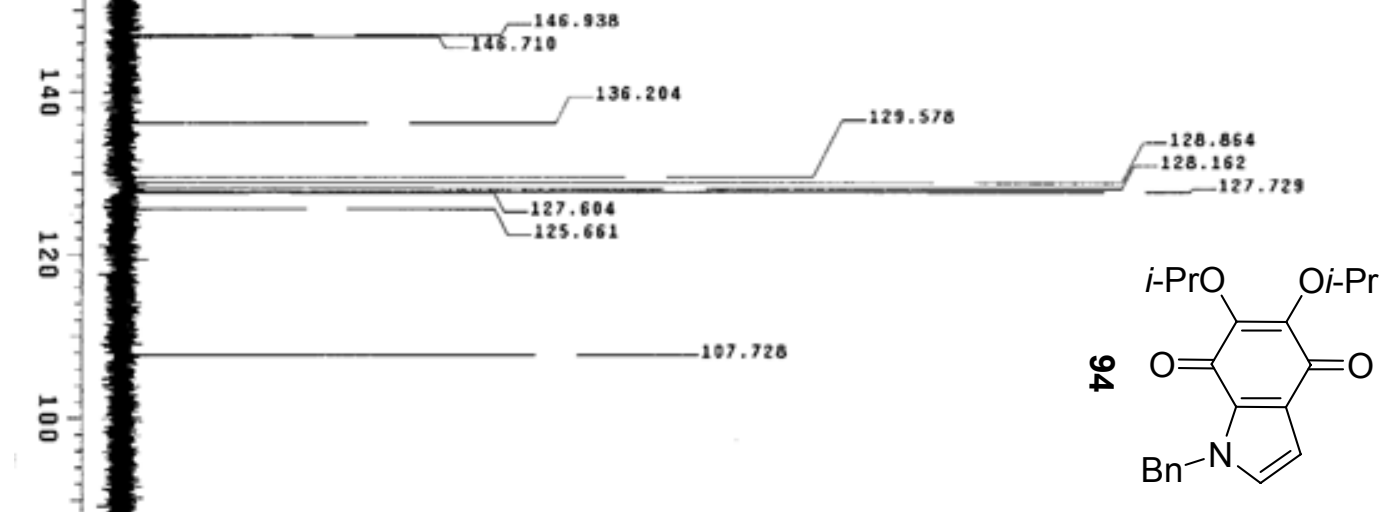

$\stackrel{\infty}{\circ}$

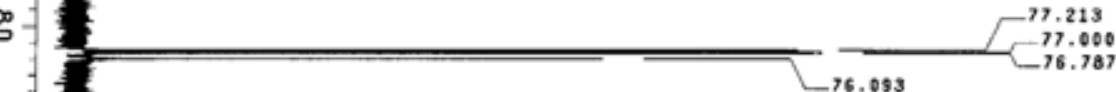

g.

$\circ$

a.

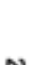

N

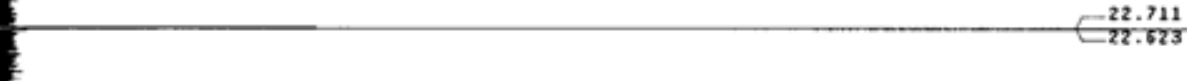

N.

뭌

Figure $97:{ }^{13} \mathrm{C}$ Spectrum of 1 -Benzyl-5,6-diisopropoxy-1H-indole-4,7-dione 94 


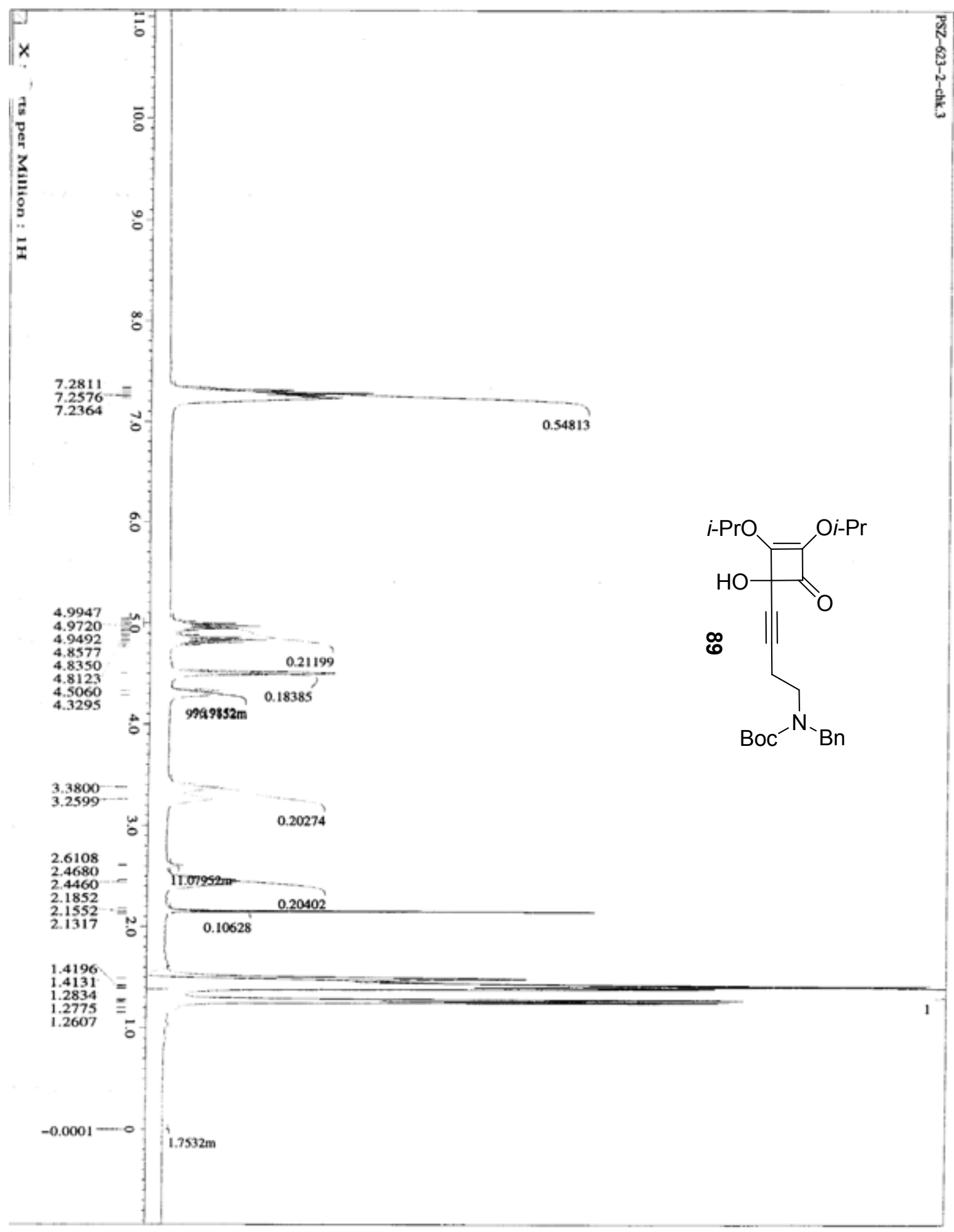

Figure 98: ${ }^{1} \mathrm{H}$ Spectrum of tert-butyl benzyl-4-(1-hydroxy-2,3-diisopropoxy-4oxocyclobut-2-enyl)but-3-ynylcarbamate 89 


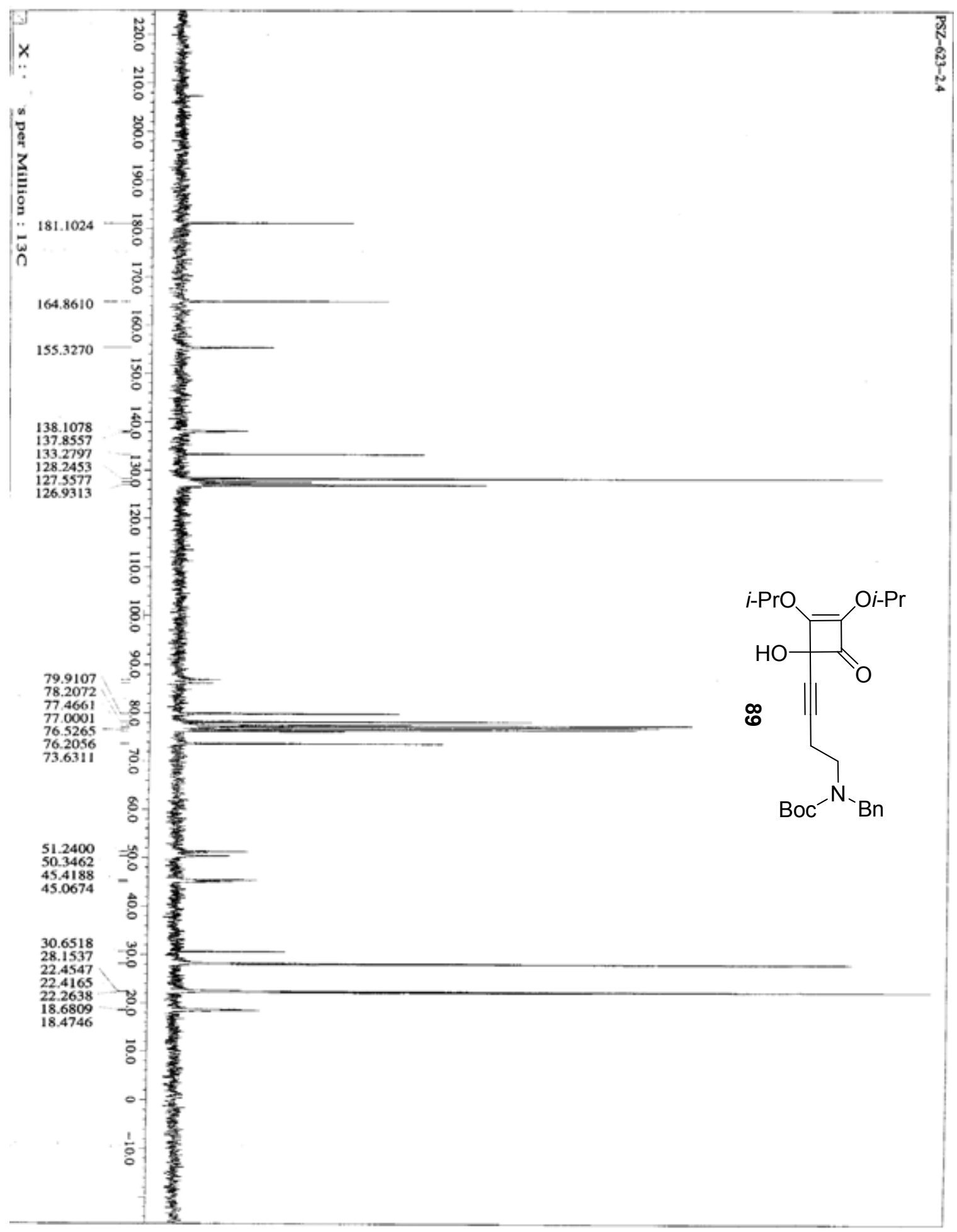

Figure 99: ${ }^{13} \mathrm{C}$ Spectrum of tert-butyl benzyl-4-(1-hydroxy-2,3-diisopropoxy-4oxocyclobut-2-enyl)but-3-ynylcarbamate 89 


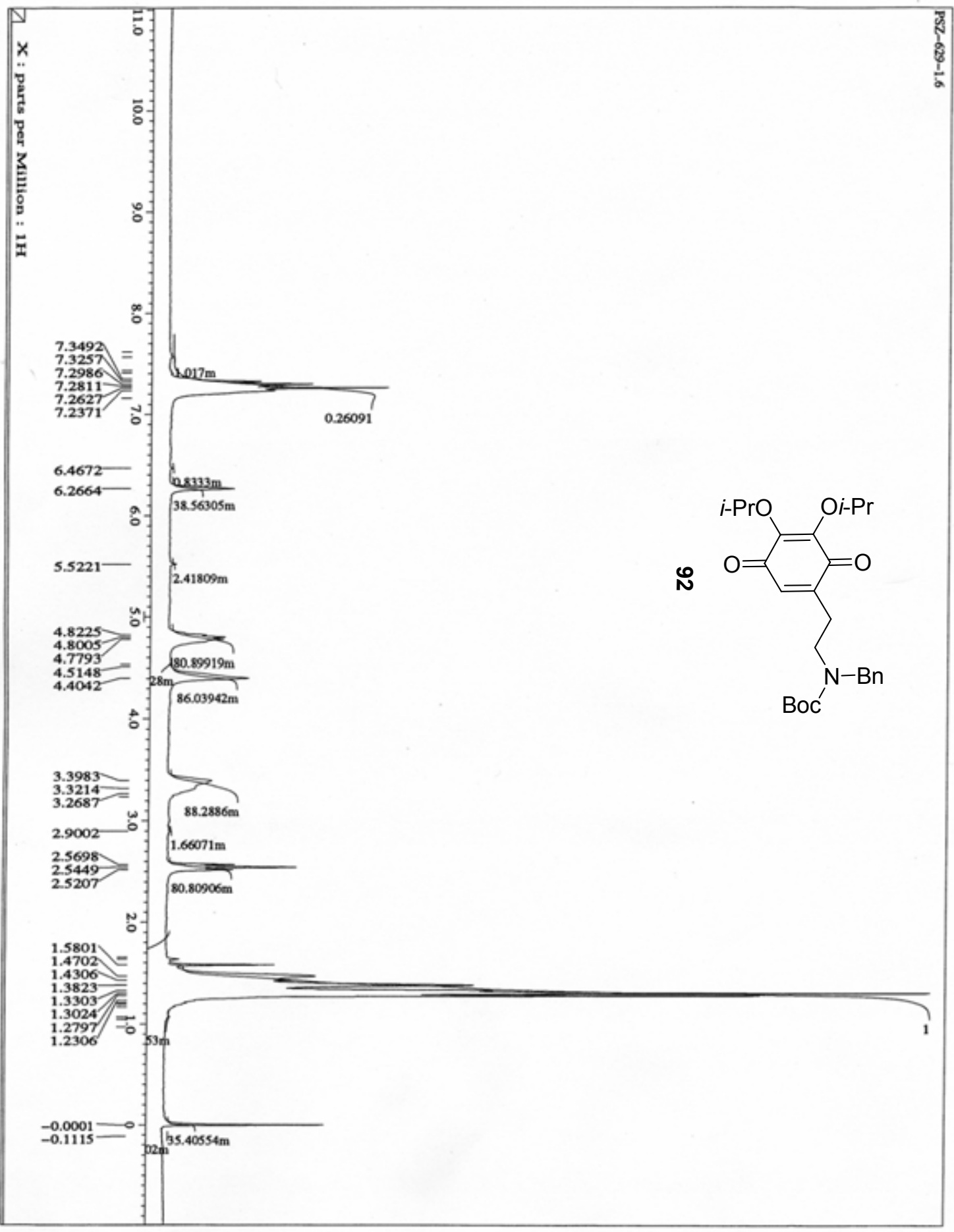

Figure 100: ${ }^{1} \mathrm{H}$ Spectrum of tert-butyl benzyl-2-(4,5-diisopropoxy-3,6dioxocyclohexa-1,4-dienyl)ethylcarbamate 92 


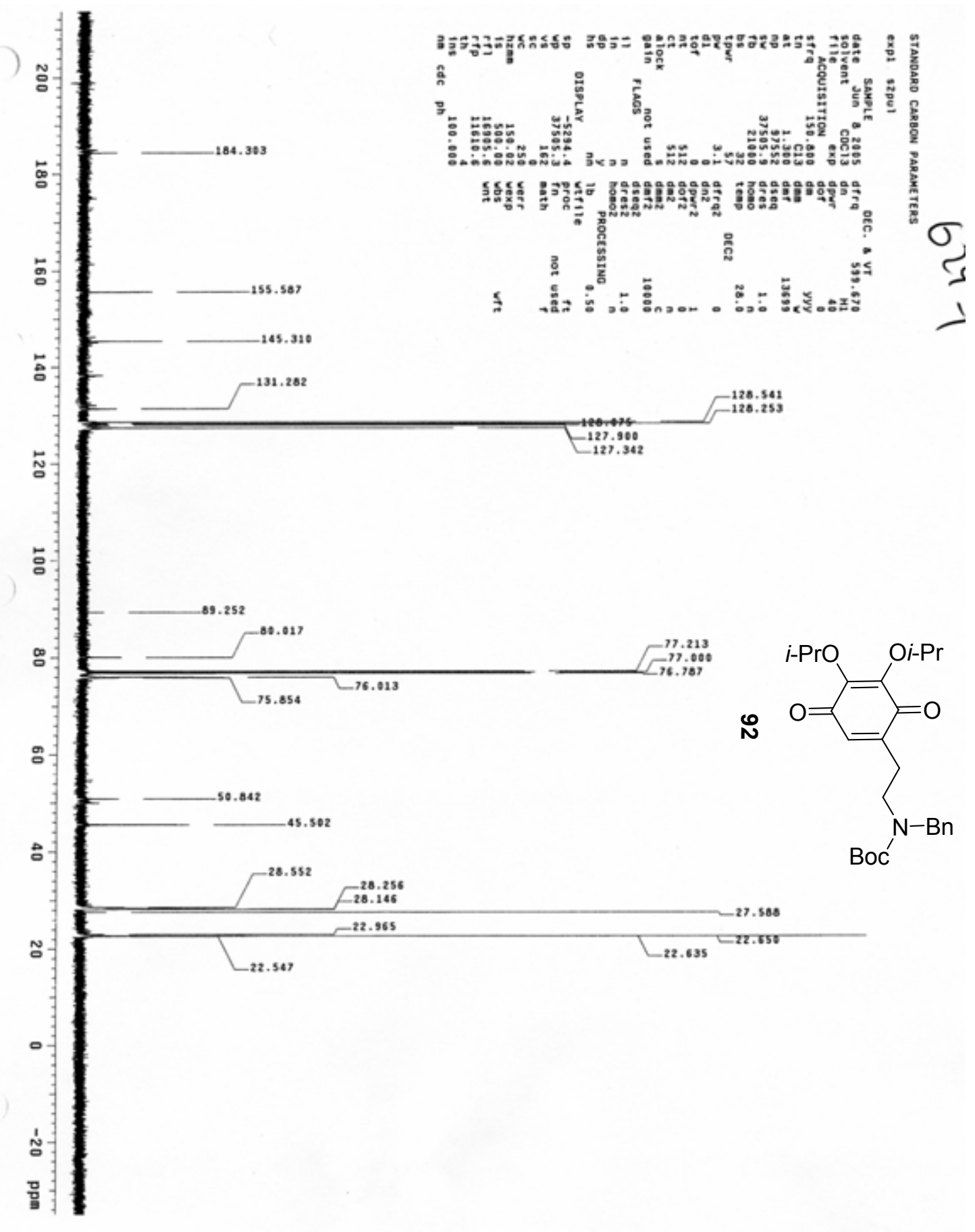

Figure 101: ${ }^{13} \mathrm{C}$ Spectrum of tert-butyl benzyl-2-(4,5-diisopropoxy-3,6dioxocyclohexa-1,4-dienyl)ethylcarbamate 92 


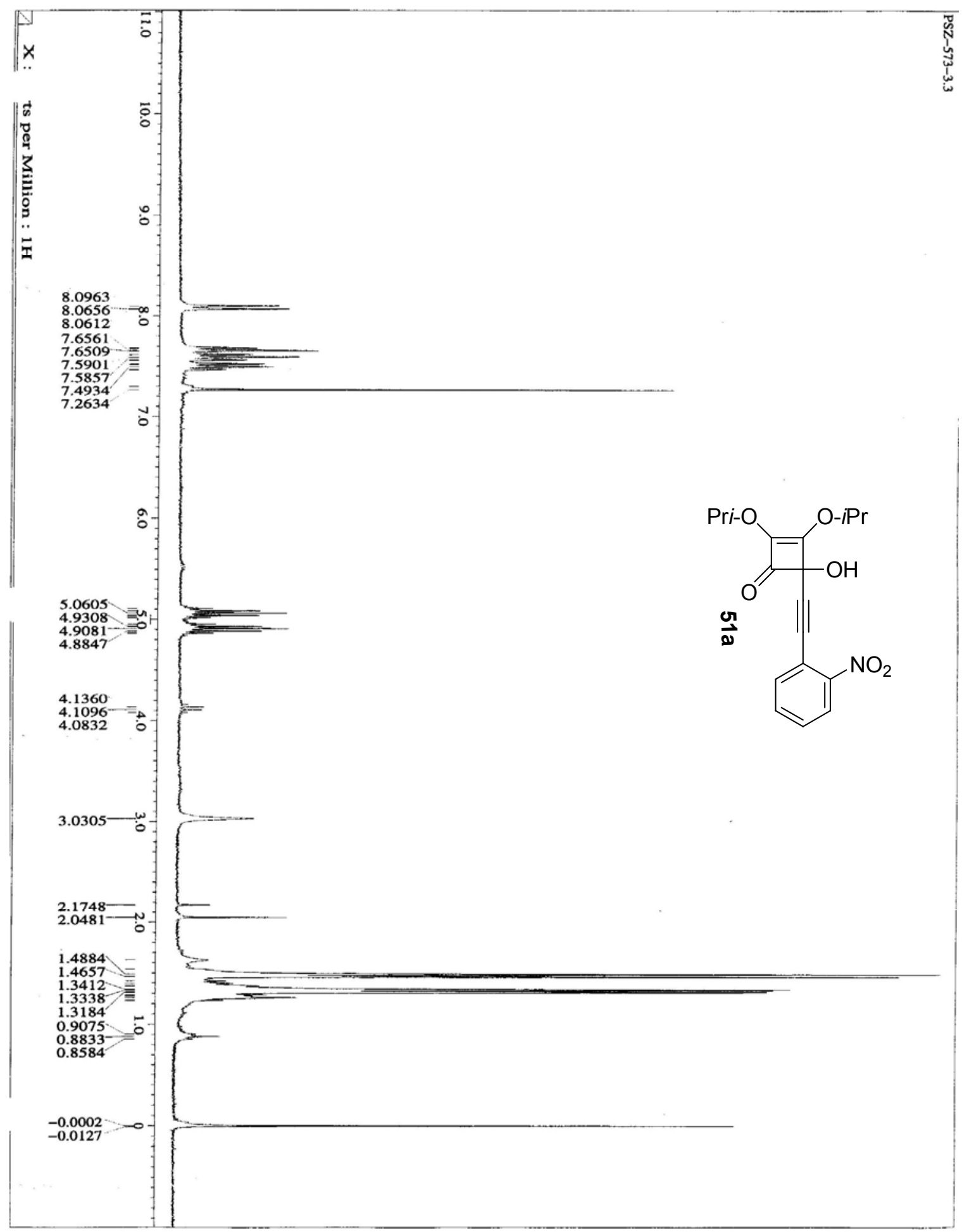

Figure 102: ${ }^{1} \mathrm{H}$ Spectrum of 4-hydroxy-2,3-diisopropoxy-4-(2-(2nitrophenyl)ethynyl)cyclobut-2-enone 51a 


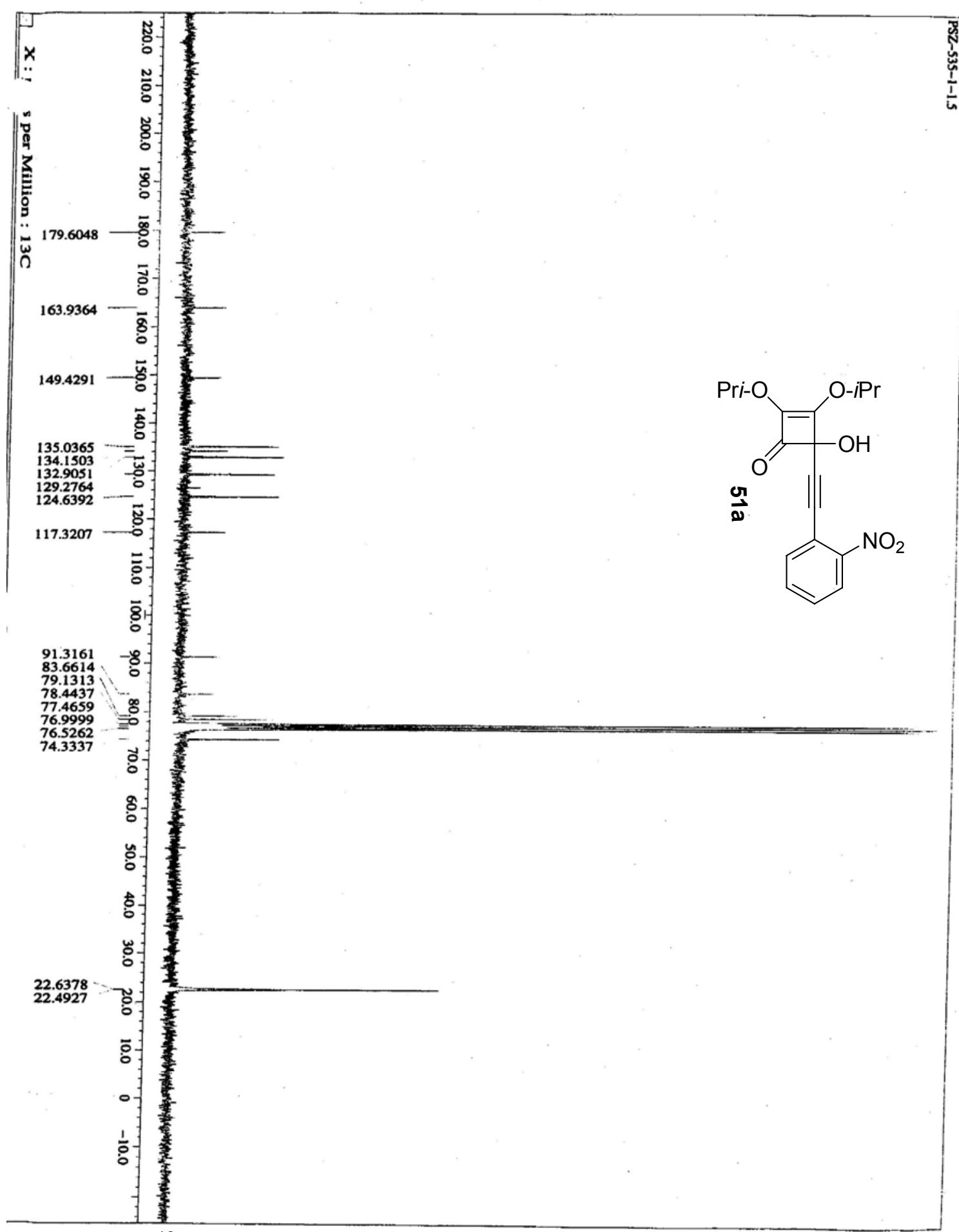

Figure 103: ${ }^{13} \mathrm{C}$ Spectrum of 4-hydroxy-2,3-diisopropoxy-4-(2-(2nitrophenyl)ethynyl)cyclobut-2-enone 51a 


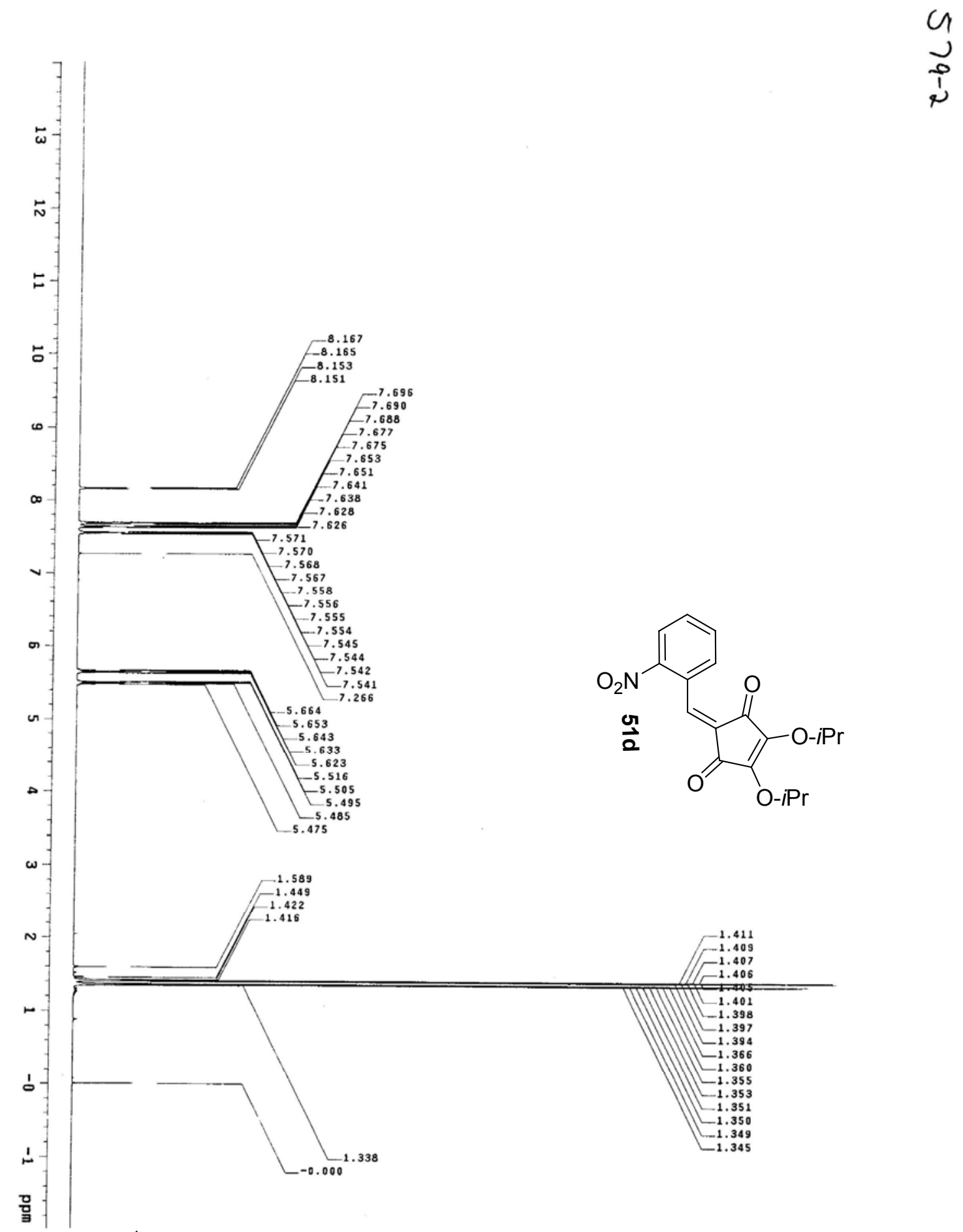

Figure 104: ${ }^{1} \mathrm{H}$ Spectrum of 2-(2-nitrobenzylidene)-4,5-diisopropoxycyclopent-4ene-1,3-dione 51d 


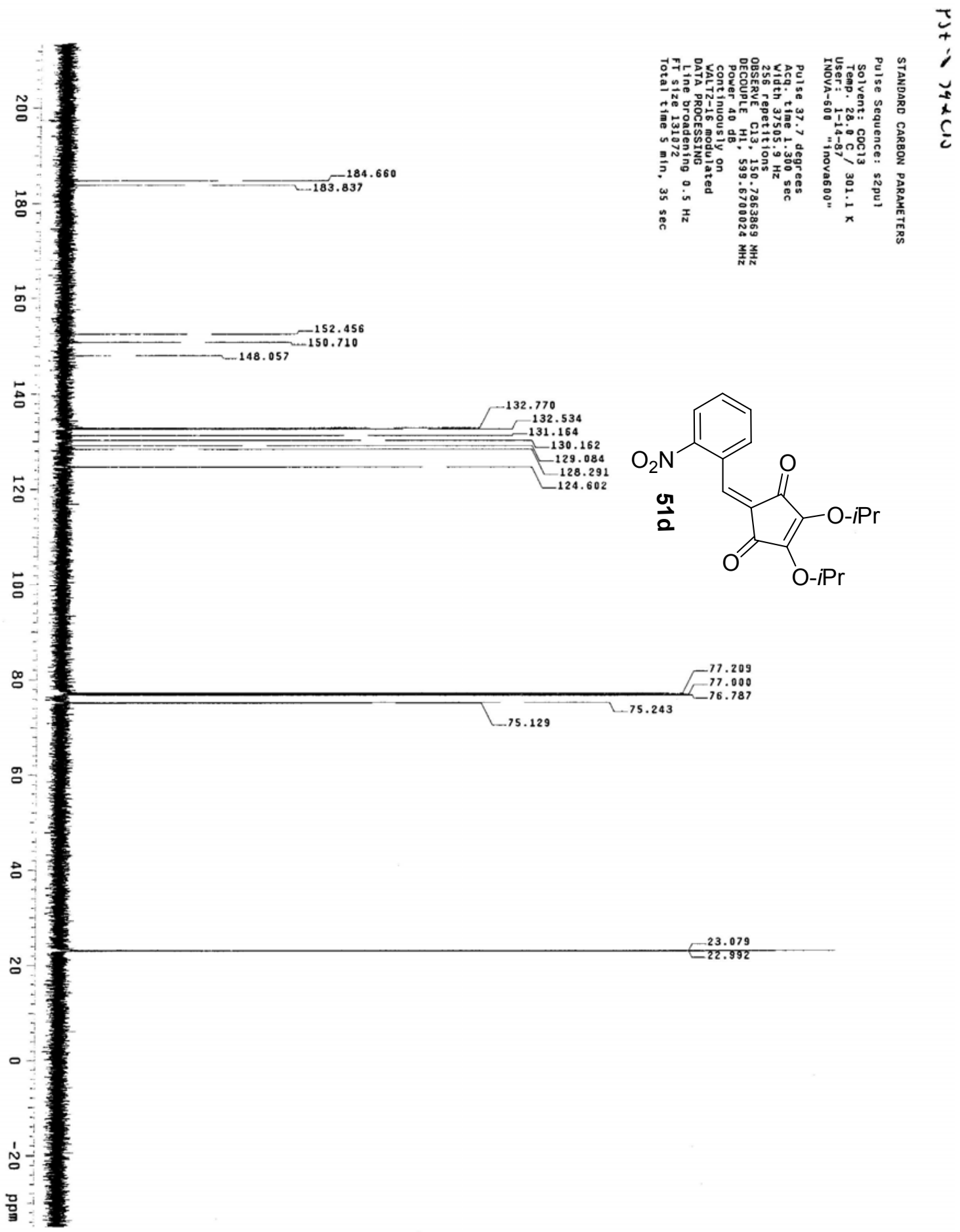

Figure 105: ${ }^{13} \mathrm{C}$ Spectrum of 2-(2-nitrobenzylidene)-4,5-diisopropoxycyclopent-4ene-1,3-dione $\mathbf{5 1 d}$ 


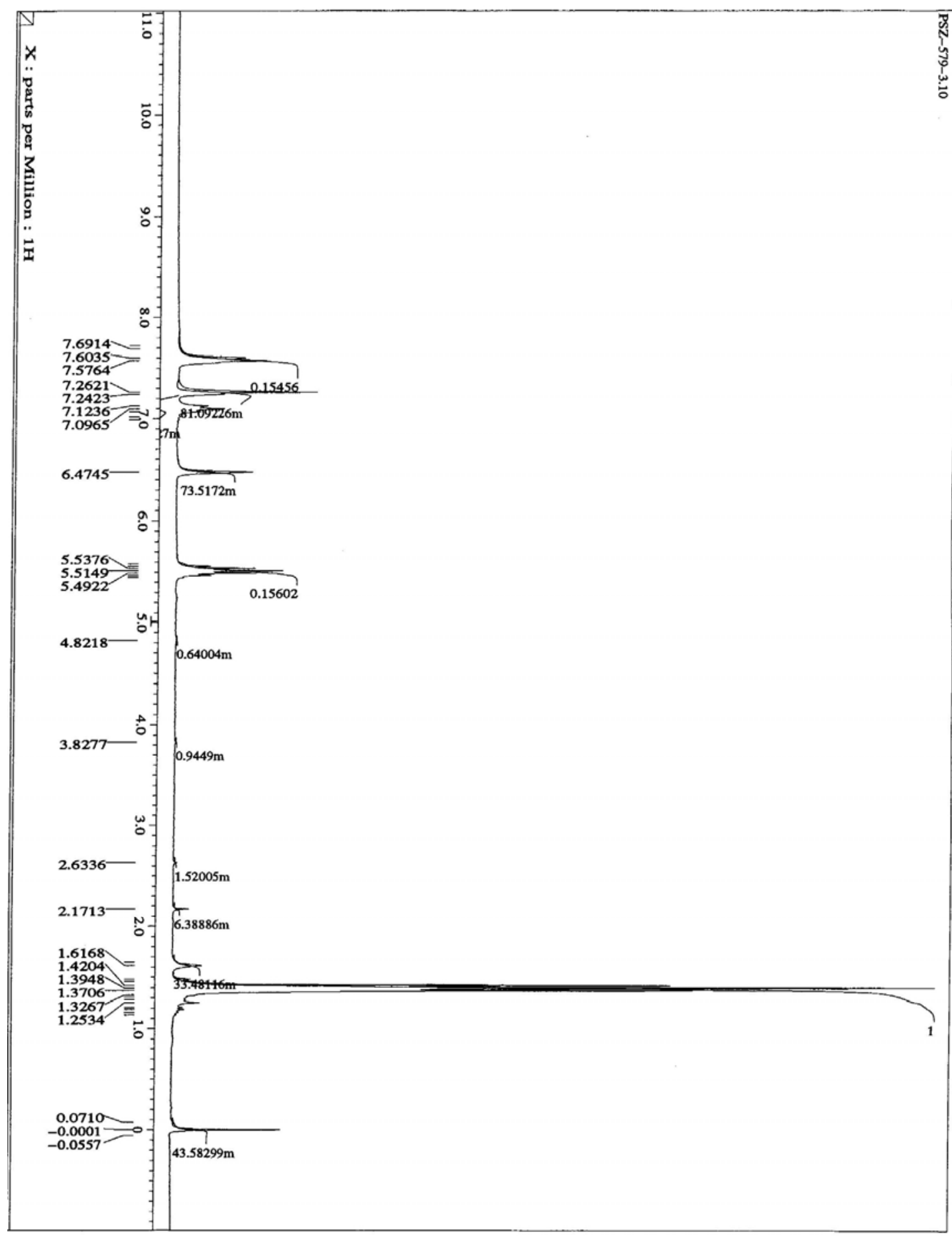

Figure 106: ${ }^{1} \mathrm{H}$ Spectrum of 2,3-diisopropoxy-5-(2-nitrophenyl)cyclohexa-2,5diene-1,4-dione 51c 

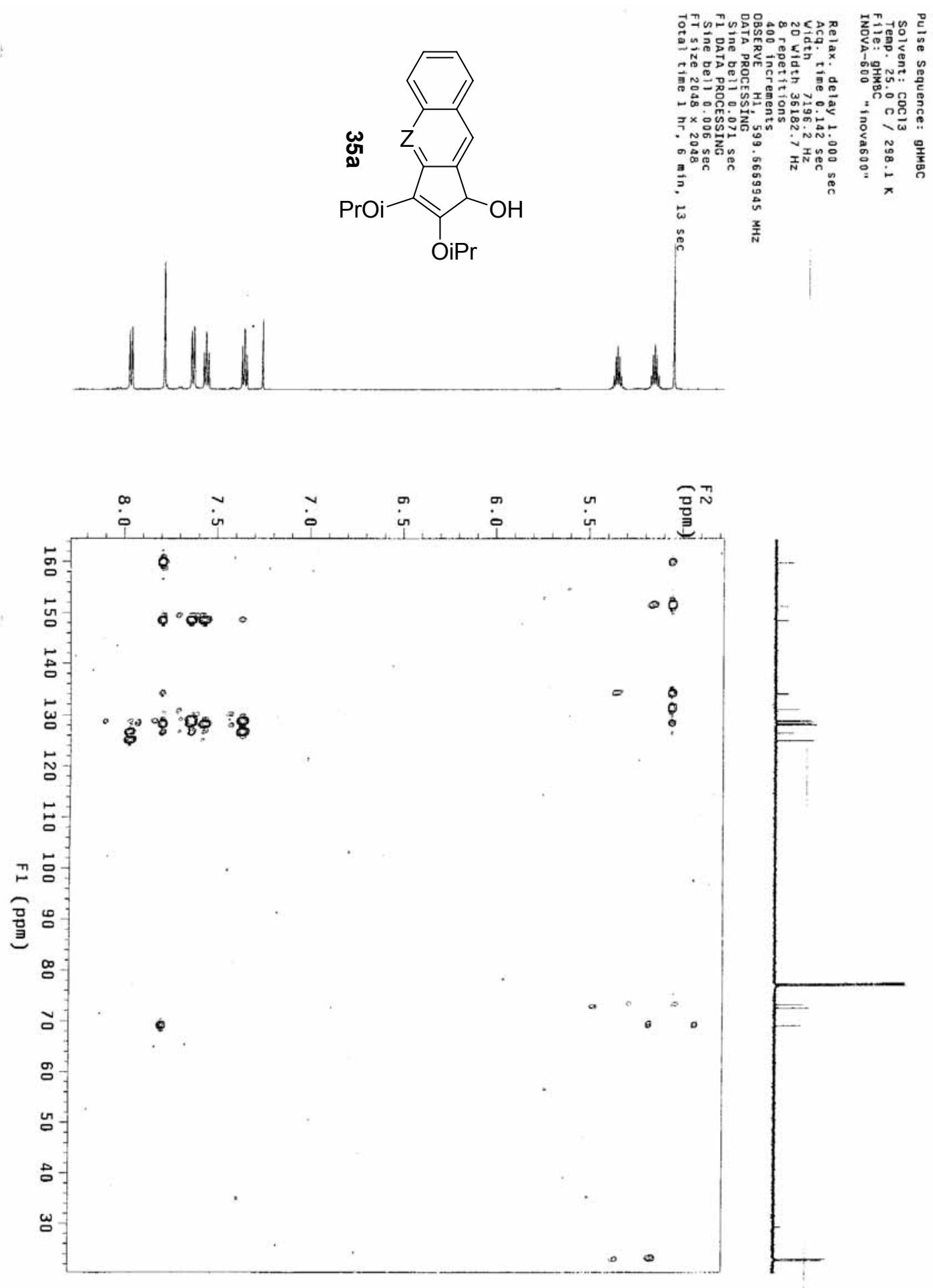

Figure 107: Expanded view of gHMBC Spectrum of 2,3-Di(1methylethoxy)cyclopenta[b]quinolin-1-ol 35a 

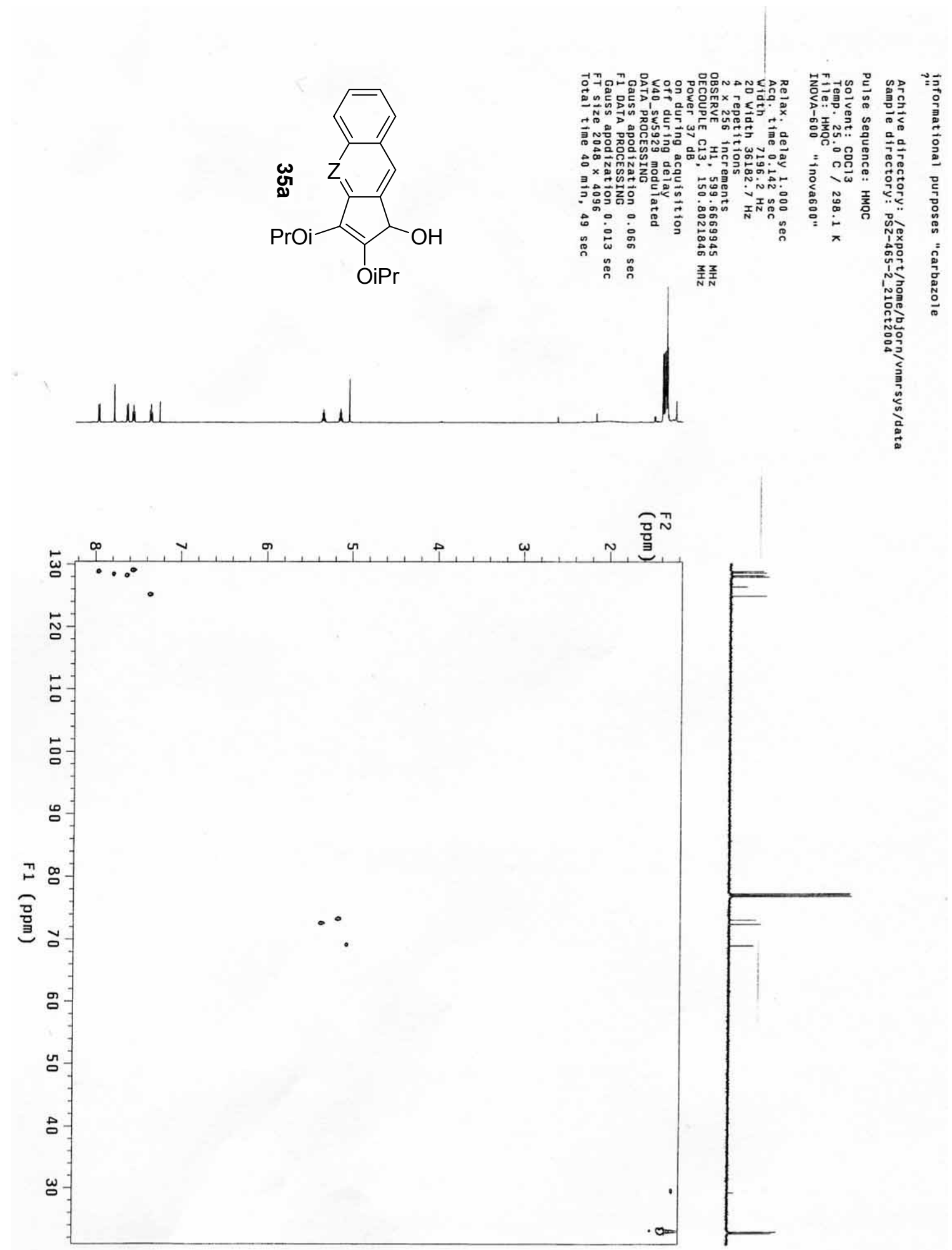

Figure 108: Expanded view of gHMQC Spectrum of 2,3-Di(1methylethoxy)cyclopenta[b]quinolin-1-ol 35a 